AperTO - Archivio Istituzionale Open Access dell'Università di Torino

\title{
Analytic Philosophy and the Later Wittgensteinian Tradition
}

\section{This is a pre print version of the following article:}

Original Citation:

\section{Availability:}

This version is available http://hdl.handle.net/2318/1727052

since 2020-02-08T16:48:42Z

Publisher:

Palgrave Macmillan

Published version:

DOI:10.1057/978-1-137-49990-5

Terms of use:

Open Access

Anyone can freely access the full text of works made available as "Open Access". Works made available under a Creative Commons license can be used according to the terms and conditions of said license. Use of all other works requires consent of the right holder (author or publisher) if not exempted from copyright protection by the applicable law. 
This is a Pre-Print Draft - Please Do Not Quote This Version Analytic Philosophy and the Later Wittgensteinian Tradition

Paolo Tripodi

Università degli Studi di Torino 
Table of Contents

Series Editor's Foreword

Acknowledgements

1. From the Golden Age to the Decline

1.1 The Rise

1.2 The Fall

2. The Core and the Periphery

2.1 Paradigm-Case Arguments

2.2 Words and Things

2.3 The Impact of Gellner

2.4 American Hegemony

3. Carnapstein in America

3.1 The Thirties and the Forties: Some Data and Trends

3.2 Wittgenstein and Carnap: Similarities and Differences

3.3 Wittgenstein and Carnap on Theories

3.4 Quine and the Science-Philosophy Divide

4. Rigourism in the Humanities

4.1 The Wittgensteinians in the Age of Quine

4.2 A Scientifically Oriented Culture. Philosophy, Economics, and the Humanities

4.3 Grammar, Anthropology, and the Autonomy of Humanistic Understanding

5. Science, Philosophy, and the Mind

5.1 Wittgenstein in the United States: Sellars and Cavell 
5.2 The Fifties and the Sixties: Some Data and Trends

5.3 Criteria and Symptoms

5.4 Reasons and Causes

5.5 The Return of Mentalism

6. Necessity, Style and Metaphilosophy

6.1 Wittgenstein and the Revival of Metaphysics

6.2 Style and/or Metaphilosophy

6.3 Philosophy at Face Value

7. Concluding Remarks. The Last Decades

7.1 A Synopsis

7.2 The Wittgensteinian Field

7.3 The Sociology of Academia and the Decline of Wittgenstein

References 


\section{Acknowledgements}

I am grateful to Annalisa Coliva for encouraging me to write this book, to Diego Marconi and Paolo Babbiotti for comments on an earlier draft, to Eugenio Petrovich for bibliographical suggestions, and to Guido Bonino for conversations on topics discussed in the book. I also wish to thank Lauriane Piette for her kind and thorough editorial help. A special thank goes to Mike Beaney and Brendan George for their patience and support over the past years.

Paolo Tripodi

Torino, September 2019 


\section{From the Golden Age to the Decline}

Imagine a philosopher who lived and worked in Oxford or Cambridge at the turn of the 1950s and the 1960s, and suppose she has been hibernating for about sixty years. After a tense stand-off, she wakes up in present-day Britain with all her memories intact. In a sense, of course, to her eyes almost everything has changed since then. But even focusing only on her professional field, namely philosophy, she feels deeply disoriented, for in the meantime many radical transformations have occurred. One of the novelties concerns the place of the later Wittgenstein - or, more generally, the weight and influence of what in this book is labelled the later Wittgensteinian tradition — in analytic philosophy. ${ }^{\text {T }}$ The imaginary philosopher remembers that in the 1950s Oxford and to a lesser extent Cambridge were the 'mecca' of analytic philosophy, and Wittgenstein — the later Wittgenstein was the champion of that philosophical tendency: a great majority of scholars in the Oxbridge analytic community shared a body of methodological and theoretical points and attitudes stemming from Wittgenstein's teaching; in those years, the later Wittgensteinian paradigm in philosophy was so dominant in Britain that to many it seemed not unreasonable to presume that it was about to have a similar impact on the philosophical landscape of all English-speaking countries, including the United States, Australia, New Zealand and Canada (Forguson 2001: 325). But when, after sixty years or so, the imaginary philosopher wakes up, her first impression is that during the hibernation period things must have gone on differently and unexpectedly. She ascertains that the later Wittgensteinian tradition

- its assumptions, purposes, methods and philosophical style - has been largely forgotten or rejected by present-day analytic philosophers. Looking closer at the present philosophical scene, however, she also notices that, after all, there are still many Anglo-American philosophers who develop Wittgenstein-inspired views in their articles and books: but this happens in a context in which the overall number of professional philosophers has increased amazingly, and where it is not uncontroversial how to define what counts as mainstream and what counts as peripheral philosophy (Weatherson 2014; Bonino and Tripodi 2018b). "How did we get here from there?" is the question recently posed by Tim Williamson (Williamson 2014). The same question is at stake in the present book.

The basis of the present work is the conviction that the imaginary hibernating philosopher's disoriented responses are by and large correct, and point in the right direction. Such responses can be roughly spelt out in the following terms: in the history of analytical philosophy from the 1950s to the present day, the later Wittgensteinian tradition gradually lost its centrality in Britain, and never reached a comparable consideration in the United States of America. The main purpose of this book is to outline an explanation of this historical-philosophical fact: the decline of the later Wittgensteinian tradition throughout the historical development of analytic philosophy, from the 
1950s to the present day. Chapter 1 sketches out the book's main explanandum. Chapters 2-7 attempt to explain it. An entirely different book would be required to account for a second fact: that on both shores of the Atlantic Ocean the Wittgensteinian tradition never ceased to exist or do a great deal of interesting philosophy; it is beyond the purposes of the present book to provide a picture of the various recent philosophical uses or rediscoveries of Wittgenstein's later philosophy. Chapter 7, however, takes a small step in that direction: it doesn't really outline the Wittgensteinian field - to borrow Pierre Bourdieu's terminology — in the recent history of analytic philosophy, but it provides some preliminary data for accomplishing the task in future work.

This is through and through a history of philosophy book. However, the historical-philosophical phenomena discussed and, hopefully, in part explained in the book are complex and multifaceted, so as to require the support of different perspectives borrowed from the history of ideas, intellectual history, and the sociology of knowledge, broadly conceived. The point is not to deny that philosophical arguments, as well as their conclusions, do matter. However, neither the arguments nor their conclusions are enough to explain philosophical success or failure, since the "intrinsic force of true ideas' perpetually meets resistance from all quarters, in the shape of interests, prejudices and passions" (Bourdieu 1999: 220). Social mechanisms and broadly cultural conditions play a role which is difficult to overestimate, though sometimes it is not easy to understand the details. Therefore this book is very inclusive methodologically, occasionally combining the traditional methods of the history of philosophy (such as conceptual analysis, rational reconstruction and the examination of the historical context) with a variety of sociological tools and concepts (both qualitative and quantitative), with categories borrowed from economic history (belonging especially to the Annales school), and with so-called distant reading methods, introduced into literary history some decades ago by Franco Moretti (Bloor 1976; Braudel 1980/1997; Bourdieu 1984a; Kusch 1995 and 2000; Wallerstein 2000; Moretti 2005 and 2013).

\subsection{The Rise}

Since perhaps not everybody is going to agree with this book's main assumptions - especially with the reality or factuality of the book's main historical-philosophical explanandum — in what follows a few preliminary words will be added concerning the rise and the fall of the later Wittgensteinian tradition in contemporary analytic philosophy. The background of the story is well known, so the details will be omitted. After returning to Cambridge in 1929, Wittgenstein was welcomed by the intellectual élite as the legendary author of Tractatus Logico-Philosophicus. As John Maynard Keynes once famously wrote in a letter to Lydia Lopokova: "Well, God has arrived. I met him on the 5.15 train" (Monk 1990: 255). In Cambridge, Wittgenstein started to give lectures and at-homes, which would in the following two decades deeply change the entire philosophical climate in Britain. 
From 1930 to 1941, and then from 1945 to 1947, many people attended his lectures and were influenced by him in various ways. Some of them were, or were going to become, professors of philosophy or other disciplines such as mathematics in British, Scandinavian, Australasian and American universities, among them George Edward Moore, Alice Ambrose, Max Black, Richard Braithwaite, Margaret Masterman, Karl Britton, Maurice Cornforth, Ruben Lewis Goodstein, Austin Duncan-Jones, Margaret Macdonald, John Wisdom, John Findlay, Douglas Gasking, Casimir Lewy, Norman Malcolm, George A. Paul, Rush Rhees, Yorick Smythies, Alan Turing, Georg Henrik von Wright, Elizabeth Anscombe, Peter Geach, Allan Cameron Jackson, Georg Kreisel, Cecil Alec Mace, and Stephen Toulmin (Hacker 1996: 77, 138).

In most cases, his pupils venerated Wittgenstein: Geach once compared Wittgenstein's classes to Quaker prayer meetings (Malcolm, 1958/2001), and von Wright observed that "to learn from Wittgenstein without coming to adopt his forms of expression and catchwords and even to imitate his tone of voice, his mien and gestures was almost impossible" (Wright 1955: 527). Wittgenstein was aware of such shortcomings of his teaching. He felt he was a failure as a teacher: as he once said, “The only seed that I am likely to sow is a certain jargon" (Malcolm, 1958/2001: 53); he also believed that "his ideas were generally misunderstood and distorted even by those who professed to be his disciples" (von Wright 1955: 527). In fact, he even doubted that "he would be better understood in the future," for "he felt as though he were writing for people who would think in a different way, breathe a different air of life, from that of present-day men" (von Wright 1955: 527). Accordingly, he shunned the idea of funding a school and, more generally, of being imitated, "not at any rate by those who publish articles in philosophical journals" (Wittgenstein 1980a: 61e). According to von Wright, "that was one reason why he did not himself publish his later works" (von Wright 1955: 527). As a matter of fact, however, his lectures and personal conversations, the circulation of the Blue and Brown Books and, above all, the posthumous publication, in 1953, of the Philosophical Investigations (later followed by the publication of several other parts of his Nachlass) made Wittgenstein's later philosophy the dominant way of thinking in Cambridge in the 1950s and 1960s (Hacker 1996: chapter $6)$.

This is not to say that everybody in Cambridge followed or at least admired the Wittgensteinian revolution in philosophy. This is rather to suggest something less general and more precise, which can be summarised in the following three points. First, almost everybody in the new generation of Cambridge philosophers was deeply impressed by Wittgenstein's later way of philosophising, and set up its own work based on that model. Secondly, even those who, like C.D. Broad and Bertrand Russell, were more critical towards it, did not deny its importance and centrality. Broad watched "with a fatherly eye the philosophic gambols of ... [his] younger friends as they dance[d] to the highly syncopated pipings of Herr Wittgenstein's flute” (Broad 1925: 7). Nonetheless, Broad felt compelled 
to say that "to refuse the chair to Wittgenstein would be like refusing Einstein a chair of physics" (Drury 1984: 141). Something similar is true of Russell, a philosopher Wittgenstein used to admire greatly, even though he later came to regard him as one who was not "going to kill himself doing philosophy" any more (Malcolm 1958/2001: 57): Russell wondered "why a whole school finds important wisdom" in Wittgenstein's later philosophy, which he regarded, on the contrary, "to have grown tired of serious thinking and to have invented a doctrine which would make such an activity unnecessary," so as to have become "at best, a slight help to lexicographers, and at worst, an idle teatable amusement" (Russell 1959: 216-7); at the same time, however, Russell could not help acknowledging that Wittgenstein's later philosophy was the leading philosophical tendency in Britain during that period, overtaking both Tractatus-inspired analysis and logical positivism.

Thirdly, and perhaps most importantly, in particular from the point of view of an "external" history of philosophy, from Cambridge the later Wittgensteinian tradition came to Oxford, and from Oxford — as Ryle once put it - it "spread waves over the philosophical thinking of much of the Englishspeaking world," especially after the second world war (Ryle 1951/2009: 259; Hacker 1996: 77). In the early 1940s the philosophical atmosphere in Oxford was still dominated by Cook Wilson realists and British idealists (Marion 2000): Wittgenstein was still a somewhat distant figure, though a younger and more logic-friendly generation was arising: for example, philosophers such as Gilbert Ryle, John Austin, Isaiah Berlin, Stuart Hampshire, and Paul Grice (Dummett 1978a: 63). After the war everything changed: Wittgenstein's name was all of a sudden on everybody's lips, not as the author of the Tractatus, but rather as the author of the Blue and Brown Books, and as the philosophical genius who taught in Cambridge (von Wright 1993: 38).

Two main factors fostered the Wittgensteinian turn in Oxford in the second post-war period. The first was the presence of Ryle, the Waynflete Professor and editor of Mind. As is well-known, Ryle had met Wittgenstein in 1929 at the Joint Session of the Aristotelian Society, they had established a friendship, and Ryle had been deeply influenced by him. After the war Ryle became the veritable deus ex machina of the British philosophical academia (Forguson 2001: 329; Magee 1971: 128): in a context characterised by the growth of the undergraduate population (more than $60 \%$ students in just two years, from 1946 to 1948), the contingent of philosophers working at the University of Oxford dramatically increased, from 11 people in 1939 to 43 people in 1950 (Forguson 2001: 328); Ryle governed this process, gathering together about twenty philosophers in Oxford, all considerably younger than himself (Rée 1993: 8). Some of them were pupils and followers of Wittgenstein: besides Waismann, there were Paul, Toulmin, Wisdom and Anscombe. ${ }^{\text {ii }}$

The second factor was the opportunity for Oxford philosophers, after 1953, to have direct and almost systematic access to Wittgenstein's later work. Thus in the mid-1950s most leading philosophers in Oxford, with the partial but significant exception of Austin — who saw himself as 
working in the tradition of Cook Wilson, Pritchard and Russell — were deeply influenced by Wittgenstein's later way of thinking: among them Hart, Hare, Foot, Urmson, Pears, Warnock, Dummett and, to a lesser extent, Grice, to name but a few; besides, of course, Ryle and his “lieutenant”, Peter Strawson (Rée 1993: 8; see also Mehta 1962: 58).

In Britain Wittgenstein's influence became overwhelming. As Stephen Mulhall has pointed out, in that period the expression 'contemporary philosophy' in introductory textbooks referred to ordinary language philosophy and to (what is in this book labelled) the later Wittgensteinian tradition (Mulhall 1994: 444). In the introduction to the first anthology devoted to the new Oxford school — Logic and Language, a collection of essays edited by Antony Flew and published in 1951 by Basil Blackwell - the editor acknowledged the debt all the contributors had towards "the genius of one man above all, ... whose name is almost unknown outside the world of academic philosophy", although "everyone who belongs to that world will see throughout this volume marks of the enormous influence, direct and indirect, of the oral teachings of Professor Wittgenstein" (Flew 1951: 93. See also Rée: 13): as Hacker once pointed out, seven of the nine articles were written by people who were directly acquainted with Wittgenstein or studied under him, namely Ryle, Findlay, Paul, Waismann, Wisdom and Macdonald, the author of two contributions; the author of the eighth paper, Herbert Hart (Hacker's supervisor in the following years), was highly influenced by Wittgenstein (Hacker 1996: 163). The same point made by Hacker has been emphasised by other followers and friends of Wittgenstein: according to Warnock, Wittgenstein extended the most powerful influence upon British philosophy during that period (Warnock 1958: 62); Hart once called the Investigations "our Bible" (Hacker 1996: 163, 311); Urmson confirmed that in that period Wittgenstein's thought permeated the philosophical atmosphere in Britain (Urmson 1961/1967: 305); Strawson attributed to Wittgenstein "an extraordinary, almost unique, power to dissolve philosophical illusion" (Pivcevic 1989: 7); and Ryle declared that "Wittgenstein has made our generation of philosophers self-conscious about philosophy itself" (Ryle 1951/2009: 266; see also Ryle 1957). Moreover, a similar picture has been confirmed even by critics and rivals of Wittgenstein: for example, Ernest Gellner described that period in Britain as one when "criticising Wittgenstein was unthinkable" (Gellner 1959/1979: 30); and Conrad Hal Waddington once said that at the Royal Society people "were not used to anybody standing up to Wittgenstein" (Robertson 1977).

The expectations created by the success of Wittgenstein's new philosophical methods were extremely high. The words uttered by Bernard Williams in a 1978 conversation with Bryan Magee describe 'The Spell of Linguistic Philosophy' very vividly, thus representing a widespread philosophical climate: 
Many questions of philosophy turned out, each of them, not to be any one question at all. They were often a collection of different worries, different puzzles, which had been put together under some simplifying formula, and when you saw through that and had analytically taken the problems apart, you'd find that many traditional questions of philosophy had not been solved but had disappeared. You no longer needed to ask them. And the promise this offered was very great - and extremely exciting. There really were people who were saying that the whole of philosophy would be over in fifty years. It would all be finished. (Williams 2001: 114)

To the eyes of one or two generations of linguistic philosophers - all of them somewhat inspired by Wittgenstein's later views - the end of traditional philosophy would be achieved thanks to the definitive dissolution of traditional philosophical problems, with the resulting extinction of both metaphysics and empiricism (Strawson 1960). Francis Sparshott, who was an undergraduate in that period, once recalled with "a deep nostalgia" the "wonderful feeling of euphoria in the air," in which students in the cafés "not only assumed that the 'ordinary language' mode had superseded all other ways of doing philosophy, but agreed that the task of philosophy would soon be finished" (Forguson 2001: 331).

Similar enthusiasm extended to other provinces of English-speaking philosophy, for two main reasons. The first is that Oxford philosophy, viewed from afar, appeared to many as a uniform and compact philosophical tendency, sometimes called 'Oxford linguistic philosophy' (Forguson 2001: 331): upon closer examination, however, the impression of homogeneity was in part an illusion (Hacker 1996: 159), especially because there was a deep difference between Wittgenstein's conception of philosophy as "grammatical clarification" and Austin's view of philosophy as "linguistic phenomenology" (von Wright 1989: 45-6); nonetheless, the presence (or the partial illusion of the presence) of a unitary "movement" facilitated the success of a philosophical style and even the emergence of an intellectual fashion. The second reason is that in the post-war period it became possible for students and professors to travel more frequently: not only did the newly established Oxford post-graduate programme in philosophy attract many $\mathrm{PhD}$ students from the United States and the rest of the world (John Searle, Peter Unger and Stephen Schiffer among them), but some American philosophers (such as Morton White, Willard Van Orman Quine, Nelson Goodman and Wilfrid Sellars) visited Oxford and had intellectual exchanges with Oxford scholars. The graduate programme was dominated by Ryle, who effectively lobbied for its institution, giving it the mark of linguistic philosophy (Forguson 2001: 334).

From the 1950 s to the mid-1960s, during the golden age of linguistic philosophy, most scholars in 
Britain shared a set of Wittgensteinian points and assumptions, both methodological and substantial. The one that this book will regard as the most important, and the one on which the next chapters will focus more closely, is the idea - defended by Wittgenstein throughout his intellectual life — that there is a deep and sharp divide between science and philosophy. On this view, science and philosophy are not just conceptually distinct: they really are separated; they operate on different levels. Science is a substantive doctrine, a general theory that aims to solve problems by discovering new truths and causally explaining and systematising empirical facts. Philosophy — that is, Wittgenstein's philosophical grammar and its descendants such as Ryle's logical geography and Strawson's connective analysis - is a second level activity, which aims to dissolve philosophical problems by reaching conceptual clarity, rather than achieve substantial and general knowledge; it works entirely a priori, by describing the conceptual connections (and exclusions) in the web of one or more words (Hacker 2001: 23).

Furthermore, in the 1950s and the early 1960s most analytic philosophers in Britain shared not only a Wittgensteinian metaphilosophical frame, but also many specific philosophical views. One point concerned logic: formal logic mirrors neither the logical structure of the world, nor the deep structure of any possible language. Another point regarded metaphysics: what is necessary is not determined by certain features of reality but is a byproduct of either our language or our conceptual scheme (in a nutshell: the necessary is what we could not conceive as being otherwise); necessary statements (including logical and mathematical statements) are not true (and impossibly false) descriptions of facts (let alone "super-facts"), but are disguised grammatical rules that govern the use of one or more words occurring in them. Still another point concerned the philosophy of language: in doing philosophy a careful examination of ordinary language is essential, though ordinary language is not the last word in philosophy; grammar is where the line between sense and nonsense is drawn. Yet another point concerned the philosophy of mind and action: Cartesianism and, more generally, mentalism are false (e.g., an "inner process" stands in need of outward criteria; a private language is impossible); explanations of actions in terms of reasons are not causal explanations; a philosophical anthropology (that is, a philosophical investigation of persons) should be conceived of as the grammatical description of the web of concepts related to actions, norms and reasons.

\subsection{The Fall}

The widespread sharing of all or most of these metaphilosophical and philosophical views was probably the distinctive feature of analytic philosophy in Britain in the 1950s and the early 1960s. As suggested by the science fiction story told above, however, in present-day analytic philosophy things have changed a great deal since that time. Virtually none of the later Wittgensteinian cornerstones mentioned above, which once were part of a body of commonly shared views in the analytic 
community, are accepted any more, let alone taken for granted, by mainstream (or, if you dislike this controversial notion, by most) analytic philosophers and by graduate students in philosophy, not only in the United States but by now in Britain as well: normally, analytic philosophers reject, or simply do not take into account, the idea that science and philosophy are deeply divided, the a-theoretical or even anti-theoretical conception of philosophy (and the philosophical style associated with it), Wittgenstein-inspired views of language and logic, the linguistic and anti-metaphysical conception of necessity, anti-mentalism, the non-causal account of reasons, and so forth.

In recent years, various Anglo-American philosophers seem to have become aware of a sort of epochal change that, according to many, took place in analytic philosophy in the last forty years, in the era of so-called "late analytic philosophy" (Bonino and Tripodi 2018b). No matter how they evaluate the facts, many of them agree, for example, that as a matter of fact in analytic philosophy the linguistic turn - to which the later Wittgensteinian tradition certainly belongs — has already gone by. According to Cora Diamond, for instance, "Various ideas about the significance of logic and language to philosophy," which were characteristic of early and middle analytic philosophy, "virtually disappear in late analytic philosophy"; she suggests that this change depends on the resurgence of metaphysics (Bonino and Tripodi 2018b: 24). John Skorupski has pointed out that late analytic philosophers by now reject earlier views about philosophy and language: "Philosophical questions, specifically, metaphysical questions are, it is now generally held, genuine questions. How they relate to science is debated. But (it is thought) they certainly cannot be dissolved by linguistic analysis" (Bonino and Tripodi 2018b: 41). And Tim Williamson has noticed that in many respects late analytic philosophy has more in common with early analytic philosophy — Russell arguably being the paradigm case - than with the intervening period of middle analytic philosophy, first of all because middle analytic philosophers such as Wittgenstein, the logical positivists and ordinary language philosophers belonged to the linguistic turn, whereas both late and early analytic philosophers are not linguistic philosophers in any distinctive sense. Of course they can be, and sometimes are, seriously concerned with language: some of them aim to understand the semantics of natural languages; others employ artificial formal languages to build systematic theories. However, as Williamson puts it, "those activities do not make one a linguistic philosopher, because they imply no special relationship of philosophy to language" (Bonino and Tripodi 2018b: 47). Of course, many disciplines study language: linguistics, history, literary studies, psychology, sociology, computer science. However, as Williamson emphasises, the linguistic turn "was supposed to be more than that. Late analytic philosophy has woken up to the failure of linguistic philosophy to deliver on its methodological promises, its failure even to study language systematically enough" (Bonino and Tripodi 2018b: 48).

The end of the linguistic turn, however, is just an example, though a central one. The decline of Wittgenstein in the recent history of analytic philosophy is a visible event. In the above-mentioned 
article devoted to the transformations of analytic philosophy in the last forty years, Williamson told an interesting anecdote taken from the peculiar context of the University of Oxford (Williamson 2014). The anecdote witnesses the decline of Wittgenstein in the recent history of analytic philosophy. The episode goes back to a 1994 meeting of the so-called Tuesday group at the University of Oxford, a seminar originally founded by Ayer in 1959, in order to counterbalance Austin's Saturday morning meetings. Williamson remembers that "Susan Hurley read a carefully reasoned paper against the Private Language Argument to an audience that included many leading Oxford philosophers. The audience was divided by age. Roughly, those over fifty did not take the possibility that Wittgenstein's argument was fundamentally flawed seriously, although they also did not explain how it worked or what it showed; those under fifty were more sympathetic to Hurley's objections" (Williamson 2014: 27-28). ${ }^{\text {iii }}$ According to Williamson, the snapshot encourages a reflection on what he calls "the fear factor":

Of course, the flame is kept alive by surviving groups of Old Believers. Some others, more willing to believe that there has been progress in philosophy since 1970, still find value in engaging with Wittgenstein's work. Nevertheless, his influence has declined drastically over the past forty years. No doubt that could be roughly measured by his proportion of citations in journals. But what strikes me most forcefully is that the fear factor has gone. As a test of authority, of intellectual or other kinds, admiration tells less than fear. In the 1970s, even non-Wittgensteinian philosophers were often afraid to speak out against Wittgenstein. They are no longer so. (Williamson 2014: 28)

Oxford, of course, offers a peculiar point of view. Compare for example the Philosophy Faculty of the University of Oxford during the golden age of linguistic philosophy — there were more than twenty philosophers, all Wittgensteinians or at any rate highly influenced by Wittgenstein - with the professors of the same Faculty who nowadays have 'Wittgenstein' in their area of specialisation; there are only six philosophers, namely Bill Child, Edward Harcourt, John Hyman, Adrian Moore, Katherine Morris, and Stephen Mulhall. ${ }^{\text {iv }}$ It is also quite impressive to list chronologically the professorial fellowships at the University of Oxford since the 1950s. Here is the list of the Waynflete Professors of Metaphysical Philosophy: Gilbert Ryle (1945-1967); Peter Strawson (1968-1987); Christopher Peacocke (1989-2000); Dorothy Edgington (2003-2006); John Hawthorne (2006-2015); Ofra Magidor (2016-present). And here are the Wykeham Professors of Logic: Alfred Jules Ayer (1959-1978); Michael Dummett (1979-1992); David Wiggins (1993-2000); Timothy Williamson (2000-present). 
As is obvious, however, the phenomenon is not limited to Oxford. For example, in a recent interview Danièle Moyal-Sharrock confirmed the state of affairs for Britain in general and for London in particular: "I founded the [British Wittgenstein] Society," she said, "in reaction to the decline of Wittgenstein's reputation in the UK, particularly London universities," so as "to help ensure that Wittgenstein's work has the impact on our civilisation that it deserves to have" (Moyal-Sharrock 2014).

Unsurprisingly, in the United States things are even worse for the later Wittgensteinian tradition. Perhaps nobody said it better than Newton Garver in the mid-1980s: ${ }^{\mathrm{v}}$

There is no doubt whatever that Wittgenstein has been noticed in America, and there is every reason to believe this will continue to be the case into the foreseeable future. On the other hand, Wittgenstein has no significant following here. People recognize him, read him, cite him, and discuss him; but few take up philosophy in his manner or modify their thinking in line with the main thrusts of his work. In literature there may be no difference between being noticed and having an impact, but there certainly is a difference in science: Velikovsky's Worlds in Collision has been widely noticed and continues to be discussed, but it cannot be said to have had an impact on modern science. In the same sense one has to say that Wittgenstein has had little impact on such American philosophers as Carnap, Hempel, Feigl, Grünbaum, Quine, Chisholm, Goodman, Rawls, Kripke, Dworkin, Gewirth, Donagan, Kaplan, Searle - even though they have all noticed Wittgenstein. The exceptions are fewer: Black, Malcolm, Bergmann (selectively), and Foot. (Netwon Garver 1987: 207)

More generally, there are many different indicators and data revealing and in some case even measuring the decline of the later Wittgensteinian tradition, both in Britain and in the United States. In the Anglo-American academic world, the main courses in philosophy are normally 'Metaphysics,' 'Philosophy of language,' 'Philosophy of science,' 'Philosophy of mind,' 'Epistemology,' 'Logic,' and so forth, and normally they are not characterised by the acceptance of a later Wittgensteinian paradigm. For the mainstream analytic eye, 'Wittgenstein' is the name of a great philosopher and a founding father, but it refers to a somewhat historical subject, not far from 'Modern philosophy,' 'American pragmatism' or the even more exotic 'Continental philosophy'.

Of course, Wittgenstein is quite unanimously considered a classic, and there are endless works of commentary, interpretation and exegesis on his thought, as well as comparative analyses of the form 
"Wittgenstein and ...". In the titles of all journal articles, books and academic dissertations recorded by the Philosopher's Index in the period 1950-2009, there are 8,679 occurrences of 'Wittgenstein,' a datum which indicates that Wittgenstein is less popular than philosophers such as Kant (occurring in 18,407 titles), Hegel (16,358), Marx (13,981), or Heidegger (11,582), but nonetheless he is more popular than philosophers such as Sartre $(5,455)$, Husserl $(5,377)$, Locke $(5,082)$, Spinoza $(4,997)$ or Dewey $(4,851)$, and far more popular than analytic philosophers such as Quine $(1,744)$ or Kripke (629) (Bonino and Tripodi 2019). Notice also that the number of occurrences of 'Wittgenstein' slightly but regularly increases, from the first to the last decade. ${ }^{\mathrm{vi}}$

Does all this mean that speaking of a decline of Wittgenstein, as is repeatedly done in this book, is nothing but an illusion? No, it only means that the decline took place in a more restricted area. The above-reported result reveals something interesting about Wittgenstein's place in contemporary philosophy, with a special focus on the English-speaking philosophical world (since the Philosopher's Index may to a certain extent have an anglophone bias) but without any constraint concerning a specific philosophical current or tradition. The decline of Wittgenstein is a more local phenomenon, which belongs to the history of Anglo-American analytic philosophy. However, it is a real and measurable phenomenon, as is clearly shown by certain results recently achieved by scientometrics. The authors of the study took into account a corpus of 4,966 articles taken from five important philosophical journals belonging to the analytic tradition - The Philosophical Review, Noûs, The Journal of Philosophy, Mind, and Philosophy and Phenomenological Research - from the period 1985-2014, and they provided a list of the most cited philosophers. There is little doubt that the results obtained strongly confirm the 'decline view' described above. Wittgenstein has only 199 citations, therefore occupying the $63^{\text {rd }}$ position in the ranking, far from the top rankings: 1) David Lewis (2119 citations), 2) Willard Van Orman Quine (921), 3) Donald Davidson (899), 4) Hilary Putnam (685), 5) Tyler Burge (668), 6) Jerry Fodor (649), 7) Gottlob Frege (574), 8) Timothy Williamson (544), 9) Bertrand Russell (540), 10) Saul Kripke (489); ${ }^{\text {vii }}$ in the ranking Wittgenstein is also exceeded by such different philosophers as Crispin Wright, Michael Dummett, Bernard Williams, Robert Stalnaker, John Rawls, George Edward Moore, Immanuel Kant, Peter Strawson, Rudolf Carnap, and Wilfrid Sellars, among others (Buonomo and Petrovich 2018: 166). Notwithstanding his lasting centrality as a subject of exegesis and research for philosophy in general (not to mention the other human sciences), the presence and influence of Wittgenstein is nowadays much less evident in current philosophical theories, as far as the analytic tradition is concerned; in the analytic context - the specific and unique context that really matters in the present book — Wittgenstein's philosophical views, especially his later views, have been increasingly ignored or neglected, his name rarely mentioned.

For example, to put it hyperbolically, it often seems that an analytic philosopher who works on the 
issue of mental causation (with the aim of achieving substantial results) would probably consider a debate on the later Wittgensteinian idea that reasons are not and cannot be causes in a somewhat similar way as a contemporary astronomer would view a debate over the Ptolemaic model; serious work - the typical analytic philosopher of mind seems to take for granted — begins after those hypotheses have been rejected or abandoned. viii This is probably one reason why several contemporary Wittgensteinian philosophers had, and still have, the impression they are being put aside without argument (and they also think that the analogy between the Wittgensteinian paradigm and the Ptolemaic one is nothing but a sign of the "scientism" of current mainstream analytic philosophy).

It was already in the 1970s that Oets Kolk Bouwsma disapproved of his students' return to philosophical theories, "as if Wittgenstein had never existed" (Rollins 1985: 210). According to the late Norman Malcolm,

One might suppose that within a few years after the publication of the Philosophical Investigations, the direction of philosophical work would have sharply altered. Philosophers would no longer be searching for the universal, the essential. But if one supposed this, one would be wrong. Books containing theories of art, of thinking, of belief, of ethics, of action, of knowledge, of language, continue to abound. (Malcolm 1993: 48)

Von Wright observed that if analytic philosophy is an ally of "the two forces which more than any other have stamped contemporary civilisation: science and technology," then "of the Investigations one might say that its spirit is alien and even hostile to the typically 'analytic' approach" (von Wright 1993: 25, 32). In 2005 Anthony Kenny confessed that

By the time I came to publish a collection of such papers in The Legacy of Wittgenstein (Oxford: Basil Blackwell, 1984) I had to lament that the philosophical influence of Wittgenstein seemed to be diminishing rather than increasing. Some of Wittgenstein's insights into philosophy of language and philosophy of mind, I had believed, constituted irreversible advances in the subject. But now they were obscured or forgotten. Metaphysical weeds that his probing should have rooted up once and for all returned in ever more abundant strength. (Kenny 2005: vii)

Hacker made a similar point, underlining at the same time a difference between the legacy of the early 
Wittgenstein and that of the late Wittgenstein:

By the mid 1960s its [Wittgenstein's later thought's] influence was already declining and twenty years later it was evident that in many respects the spirit of the Tractatus, merged with ... scientistic character of post-positivist ideas derived in part from members of the [Vienna] Circle, had triumphed over the spirit of the Investigations and its Oxonian offspring. (Hacker 1996: 1)

A brief look at the Philosophy Family Tree - a "genealogy" of philosophers, in which the "parent" relation is the relation between dissertation advisor and dissertation advisee - provides some hints of the decline of Wittgenstein in Anglo-American analytic philosophy. ${ }^{\text {ix }}$ Wittgenstein has only 4 direct pupils (Anscombe, A.C. Jackson, Gasking, and Goodstein) and 115 descendants (i.e., the pupils of the pupils). However, if our purpose is to provide an approximate and preliminary map of Wittgenstein's influence on the Anglo-American academy, we should be aware that this data has a very low recall, since there are too many false negatives: consider, for example, people such as Max Black, whose advisor was Susan Stebbing, or Malcolm, who studied under Moore, or as von Wright, who was originally supervised by Eino Kaila; it is difficult to deny that all of them are Wittgensteinian philosophers (perhaps Black is the least orthodox of the three), so they should be included in the list. On the other hand, if one takes a more inclusive attitude, the data increases recall but loses precision: many false positives - in particular, many non-Wittgensteinian analytic philosophers — are included in the list. Consider some examples. Malcolm seems to have had 70 advisees, but 47 of them had Sydney Shoemaker as "forefather," and this makes it likely that their original relationship with Wittgenstein has disappeared or, at least, become looser and looser. Von Wright's most famous pupil, namely Jaakko Hintikka, worked at least in part outside the Wittgensteinian orthodoxy. Anscombe had 3 advisees, that is, Kenny, Philippa Foot, and Michael Dummett, the last two having in turn 37 advisees: some of them were more analytic than Wittgensteinian, some others cannot be considered Wittgensteinian under any reasonable respect. The genealogy of Reuben Goodstein includes Johan van Benthem, whose logical work, at least prima facie, cannot be labeled 'Wittgenstein-inspired' under any respect. If one tries to obtain a rough and ready equilibrium between recall and precision, considering all the branches starting with people such as Black, Malcolm, von Wright, Rhees, Hacker, Kenny, Geach, Ambrose and Winch, one counts less than one hundred "somewhat more orthodox" Wittgensteinians. This number can be tentatively evaluated by comparing it with the list of advisees which one finds in the branches starting with Quine: 247 advisees, among them Donald Davidson, David Lewis and Gilbert Harman.

A comparable picture also emerges when one takes into account different kinds of data, such as 
the articles published in analytic journals, philosophy series and encyclopaedias of philosophy. First of all, notice that in 1978 the journal Philosophical Investigations was founded. The founding editor was Frederick E. Mosedale. But soon afterwards, and for many years later, the journal was edited by Dewi Z. Phillips, a Wittgensteinian philosopher of religion belonging to the so-called Swansea School, associated with the names of Roy F. Holland, Peter Winch and Rush Rhees. Since then, the journal has focused on Wittgenstein's philosophy, the philosophy of his pupils and followers, and a Wittgenstein-inspired critique of the current analytic mainstream. Now, a question naturally arises: Why did the Swansea scholars feel the need to launch such a new journal? In an article published in the same year - 1978 - on Metaphilosophy, with the title 'On Saying What is Obvious,' Mosedale seemed to provide a general answer, albeit indirectly:

I am interested in understanding the decline of interest in ordinary language (OL) philosophy. Perhaps it is more accurate to say that I am interested in understanding how contemporary philosophers have made their peace with one of the challenges presented by OL philosophers. I assume that many philosophers have lost interest in OL philosophy because they have somehow come to see that this challenge is defective. I, as yet, have been unable to decide whether the challenge is defective. What have others detected which I have not? (Mosedale 1978: 14)

Taking a slightly different perspective, one can also easily conjecture that the foundation of such a full-blooded Wittgensteinian journal is perhaps symptomatic of the fact that at the end of the 1970s it had already become relatively more difficult — of course, not impossible but still difficult, at least more difficult than it used to be - to publish articles written in the spirit of Wittgenstein in leading analytic journals such as The Journal of Philosophy, Mind and The Philosophical Review. ${ }^{\mathrm{x}}$

Consider, furthermore, the authoritative philosophy series The Library of Living Philosophers, edited by Paul Arthur Schilpp (since 1981, from Lewis Edwin Hahn). It contains only one monograph dedicated to an orthodox Wittgensteinian philosopher, namely von Wright, published in 1989. Notice also that — as Cora Diamond once observed — in the 1996 Supplement of the Encyclopedia of Philosophy "there [was] nothing ... on Wittgenstein on knowledge, belief.... Wittgenstein [was] a non-figure for post-1967 philosophy of logic"; in a such a context, Diamond felt the need "to advise students with an interest in Wittgenstein that, if it is possible for them to do so, they play down that interest when they apply for positions teaching philosophy" (Diamond 2001: 113). Lars Herzberg made analogous considerations about the ninth volume of the Routledge Encycopedia of Philosophy: "Certain philosophers in the tradition from Wittgenstein, such as Rush Rhees and Cora Diamond, are 
almost totally neglected. ... It is also interesting to note that in the article on Wittgenstein, Saul Kripke is singled out as the outstanding guide to his later thought" (Hertzberg 2006: 83). Hertzberg also emphasised a structural asymmetry:

The marginalisation of Wittgenstein often takes the form of regarding philosophers whose work is inspired by his as forming their own enclave. In the leading journals of the field, one would rarely find a work, say, by Quine or Davidson, or a work written in their spirit, reviewed by someone from a Wittgensteinian tradition, while it is quite common for philosophers, say, of a Quinian, Davidsonian or other mainstream persuasion to review works written by philosophers influenced by Wittgenstein. The latter is of course entirely as it should be; it is the former situation that is regrettable. (Hertzberg 2006: 84)

For the present purposes, the above evidence of the decline of the later Wittgensteinian tradition in the analytic philosophical community, if compared to the central place it occupied during the golden age of linguistic philosophy in the 1950s and 1960s, is something more than a mere sketch or suggestion: it is a fact. A fact confirmed by evidence taken from multiple sources: historicalphilosophical evaluation, academic history, editorial and publishing data, personal memories, citation analysis. Therefore it is likely that the historical-philosophical picture outlined in this chapter (though not perhaps every detail of it) will satisfy those who already shared the same viewpoint: for example, Frascolla, Marconi and Voltolini, who wrote that "there is little doubt that interest in Wittgenstein's philosophy has been declining in the last twenty years", and "this is particularly true with analytic philosophers" (Frascolla, Marconi and Voltolini 2010: 1), or Hanjo Glock, according to whom nowadays "there is a pervasive feeling that his [Wittgenstein's] influence is in decline", this impression being "not confined to Wittgenstein's detractors", but being also "shared by many of his admirers" (Glock 2008a: 375). Nonetheless, it is also possible that those who previously had a different opinion or feeling are not convinced yet. In particular, there could be two kinds of sceptics. Those, for example, who believe that Wittgenstein is still as central as always in analytic philosophy, perhaps because this is suggested by their peculiar subjective viewpoint; citation data provided above suggests that they are probably overgeneralising to the entire landscape from more or less scattered impressions deriving, as it were, from their own private garden. On the other side, those who find it neither surprising nor interesting that a philosopher who died nearly seventy years ago is not mainstream any more; therefore they maintain that there is nothing worth investigating in this respect.

Both kinds of sceptical readers may be asked to suspend judgment for a moment, regarding the 
starting point of this book - what is actually its main explanandum, namely, the fact that Wittgenstein's later philosophy has lost its centrality in Britain and never reached a comparable position in the United States — as something like an "excuse" and a "chance" to narrate a hopefully interesting story of a significant part of the history of analytic philosophy. Here it is worth emphasising once again that this investigation focuses narrowly on the history of analytic philosophy, since it will neither take into account the great amount of exegetical or historical works on Wittgenstein's philosophy, the so-called Wittgenstein studies; nor will it touch upon the large and multifaceted sets of questions concerning the non-analytic uses of Wittgenstein. ${ }^{x i}$ This is, at least in part, a novel account, for the account of the same facts provided by Peter Hacker in his Wittgenstein's Place in Twentieth Century Analytic Philosophy - according to which, roughly, the decline of Wittgenstein's influence amounts to the end of analytic philosophy (Hacker 1996: chapter 8) - is difficult to accept entirely, first of all because it runs the risk of confusing the description of the historical-philosophical processes with their evaluation. However, it goes without saying for everyone who reads both this introductory chapter and the next ones, this book is greatly indebted to Hacker's work. Moreover, this book is not a rational reconstruction and is critical towards the view, often accepted or even taken for granted by analytic philosophers, that the driving forces in the history of philosophy are first and foremost philosophical arguments. The book is sympathetic to the perspective according to which the driving forces operate underneath the surface of arguments, at a broadly cultural and even social level (see, for example, Bourdieu 1984a and 1999, Bloor 1976, Kusch 1995). The book can be regarded as an attempt to show or perhaps just suggest the validity of that perspective in a particular case-study, the story of the decline of Wittgenstein in the history of analytic philosophy. However, this attempt is made not by moving entirely in the fields of intellectual history and the sociology of philosophy: the main topic of the book is still, after all, a battery of philosophical arguments; yet, its aim is to present, understand and evaluate such arguments in the broadly cultural and, to a lesser extent, social context.

Notes

\footnotetext{
${ }^{\mathrm{i}}$ Throughout the book (in fact, even in the title), the concepts analytic philosophy and later Wittgensteinian tradition are employed, though both of them are inevitably vague and theory-laden. Both concepts have a less controversial core: for example, there is no doubt that Russell, Carnap, Quine and David Lewis are analytic philosophers, whereas Anscombe, Malcolm, Kenny and Hacker are somewhat "orthodox" Wittgensteinians. These concepts also have a more controversial periphery. For example: Is Wittgenstein himself an analytic philosopher? And what about the fact that Kripke is at the same time a full-blooded analytic philosopher and a sui generis Wittgensteinian, or that philosophers so different from each other as Crispin Wright and John McDowell may both be seen as heterodox Wittgensteinians? However, a preliminary clarification - never mind a definition - of these notions would require the writing of a separate monograph (by the way, Glock 2008b is, among other things, that work). The present book is based on the assumption that, though fuzzy and somewhat controversial, the concepts of analytic philosophy and later Wittgensteinian tradition are indispensable and, in fact, fertile. This is enough for our present purposes.

${ }^{\text {ii }}$ Lynd Forguson analysed the subjects discussed in examinations at the University of Oxford, in both Greats and PPE:

"The 1946 examinations in these subjects are practically indistinguishable in general philosophical orientation from those
} 
in the immediate pre-war years. However, questions reflecting the special interests of the Oxford ordinary language philosophers began to appear on both papers of the "Greats" examination as early as 1947. They occur with increasing frequency throughout the 1950s, with the 1957 Logic paper on the "PPE" examination containing no fewer than eleven of fourteen questions inviting an ordinary language approach" (Forguson 2001: 333). As to B.Phil examination papers, "in the early years, the ordinary language philosophy approach was also much in evidence among the questions, from the first examination in 1948 through the early 1960s" (Forguson 2001: 334).

iii Oxford's peculiar place in this story emerges from a second episode told by Williamson. It took place in 2000 in a graduate class on philosophical logic at the University of Oxford. A student kept on defending the Wittgensteinian view that contradictions are meaningless rather than false. Williamson replied by providing the "standard" responses: contradictions have true negations, whereas the negation of a meaningless sentence is itself meaningless. Feeling perhaps that it was a dialogue de sourds, eventually Williamson "became exasperated and said, 'Maybe Wittgenstein was just wrong; it wouldn't be the first time'. There was a collective gasp of shock". Williamson commented: "I have never again witnessed such a reaction when Wittgenstein's name was taken lightly" (Williamson 2014: 28).

${ }^{\text {iv }}$ All of them took their DPhil at Oxford. It might be interesting to see who their supervisors were. Bill Child: David Pears and, after his retirement, David Charles (personal communication). Edward Harcourt: Michael Dummett, until his retirement, then Paul Snowdon and Bernard Williams; however, the first person who taught Wittgenstein to Harcourt was Kathy Wilkes, who was a graduate student at Princeton at the time of Rorty and Harman (personal communication). John Hyman: Peter Hacker (Glock and Hyman 2009). Adrian Moore: Michael Dummett (however, as an undergraduate at Cambridge he attended lectures by Elizabeth Anscombe and Bernard Williams) (Lodge 2018). Katherine Morris had multiple supervisors: Brian Farrell, Richard Wollheim, Gareth Evans, Jennifer Hornsby and David Pears (personal communication). Stephen Mulhall: Peter Hacker, but Anthony Kenny gave a bit of bibliographical advice (personal communication).

${ }^{\mathrm{v}}$ This doesn't mean that his remarks and omissions are entirely shareable: for example, it is surprising that among the exceptions he mentioned neither Sellars nor Cavell.

${ }^{\text {vi } H e r e ~ a r e ~ t h e ~ p e r c e n t a g e s ~ o f ~ t i t l e s ~ c o n t a i n i n g ~ ' W i t t g e n s t e i n ' ~ o v e r ~ a ~ c o r p u s ~ o f ~ m o r e ~ t h a n ~ 19,500,000 ~ t i t l e s: ~} 0.0076 \%$ in the $1950 \mathrm{~s} ; 0.0226 \%$ in the $1960 \mathrm{~s} ; 0.0401 \%$ in the $1970 \mathrm{~s} ; 0.0534 \%$ in the $1980 \mathrm{~s} ; 0.0573 \%$ in the $1990 \mathrm{~s} ; 0.0680 \%$ in the 2000s. Similar results come out from a search using Google Ngram-Viewer (rather than the Philosopher's Index): https://books.google.com/ngrams.

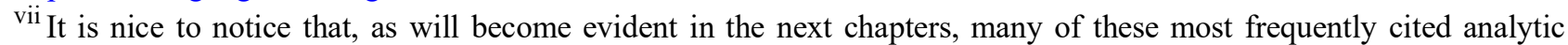
philosophers have a central role in the story reconstructed in the present book. Arguably, this will make the provided explanation of the decline of Wittgenstein more elegant, if not more convincing.

viii The analogy with the Ptolemaic-Copernican controversy is in part a hyperbole: this is shown, to mention just an example, by the well-known and highly respected work that Julia Tanney has recently done on reasons and causes (Tanney 2015). Yet, indeed, it is a hyperbole only in part.

ix The Tree has some or perhaps many lacunas. However, it can be taken into account with the due caution.

${ }^{\mathrm{x}}$ Notice also, incidentally, that up to 1984 the masthead of the journal Philosophical Investigations stated: "The journal seeks to express, extend or criticise ways of philosophising influenced by Ludwig Wittgenstein, J. L. Austin and Gilbert Ryle." However, in the first issue of 1985 this statement was removed without discussion and has never reappeared since. As Tommi Uschanov noticed, "this was probably due merely to the lack of submissions about Austin and Ryle" (Uschanov 2000; see also Uschanov 2002) for, as Lynd Forguson put it, OLP had by then become "a kind of disease similar to deconstruction" (Forguson 2001, 326).

${ }^{x i}$ To be frank, there is another restriction to mention here: the focus in this book is almost entirely limited to philosophical fields such as epistemology, philosophy of language, philosophy of mind, metaphysics, and so forth, whereas moral and political philosophy are not taken into due consideration. Arguably, this restriction is not without consequences, for (i) the (recent) history of moral and political philosophy in the analytic tradition has its peculiarities (see for example the interview to Jonathan Wolff in Bonino and Tripodi 2018b: 48-50); (ii) some of these peculiarities concern the philosophical legacy of Wittgenstein (think for example to the centrality for moral philosophy of a Wittgenstein-inspired author such as Bernard Williams, or to the role played by Elizabeth Anscombe in fostering a normative, substantive turn in moral philosophy). 


\section{The Core and the Periphery}

The earliest attacks against the later Wittgensteinian tradition were part of the 'intellectual war' between the London School of Economics and the Universities of Oxford and Cambridge. One of the sources of discord, though by no means the only one (suffice it to think of the Keynes-Hayek debate in economics), was the well-known antagonism between Wittgenstein and Popper, the philosophical champion of the LSE. ${ }^{x i}$ Popper regarded himself as the one mainly responsible for the fall of logical positivism, but he arguably also had a role in the decline of Oxford linguistic philosophy. In the vein of Russell's remarks on the slight help for lexicographers provided by Wittgenstein's lazy later philosophy (Russell 1959a: 217), in the preface to the first edition of his The Logic of Scientific Discovery Popper had dismissed Wittgenstein's semantic views of the a priori as purely verbal minutiae and problems about mere words (Coffa 1991: chapter 18); against this view he quoted Kant, according to whom, "Whenever a dispute has raged for any length of time, especially in philosophy, there was, at the bottom of it, never a problem about mere words, but always a genuine problem about things" (Popper 1935/1959/2002: xv). In 1945 Popper had also criticised the "scholasticism and mysticism" of Wittgenstein's doctrine "that while science investigates matters of fact, it is the business of philosophy to clarify the meaning of terms," noting that "it is characteristic for the views of this school that they do not lead to any chain of argument that could be rationally criticised, and that it therefore addresses its subtle analyses exclusively to the small esoteric circle of the initiated" (Popper 1945/2009: 19). In a long footnote, he also claimed that "Wittgenstein's method leads to a merely verbal solution," suggesting that we are "faced with that kind of position which I have described elsewhere, in connection with Hegel, ... as a reinforced dogmatism;" then he concluded that "not only does Wittgenstein's theory invite every kind of metaphysical nonsense to pose as deeply significant; it also blurs what I have called ... the problem of demarcation" (Popper 1945/2009: 282-3). Wittgenstein, for his part, always had little regard for Popper's (social) philosophy, which he presumably found vulgar and simplistic, and it is likely that he was offended by those footnotes; therefore when in 1947 Ryle published an approving review of The Open Society and its Enemies in Mind, Wittgenstein did not hesitate to break a friendship dating back to 1929 (Ryle 1947; Hacker, 1996: 313). Popper, of course, did not hold back his tendency to criticise Wittgenstein, and in 1959, in the preface to the second edition of The Logic of Scientific Discovery, he directed his arrows against the methodological hegemony of linguistic analysis in Britain, confessing that he did not "care what methods a philosopher (or anybody else) may use, so long as he has an interesting problem, and so long as he is sincerely trying to solve it" (Popper 1935/1959/2002: xix). 
It is not therefore surprising that the protagonists of the early attacks on linguistic philosophy came from the LSE. One of them was the philosopher John Watkins, who taught at the LSE and was heavily under the spell of Popper, so that for a while he was regarded, as witnessed for example by Paul Feyerabend, as Popper's 'pit bull' (Feyerabend 1995: 95; see also Musgrave 1999). ${ }^{x i}$ The episode in question took place in 1957, when Watkins published in Analysis a sharp criticism of so-called paradigm-case arguments (Watkins 1957a). ${ }^{x i}$ Some linguistic philosophers believed that being called ' $\mathrm{P}$ ' is (with some qualifications) a sufficient condition for being a P. This belief had important philosophical consequences. Suppose for example that someone, say, a sceptic, claims that something, the Ps, does not exist. Then you notice that not only is this $o$ in front of us paradigmatically called 'P,' but $o$ clearly exists (it is right here, in front of us). To deny that this $o$ is a $\mathrm{P}$ is a sign that one is not fully grasping the meaning of ' $\mathrm{P}$,' because the paradigmatic application of ' $\mathrm{P}$ ' to $o$ is at least partly constitutive of the meaning of 'P.' Therefore, either the sceptic does not fully understand what ' $\mathrm{P}$ ' means, or he is using ' $\mathrm{P}$ ' in some non-standard or deviant sense. For example, if something is paradigmatically called 'table' (that is, if it is uncontroversial that any reasonable speaker, who is fully competent about how the word 'table' has to be used in English, calls it 'table'), then it is indeed a table. Therefore a sceptic about material things, i.e., one who denies that there are things like, say, tables, chairs, and people, is either foolish or semantically deviant. So that scepticism about tables is easily refuted by exhibiting a paradigmatic application of the word 'table.'

The argument was potentially very general, and it was easy to find applications of it in Oxford philosophy in the 1940s and 1950s. Austin, for example, presented a paradigm-case argument discussing perception with Ayer. Ayer claimed that all perception should be explained in terms of sense data (Ayer 1940). Austin noticed that Ayer's argument entailed that one never sees a material object, and that there is no perception of material objects such as chairs, but only perception of sense data. However, he argued, look, this is a chair; you cannot deny that this is what we all paradigmatically call 'chair' (Austin 1962a).

It is controversial among interpreters whether Wittgenstein himself put forward this kind of argument. Perhaps he came close to doing so in the following passage from the Investigations:

If anyone said that information about the past could not convince him that something would happen in the future, I should not understand him. One might ask him: What do you expect to be told, then? What sort of information do you call a ground for such a belief? What do you call "conviction"? In what kind of way do you expect to be convinced?-If these are not grounds, then what are grounds? (Wittgenstein 1953: § 481) 
At any rate - what is most relevant for the present purposes - it is uncontroversial that several Wittgenstein-inspired philosophers such as Urmson, Flew, Malcolm, and Black produced paradigmcase arguments. A special role in this story was played by a combination of views originating from Moore, reinterpreted by Wittgenstein, and borrowed by Malcolm. In his attempt to defend common sense against the Cartesian sceptic, Moore famously stood up and declared: "Here is one hand, ... and here is another hand" (Moore 1939: 166). According to him, these truisms express or describe special empirical facts, which we know with absolute certainty. Wittgenstein, especially in his later thoughts then merged into On Certainty, interpreted Moore's truisms as having the peculiar function of rules that are partly constitutive of our rationality, rather than as empirical or factual self-evident assertions (Wittgenstein 1969; see also Coliva 2010). In the 1940s Malcolm came to Cambridge from the United States to investigate (how to refute) scepticism under the supervision of Moore, but then he met Wittgenstein and became a pupil of his and, in the next decades, his principal "voice" in America. In 1942 Malcolm used to believe that "ordinary language is correct language" (Malcolm 1942/1964: 15); but when other philosophers, such as for example Roderick Chisholm, replied that it would be absurd to argue, say, against Columbus that people paradigmatically applied the word 'round' to things such as apples and cherries, rather than to the Earth, which on the contrary they paradigmatically called 'flat', Malcolm came to weaken his dubious claim. Nevertheless, he never ceased to apply paradigm case arguments or stress the philosophical authority of ordinary language (Chisholm 1951; Malcolm 1951; see also Soames 2003: chapter 7). For example, he was still ready to refute scepticism about the reality of the past by pointing to a paradigmatic application of expressions such as 'I had breakfast one hour ago.' Any competent speaker has to accept that this is a case of past event. If they do not assent to it, they do not fully grasp the meaning of some words occurring in sentences such as 'I had breakfast one hour ago' and/or in expressions such as 'past event,' or perhaps they are using such words in non-standard ways (Malcolm 1951).

Max Black, to provide a further example, considered the case of a sceptic about causes, who denies that there are and, in fact, can be causes, since he thinks that the very notion of a cause is self-contradictory. Black refuted this kind of sceptic by pointing out the case of a thirsty man who stretches out his hand, picks up a bottle and drinks. This, he remarked, is what we normally call 'making something happen'; it is, more precisely, a paradigmatic application of the expression 'making something happen'. Therefore, he concluded, there are cases of making something happen and, a fortiori, there are causes. Either the sceptic does not have a full understanding of the word 'cause' or the expression 'making something happen,' or he is using these terms in some deviant or non-standard sense (Black 1958b). Similarly, Flew provided an argument concerning the validity of induction (Flew 1956); and other examples could be given as well (e.g., Urmson 1956; see also Marconi 2009). 
In his 1957 article Watkins criticised the view of meaning associated with paradigm-case arguments. Supporters of paradigm-case arguments, he pointed out, misleadingly identify connotation (meaning) with denotation (reference), or were at least convinced that connotation is derivative with respect to denotation. For example, they claimed that if a speaker is not willing to assent to a sentence such as 'This is a cat,' i.e. if she is not willing to apply referentially the word 'cat' to this animal in front of her, then she does not have a full grasp of what 'cat' means. Paradoxically enough, this bad conception of meaning was quite similar to the so-called Augustinian picture of language described and criticised by Wittgenstein at the beginning of the Investigations (Wittgenstein 1953: $\S \S 1$ and ff.). However, Watkins remarked, not only is meaning also connotation, that is, not only does it also depend on a set of criteria, on a definition, and so forth; but nor can we rule out the possibility that denotation depends on connotation, so that - so to speak - connotation comes first. But then a sentence such 'o is a P' (e.g., 'This, in front of me, is a cat') is factual rather than conceptual, empirical rather than meaning-constitutive, open to falsification rather than "analytically" true (Watkins 1957a and 1957b; cf. Flew 1957, Richman 1961 and Williams 1961). In modern, updated terms, one could say that paradigm-case arguments depend on a referential view of lexical competence, not giving due consideration to its inferential aspects (Marconi 1997). Taking into account inferential competence as well, one would make room for a possible counter-objection from the sceptic, who could easily acknowledge that this $o$ (this object in front of her) exists; however, the sceptic could argue, though it appears to be a $\mathrm{P}$, actually it is not a real $\mathrm{P}$, because being a $\mathrm{P}$ depends on a definition or set of criteria Q1... Qn, whereas this $o$ is not Q1 or ... or Qn; hence, it cannot be a P: for example, this existing object is not a cat but, say, a Martian artefact extremely similar to (or even indiscernible from) a real cat, for it does not meet the criteria that determine its deep nature or essence (Marconi 2009).

Watkins's attack on paradigm-case arguments was connected to two major philosophical issues, which were to become crucial for the future of the later Wittgensteinian tradition. First, a peculiar picture of science: more precisely, a view of the criteria for the demarcation of science from pseudoscience, and a view of the role played in science by observation and theory, respectively. Second, a metaphilosophical view of the relationship between science and philosophy, the so-called continuitydiscontinuity issue. As to the first issue, notice that ordinary language philosophers may happen to be faced with a scientist, rather than with a traditional sceptic. Apparently, Wittgensteinian philosophers had in mind ordinary language terms ('table,' 'cat,' 'breakfast,' 'hand' and so forth) and, in particular, observational terms. However, one could ask, in analogy with Watkins, what about theoretical terms, i.e., terms that — as a scientific realist would argue — refer to unobservable entities, whose existence is postulated by virtue of merely theoretical (non-observational) reasons? What 
comes first, the observational or the theoretical? As to the latter issue, according to linguistic philosophers there are uses of words, call them paradigmatic uses, which are (partly) constitutive of semantic competence. There are also uses that are non-constitutive, call them factual or empirical. Consequently, there is a difference between conceptual and factual statements; a difference on which the philosophy-science divide is ultimately based too.

\subsection{Words and Things}

It is likely that paradigm-case arguments were the first among the later Wittgensteinian cornerstones to be demolished in the history of analytic philosophy (Burge 1992: 13); and Watkins was partly responsible for that. It took longer, however, until philosophers came to appreciate entirely the important general and metaphilosophical consequences of the debate. In the same years, however, a second episode relating to the LSE's assault on Oxford linguistic philosophy proved to have a much wider impact than Watkins's criticism of paradigm-case arguments: the publication in 1959 — by Victor Gollancz, Ltd. — of Ernest Gellner's famous or, according to many, infamous book Words and Things: a Critical Account of Linguistic Philosophy and a Study in Ideology (Gellner 1959/1979). The buzz of the work was so strong that one might be tempted to think that its analysis could provide a possible answer to the general question raised in this book, namely: How to explain the decline of the later Wittgensteinian tradition in the history of analytic philosophy?This is exactly what Tommi Uschanov did in a couple of interesting articles published at the beginning of the 2000s, both devoted to "the strange death of ordinary language philosophy". According to Uschanov, the decline of Wittgenstein's later philosophy or, as Uschanov prefers to say, "the way in which OLP has been written out of history in recent decades is largely the result of Gellner's widespread influence" (Uschanov 2000 and 2002). ${ }^{\mathrm{xi}}$

A Czech, and then naturalised British anthropologist and sociologist, Gellner was at the time of publication a colleague of Watkins and Popper and Reader in Sociology at the London School of Economics, where he was also responsible for teaching philosophy. Some years earlier, however, he had studied philosophy at Balliol College, Oxford, thus becoming well-acquainted with leading linguistic philosophers such as Ryle, Pears, Anscombe, Urmson, Hampshire and Hare. In the early fifties, Gellner used to give talks in Oxford and write papers in a style similar to that of linguistic philosophers; Ryle appreciated his work and allowed him to publish in Mind (Hall 2011: 107, 159; see, for example, Gellner 1951). During the mid-1950s, however, he began diverging intellectually from Oxford philosophy, even from those people to whom he was personally close (Hall 2011: 159). Soon the later Wittgenstein became his bête noire, so that in 1959, encouraged by Russell (who wrote a laudatory preface), he published Words and Things. In doing so, in the British philosophical field he became a sort of "ally" of Russell himself, the author of the two quotations inserted by Gellner at 
the beginning of the text, as an epigraph:

The later Wittgenstein ... seems to have grown tired of serious thinking and to have invented a doctrine which would make such an activity unnecessary. I do not for one moment believe that the doctrine which has these lazy consequences is true.

The desire to understand the world is, they think, an outdated folly. (Russell 1959 a)

At the same time, Gellner was also on the same anti-Wittgensteinian side as his colleagues at the LSE, Popper and Watkins. He had been personally acquainted with Popper since the 1940s and had always admired his thought, though he sometimes assumed a critical attitude and often kept a certain distance (Hall 2011: 93, 106).

Gellner's criticism of linguistic philosophy was two-fold: philosophical and sociological. As Martin Kusch once emphasised, in philosophical controversies charges of relativism, irrationalism and total scepticism occupy a central role (Kusch 1995: 270). This is particularly true of Gellner's criticism of linguistic philosophy, in which these kinds of charges are made on almost every page, often flavoured with sarcasm and irony: linguistic philosophy implies relativism (Gellner 1959/1979: 116) and is tangled up in behaviourism (1959/1979: 121); linguistic philosophy has an anti-scientific and quasi-religious character, based on "face-saving devices" such as withdrawals, caution, ambiguity, ineffability, ad-hoc-ness, insinuation and taboos, which preserve it from falsification; linguistic philosophy is also based on the illusion of neutrality and superiority, which depends on its relying on the incontrovertible authority either of Wittgenstein ("one of the sages of Lagado") or of ordinary language, which linguistic philosophers regard as "somehow sacrosanct and outside the fray and neutral in virtue of some kind of fundamental and absolute status" (Gellner 1959/1979: 148-9, $188,136,158)$.

Moreover, according to Gellner, linguistic philosophy is embedded into an "a-historical atmosphere" (Gellner 1959/1979: 120) and its vision of the history of thought is, to say the least, naïve. "There is a first stage of intellectual innocence and health," he wrote, "in which people just use language, without puzzling about it and hence without puzzling philosophically about the world" (Gellner 1959/1979: 171). The next stage is when people begin to puzzle about the world, and this makes them postulate philosophical theories and "occamistically" suppose that there are only one or two ways to use language, rather than a hundred and more. Sooner or later ("probably sooner," as Gellner pointed out) they find themselves in trouble. "But the cure is simple," and it consists in "the 
cult of the idiosyncrasy of various kinds of use of language" fostered by Wittgenstein in the Investigations and anticipated by Moore (Gellner 1959/1979: 172).

Gellner also reported four more fundamental "mistakes or half-truths" perpetuated by linguistic philosophers. First, the paradigm-case argument, which Gellner characterised as an "argument from the actual use of words to the answer to philosophical problems, or from a conflict between the actual use of words to the falsity of a philosophical theory" (Gellner 1959/1979: 30). Second, a generalised version of the naturalistic fallacy, according to which linguistic norms can legitimately be inferred from currently accepted usage (Gellner 1959/1979: 36-39). Third, the contrast theory of meaning, which holds that any meaningful term must have both a possible example and a possible counterexample, a correct application and an incorrect one: concepts used "without antithesis" are meaningless, because nothing could conceivably count as their misapplication (Gellner 1959/1979: 39-43). Fourth, polymorphism, a doctrine that emphasises the great variety of linguistic uses for any given word, and from this insistence on the variety of uses, both between and within concepts, it (according to Gellner incorrectly) draws the conclusion that general assertions about the use of words are impossible (Gellner 1959/1979: 30; see also 1959/1979: 44-50).

In Gellner's view, these four pillars of linguistic philosophy have a great deal in common: they are all rooted in a common model of how language works; and they are all related to a misleading metaphilosophical picture, according to which philosophy is nothing but a piecemeal descriptive activity, whose aim is clarification and the "dissolution of philosophic problems by appeals to the actual use of words" (Gellner 1959/1979: 43). In fact, according to Gellner, in linguistic philosophy these two elements - a model of how language works and a therapeutic metaphilosophy — are strictly interrelated, so as to form "an amusing symbiosis, a logical circularity":

If philosophy is essentially therapeutic, then indeed attention to the individual cases is essential, and generalities are irrelevant (for therapy is always of the individual) even if true, and hence one must see language polymorphically. In the reverse direction: if the correct view of language is polymorphic, then indeed philosophy must be therapeutic, for in an inherently diversified field, where nothing general can be said, we can cure but we cannot build theories. (Gellner 1959/1979: 258)

Gellner provided several examples of how linguistic metaphilosophy worked by referring to Wisdom ("Philosophy begins and ends in platitude") and, of course, to Wittgenstein ("Philosophy only states what everyone admits," "Philosophy may in no way interfere with the actual use of language; it can in the end only describe it. For it cannot give it any foundation either. It leaves everything as it is") 
(Wittgenstein 1953: $\S \S 599,123$ ). But he also attached paramount importance to Moore's quotation from Bishop Butler in Principia Ethica: "Everything is what it is and not another thing" (Moore 1903; Gellner 1959/1979: 49, 100). This, Gellner suggested, had often been interpreted by linguistic philosophers as meaning that "everything is what it is said to be and should not be explained in terms of something else" (Gellner 1959/1979: 91), but he also emphasised that, to his eyes, the crucial point of this metaphilosophical stance was the insistence on the idea that philosophy is a "second-order study," so that "its findings cannot be about "first-order' issues, or, in plainer words, about the world" (Gellner 1959/1979: 100-1).

This brings us to Gellner's most famous objection to Oxford linguistic philosophy, namely, that it is deeply conservative, "conservative in a general, unspecific way," for it focuses on "showing that the reasons underlying criticisms of accepted habits are in general mistaken" (Gellner 1959/1979: 224-225). A mix of modesty (it does not interfere with anything) and messianic style (it fosters a revolution in philosophy), not only does linguistic philosophy defer to the linguistic habits of common men, a "prostration" before common sense that, following Russell, Gellner compared to Tolstoy's attitude towards the peasants (here Gellner commented with dry humour: "Fortunately, Tolstoy's muzhiks were not able to take up and propagate his doctrine. Wittgenstein's did") (Gellner 1959/1979: 113; Russell 1959b: 8-9). ${ }^{\text {xi }}$ But linguistic philosophy also preserves the social status quo, the status quo of Oxford upper class, the ivory tower to which most of its members used to belong (Gellner 1959/1979: 60, 235; see also Cohen 1960). Linguistic philosophy is a philosophy suitable for gentlemen:

\footnotetext{
Nothing is justified. It is merely explained that justification is redundant, that the need for it is pathological. The philosophy is simultaneously esoteric it is so refined and subtle in its effects that a prolonged habituation to its practices, and hence leisure, is necessary before one sees the point — and yet its message is that everything remains as it is, and no technicality is required. No vulgar new revelation about the world, no guttersnipe demands for reform, no technical specialisms are encouraged.(Gellner 1959/1979: 238)
}

To make this point clearer, Gellner revisited Thorstein Veblen's Theory of Leisure Class, characterising the minute pedantry of linguistic philosophy in terms of conspicuous triviality, a kind of conspicuous waste of time, talent and, ultimately, money (Gellner 1959/1979: 246; see also Veblen 1899). Gellner emphasised two consequences of the above-mentioned social conditions of linguistic philosophy: first, a special sense of decorum, which rules out as indecorous any attempt to criticise it radically, so that any "external" criticism is banned and only intra-paradigmatic micro-debates are 
allowed (Gellner 1959/1979: 191); second, an ideology (Gellner 1959/1979: 231, 237-8), based on the repulsion towards or lack of interest in science and "technicality," power and responsibility, critical ideas (Gellner 1959/1979: 239). Linguistic philosophers share an entirely misleading picture of how science works: in this regard, Gellner refers to the "strong arguments ... against seeing science in this way ... powerfully expounded by Professor K.R. Popper” (Gellner 1959/1979: 67-8). Linguistic philosophers are professional, academic philosophers, but they have been "trained in an untechnical, literary manner" (Gellner 1959/1979: 240). They have the cult of (verbal) meticulousness, but scorn arguments (1959/1979: 241). They insist on the practical irrelevance of philosophy (Gellner 1959/1979: 241-2) and, as they sometimes explicitly state, have a strong preference for "the ritual as a case of l'art pour l'art" (or "pure research"), which is easily explicable in the above-mentioned Veblenesque terms (Gellner 1959/1979: 252).

\subsection{The Impact of Gellner}

There are three related questions concerning Gellner's attack on linguistic philosophy, which should be kept apart from one another. The first concerns Gellner's philosophical arguments: are they tenable? No direct answer to this question will be provided here. The second question is: Is Gellner's sociological analysis by and large correct? This questions will be briefly taken into account in chapter 4 below. Let us now focus on the third question, the most important for the present purposes: Is Gellner's attack really responsible for the decline of the later Wittgensteinian philosophical tradition? In answering this question, one must distinguish between two different contexts: the context of analytic philosophy, in which arguably we can properly speak of a decline of Wittgenstein, on the one hand, and the wider and more heterogenous context of non-analytic philosophies, non-philosophical academic disciplines and non-academic culture, which falls largely outside the scope of the present investigation, on the other hand. In the latter contexts, the widespread influence of Words and Things was undeniable; and it is likely that the main reason for its popularity was, as Uschanov remarked, its novel attempt to explain the conservatism of linguistic philosophy not only philosophically but also sociologically (Uschanov 2000). ${ }^{\mathrm{xi}}$ Consider, for example, the way in which Herbert Marcuse criticised Wittgenstein in his One-Dimensional Man (1964), or the pages dedicated to Wittgenstein in Perry Anderson's 'Components of the National Culture' (1968): they are quite explicitly reworked versions of Gellner's 1959 main arguments (Marcuse 1964; Anderson 1968). A more tacit influence is recognisable in such different readers of Wittgenstein as Jürgen Habermas and Gilles Deleuze, to mention just a couple of them (Uschanov 2000).

In the former context, however, that is, in the context of the rise of analytic philosophy, the tangle is much more complicated and difficult to unravel. Around twenty years after the publication of Words and Things, most Anglo-American analytic philosophers considered Oxford linguistic philosophy a 
dead intellectual option, for reasons not so dissimilar to those wished for by Gellner: its hostility towards science, its "obscurantism", and its opposition to philosophical progress; its sacred devotion for ordinary language; its relativistic claim that all forms of life, the religious as well as the scientific ones, are equally legitimate; and, above all, its trivialisation of the task of philosophy, which Gellner compared to a dangerous euthanasia of philosophy (Gellner 1959/1979: 49).

Nevertheless, it is a strong overstatement to suppose, as Uschanov tends to, that the attitude taken by analytic philosophers towards Wittgenstein's later philosophy, never mind the decline of the later Wittgensteinian tradition in the history of analytic philosophy, depended on Gellner's impact. Nowadays, Words and Things is nearly forgotten within the analytic community (Uschanov 2000). ${ }^{\mathrm{xi}}$ Moreover, even though immediately after its publication Words and Things temporarily became, as Marshall Cohen noted, “the most discussed work of English philosophy since A.J. Ayer's Language, Truth and Logic" (Cohen 1960: 178; see also Ayer 1936), since the beginning its reception on both shores of the Atlantic was - with few exceptions - overwhelmingly hostile. As editor of Mind, Ryle wrote to the publishers, Victor Gollancz Ltd:

You recently sent me a review copy of Words and Things by Ernest Gellner. I am returning it to you (separately) since I shall not have a review of the book in Mind. Abusiveness may make a book saleable, but it disqualifies it from being treated as a contribution to an academic subject. (cited in Russell 1997: 607)

In a letter to the Times Russell protested that Mind should not boycott books that do not endorse its editor's views, and in turn Ryle replied that "in the book referred to by Earl Russell ... about 100 imputations of disingenuousness are made against a number of identifiable teachers of philosophy; about half of these occur on pages 159-192 and 237-265" (Metha 1962: 3). Gellner himself participated in the discussion, attributing to Ryle a sheer misunderstanding: the problem of linguistic philosophy is its inherent evasiveness, which does not require any conscious dishonesty.

Then the controversy expanded in the Economist and other journals. On the side of Gellner and Russell there were Conrad Dehn (a correspondent), Leslie Farrell (private solicitor to the Queen), Thomas Creed (a Queen's Consel), Arnold S. Kaufman and Bernard Crick (the political scientists), Joan Robinson (the Cambridge post-Keynesian economist) and I.A. Richards (the literary critic) (Mehta 1962; Uschanov 2000). Only very few professional philosophers belonged to this small proGellner group: the previously mentioned John Watkins, Geoffrey Mure, one of the last British Idealists, and the American philosopher Hans Meyerhoff (Mehta 1962; Musgrave 1999; Watkins 1960; Uschanov 2000). Besides them, the vast majority of academic philosophers defended the reputation 
of both Mind and its editor, and emphasised the abusiveness of Gellner's attack: this was, no doubt, the main keyword, considering the reviews in their entirety, from the review written by Alec Kassman, editor of the Proceedings of the Aristotelian Society, to that sent by Kevin Holland, an Oxford undergraduate (Mehta 1962). This attitude was also shared, as was easily foreseeable, by Oxford linguistic philosophers such as John Wisdom, Brian McGuinness, Geoffrey Warnock and Michael Dummett, according to whom Words and Things did not even have "the smell of honest or seriously intentioned work" (Dummett 1960/1978: 436; see also Uschanov 2000). More significantly, the same attitude was almost unanimously taken by the reviewers of such journals as The Journal of Philosophy (Arnold Isenberg), The Philosophical Review (Willis Doney, one of Malcolm's pupils), the Times Literary Supplement (an anonymous reviewer), Synthese (Gabriël Nuchelmans), The British Journal for the Philosophy of Science (Anthony Quinton), The Philosophical Quarterly (Stephan Körner) (Isenberg 1961; Doney 1962; Anonymous 1959; Nuchelmans 1961; Quinton; Körner 1959). All of them complained about Gellner's rude and ultimately abusive style, which may perhaps characterise a (talented) caricaturist, as John N. Findlay described Gellner on the Indian Journal of Philosophy, though not a professional philosopher and serious academic scholar (Findlay 1961b). The same views were accepted by most Anglo-American academic philosophers, from Alan Donagan to Morton White, from Alasdair MacIntyre to Richard M. Hare up to Ayer, even though he was antagonistic to linguistic philosophy and a recent victim of Ryle's and Austin's academic power in Oxford (Uschanov 2000; Donagan 1959; White 1960a; MacIntyre 1959; Hare 1960; Ayer 1959); even the most neutral and sympathetic reviewers such as Watkins himself, H.B. Acton, P.L. Heath, and the Oxford logician William Kneale made several concessions to Ryle's academic viewpoint (Acton 1959; Heath 1962; Kneale 1959). Marshall Cohen radically emphasised the role played in this story by common academic membership when he suspected Gellner of professional envy towards the prestigious Oxford professors he used to spend time with some years earlier (Cohen 1960).

The story of the reception of Gellner's work is quite telling, and it can be used to set the stage for this and the next chapters. To a large extent independently of Gellner, in the decades following the publication of Words and Things many analytic philosophers, especially in the United States, reached some of the anti-Wittgensteinian conclusions achieved by Gellner in his 1959 work. Russell had been somewhat prophetic when he wrote in the preface to Words and Things: "Whatever may be the first reaction to Mr. Gellner's arguments, it seems highly probable - to me, at least - that they will gradually be accorded their due weight" (Russell 1959b: 13). Consider, for example, the question posed by Gellner some years after the publication of Words and Things: 
If you do not feel a generalised intellectual anxiety, if you feel no need to find and make explicit and to evaluate the basic premisses of your activities, why the devil philosophise in the first place? (Gellner 1964: 60)

Or consider, more precisely, Gellner's argument that, once completed, the Oxford euthanasia of philosophy would for linguistic philosophers mean the chance to find themselves out of a job (Gellner 1959/1979: 49). Similarly, in 1958 C.D. Broad had complained:

An influential contemporary school, with many very able adherents in England and the U.S.A., would reduce philosophy to the modest task of attempting to cure the occupational diseases of philosophers. In their writings the word 'Philosopher' is commonly used to denote the holder of some opinion ... which the writer regards as characteristically fatuous... . (I will not speculate) how long an impoverished community, such as contemporary England, will continue to pay the salaries of individuals whose only function, on their own showing, is to treat a disease which they catch from each other and impart to their pupils. (Broad 1958: 102; see also Gellner 1959/1979)

The spirit, though not the letter, of the Gellner-Broad argument seems to be endorsed in one of the most recent and well-known analytic criticisms of linguistic metaphilosophy, namely, the one presented by Timothy Williamson in his discussion of Paul Horwich's Wittgenstein's Metaphilosophy (Williamson 2013: e8; see also Horwich 2010 and 2013). The unique purpose of Horwich's later Wittgensteinian philosophy, Williamson remarks, seems to be to therapeutically criticise traditional theoretic philosophy, making fully explicit its misleading scientism, its tendency to overgeneralise from few scattered data, in a word: its dogmatism, in Wittgenstein's sense. In this picture, however,

$90 \%$ of philosophy is a waste of space, while the remaining $10 \%$ consists of praiseworthy demolitions of the $90 \%$. Horwich does not explain why taxpayers should be expected to fund a branch of the academy with that structure. Would it not be cheaper and more effective simply to abolish philosophy altogether? (Williamson 2013: e8)

More generally, Williamson's anti-exceptionalist conception of philosophy, according to which the aim of (analytic) philosophy is to answer questions taken at face-value, generalising and explaining 
all (or most) available data, seems to agree, in many respect, with Gellner's attack on linguistic philosophy (Williamson 2007; see chapter 6 below for a more detailed discussion).

The similarity is quite striking. One way to highlight it is to tell the story of how linguistic philosophy was undermined by analytic philosophers in the two or three decades following the publication of Words and Things, especially in the United States. This story will be extensively reconstructed in the next chapters (see especially chapters 4 to 5). For the moment, it will suffice to say that American analytic philosophers rediscovered some of the critical, anti-Wittgensteinian views that had been previously put forward by Gellner: they defended these views by using different arguments and adopting a more professional and scientific philosophical style, but they agreed with Gellner about some basic metaphilosophical issues, including the relationship between science and philosophy, the role of general explanatory theories in philosophy and the critique of the absolute authority of ordinary language. ${ }^{x i}$

On the other hand, however, most Anglo-American philosophers, in particular those who belonged to the rising analytic tradition, reacted with hostility towards Words and Things. Thus it is natural to ask: Why? Part of the answer seems to be: because of its style. Most reviewers shared the view that Gellner's style and rhetoric were strongly insinuating and crudely polemical, and they almost unanimously found it not only deplorable but totally illegitimate in the academic context. Because of its style - which they described as journalistic rather than academic, witty rather than serious, expressing a polemic rather than an argument - they did not acknowledge Gellner as part of the scientific community, either in Britain and or the United States. Analytic philosophy was (and still is) altogether academic, ${ }^{\mathrm{xi}}$ and a professional style was a conditio sine qua non for membership in the philosophic academia. Therefore the radical difference in style prevailed over substantial and metaphilosophical agreement.

\subsection{American Hegemony}

A slightly different issue deserves attention here. It is likely that not even the overall attack coming from the London School of Economics - including not only Gellner's invective but also Popper's unpleasant comments on Wittgenstein and Watkins's critique of paradigm-case arguments — should be identified as mainly responsible for the strange death of linguistic philosophy. Again, here the question is: Why? Arguably, part of the answer is that these attacks came from the "periphery". The London School of Economics was becoming more and more influential (Popper arrived there from New Zealand in 1946), but it was still somewhat peripheral, with respect to Oxford or Cambridge (Lacey 2004: 132; Akehurst 2010: 11; Rée 1993: 7). Russell, the main sponsor of Gellner, was 87 years old: he had published his last scientific (rather than popular) works many years earlier and this, 
despite his everlasting authority, made him in a sense a somewhat marginal figure. Finally, and most importantly, from a geopolitical and economic point of view the centre of the world had moved: Britain used to be the "core" of the leading global empire, but it had irremediably become more peripheral, with respect to the United States (see, for example, Arrighi 1994: 47-74, 159-195).

The post-war hegemony of the United States had conspicuous effects not only on habits but also on culture, including academic philosophy. No detailed argument will be given in support of this rather uncontroversial claim; a few data and remarks will suffice to illustrate it. During the 1950s and 1960 s, there was a multiplication of universities, departments, journals, books, professors and researchers in the United States; significant funding was allocated to research programs and academic philosophers themselves, especially in publicly funded universities such as New York, Ohio, Wisconsin and California, but also in the private ones. From 1945 to 1975 the number of undergraduates increased by nearly 500 percent, and that of graduate students by almost 900 percent (Geiger 1999: 61 ). In the $1960 \mathrm{~s}$ the number of undergraduates doubled (from 3.5 million to 8 million), the number of doctorates awarded tripled, the number of hired professors increased exponentially, and at the peak of the process (1965-1972) new community colleges were opening every week (Metzger 1987: 124). In particular, philosophy departments in the United States developed and specialised as never before (Kuklick 2001: 14). The members of the American Philosophical Association numbered about 260 in 1920, 1 thousand in 1960, and would become more than 8 thousand in the 1990s (Kuklick 2001: 258; see also Schwartz 1995 and Soames 2008/2014 for similar data). Taking into account all the universities in the United States, the overall total of doctoral dissertations in philosophy numbered about 5 hundred in the 1940s, it became more than 1 thousand in the 1950s, and then doubled in the 1960s (more than 2 thousand $\mathrm{PhD}$ dissertations in philosophy) and again in the 1970s (more than 4 thousand theses) (www.proquest.com).

In the 1950s, Harvard, the "American Cambridge," was perhaps the most important philosophy department in the United States, followed by Michigan, Princeton, Yale, Columbia, and, to a lesser extent, Cornell, UCLA, Chicago, Brown, and Berkeley. In the mid-1960s, Harvard was still at the top, but it had been joined by other universities, for example Princeton, and there were several new entries in the ranking: MIT, Pittsburgh, Southern institutions such as Virginia, Duke and North Carolina, and Catholic universities such as Fordham and Notre Dame. As a consequence, little by little Harvard lost its privileged position and became nothing but a primus inter pares. More funds to universities and research centres also meant new opportunities for researchers to travel and study in different countries and states (California universities, to mention just one example, benefited from coast to coast air travel). This exponential development led to the creation of a "Harvard-Oxford axis," more and more dominated by the Americans (Kuklick 2001: 243). The academic exchanges increased rapidly: for example, American philosophers such as Goodman, Quine and Morton White 
spent a period in Oxford; Wilfrid Sellars gave lectures in London. British philosophers such as Grice and Austin lectured in Harvard, followed by Hart, Ayer and Bernard Williams. Donald Davidson, Daniel Dennett, Burton Dreben, Robert Nozick, Saul Kripke, David Lewis, Martha Nussbaum, Sydney Shoemaker, and Paul Ziff visited Britain, before coming back to their universities in the United States.

More importantly, in Britain professional philosophers' salaries and quality of life gradually decreased, if compared with those of their colleagues in the United States, thus causing a serious brain drain (Balmer, Godwin and Gregory 2009). The very expression ‘brain drain' was first coined by the British Royal Society in 1963 to describe the outflow of natural and social scientists from Britain to the United States and Canada in the 1950s and early 1960s. The report ('The Emigration of Scientists from the UK') highlighted the migration of UK-trained scholars to the United States, claiming that around 7\% of British PhD candidates migrated permanently to the US (Royal Society 1963). This salary-driven brain drain is a clear sign of the reversed core-periphery relationship between the former empire and the former colony (Giannocolo 2004; Balmer, Godwin and Gregory 2009). As emphasised by the Royal Society, the brain drain had relevant economic effects in the United Kingdom: not only the cost of educating the migrants, but also the "much more serious economic consequences of the loss to this country of the leadership and the creative contributions to science and technology which they would have made in their working lives" (Royal Society 1963).

The emigration of British philosophers was part of the same process. As John Searle once recalled, when in 1959 he left the University of Oxford, where he held a non-temporary position, to return to California, most of his Oxonian colleagues asked him if he had gone crazy. Fewer than ten years later, the same people called him to ask whether there was a vacant position in Berkeley. ${ }^{\mathrm{xi}}$ The anecdote somehow reveals a general process. For example, Hampshire went to Princeton, Grice to Berkeley, Ninian Smart to Santa Barbara, Hare to Gainsville in Florida, Richard Wollheim to Davis, Columbia and Berkeley, and the same would happen in the following years with the younger generations. In fact, the process has still been going on in the more recent decades, as is evident in the following impressive, but largely incomplete, list of contemporary native British philosophers who work, or have spent a long period working, in American philosophy departments: Julia Annas (Arizona), John Campbell (Berkeley), Jonathan Dancy (Texas), Kit Fine (NYU), Susan Haack (Miami), Richard Holton (MIT), Paul Horwich (CUNY), Philip Kitcher (Columbia), Rae Langton (MIT), John McDowell (Pittsburgh), Colin McGinn (Rutgers), Christopher Peacocke (Columbia), Mark Sainsbury (Texas), Galen Strawson (CUNY), and Michael Tye (Texas) (Leiter 2004).

The various kinds of asymmetrical relationships between the core and the periphery have been widely investigated, not only in post-Keynesian macroeconomics (Minsky 1982, Frenkel and Rapetti 2009) and in economic and social history, under the influence of both the Annales school and the 
Marxist tradition (Braudel 1979, Wallerstein 1974, Arrighi 1994), but also in the historical studies of culture, for example in the history of literature (Moretti 2013), and even in the sociology of philosophy (Bourdieu 1999). Of course, there are many different ways to be a periphery: in the post-WWI period, for example, the former core (the United Kingdom), the main rival (Germany) and the developing countries were all somewhat peripheral with respect to the United States. Moreover, many different core-periphery models are available. For the purposes of the present book, however, the investigation will be heuristically guided by quite a simple model, according to which the international circulation of ideas roughly works as follows: the hegemonic country, in this case the United States, has to a certain extent the role of determining the philosophical agenda, whereas the philosophical development of the periphery, the United Kingdom, is at least in part subordinated to the constraints imposed by the core.

There are independent grounds to rely on this simple model, for it seems to be, at least prima facie, by far the best confirmed and the most explanatory one. Consider briefly, for example, the history of literature. Franco Moretti famously attempted to apply Wallerstein's world-system theory to the historical development of world-literature, more precisely, to the comparative history of the novel in the period between the French Revolution and the first three decades of the twentieth century (Moretti 2000/2013). Wallerstein's tripartition of core, semi-periphery and periphery appealed to him "because it explained a number of empirical findings: ... France continental centrality ...; the peculiar productivity of the semi-periphery ...; the unevenness of narrative markets ... - all these, and more, strongly corroborated Wallerstein's model” (Moretti 2000/2013: 43). Furthermore, Wallerstein's theory explained the way in which national literatures developed, showing "the power of core literature to overdetermine, and in fact distort, the development of most national cultures" (Moretti 2000/2013: 44). When considering Moretti's attempt, one may wonder whether there are relevant differences in the structure of the literary system with respect to the economic system and, more generally, whether "world-system theory, with its strong emphasis on a rigid international division of labour, [is] a good model for the study of world literature" (Moretti 2003/2013: 111). After all, world literature seems to be more variegated and flexible than in the economic case: the core does not seem to have "a monopoly over the creation of forms that count", and "themes and forms can move in several directions - from the centre to the periphery, from the periphery to the centre, from one periphery to another, while some original forms of consequence may not move much at all" (Kristal 2002: 73-74). All this is likely to be true, but Moretti's comments on this objection can serve as a partial justification for the methodological choices made in the present book (namely, the application, for explanatory purposes, of the simple and more traditional core-periphery model): 
Yes, forms can move in several directions. But do they? This is the point, and a theory of literary history should reflect on the constraints on their movements, and the reasons behind them. What I know about European novels, for instance, suggests that hardly any forms 'of consequence' do not move at all; that movement from one periphery to another (without passing through the centre) is almost unheard of; that movement from the periphery to the centre is less rare, but still quite unusual, while that from the centre to the periphery is by far the most frequent. (Moretti 2003/2013: 112)

In a nutshell: the traditional model is more likely to occur. Moretti also acknowledged the claim according to which "literary and economic relationships run parallel may work in some cases, but not in others" (Kristal 2002: 69, 73). In other words: "Material and intellectual hegemony are indeed very close, but not quite identical" (Moretti 2003/2013: 114). For example, in the eighteenth and nineteenth centuries, “the long struggle for hegemony between Britain and France ended with Britain's victory on all fronts - except one: in the world of narrative, the verdict was reversed, and French novels were both more successful and formally more significant than British ones" (Moretti 2003/2013: 114). Another famous example is Petrarchism, "which reached its international zenith when its wealthy area of origin had already catastrophically declined" (Moretti 2003/2013: 114).

These considerations invite us to be careful when applying the core-periphery model to the history of analytic philosophy and the later Wittgensteinian tradition, but arguably they do not provide grounds to abandon, at least at the beginning of the investigation, the traditional Wallerstein-inspired perspective, the same as Moretti himself adopted most of the time, namely, the view according to which the economic core is also culturally — and, in our case, philosophically — hegemonic, whereas the economic periphery or semi-periphery is, at least in the medium run, culturally — and philosophically - subordinate. Notice, after all, that the explanandum in the present book is the decline of a semi-peripheral philosophy, the later Wittgensteinian tradition and the rising of a core philosophy, American analytic philosophy. Notice also, and perhaps more importantly, that a traditional coreperiphery model - in particular, the view according to which the brain drain process and, specularly, the widespread influence of American philosophy had strong effects on the development of philosophy in the United Kingdom - had often been assumed by those who followed the scene closely in the 1960s in Britain. Consider, for example, Bryan Magee's 1971 preface to Modern British Philosophy, the volume containing his well-known BBC conversations with thirteen eminent British philosophers. ${ }^{\text {xi }}$ Magee provided a clear description of a new state of affairs: due to "an unprecedented openness to influences from outside," he explained, "the present volume could be misleading: it probably represents the last attempt that will be possible to discuss contemporary British philosophy solely 
in terms of British philosophers and their work. Even so," he pointed out, "the living philosopher referred to by more contributors than any other in this volume is the American Chomsky. Another American, Quine, is described by Stuart Hampshire as 'the most distinguished living systematic philosopher'. Anthony Quinton discusses Australian materialism" (Magee 1971: 9). Magee went to the heart of the core-periphery issue:

British philosophy is no longer autonomous in the way it once was - indeed, it seems on the way to becoming the chief province in a territory whose capital is elsewhere. A chance but expressive fact is that when the first letters of invitation were sent to the contributors to this volume it was found that six of the thirteen were currently in North America. Not long ago this would not have been the case: today it is utterly unsurprising. Also, more and more of our philosophers are choosing to publish their most important papers in American journals. Mind may still be the leading philosophical journal in England but it is no longer the leading philosophical journal in English. (Magee 1971: 9)

Magee's remarks and, more generally, the considerations presented in the present chapter may be regarded as a preliminary and rough justification for the working hypothesis that to understand the story of the later Wittgensteinian tradition in the history of analytic philosophy one has first of all to look at the United States. Hopefully, the confirmation of this hypothesis will come at the end of the investigation. For example, as will become clear in chapter 6, in the mid-1970s philosophy in Oxford would "resemble philosophy everywhere else in the English-speaking world: broadly analytic in orientation, but with no remaining trace of the Austin-Ryle emphasis on mining the subtleties of ordinary language for philosophical gold" (Forguson 2001: 341).

By considering the American philosophical academia as a field of reception for the philosophy of Wittgenstein, the present book aims under some respects to be a contribution to the clarification of the peculiar "logic" of the international circulation of ideas, as described by Bourdieu (e.g., Bourdieu 1999). One underlying assumption in this kind of investigation is the principle of symmetry formulated by David Bloor in his strong programme for the sociology of scientific knowledge: the same kinds of explanations have to be applied for the success (or the failure) of both true and better justified theories and of false and less justified ones (Bloor 1976). It goes without saying that social and institutional conditions are among the relevant explanatory factors. Not only, as Bourdieu emphasised, is intellectual life "home to nationalism and imperialism, and intellectuals, like everyone else, constantly peddle prejudices, stereotypes, received ideas, and hastily simplistic representations which 
fuelled by the chance happening of everyday life, like misunderstanding, general incomprehension, and wounded pride", but also "international exchanges are subject to a certain number of structural factors which generate misunderstandings" (Bourdieu 1999: 220-221). A fundamental factor is that texts circulate without their context, that is, without the field of production whose product they are; this often generates every sort of misunderstanding, since the recipients are themselves in a different field of production, and they re-interpret the texts on the basis of the structure of the field of reception (Bourdieu 1999: 221). 'Misunderstanding' seems to be a keyword here. As Bourdieu puts it, both alliances and hostilities among authors and traditions are often based on mutual misunderstanding (Bourdieu 1999: 228). More in general, the sense and function of a foreign work is equally determined by the field of origin and the field of reception: not only are the sense and function of the original field often unknown in the new context, but also the process of transfer from a domestic field to a foreign one is made up of a series of social operations such as selection ("what is to be translated, what is to be published, who will be translated by, who will publish it"), labelling and classification by the publishers, choice of the series in which it is to be inserted and that of the translator and the writer of the preface, the reading process itself, and so forth (Bourdieu 1999: 223-224). Independently of any intention to manipulate information, the scholars involved in the reception process have their own profits, prejudices and passions: their interest in a foreign author or tradition, for example, can be assimilated to "a sort of affinity through the occupation of a similar or identical place in the different fields" (Bourdieu 1999: 222).

The story of the reception of Wittgenstein in America is a good example of the kind of process described by Bourdieu: an interest-laden process, produced by the dialectic between the field of origin and the field of reception and characterised by partial misunderstanding; a process in which disagreement was ultimately motivated by differences in style, cultural aims and preoccupations, and metaphilosophy, rather than by straightforward philosophical arguments. In the early reception of Wittgenstein, the main misunderstanding depended on a striking confusion between Wittgenstein and Carnap; the description and analysis of this confusion is the main aim of the next chapter.

\footnotetext{
Notes

${ }^{x i}$ The struggle between Ayer, on the one hand, and Ryle and Austin on the other hand, is part of the same story. Shortly after returning to Oxford at the end of the war, Ayer was appointed at the University of London, coming back to Oxford only in 1959 as the Wykeham Professor of Logic (Forguson 2001: 339).

${ }^{x i}$ In Watkins's obituary on the Independent Alan Musgrave wrote that "if Thomas Henry Huxley was Darwin's bulldog, then Watkins was Popper's" (Musgrave 1999).

${ }^{x i}$ See also Richman 1961; Donnellan 1967; Hanfling 2000; Marconi 2009.

${ }^{x i}$ The above-mentioned articles are, more precisely, two versions of a single study. It may be worth underlying here that the conviction, according to which Uschanov provided a good answer to our main question or, at least, an answer pointing in the right direction was also shared by Hilary Putnam, one of the first-person protagonists of the story that the present book attempts to reconstruct (personal communication, 2005).
} 
${ }^{x i}$ According to Gellner, in its preference for the "simple unspoilt popular view against the reasoned subtleties of the ratiocinator, Linguistic Philosophy is a kind of Populism," where the folk is the philosophical folk of North Oxford (Gellner 1959/1979: 239).

${ }^{\mathrm{xi}}$ Actually, Russell was the first to declare (in the preface) that he found the later, sociological chapters even more interesting than the earlier, philosophical ones (Russell 1959b: 13).

${ }^{\mathrm{xi}}$ Notice also that from 1959, when it was published, to the 1980s, when the decline of Wittgenstein had already become apparent, Gellner's book had only a handful of citations in articles published in most Anglo-American philosophic journals. A rapid search confirms this claim: there are less than ten citations of Words and Things in all the articles published in philosophical journals contained in J-STOR from 1959 to 1980. There are on the other hand many reviews, but they have not been included in the search, because they are analysed separately below.

${ }^{x i}$ This, of course, is not to say that they entirely assumed Gellner's perspective: they accepted neither Gellner's quest for a sociological analysis of philosophy nor his critical attitude towards the ahistorical character of linguistic philosophy; in fact, under many respects analytic philosophy was just as ahistorical as its Oxonian antecedent, and it was a long time before people could glimpse a historical turn in analytic philosophy (Reck 2013; Beaney 2013).

${ }^{x i}$ Perhaps the recent publication of "popular" works by leading analytic philosophers such as Williamson and Paul Boghossian is a first sign that the strictly academic nature of analytic philosophy is developing and may change in the future (Boghossian 2006 and Williamson 2015).

${ }^{x i}$ This is what Searle told to Bruno Bara during an interview held in Turin in 2006.

${ }^{\mathrm{xi}}$ The interviewees were Gilbert Ryle, Alfred Jules Ayer, Peter Strawson, Alasdair MacIntyre, Geoffrey Warnock, Stuart Hampshire, Bernard Williams, Richard Wollheim, Alan Montefiore, Ninian Smart, David Pears, Anthony Quinton and Karl Popper (a naturalised British citizen). 


\section{Carnapstein in America}

To get an approximate idea of the early reception of Wittgenstein in the United States, it seems reasonable to look at The Journal of Philosophy and The Philosophical Review, two of the most (arguably, the two most) authoritative and representative American philosophical journals during the period 1920 to 1950 . The description and evaluation of the 1920s is no sooner said than done. Charles K. Ogden and Frank Ramsey's English translation of Wittgenstein's Tractatus Logico-Philosophicus appeared in 1922, but throughout the 1920s the book had almost no impact on the American philosophical scene: there are only 5 articles published in The Journal of Philosophy and The Philosophical Review in this decade, in which the name 'Wittgenstein' occurs at least once in the fulltext (the $0.6 \%$ of the entire corpus), and none of them is directly devoted to the philosophy of Wittgenstein.

\subsection{The Thirties and the Forties: Some Data and Trends}

Things slightly changed during the 1930s, but the reception of Wittgenstein was then characterised by incomplete understanding. In the period from 1931 to 1940, the two above-mentioned journals contain the name 'Wittgenstein' in the full-text of 38 articles ( $4.5 \%$ of the overall corpus): 32 of them ( $84 \%$ of the Wittgenstein subcorpus) refer to the Tractatus, 5 to both the Tractatus and the so-called period of transition (i.e., Wittgenstein's philosophical development in the 1930s). ${ }^{x i}$ Only 2 articles were written by authors who were personally acquainted with Wittgenstein: one was Moritz Schlick, who met Wittgenstein several times in Vienna, together with Friedrich Waismann and (initially) other members of the Vienna Circle (Waismann 1979); the other was Casimir Lewy, who attended some of the lectures delivered by Wittgenstein in Cambridge (Lewy 1940 and Schlick 1936; see also Hacker 1996). Some authors regarded Wittgenstein as a logician or a philosopher of logic, naturally relating him to his mentor Russell. Other authors discussed Wittgenstein's metaphysics and his critique of metaphysics. But the most striking data concerns the sheer confusion between Wittgensteinian philosophy and logical positivism: 14 articles (37\% of the entire corpus) considered Wittgenstein a logical positivist tout court, without any qualification or doubt; a further 9 articles (24\%) more correctly presented him as strictly related to logical positivism (more precisely, to Schlick, Carnap, Ayer, or to the entire movement). Most articles were written by American philosophers.

For example, in their widely read 'Logical Positivism: a New Movement in Philosophy,' published in The Journal of Philosophy in 1931, Albert E. Blumberg and Herbert Feigl wrote that the "foremost philosophical exponents" of the new movement were "R. Carnap (Vienna), H. Reichenbach (Berlin), M. Schlick (Vienna), and L. Wittgenstein (Cambridge, England)." They also remarked that "recent American publications by P.W. Bridgman, Suzanne K. Langer, and C.I. Lewis exhibit[ed] related 
tendencies" (Blumberg and Feigl 1931: 281). Four years later, the psychologist Edward Tolman repeated that "logical positivists" were "such men as Wittgenstein, Schlick, Camap in Europe and Bridgman, C.I. Lewis, Feigl and Blumberg in this country [the US]" (Tolman 1935: 364). And even Ernest Nagel's informative and impressively well-balanced 'Impressions and Appraisals of Analytic Philosophy in Europe,' published in 1936 in The Journal of Philosophy (when Nagel returned to New York after a sabbatical year in Cambridge, Vienna, Prague, Warsaw and Lwów), went in a similar direction. On the one hand, Nagel presented Carnap and Wittgenstein as the two most original voices in the new philosophical tendency, without highlighting the differences between them; on the other hand, it is evident from his article that Nagel was much more familiar with Carnap's philosophy than with Wittgenstein's (notice, in addition, that he was personally acquainted with Carnap, whereas he never met Wittgenstein). The resulting impression for a contemporary reader is that in Nagel's work there was a sort of implicit overlapping of the two philosophical views, in which Wittgenstein turned out to be a somewhat more obscure and less scientific doppelgänger of Carnap (Nagel 1936).

There may be several reasons why in the 1930s philosophers in America so often mistook Wittgenstein's philosophy for logical positivism. One reason is that the picture of Wittgenstein as a logical positivist was drawn by assembling data gathered mainly from Britain, and even in Britain in that period the picture was somewhat confused. Consider for example the case of Susan Stebbing, one of the main representatives of the Cambridge school of analysis. She played a major role in introducing logical positivism into Britain, not only in her article on 'Substances, Events, and Facts,' published in The Journal of Philosophy in 1932, but also in her later contributions where she included the views of Wittgenstein in logical positivism, interpreting them through the lens of the writings of various members of the Vienna Circle, such as Schlick, Carnap, and Waismann, with whom she was acquainted (Beaney and Chapman 2017). Another reason is that American philosophers themselves were more familiar with logical positivism, the familiarity being, if not caused, at least much increased by the massive brain drain of European researchers into the United States, which occurred in the 1930s due to the rise of Nazism. As is well-known, together with people such as Einstein, Tarski, and Gödel, many logical positivists emigrated to the United States: Feigl in 1931, Menger, Frank, Carnap, Kaufmann, Hempel and Bergmann, to mention just some of them, between 1933 and 1940.

In the following decade, the 1940s, the incomplete understanding of Wittgenstein's philosophy gave way to lack of interest. There are only 14 articles in The Journal of Philosophy and The Philosophical Review in which 'Wittgenstein' is mentioned in the full-text (1.5\% of all the articles): 7 were devoted to the Tractatus, 2 to both the Tractatus and the transition, 6 to the developments of Wittgenstein's thought. Only one author, namely Karl Britton, was personally acquainted with Wittgenstein (Britton 1947). Wittgenstein was normally seen as half logician, half metaphysician. 
The first quasi-exegetical papers appeared (e.g., Edwards 1949). There were 2 articles (13\%) in which Wittgenstein's philosophy was still barely assimilated within logical positivism, and 5 articles (33\%) which emphasised the similarities (verificationism, above all) between Wittgenstein and the logical positivists (Carnap, in particular). A critical attitude towards Wittgenstein was also emerging, as for example in Roy Wood Sellars's 1946 paper on 'Materialism and Relativity: A Semantic Analysis,' in which Sellars remembered "the period, when, surrounded by relativity enthusiasts, and the mystagogues of the Wittgenstein revelation I could only, like poor Galileo, murmur: 'And yet there is a material universe and we are parts of it"” (Sellars 1946: 45).

The lack of interest towards Wittgenstein in the United States in the 1940s, as well as the enduring misunderstanding of his thought, can arguably be explained by several factors. First, during the 1930s and 1940s, even in Europe it was not easy to understand what Wittgenstein was trying to do in his later work: many people just started to understand what was going on in the Tractatus, when he radically changed his philosophical methods and perspectives. In the United States, such understanding was further complicated by the linguistic divide - Wittgenstein's work was originally written in German - and, more generally, by the larger cultural distance: Wittgenstein's thought (both early and late) was deeply rooted in the Viennese mentality, culture and language. However, it took quite a long time before European scholars realised that Wittgenstein's intellectual character fully belonged to the fin-de-siècle and pre-war Vienna (Janik and Toulmin 1973, Schorske 1980): to quote just one example, it is worth noting that still in the late-1950s and early-1960s a philosopher such as Hans-Georg Gadamer who, as we know in retrospect, could have found a philosophical ally and a source of inspiration in the author of the Philosophical Investigations, avoided any serious discussion of Wittgenstein's philosophy, which he kept on identifying, for a long time, with the "empiricist" and "positivist" position of the Vienna Circle (Gadamer 1960). ${ }^{\mathrm{xi}}$ In continental Europe things changed only in the 1960s, perhaps up until the day when, in 1970, Jürgen Habermas presented the later Wittgenstein's work as positive, anti-positivist and anti-metaphysical (Habermas 1965; but see also Apel 1965). In the United States, a much greater linguistic and cultural distance made the process of understanding and assimilating Wittgenstein's later ideas slower and more difficult than in continental Europe.

\subsection{Wittgenstein and Carnap: Similarities and Differences}

The most striking element of the early reception of Wittgenstein in America is no doubt the confusion with Carnap. This issue deserves further analysis. The first question is: was it complete and utter confusion, or was it somewhat legitimate? The answer is that it would be unfair to regard people such as Nagel, Blumberg, Feigl, Tolman and Stebbing — who, among the others, somewhat assimilated Wittgenstein to Carnap - as completely deceived and misled. As is well-known, in the first half of 
the 1930s Carnap's philosophical development had a good deal in common with Wittgenstein's, so that the differences between them were subtle and not easy to discern. First of all, both Wittgenstein and Carnap were suspicious towards the notions of meaning and reference; in particular, they both rejected any attempt to identify the former with the latter. Both pursued an alternative semantic agenda, in which semantic issues were interpreted as "formal" issues: they used to say that the meaning of a linguistic expression is determined by its grammar (Wittgenstein) or by its logical syntax (Carnap). They both used such words ('grammar', 'syntax') in partly idiosyncratic ways: grammar in Wittgenstein's sense is the totality of the rules that govern linguistic uses; a (logical) syntax in Carnap's sense includes formation rules (rules for constructing well-formed sentences by combining the basic symbols of a language), transformation rules (rules that specify when a sentence of a language $\mathrm{L}$ can be deduced from other sentences of L), and all the other formal properties of the language, which can be defined on the basis of such rules (first and foremost, analyticity) (Carnap 1934: $§ \S 21-23)$.

Moreover, in the 1930s both Wittgenstein and Carnap rejected the semantic uniformity thesis, that is, the idea - defended for example by the picture theory of language presented by Wittgenstein in the Tractatus - according to which any meaningful sentence is a descriptive assertion, i.e. a sentence which describes a state of affairs and says that it obtains, so that a sentence is true if the state of affairs obtains, and false otherwise (similarly, any word is a name, the meaning of a word is the named object, the primary and in fact unique semantic relation is naming or denoting). Such a rejection allowed Carnap and Wittgenstein to undermine realism or platonism in the philosophy of logic and the philosophy of mathematics (where platonism is the view according to which logic and mathematics are scientific theories similar to physics, for their sentences describe a Platonic realm of abstract entities, in a way similar to that in which the sentences of physics describe a physical realm of concrete, spatiotemporal entities). In their view, for example, it is a mistake - actually: a senseless absurdity - to say that a tautology such as 'p or non-p' is a necessarily true sentence, which correctly describes a necessary fact (the fact that $p$ or non-p); and it is no less misleading to say that the necessary truth of the tautology derives from the meaning of its symbols (for example, from the meaning of the connectives that occur in it). Rather, tautologies have a status similar to that of grammatical/syntactic rules, which are (partially) constitutive of the meaning of some symbols or words (e.g., 'or' and 'not') occurring in them; qua rules, they are neither descriptive nor - properly speaking — true or false. Something similar holds for arithmetical propositions such as ' $2+2=4$,' as well as for geometrical theorems such as 'The sum of the angles in a triangle is 180 degrees': Wittgenstein regarded them as grammatical sentences, whilst Carnap saw them as analytic sentences, in the syntactic sense of the word 'analytic' (where a sentence is analytic just in case its validity is solely determined by the rules of logical syntax, rather than on how the world is). Such sentences are 
not descriptive assertions but rather - to a certain extent — constitutive rules, which partially determine the meaning of some symbols or words occurring in them. In other words: they declare that sentences such as, say, ' $2+2=5$ ' or 'The sum of the angles in a triangle is 179 degrees' are senseless.

By regarding logical laws, arithmetical equations and geometrical axioms and theorems as belonging to grammar or to logical syntax (rather than as being factual or descriptive statements), Carnap and Wittgenstein found a novel explanation for their being knowable a priori: one knows such necessary propositions (the propositions expressed by the grammatical or analytic sentences) a priori because one's assenting to them is constitutive of one's semantic competence; in other terms, if one does not assent to, say, 'p or not-p', ' $2+2=4$ ' or 'The sum of the angles in a triangle is 180 degrees,' then one does not fully understand one or more words occurring in such sentences (Coffa 1991: chapter 14; see also Tripodi 2013a).

Moreover, the "semantic revolution" allowed Wittgenstein and Carnap, among other things, to provide a novel account of the senselessness of metaphysics. Metaphysics is senseless because it systematically and inadvertently confuses a grammatical rule with a factual proposition, a syntactic rule with an empirical proposition; as Wittgenstein put it, it confuses "the hardness of a rule with the hardness of a material" (Wittgenstein 1956: III, 87). That is why the metaphysical disagreement between, say, realists and idealists is only apparent, and should be dissolved by showing that it depends entirely on the adoption of one grammar or syntax, rather than another one (Carnap 1928b).

Behind Carnap's and Wittgenstein's common views on meaning, a priori knowledge, and metaphysics lay the last but perhaps most general, and therefore most significant, point of consonance between them, namely, their conception of philosophy as distinct from the natural sciences: they both agreed that natural science is a substantive theory, which aims to discover new facts, whereas philosophy - conceived of as grammar or as logical syntax — is a second-level activity, which operates a priori on the basis of the analysis of language and concepts, and aims to obtain a better insight and conceptual clarity of old truths, rather than to acquire more factual knowledge of new truths.

On the other hand, however, besides the above-mentioned undeniable similarities, there were also deep, significant differences between Wittgenstein and Carnap, which should not be underestimated. Here is a brief, not exhaustive list of these differences. Firstly, Wittgenstein was of a very different temperament and ideology from Carnap. Carnap was a "calm man" who personified the values of tolerance, collective cooperation, scientific progress and socialism. His scientific model was the laboratory, where people cooperate to achieve knowledge (Coffa 1991: 408). As is well-known, in the 1920s he worked on the neo-Kantian project of justifying the objectivity of scientific knowledge by building a 'system of constitution,' and in 1928 he published Der logische Aufbau der Welt, an 
epoch-making book which was the main expression of that project (Carnap 1928a; see also Richardson 1998). In the final title of the book he used the term 'construction' ('Aufbau,' first suggested by Schlick) rather than the more appropriate and technical Kantian term 'constitution.' He did so because in his intellectual world 'Aufbau' had become a keyword in the sense of Raymond Williams (1976), i.e. a word that to many of his contemporaries called to mind the political and social reconstruction of the German country from the ruins of the Great War, and the consequent advent of a new era, based on a scientifically oriented culture and education (Galison 1993, Carus 2007, Bouveresse 2012). Moreover, in 1929, as is even better known, he signed the manifesto of the Vienna Circle, The Scientific Conception of the World, whose general and widely shared views were a liberal, rational, non-dogmatic and even anti-religious spirit, the search for progress, the belief that all genuine problems are solvable scientifically, the commitment to oppose metaphysics, the attempt to find a sophisticated and reformed form of empiricism, and the desire to fuse together science with life (Carnap, Hahn, Neurath 1929). Wittgenstein, on the other hand, felt he was an alien in such a cultural and ideological climate. In the draft for a preface that he wrote in 1930 - one year after the publication of the Viennese manifesto (to which he was, right from the beginning, very hostile) - he famously stated his conflicting cultural values:

This book is written for those who are in sympathy with the spirit in which it is written. This is not, I believe, the spirit of the main current of European and American civilization. The spirit of this civilization makes itself manifest in the industry, architecture and music of our time, in its fascism and socialism, and it is alien and uncongenial to the author. ... I have no sympathy for the current of European civilization and do not understand its goals, if it has any. So I am really writing for friends who are scattered throughout the corners of the globe. It is all one to me whether or not the typical western scientist understands or appreciates my work, since he will not in any case understand the spirit in which I write. Our civilisation is characterised by the word 'progress.' Progress is its form rather than making progress being one of its features. Typically it constructs. It is occupied with building an ever more complicated structure. And even clarity is sought only as a means to this end, not as an end in itself. For me, on the contrary, clarity, perspicuity are valuable in themselves. I am not interested in constructing a building, so much as having a perspicuous view of the foundations of possible buildings. So, I am aiming for something different than the scientists and my thoughts move differently than do theirs (Wittgenstein 1980a: 7-8) 
Wittgenstein's humanistic and pessimistic Weltanschauung was more similar to writers such as Georg Christoph Lichtenberg and Karl Kraus, with whom he also shared the conviction according to which 'progress' - differing from related concepts such as change, growth and development — distinctly expresses a value notion (von Wright 1993: 210-211). In 1909 Kraus published a famous article entitled Der Fortschritt (Progress), which, as Jacques Bouveresse pointed out, Wittgenstein may have read (Bouveresse 2011: 301-302). Kraus wrote:

A newspaper phrase conveying a lively image has suggested itself to me. This is how it is worded: we are under the sign of progress. Only now do I recognise progress for what it is - a mobile decoration. We stay ahead and keep walking in place. Progress is a standpoint (Standpunkt) and looks like movement. Only occasionally does something twist itself around in front of my eyes: it is a dragon guarding a hoard of gold. Or else it moves around through the streets at night: that is the street sweeper's rolling broom that stirs up the dust of the day, so that it will settle somewhere else. Wherever I went, I could not help but run into it. If I went back, it came at me from the other side, and I recognised that a political program contrary to progress was useless, because progress is the unavoidable development of dust. Fate floats in a cloud, and progress, which catches up with you when you think you are getting away from it, comes from over there like the Deus ex machina. It slips through and reaches the fleeing foot and in the process takes as much dust out of your way as it is necessary to spread so that all lungs have their share in it, for the machine serves the great progressive idea of spreading dust. In the end, though, the full meaning of progress occurred to me while it was raining. It was raining unceasingly and humanity was thirsty for dust. There was none, and the street sweeper could not stir it up. But behind it, a water cart followed deliberately, not letting the rain deter it from preventing the dust that could not develop. That was progress. (Kraus 1909/1987: 197)

In line with this view, Wittgenstein used a sentence by Johann Nestroy as the motto for the Investigations: "It is in the nature of all progress that it looks much greater than it really is" (Wittgenstein 1953; see also Stern 2002). His critical attitude towards progress and, more generally, the scientific image of man in the world was based not only on his cultural pessimism but also on what might be 
called his humanism: "Scientific questions may interest me," he once wrote, "but they never really grip me. Only conceptual and aesthetic questions have that effect on me. Ultimately, whether scientific problems are solved leaves me cold; but not those other questions" (Wittgenstein 1980a: 79).

Moreover, his critical attitude also depended on his view of religious belief. He was convinced that there is a gulf between a believer such as Tolstoy — whom he greatly admired — and a nonbeliever (Tripodi 2013b: 64-66; see also Tolstoy 1896; Monk 1990: 116). For example, the former, but not the latter, believes in the last judgement: they do not believe the same thing, yet they do not believe different things either (Wittgenstein 1966: 55). Their distance from one another is so great that there cannot be real disagreement between them. The gulf between them does not have a linguistic nature. In his 1938 lectures on religious belief he came close to considering this possibility: "It is not a question of my [as a non-believer] being anywhere near him [the Tolstoy kind of believer], but on an entirely different plane, which you could express by saying: 'You mean something altogether different, Wittgenstein"” (Wittgenstein 1966: 53). Then he immediately rejected that solution: "The difference might not show up at all in any explanation of meaning" (Wittgenstein 1966: 53). This entailed, of course, that the difference in question might not be a difference of meaning at all (Wittgenstein 1958: 1). At the same time, Wittgenstein rejected the expressivist account of the gulf between believers and non-believers. During his lectures he once discussed the case in which "someone, before going to China, when he might never see me again, said to me: 'We might see one another after death"”. At that point Casimir Lewy commented: "In this case, you might only mean that he expressed a certain attitude". So that Wittgenstein replied: "I would say, 'No, it isn't the same as saying 'I'm very fond of you' - and it may not be the same as saying anything else. It says what it says. Why should you be able to substitute anything else?" (Wittgenstein 1966, 70-1; see also Schroeder 2007: 446; Kusch 2011 and Tripodi 2013b). ${ }^{\mathrm{xi}}$ Moreover, there are grounds for attributing to Wittgenstein an epistemological distinction between the evidence of the heart, which provides grounds for religious belief, and logical/rational and empirical evidence, which provides grounds for our ordinary, scientific and philosophical beliefs (Tripodi 2013b: 70, Coakley 2002: 140, Cottingham 2010: 223; see also Pascal 1670/1976). Tolstoy's religious beliefs, Wittgenstein tells us, are based “on evidence which taken in one way would seem exceedingly flimsy" (Wittgenstein 1966: 57-8), where "taken in one way" seems to mean the same as "taken in the ordinary sense," that is, as logical or empirical evidence. In his view, the controversies between a Tolstoy kind of believer and a nonbeliever "look quite different from any normal controversies" because "reasons look entirely different from normal reasons" (Wittgenstein 1966: 55-56, italics added). Summarising, he was arguably an epistemic relativist of a sort: in his (largely implicit) view, there are two alternative and incompatible systems of beliefs, which are based on entirely different kinds of reasons, so that the gulf between 
the two systems is epistemological, rather than linguistic; moreover, non-believers cannot rationally persuade believers, and vice versa, though they understand each other, at least in part (Tripodi 2013b; see also Coliva 2010: 202-3). It goes without saying that this kind of epistemic relativism is utterly incompatible with any attempt to criticise religion scientifically or rationally, in the vein of the Viennese manifesto or, for that matter, of Russell.

Besides the cultural, ideological and even religious dissonances, there were several characteristically philosophical differences between Wittgenstein and Carnap. First, they had different attitudes towards empiricism. Throughout the history of philosophy, mathematical knowledge has often been seen as a counterexample to the main empiricist thesis, according to which all knowledge stems from experience. Carnap did not accept the naïve view that such a counterexample could be met by assuming a combination of the no-content theory of logic presented by Wittgenstein in the Tractatus (= logical truths are empty tautologies), and of Russell's logicism (= mathematics can be reduced to logic), since he was aware that many logical truths in Russell's Principia Mathematica were not tautologies at all. Somewhat similarly, nonetheless, he thought that a combination of logicism with his syntactical notion of analyticity (a sentence is analytic just in case it is deducible from an empty set of premises) allowed him to save empiricism from the traditional counterexample of mathematics: if mathematical truths are analytic in the syntactic sense, then their truth depends exclusively on the rules of syntax, rather than on how the world is, and mathematical "knowledge" is not genuine knowledge. Wittgenstein never shared Carnap's empiricist motivations, but of course this was not because he was a rationalist.

Secondly, like both Russell and Ramsey before him, Carnap did not share the showing-saying distinction drawn by Wittgenstein in the Tractatus (Russell 1922; Ramsey 1931): though he initially underestimated the significance of Hilbert's metamathematics, after his encounter with Gödel's and Tarski's metalogic (which provided evidence for the fact that one can obtain amazing logical results by using metalanguages) Carnap defended the view according to which we can in a metalanguage speak of the object language, in particular of its syntactic rules (Gödel 1931; Tarski 1933/1935). Since there are many, diverse object languages, and there are many, diverse possible axiomatic choices at the metalinguistic level, Carnap reached the conclusion that the choice of the rules of a language are arbitrary and conventional (Carnap 1934: $\S 86$ ). Hence, in his famous principle of tolerance he stated that the choice of a language (or a system of logic) as a whole cannot depend on its truth or correctness, let alone on its being metaphysically well-grounded, but rather on external, pragmatic considerations (Carnap 1934: $\S \S 17,78$ ). Wittgenstein, on the contrary, was primarily interested in ordinary language (rather than in ideal, regimented languages), but in his view ordinary language though not incorrigible - is not something we can arbitrarily establish by convention, but is rather a 
given fact that we can acknowledge and describe, a fact of our human nature (or, if you like, of our "form of life"), a fact determining the bounds of sense (that is, what can and what cannot be said meaningfully) (Stroud 1965). ${ }^{\mathrm{xi}}$

\subsection{Wittgenstein and Carnap on Theories}

These considerations bring us to a further, and more important, difference between Wittgenstein and Carnap, a meta-theoretical difference in their attitude towards the role, the importance, and the claims of theories, both in philosophy and in science. What is a theory? Approximately, a theory is an organised set of declarative sentences endowed with the following properties. A theory is systematic and general: it organises a series of data, showing how to generalise in many directions, ideally until all data of the same kind is covered. It aims to be explanatory: its goal is not only to improve our understanding of a certain phenomenon, but also to increase our knowledge of it and of its causal story, and our ability to predict its behaviour. Sometimes one cannot generalise, systematise and explain unless one postulates the existence of unobservable entities. Both generalisation and theoretical postulation can lead to the discovery of new facts: in such cases the theory has epistemic value or, in other words, it is substantive. Wittgenstein and Carnap agreed that the natural sciences consist of substantive theories, aiming to discover previously unknown facts of the world, whereas philosophy is a second-level activity, aiming to obtain conceptual clarity (rather than factual knowledge) by means of conceptual and linguistic analysis (Wittgenstein 1922: prop. 4.112; 1953 : $\S \S 119-24$; Carnap 1950a: $\S 1)$. Thereafter, they went their separate ways.

Wittgenstein considered the tendency of theories to generalise and systematise as something philosophically dangerous and culturally deplorable: a symptom of the intellectual hybris of contemporary times. He drew a demarcation line between good (scientific) theories and bad (philosophical and pseudoscientific) ones. The theories of the former kind aim to generalise and systematise, but only to the extent that they can, at least in principle, be subjected to empirical confirmation (or disconfirmation), typically by experiment, and to the extent that they can provide causal explanations: experimental physics, of which - not least thanks to his past as a student of engineering - he had a more than elementary knowledge, was in his view the typical example of that kind of scientific theory (Monk 1990: 36-42). ${ }^{x i}$ The theories of the latter kind, on the contrary, are misleading and dogmatic: here Wittgenstein had in mind, on the one hand, traditional metaphysics and Freud's psychoanalysis (based on a confusion between factual and conceptual claims, and between the causes and reasons of actions, respectively), and, on the other hand, the Tractatus 's theory of language and even Darwin's theory of evolution (which overgeneralise from limited data, based on superficial analogies) (Wittgenstein 1953: §§ 251-2; 1967: § 458; 1979: 39-40; Drury 1984: 160-1; Bouveresse 1991). Such a distinction between good and bad theories had, in Wittgenstein's view, two 
main consequences. In philosophy, one should give up not only any claim to discover facts but also any attempt to generalise and even explain something; on the contrary, one should recognise certain phenomena as something primitive, and be satisfied with a perspicuous description of ordinary linguistic facts that are not hidden but are rather always, as it were, under our noses; and one should never forget that, by virtue of the amazing variety of linguistic uses, it is impossible for such a description to be a well-balanced systematisation. Here are some of Wittgenstein's most famous later meta-philosophical formulations:

It was true to say that our considerations could not be scientific ones. It was not of any possible interest to us to find out empirically 'that, contrary to our preconceived ideas, it is possible to think such-and-such' - whatever that may mean. (The conception of thought as a gaseous medium.) And we may not advance any kind of theory. There must not be anything hypothetical in our considerations. We must do away with all explanation, and description alone must take its place. And this description gets its light, that is to say its purpose, from the philosophical problems. These are, of course, not empirical problems; they are solved, rather, by looking into the workings of our language, and that in such a way as to make us recognise those workings: in spite of an urge to misunderstand them. The problems are solved, not by giving new information, but by arranging what we have always known. Philosophy is a battle against the bewitchment of our intelligence by means of language. (Wittgenstein 1953: § 109)

Philosophy simply puts everything before us, and neither explains nor deduces anything. - Since everything lies open to view there is nothing to explain. For what is hidden, for example, is of no interest to us. One might also give the name "philosophy" to what is possible before all new discoveries and inventions. (Wittgenstein 1953: § 126)

The second consequence of the distinction between good and bad theories has to do with Wittgenstein's conception of science, rather than of philosophy. The point is, in a nutshell, that his view of science sometimes appeared to be narrowly empiricist and verificationist, though this is not so easy to see, for several reasons. Wittgenstein never was, and never intended to be, a philosopher of science: he was above all interested in dividing science from philosophy from a methodological point of view. Moreover, he did not suggest, as a naïve empiricist, that science is a mere collection of 
observations: he clearly recognised - as an ante litteram Kuhn, so to speak ${ }^{\mathrm{xi}}$ - that in the logic of scientific discovery empirical investigations presuppose a conceptual or grammatical apparatus, some "postulates", "norms of expression", "forms of representation" that have, in turn, no empirical foundation (actually, they have no foundation at all) (Wittgenstein 1979: 15-6, 39-40, 70-1, 98; 1933/1969: 23, 56-7; 1969: §§512-16; 1980a: §225; see also Glock 1996: 343). Finally, semantic verificationism (the view according to which the meaning of a sentence is the method of its verification) was nothing but a footnote in his philosophical history (a footnote dating back to the late 1920 s and the early 1930s). ${ }^{x i}$ Nonetheless, it is not unreasonable to suggest that he sometimes assumed quite a narrow criterion of demarcation between science and pseudoscience: a criterion based on the idea that an investigation of a phenomenon $\mathrm{X}$ cannot be scientific unless it puts forward hypotheses that can in principle be empirically tested, increase our factual knowledge of X, provide causal explanations of X, and allow us to make new predictions. Scattered throughout Wittgenstein's Nachlass, there is some evidence of this view. For example:

One of the most important things about an explanation [in Physics R, T] is that it should work, that it should enable us to predict something [successfully - T]. Physics is connected with Engineering. The bridge must not fall down. (Wittgenstein 1966: 27)

When we are studying psychology we may feel there is something unsatisfactory, some difficulty about the whole subject or study - because we are taking physics as our ideal science. We think of formulating laws as in physics. And then we find we cannot use the same sort of 'metric,' the same ideas of measurement as in physics. (Wittgenstein 1966: 42)

Moreover, as Waismann, following Wittgenstein, put it:

Hypotheses are the connecting link we insert between the actual experiences of the past and the actual experiences of the future. Indeed, to an astronomer it never really matters whether the law of gravity 'is valid for all eternity' this would be a question which we could never come any closer to answering ... - but whether it stands the test, whether he succeeds with this assumption. (Waismann 1977: 39-40)

Wittgenstein shared Carnap's idea that conventions play a central role with respect to scientific laws. 
However, he cautioned not to overestimate their importance. In this connection, for example he wrote:

Now perhaps one thinks that it can make no great difference which concepts we employ. As, after all, it is possible to do physics in feet and inches as well as in metres and centimetres; the difference is merely one of convenience. But even this is not true if, for instance, calculations in some system of measurement demand more time and trouble than it is possible for us to give them. (Wittgenstein 1953: § 569)

In his view, there was no room for "the prattle that physics nowadays no longer works with mechanical models but 'only with symbols"” (Wittgenstein 1932/2005: 97e).

Yet, Wittgenstein's main aim in philosophy was not to provide an account of science itself. Therefore, a better way to understand his conception of science is to look not only at his remarks on the science-philosophy divide (such as the meta-philosophical remarks quoted above), but also on his remarks on pseudoscience. For example, though he always respected and even admired Freud, Wittgenstein had many concerns with psychoanalysis (Bouveresse 1991). In particular, he rejected the idea that psychoanalysis is scientific. Not only does psychoanalysis overgeneralise (e.g., from the reasonable idea that something, in dreams, can have meaning, it draws the conclusion that everything, in dreams, has meaning) and introduce mysterious and non-verifiable "explanatory" concepts and mechanisms, such as the unconscious, the repressed, the return of the repressed and so forth (MacIntyre 1958); but also, and more importantly, it demands discovering deep, hidden causes of jokes, lapses, missed deeds, and dreams, whereas in fact it provides only the reasons for the agents' behaviour: the difference is crucial and straightforward, for the reason of an action is what the agent sincerely claims to be his reason, whereas we can only make fallible hypotheses about the causes of our behaviour (Wittgenstein 1958: 15; see also Schroeder 2010, Tripodi 2015, and chapter 5 below). Therefore, the way in which psychoanalysis operates resembles the way in which aesthetics (rather than science) works: it organises certain representations or facts in a certain way, with the aim of eliciting the reader's or the hearer's satisfaction and assent.

Moreover, Wittgenstein extended to Darwin some of the doubts he raised about Freud. In the Tractatus he had written: "Darwin's theory has no more to do with philosophy than any other hypothesis in natural science" (1922: prop. 4.1122). But later on he apparently changed his mind, criticising Darwin for philosophical reasons. In his 1938 lectures on aesthetics (one of his favourite terms of comparison in his remarks on psychoanalysis), he wrote about "the Darwin upheaval":

One circle of admirers who said: "Of course", and another circle [of enemies 
- R] who said: "Of course not". Why in the Hell should a man say 'of course'? (The idea was that of monocellular organisms becoming more and more complicated until they became mammals, men, etc.) Did anyone see this process happening? No. Has anyone seen it happening now? No. The evidence of breeding is just a drop in the bucket. But there were thousands of books in which this was said to be the obvious solution. People were certain on grounds which were extremely thin. Could there not have been an attitude which said: "I don't know. It is an interesting hypothesis which may eventually be well confirmed"? This shows how you can be persuaded of a certain thing. In the end you forget entirely every question of verification, you are just sure it must have been like that. (Wittgenstein 1966: 26-27)

On this basis, during a walk in the zoological garden with his pupil Maurice O'Connor Drury, he criticised Darwin as if he were criticising a philosopher. After admiring the immense variety of flowers, shrubs and trees, and the similar multiplicity of birds, reptiles and other animals, he confessed: "I have always thought that Darwin was wrong: his theory does not account for all the varieties of species. It does not have the necessary multiplicity. Nowadays some people are fond of saying that at last evolution has produced a species that is able understand the whole process which gave it birth. Now that you cannot say". And when Drury remarked, "You could say that now a strange animal that collects other animals and puts them in gardens has evolved. But you cannot bring the concepts of knowledge and understanding into this series. They are different categories entirely," Wittgenstein seemed to agree: "Yes, you could put it that way" (Drury 1984: 160-1).

These remarks highlight a further controversial aspect of Wittgenstein's attitude towards science. His metaphilosophical commitments notwithstanding, it seems controversial that Wittgenstein, qua philosopher, really left everything in science as it is. For example, not only did he criticise the mathematicians' realistic biases, but he also provided a philosophical attack on the overall discipline of set theory; and with psychology he did something similar, suggesting that,

The confusion and barrenness of psychology is not to be explained by calling it a "young science"; its state is not comparable with that of physics, for instance, in its beginnings. (Rather with that of certain branches of mathematics. Set theory.) For in psychology there are experimental methods and conceptual confusion. (As in the other case conceptual confusion and methods of proof.) The existence of the experimental method makes us think we have the means of solving the problems which trouble us; though problem 
and method pass one another by (Wittgenstein 1953: II, § XIV, 232)

It is true that, as has often been said, Wittgenstein's philosophical or methodological target, as distinct from his ideological one, was scientism - the imperialist tendency of scientific thinking which results from the idea that science is the measure of all things - rather than science (Glock 1996: 343). It should be added, however, that not only did Wittgenstein, as a full-blooded antifoundationalist, think that science had no better foundation than other human activities (hence, it had no special epistemological privilege either), but also that he was from time to time inclined to suggest that science should not cross the grammatical boundaries of sense, as they are traced in the grammar of ordinary language: for example, he sometimes seemed to think that psychologists should not consider understanding - which is a certain kind of ability, or set of abilities — as a mental process, for, as Ryle would put it, that would be nothing but a categorical mistake (the qualification "from time to time", however, is required, for in Wittgenstein's later philosophy, especially in the remarks collected in On Certainty, there also seems to be a partly different tendency, based on the metaphor of "the movement of the waters on the river-bed and the shift of the bed itself", which are such that "there is not a sharp division of the one from the other") (Wittgenstein 1969: § 97).

As already stressed above, in line with Wittgenstein's meta-philosophical views, Carnap worked on the presupposition that there is a sharp divide between science (which aims to obtain substantive knowledge) and philosophy (which aims to achieve conceptual clarity). However, science always occupied a more central place in Carnap's interests than in Wittgenstein's. Just to mention a few episodes from Carnap's intellectual biography: when he was a young student in Jena, he studied both philosophy and logic (under Bruno Bauch and Frege respectively) and theoretical physics (under Max Wien), and up to a certain point he was hesitant as to whether he should become a physicist or a philosopher (Carnap 1963a); in the 1920s, he took part in the debate on the epistemology of Einstein's metaphysics (Carnap 1922); in the last twenty years of his life he was mainly, if not exclusively, a philosopher of science, whose main concerns were the issues of confirmation and probability (Carnap 1950a). Moreover, though from his very beginnings as a neo-Kantian he shared Wittgenstein's epistemological anti-foundationalism (Friedman 1987, 1992; Richardson 1998), throughout his career he ascribed to science a somewhat privileged epistemological position, considering it as a model of rigour and seriousness. Last, but not least, he rejected both Wittgenstein's narrow conception of science (according to which empirical verifiability is the criterion of demarcation between sciences and pseudo-sciences), and Wittgenstein's radically a-theoretical (or even antitheoretical) conception of philosophy. The former point was part of Carnap's famous (and, in the opinion of many, incomplete) attempt to liberalise empiricism (Hempel 1958, 1965, 1973). Not only in the Viennese debate over the so-called protocol sentences did Carnap take the side of Neurath's 
fallibilism and anti-foundationalism against Schlick's strict verificationism (Carnap 1932), but in Testability and Meaning, published in English in 1936 - when Schlick was assassinated and Carnap was forced by the rise of Nazism to emigrate to the United States - he also underlined that contemporary natural sciences have an important theoretical component, replacing the view that theoretical terms are nothing but useful abbreviations of observational terms with the view that the theoretical vocabulary is reducible to observational terms: the difference between an explicit definition and a reduction in Carnap's sense was that a reduction sentence partially determines the meaning of the theoretical terms occurring in it (Carnap 1936); consequently, later on Carnap came to consider theoretical languages as only partially interpreted (Carnap 1939), up to the time when, in 1956 , he conceived of the relation between theoretical language and observational language as a more and more indirect, looser connection, suggesting for example that some theoretical terms are not reducible to observational terms, but they acquire their meaning by virtue of complex inferential relations with other theoretical terms (Carnap 1956).

\subsection{Quine and the Science-Philosophy Divide}

In the light of the similarities and differences between Carnap and Wittgenstein, the "identification error" made by many American philosophers is hopefully more understandable, if not justifiable. However, for the purposes of this book a second question needs now to be raised: What kind of consequences did the confusion between Wittgenstein and Carnap have for the early reception of the philosophy of Wittgenstein in America? The answer is: negative effects, first of all because, as is well-known, from the mid-1930s (when Carnap started to work at the University of Chicago) to the early 1950s (when, as we shall see in the next chapters, the later Wittgensteinian tradition ceased to be a widely unknown and mysterious object in the US), Carnap found himself under the (friendly) fire of Quine. Since Carnap was, as it were, the closest available approximation to Wittgenstein's philosophy (the subtlest differences being invisible to most American philosophers), Wittgenstein ended up being an indirect victim of Quine's attack on Carnap. The story of how, together with Goodman and other American philosophers, Quine "introduced" Carnap (under whom he had studied in Prague in 1933) to the American philosophical academia is well-known, so in what follows it will be only briefly outlined.

In a nutshell: Carnap was presented as a great and influential philosopher, a master, but one who had made epochal mistakes. This applies to all the three main projects in which Carnap had taken part since the mid-1920s: the neo-Kantian, the syntactic and the semantic. In 1951 Goodman and Quine presented Carnap's Aufbau as the most ambitious attempt in the history of empiricism and, at the same time, they declared its bankruptcy: in the course of a technical discussion, Goodman argued that the quasi-analysis method adopted by Carnap in his 1928 book could not in principle work 
(Goodman 1951); Quine highlighted that the Aufbau provided "no indication, not even the sketchiest, of how a statement of the form 'Quality q is at point-instant $\mathrm{x}$; $\mathrm{y}$; $\mathrm{z}$; $\mathrm{t}$ ' could ever be translated into Carnap's initial language of sense data and logic", for "the connective 'is at' remains an added undefined connective" (Quine 1951b). Despite the details, and even to some extent despite the overall plausibility of their arguments, Goodman and Quine spoiled the reputation of the Aufbau. As is now well-known, however, they partly misrepresented Carnap's 1928 project (Richardson 1998): they described it as the "Russellian" attempt to translate any statement concerning the external world into another statement consisting exclusively of expressions that refer to sense-data, whereas Carnap intended, rather, to show and warrant the objectivity of scientific knowledge by translating, in a neoKantian spirit, any scientific statement into a purely structural one (Leitgeb 2011). Goodman and Quine considered the Aufbau as an old empiricist work, as the "the culmination of the phenomenalism that evolved through Hobbes, Locke, Berkeley and Hume," though the first three names never occurred in Carnap's text, ${ }^{x i}$ and the last one occurred just once (Quine 1995: 13). Finally, they represented it as a foundational enterprise, whereas since the mid-1920s Carnap had clearly stated that the choice of the basis of the constitution-system was a matter of linguistic convention (Carnap 1928a). It is perhaps worth adding that, when Carnap arrived in the United States, he himself tended to remove emphasis from the "continental" (i.e., neo-Kantian and Husserlian) roots of this philosophical thinking (an element which almost no historian of early analytic philosophy would now continue to question): this is particularly clear in Carnap's 1963 autobiographical reflections, where he presented himself as a 360-degree "analytic" philosopher, i.e., a disciple and follower of Frege, Russell and Wittgenstein (Carnap 1963a; see also Bonino and Tripodi forthcoming). He stated:

\footnotetext{
While writing the present section, I looked at the old book for the first time in many years. I had the impression that the problems raised and the general features of the methods used are still fruitful, and perhaps also some of the answers I gave to particular problems. But it might chiefly be of interest to those who still prefer a phenomenalistic basis for the construction of the total system of concepts. (Carnap 1963a: 18-19)
}

It is not easy to say, without further investigation, what the motivation of Carnap's selfreinterpretation was. A plausible conjecture is that he spoke to those analytic philosophers such as for example Goodman, who were still interested in constructing a system of scientific concepts on a phenomenal basis (Goodman 1951). More generally, it is likely that he felt that in his new working environment nobody was still interested in the neo-Kantian problems that had once motivated his "old book" (as he labelled it). Moreover, Carnap's was not the only attempt at "autobiographical 
revision" by an author emigrating to the US from central Europe because of the rise of Nazism, in order to purify his philosophy from its neo-Kantian origins and vocabulary: think, for example, of the analogous cases of Hans Kelsen and Gustav Bergmann (Bonino and Damele 2018). It is likely that his immigration mattered: not only was he grateful to the country that had taken him in, considering him a leading philosophical figure and welcoming him into the academia, at the Universities of Chicago and later at that of Los Angeles; but the emigration, the German past and the escape from Nazism could also have had the psychological effects of a sort of philosophical suppression. ${ }^{\mathrm{xi}}$

The Aufbau's constitution-system was the first Carnapian project to be subjected to Quine's criticism. As for the syntactic project elaborated in the Logical Syntax (1934), it was abandoned by Carnap himself shortly before leaving Europe. In the early 1930s, Carnap acknowledged the high value of Tarski's work in logic. Initially he borrowed the distinction between object language and metalanguage, finding in it a (further) reason to accept the principle of tolerance and to distance himself from Wittgenstein's showing-saying divide, according to which the semantic properties of linguistic expressions are among the things that show themselves but cannot be properly said. Initially, however, Carnap kept on thinking that discourse on meaning requires a syntactic paraphrase (in the so-called formal mode of speech), and, more generally, he shared Wittgenstein's and Neurath's suspicion towards the notions of meaning and reference, considering them as a prelude to metaphysics, since they invite dealing with the world regardless of the conventional adoption of a language, and independently of the empirical limits of our epistemic resources (Carnap 1934). It was only around 1935 - the year in which the German translation of Tarski's essay on truth was published - that he properly understood and appreciated Tarski's work on the notion of truth (Tarski 1933/1935), so as to start to develop a truth-conditional semantic himself (Coffa 1991; Wagner 2009). Wearing the semantic glasses, Carnap turned his view upside down: he used to think that semantics violated verificationism and his anti-metaphysical ideals; now he became aware that, by accepting Tarski's semantics and putting aside his verificationist idiosyncrasies (as suggested, incidentally, by his own principle of tolerance and his tendency to liberalise empiricism), it became possible to analyse not only the notion of logical truth (as he himself had attempted to do in the Syntax), but also — in a simpler, more elegant and natural way — the notion of truth simpliciter, now conceived of, in Tarski's terms, as a property of sentences. Above all, as Carnap explicitly underscored, contra Neurath, during a conference held in Paris in 1935, Tarski's definition of truth was to be regarded as a technically fruitful and rigorous, but philosophically neutral tool, free from any embarrassing commitment to realism and platonism (Mormann 1999; Mancosu 2008; Coffa 1991: chapters 16-17; Reck 2013). So when, in 1936, Tarski put forward an analogous, satisfactory explication of the semantic notion of logical consequence, Carnap abandoned any hesitation and started to give his 
contribution to the semantic tradition of Bolzano, Frege and the Tractatus, which tried to specify the truth-conditions of, and the inferential relationships between, sentences belonging to more and more complex, richer languages (Coffa 1991; Tarski 1936). Carnap's main semantic project — formulated in 1942 with the publication of the Introduction to Semantics and culminating in 1947 with Meaning and Necessity - was to specify a formally rigorous notion of analyticity (indeed, a semantic rather than a syntactic notion), whose theoretical role was to account for both necessity and a priori knowledge of logical truths (Carnap 1942 and 1947). Such a project had its roots in Carnap's never abandoned ideal of conceiving of scientific theories as systems made up of an empirical or synthetical component on the one hand, and a logical-mathematical or analytical component on the other hand.

Carnap's semantic turn was something of a surprise for some of those philosophers, such as for example Neurath and Bergmann, who had belonged to the same Viennese philosophical milieu (Bergmann 1944, Bergmann 1945). During the 1940s Carnap's turn was widely criticised in the United States, for example by philosophers such as Everett Hall, Max Black, and Wilfrid Sellars (Hall 1944, Black 1945, Sellars 1948; see also Hochberg 1994, Hochberg 2001: 2-10, Bonino 2007, Bonino and Tripodi 2018a). The crucial episode, however, occurred at the beginning of the 1940s, when Carnap's semantic project was discussed and demolished by Nelson Goodman, Tarski himself (at that time Professor of Logic at Berkeley) and, above all, W.V.O. Quine. As is well-known, after Quine took his $\mathrm{PhD}$ in 1932 under the supervision of Whitehead, he went to study in Europe. When he was in Vienna, he wrote "a note to the great Wittgenstein," with the aim of having "an audience with the prophet". "It remains to be seen," Quine wondered in a letter to his parents, "whether he will act on my request (for he doesn't know how nice I am)". However, as Quine commented many years later, "of course he did not answer" (Quine 1985: 88). Symbolically, this anecdote could be seen as a suggestive turning-point in the history of analytic philosophy, not only because it is interesting to imagine what could have happened if on that occasion Quine had met Wittgenstein in Vienna, but also because, straight after that, Quine went to Prague instead, and became a pupil of Carnap. In 1936, he published 'Truth by Convention,' in which he criticised the idea that logical truths can be known a priori because they entirely depend on linguistic stipulations: according to Quine, if one does not presuppose logic, one cannot even derive logic (that is, the potentially infinite set of its truths) from a class of axioms introduced by stipulation (Quine 1936/1966). In the same year, he came back to the United States, and started to teach at Harvard, in a department in which there were professors such as Whitehead, the new realist Ralph Barton Perry, the logician and mathematician Henry Schiffer, and the pragmatist C.I. Lewis. In that period, Quine was still firmly anchored in three cornerstones of Carnap's conception of analyticity (Frost-Arnold 2013): he took for granted that logical and mathematical truths were analytic; in fact, he accepted an extensional treatment of analyticity, like that proposed by Carnap in the Syntax; and he was even willing to attribute scientific respectability 
to a peculiar semantic notion of logical or analytical truth (where a sentence is logically true if, and only if, it is true and remains true under all reinterpretations of its non-logical vocabulary, assuming one has preliminarily filled out a list of all logical words such as 'every', 'none', 'if-then', 'not', and so forth) (Quine 1936/1966). Within fifteen years, Quine would change his mind about almost all such issues, replacing the constructive criticism of 'Truth by Convention' with a much more radical set of objections, aiming to destroy the ground of Carnap's semantic project. This radicalisation depended on three main factors.

First, Quine noticed that logical truths are only a subclass of analytic truths: 'Every bachelor is unmarried,' for example, is analytic but not logically true, since there are reinterpretations of, say, 'bachelor,' which make the sentence false (Quine 1943). Therefore, the 1936 respectable semantic notion of analyticity was not general enough. Carnap would answer that critique in 1952, maintaining that analyticity in the wide sense presupposes a number of meaning postulates, i.e., stipulations concerning the meaning of certain linguistic expressions (e.g., 'For every $\mathrm{x}$, if $\mathrm{x}$ is a bachelor, then $\mathrm{x}$ is unmarried') (Carnap 1952). During the 1940s, on the contrary, Carnap was apparently not impressed by Quine's remark. Therefore, he kept on looking for a satisfactory explanation of the semantic notions such as logical truth and analyticity. Carnap's semantics was based on the notions of extension and intension, which are to be seen as explications of Frege's notions of Bedeutung and Sinn (Frege 1892). The extension of a sentence is its truth value; the extension of a predicate is the class of objects to which the predicate applies; the extension of a singular term is the object it refers to. Two expressions have the same intension if, and only if, they have the same extension in all state descriptions, where a state description $D$ is a set of sentences of a language $L$ such that, for any atomic sentence $p$ of $L$, it includes either $p$ or not- $p$, but not both. Therefore, two sentences have the same intension (that is, they express the same proposition) just if they have the same truth value in any state description (or, which is the same, just if they hold in the same state descriptions); two predicates have the same intension (they express the same property) just if they refer to the same class in any state description; two singular terms have the same intension (they express the same individual concept) just if they refer to the same entity in any state description. By using such a conceptual apparatus, Carnap achieved two main goals. First, he constructed a rigorous explication of analyticity in terms of L-truth, where a sentence is L-true just if it holds in all state descriptions. Secondly, he applied the Tarski-style semantic analysis to modal discourse. Consider, for example, the sentence 'Necessarily 9>7,' which is true: as Quine noticed, modal contexts are referentially opaque, for in such a sentence we cannot replace co-referring expressions (e.g., '9' and 'the number of planets,' or '9>7' and 'Torino is in Italy') salva veritate (Quine 1943). From this, however, Carnap did not conclude, with Quine, "so much the worse for modal logic," but he pointed out that his method of extension and intension allowed him to provide a compositional analysis of modal sentences, for the 
principle of substitutivity salva veritate of expressions having the same intension (for example, ' 9 ' and ' $7+2$ ', or, respectively, ' $9>7$ ' and ' $2+2=4$ ') holds for modal sentences such as 'Necessarily 9>7'.

Carnap's semantic treatment of modal contexts gave Quine the second reason to change his attitude from reformist to negative, not only because he considered intensional concepts as intrinsically flawed (in fact, assuming an old-style positivist pose, he declared to find them entirely unintelligible), ${ }^{\mathrm{xi}}$ but also for a more specific reason. It happened, indeed, that in two pioneering papers, appearing in 1946 and 1947, with the aim of investigating the interactions between quantifiers and modal operators, Ruth Barcan Marcus introduced the first axiomatic systems for quantified modal logic (Barcan Marcus 1946 and 1947; see also Williamson 2013: chapter 2). Two of Barcan's achievements were subjected to harsh criticism by Quine. First, Barcan Marcus formulated, in Lewis and Langford's S5, the axiom - later called 'Barcan formula' - according to which, if it is possible that something has a certain property, then there is something that possibly has that property: in Quine's view, such a formula (which is equivalent to "if everything necessarily has a certain property, it is necessarily the case that everything has that property") was nothing but the expression of the link between quantified modal logic and an absurd, old-fashioned form of Aristotelian essentialism, the thesis that things intrinsically have necessary and essential properties. Secondly, Barcan proved a theorem according to which a true identity statement can never be contingent, that is, if it is true that $\mathrm{a}=\mathrm{b}$, then it is necessarily true that $\mathrm{a}=\mathrm{b}$ : Quine and most of his contemporaries considered such $\mathrm{a}$ thesis as a reductio ad absurdum of quantified modal logic, taking for granted that, for example, if the universe had been different from how it actually is, Hesperus and Phosphorus would have been two different planets. In the academic year 1947-48, Barcan Marcus attended, as a post-doc, Carnap's lectures at the University of Chicago. In that period, Carnap was himself constructing some systems of quantified modal logic, with the aim of providing for them a semantic treatment: consequently, it goes without saying, he was criticised by Quine. Quine noticed that de dicto modalities (e.g., 'Necessarily, every bachelor is unmarried') could be considered, in the spirit of Carnap, as analytic or conceptual truths (assuming that, say, the concept bachelor is associated by definition to the concept unmarried), whereas, on the contrary, if one accepts a quantified modal logic as strong as $\mathrm{S} 5$, there is no way to prevent the proliferation of de re modalities (e.g., 'Every bachelor is necessarily unmarried'), thus generating metaphysical monstrosities, such as the alleged existence, in every bachelor, of the necessary property of being unmarried. This objection amounted to a classical $t u$ quoque argument, addressed to a philosopher such as Carnap who, twenty years earlier, passed into the annals of history as the one who declared the advent of a new form of empiricism and a scientific conception of the world (Quine 1947, 1953a).

The third reason why Quine's attitude towards Carnap's conception of analyticity (and its explication in terms of L-truth) became more and more exacerbated goes back to the academic year 
1940-41, when at Harvard there were at the same time Quine, Goodman (a doctoral student at that time), Russell, Hempel, Tarski and Carnap; during the seminar, Tarski presented his view of a nominalist (or, as they used to say, finitist) language for mathematics and the natural sciences (FrostArnold 2013). Tarski maintained that a language cannot be intelligible and scientific, unless it is as we would say nowadays - a first order language (in particular, a language containing only individual variables, and no variables for classes of individuals), a language having nothing but concrete spatiotemporal objects in its domain, a language that does not allow one to speak of infinite cardinalities. Tarski's project was to provide a finitist account of arithmetic: an ambitious task, given that numbers are, at least prima facie, abstract entities belonging to infinite sets. In their 1947 article, 'Steps Toward a Constructive Nominalism,' Quine and Goodman took Tarski's challenge very seriously (Goodman and Quine 1947). Moreover, Quine found in Tarski's project the most radical reason to reject Carnap's semantics, namely, the idea that even arithmetic can be synthetic, rather than analytic. Carnap's reaction was one of surprise and even scorn, for it seemed to him that his interlocutors were simply coming back to Mill's empiricism (Carnap 1963a). After all, it is likely that he had had a similar reaction in 1930, when, during a conversation in a Viennese café, Tarski kept on denying that tautologies do not tell us anything about the world, and that between tautologies and empirical sentences there is a difference in principle, rather than a mere difference in grade (Haller, 1992; Mancosu, 2005). ${ }^{x i}$

The synthesis of Quine's criticism of Carnap was, as is well-known, the 1951 article on the 'Two Dogmas of Empiricism,' one of the most influential works in twentieth-century analytic philosophy (Hunter 1995: 305). Quine maintained that the notion of analyticity is impossible to clarify; in fact, it is not fully intelligible. Therefore, any scientific philosophy should do without it. Quine noticed that there is a cluster of concepts (such as synonymy, semantic rule and necessity), which are strictly connected with the concept of analyticity: the truth of an analytic statement such as "No bachelor is a married man' seems to depend on a definition such as "Bachelor' means unmarried man" (by the same token, a sentence belonging to an artificial language is true in virtue of semantic rules); and two synonymous expressions can be inter-substituted salva veritate not only in modal contexts, but also in the context of the operator 'it is analytic that'. Quine's verdict is well-known: all these notions (synonymy, necessity, analyticity, semantic rule) are intensional, and therefore obscure, and there is no chance of making them scientifically respectable. At any rate, Quine added that within a scientific theory one cannot draw a sharp divide between analytic statements (conceived of as the byproduct of the conventional choice of a language) and synthetic ones (regarded as factual descriptions of the world), since they are always intertwined with one another. To show this, he gave new life to Pierre Duhem's epistemological holism, according to which no individual statement or hypothesis can be empirically confirmed (or disconfirmed), but only the theory as a whole (or as a subset of its 
statements) (Duhem 1906). Quine compared science to a "'system,' a 'web,' a 'field of force' whose boundary conditions are experience," thus strengthening Tarski's radically fallibilist perspective. He remarked: "any statement can be held true come what may, if we make drastic enough adjustments elsewhere in the system. Even a statement very close to the periphery can be held true in the face of recalcitrant experience by pleading hallucination or by amending certain statements of the kind called logical laws". On the other hand, he also stated: "By the same token, no statement is immune to revision. Revision even of the logical law of the excluded middle has been proposed as a means of simplifying quantum mechanics; and what difference is there in principle between such a shift and the shift whereby Kepler superseded Ptolemy, or Einstein Newton, or Darwin Aristotle?" (Quine 1951b: 40). It is likely that Quine knew that a fallibilist view similar to the so-called Duhem-Quine thesis had also been formulated by Neurath, Einstein, and even by Carnap himself (for example, in the Logical Syntax). Nonetheless, he thought that Carnap had not been able to draw the due consequences: in particular, Carnap took a pragmatic attitude towards the problem of choosing a form of language, or a scientific framework, but he kept on maintaining the analytic-synthetic distinction. Quine's radical pragmatism, on the contrary, would have led to an undogmatic empiricist epistemology, in which there was no place for a scientifically legitimate notion of analyticity.

Arguably, Quine's arguments against analyticity were not fully sound: for example, Quine seemed to throw away our robust intuition of synonymy very quickly (Williamson 2007: 50; see chapter 6 below for some considerations on this). ${ }^{\mathrm{xi}}$ Moreover, it is likely that his arguments were not entirely original either: around 1950 several analytic (or proto-analytic) philosophers beside him felt the need to criticise Carnap's framework based on the semantic notion of analyticity (among them Goodman 1949, Pap 1949, White 1950, Mates 1951, Martin 1952, Sellars 1953a and Bergmann 1955). However, Quine's attack on Carnap was extremely successful, for at least two different reasons. First, it unmasked the (alleged) Achilles's heel of Carnap's philosophy (and, more generally, of any "linguistic" philosophy in a wide sense), namely, the claim that an attempt to do philosophy seriously or scientifically — thus avoiding metaphysical absurdities — is based on a (semantic, logical and epistemological) distinction between a conceptual (or analytic) component and a factual (or synthetic) component; according to many, this vulnerability of Carnap's view would only become clearer about twenty years later (with Kripke 1972/1980), but Quine was one of the first to reveal it (Williamson, 2007: 50-2). Secondly, Quine replaced the "failed" Carnapian semantic program with a new philosophical task: answering the simple question "What is there?" by providing an inventory of what exists, that is, the list of entities which, according to our best theories, populate the world (Quine, 1948). To foster ontology - a word and a kind of research he met in the early 1930s at the University of Warsaw (for example, in Leśniewski's courses) - Quine provided analytic philosophers with a motivation, a method and a tradition (Simons, 2013: 719). In his view, a study in ontology is guided 
by aesthetic preferences (such as his personal idiosyncrasy for densely populated lands) and by metatheoretic principles (such as his claim "no entity without identity"): based on these preferences and principles, Quine and Goodman rejected possibilia, universals, abstract entities, fictional, nonexistent, impossible objects (Goodman and Quine, 1947). A study in ontology requires three steps: taking into account our best — i.e., most explanatory, general, simple, elegant — scientific theories (typically, physical and mathematical theories); translating the language of the theory into a "canonical notation"; expressing perspicuously (by means of existential quantification) the ontological commitment of the theory. Thirdly, and lastly, based on such considerations, Quine pigeonholed ontology in the analytic tradition of ideal language, which was at its best exemplified by Russell's 1905 treatment of definite descriptions (Russell 1905).

In those years, nobody in the United States could equal Quine's philosophical and academic achievements. He occupied the centre of the scene, setting up the agenda for a generation of analytic philosophers. As is well-known, Quine despised the history of science (let alone the history of philosophy), for he was convinced that "an advance in science resolves an obscurity, a tangle, a complexity, an inelegance, that the scientist then gratefully dismisses and forgets", whereas "the historian of science tries to recapture the very tangles, confusions, and obscurities from which the scientist is so eager to free himself" (Quine 1985: 194). Nonetheless, he himself was a master in providing the rising analytic philosophy with a convincing self-narrative: one of the cornerstones of his rational reconstruction was the idea of a "return to Russell"; Russell as a philosopher of language (rather than as a linguistic philosopher such as Wittgenstein and Carnap), Russell as an ontologist, an anti-Meinongian philosopher who wanted to cut Plato's beard by using mathematical logic as an Ockhamian razor (Quine 1948 and 1966). Carnap did not of course like this fascinating but unreliable story, because, among other reasons, he always considered Russell as a father of logical positivism. Moreover, he liked even less Quine's charge of realism and platonism, based on the claim that his (Carnap's) semantic theories were ontologically committed to the existence of abstract entities (Quine 1948: 33). Carnap could not accept this charge, since throughout his life he shared Wittgenstein's attempt to criticise and demystify platonism in the philosophy of mathematics. Therefore, as is wellknown, he responded vigorously. In 1950 he published 'Empiricism, Semantics, and Ontology,' where he made it clear how liberal empiricists could overtake their nominalistic hesitations, thus adopting a language in which it is possible to refer to abstract entities without hypostatising them, that is, without assuming any realistic or Platonic metaphysics (Carnap, 1950b). Carnap gave new form to the deflationary (rather than conciliatory) philosophical attitude he always took with respect to the problem of ontological disagreement. In his 1922 dissertation, he attempted to dissolve the apparent disagreement between mathematicians, physicians and neo-Kantian philosophers; in the Aufbau and the Scheinprobleme (Carnap 1928a and 1928b), he drew a distinction between a 
metaphysical use and an empirical use of the term "real"; in the Syntax he formulated the principle of tolerance, so as to avoid metaphysics by bringing the contrast between rival theoretical systems back to the conventional choice of a language (Carnap 1934). Now, in 1950, he introduced the notion of linguistic framework: "If someone wishes to speak in his language about a new kind of entities, he has to introduce a system of new ways of speaking, subject to new rules; we shall call this procedure the construction of a linguistic framework for the new entities in question" (Carnap, 1950b: 631). When a linguistic framework has been introduced, it is possible to raise two kinds of questions of existence. Internal questions concern the existence of something within the framework: for example, within the logical framework of arithmetic, one can answer the internal question 'Are there numbers?' by applying purely logical or analytic methods (here the affirmative answer follows trivially from the analytic sentence '5 is a number'). External questions, on the contrary, even though they can be phonetically and syntactically indiscernible from internal ones (the very sentence 'Are there numbers?' provides an example of this kind of ambiguity), concern the existence of the systems of entities as a whole: if we interpret them as practical questions, i.e. questions concerning the pragmatic reasons to adopt or not to adopt a certain framework (such as the framework of natural numbers), they are fully legitimate; however, if considered as theoretical questions, that is, as questions intended to establish whether a certain class of entities (such as the class of natural numbers) exists regardless of the choice of a framework, they are illegitimate and, actually, nonsensical (Carnap 1950b). The internal-external divide allowed Carnap to turn the charge of (bad) metaphysics against Quine. Empiricists can employ the language of mathematics and, in particular, quantify over abstract entities without profanation, as long as they are aware of the fact that such entities exist only within a certain linguistic framework, which is somewhat useful to the scientific enterprise. The greater difficulties arise when empiricists (such as Quine) take ontological questions at face value, ending up advancing arguments which make no more sense than those formulated by the metaphysical realists.

However, Quine replied in turn, criticising the new Carnapian distinction (Quine 1951a). First of all, he maintained that the internal-external distinction could be paraphrased in terms of the more fundamental distinction between subclass and category questions (where external questions = category questions, conceived of as proposals for the adoption of a given language, whereas internal questions $=$ subclass questions + category questions, conceived of as questions raised within an already adopted language and answered by trivially analytic or contradictory statements) (Quine 1951a: 201). For example, a question such as 'Are there numbers?' is a category question if it is raised in a language (such as the language of arithmetic) endowed with specific variables for numbers, and only for numbers, whereas it is a subclass question if it is formulated in a language (such as the language of Principia Mathematica or set theory) whose variables take not only numbers but also entities of a different kind (such as classes) as their values. Therefore the internal-external distinction 
simply depends, in a language, on a certain style of variables (Quine, 1951a). This amounts to a reductio of Carnap's position, for according to Quine one can draw a distinction between internal and external questions only if one has adopted a certain kind of language, rather than another, in spite of the principle of tolerance. Moreover, Quine remarked that, in Carnap's view, a genuine ontological question such as 'Are there numbers?' is (under a certain interpretation) a question which, given a language (or a linguistic framework), can be answered analytically. But since, as Quine argued, the notion of analytic-in- $\mathrm{L}$ is nothing but an irremediably flawed dogma of empiricism, so much the worse for the internal-external distinction (Quine 1960a). ${ }^{\mathrm{xi}}$

From a meta-philosophical point of view, Quine pushed philosophy towards methodological naturalism, the view according to which science and philosophy are continuous with each other, for any statement of the former can be relevant to the latter, and vice versa. This metaphilosophy was at least in part in accordance with the manifestos for naturalism presented, from 1944 to 1949, by philosophers such as John Dewey, Sidney Hook, John Randall, and Ernest Nagel, on the one hand, and R.W. Sellars, Marvin Farber e Vivian Jerauld McGill, on the other hand (Krikorian 1944; Sellars, McGill, Farber 1949; see also De Caro and Macarthur 2004). But what is most relevant for the present purposes is that Quine's "continuist" theses were at odds with the metaphilosophical views shared not only by Carnap but also by Wittgenstein and the entire later Wittgensteinian tradition. 


\section{Notes}

${ }^{x i}$ One occurrence of 'Wittgenstein' is too generic to understand which specific Wittgensteinian contribution to philosophy (if any) the author of the article had in mind.

${ }^{x i}$ The same attitude and the same evaluation were also shared by, amongst others, Jan Patočka, one of the first continental critics of Wittgenstein (Sebestik 1990: 198).

${ }^{x i}$ On a different occasion, Wittgenstein pointed out that by employing the sentence 'God's eye sees everything' a believer associates a particular use with a picture. This provoked the reaction of Yorick Smythies, one of Wittgenstein's catholic pupils, who was worried that Wittgenstein was proposing a reduction of the religious into non-religious terms. Then Wittgenstein, in turn, replied passionately: "Rubbish. I meant: what conclusions are you going to draw? etc. Are eyebrows going to be talked of, in connection with the Eye of God? 'He could just as well have said so and so' — this [remark] is foreshadowed by the word 'attitude'. He could just as well have said something else. If I say he used a picture, I do not want to say anything he himself would not say. I want to say that he draws these conclusions. Isn't it as important as anything else, what picture he does use as?" (Wittgenstein 1966: 71).

${ }^{\mathrm{xi}}$ Here it has been roughly assumed that Stroud (1965) was by and large right against Dummett's (1959) interpretation of Wittgenstein as a full-blooded conventionalist.

${ }^{\mathrm{xi}}$ This is not to say that Wittgenstein was not acquainted with theoretical physics. There is some evidence, for example, that Einstein's use of thought experiments had a lasting influence on his later way of doing philosophy (Penco 2010). Yet, it is fair to say that Wittgenstein never focused his attention on the epistemology of theoretical science, and, when he made a methodological comparison (perhaps better: a contrast) between science and philosophy, he seemed to have in mind the paradigm case of experimental physics.

${ }^{\mathrm{xi}}$ Actually, most historians now share the conviction that not only Wittgenstein, but also the pragmatists, the Neo-Kantians and some of the logical positivists (including Carnap) anticipated Kuhn's anti-foundationalist views about the theoryladenness of science (Kuhn 1962).

${ }^{x i}$ Yet, an important footnote, which ultimately led him to embrace semantic pluralism (roughly, from "there are many methods of verification" to "there are many language-games").

${ }^{x i}$ Moreover, the very presence of Hobbes in the list looks strange.

xi Consider, by analogy, Ronald Giere's interesting conjecture concerning Hans Reichenbach's famous discovery/justification distinction. According to Giere, from the point of view of the exiled philosophers of science seeking to establish home in the United States, the "distinction says: Don't think about the fact that I am a German immigrant, or speak with an accent; just consider the validity of my ideas" (Giere 1996, 346; see also Howard 2003: 55). xi This attitude goes back to Quine (1934).

${ }^{x i}$ In a 1935 letter to Neurath Heinrich Neider attributed to Tarski the following comment: "I have never uttered a sentence which I have not considered to be revisable" (Mancosu, 2005: 331).

${ }^{\mathrm{xi}}$ Notice, however, that the very notion of synonymy was criticised, in the same period, also by Goodman; see Goodman (1949).

${ }^{x i}$ Quine's attack on Carnap's analytic-synthetic and internal-external distinctions were not isolated incidents but rather all part of the process of assimilating logical positivism into the American philosophical world. This process often took the form of a critique. There are plenty of possible examples in this respect, from Hempel to Kuhn to Sellars, to mention just a few of them. 


\section{Rigourism in the Humanities}

Wittgenstein died in 1951, the same year in which Quine published 'Two Dogmas of Empiricism.' Looking at things in retrospect, one would suppose that the Wittgensteinians - especially the pupils and followers of Wittgenstein in Oxford and Cambridge - would have performed or at least prepared a reaction to Quine, challenging his arguments against the conceptual-factual divide and the resulting metaphilosophical picture based on methodological naturalism and the continuity thesis. Arguably, there were grounds to claim that Quine's attack on Carnap could not and therefore should not be automatically applied to Wittgenstein. First of all, Quine's main polemical target, that is, Carnap's notion of an analytic sentence, did not coincide either extensionally or intensionally with Wittgenstein's concept of a grammatical proposition (Schröder 2009). Analyticity is a property of types of statements, which depends on formal features, whereas grammaticality applies to tokens, i.e., to particular rules (Glock 1994: 198). Moreover, many grammatical propositions in the sense of Wittgenstein — such as, for example, colour incompatibility statements ('A surface cannot be entirely red and entirely green at the same time'), arithmetic equations, geometric theorems, and Moore's socalled truisms ('Here is a hand', 'The Earth has existed for many years past') — are grammatical but not analytic (Wittgenstein 1956/1978: III, § 42; Moore 1939; Wittgenstein 1969: § 84). ${ }^{\text {xi }}$ Even more crucially, grammatical propositions are neither true nor false: they are (disguised) norms that do not follow from the preexisting meaning of the linguistic expressions occurring in them but are rather (partly) constitutive of it. On the contrary, Carnap's analytic assertions are (regarded as) necessarily true.

Accordingly, the view of linguistic competence defended by Carnap and criticised by Quine held that knowledge of language is propositional knowledge, a form of knowing that, typically understood in terms of knowledge of meaning postulates (Carnap 1952). Wittgenstein, however, did not accept this view, but regarded linguistic competence as a practical ability, a form of knowing how, conceived of in terms of the capacity to understand and use words according to rules. Therefore, supposing that Quine's arguments showed that there is no real distinction between linguistic competence qua propositional knowledge and general scientific knowledge, it was still open whether a practical ability could also be reduced into propositional terms (Marconi 2012: 179-180). ${ }^{\mathrm{xi}}$ By a similar token one can claim, following Quine, that scientific assertions and hypotheses are relevant to philosophical arguments only if one assumes that there are indeed philosophical arguments or, which is the same, that philosophy aims to establish theses; but this is exactly the view rejected by Wittgenstein, when he asserted: "In philosophy we do not draw conclusions"; "philosophy only states what everyone admits" (Wittgenstein 1953: § 599; see also Marconi 2012: 180).

Moreover, two of Quine's favourite epistemological views, namely, confirmation holism and the 
related radical fallibilism, were to a large extent shared not only by Duhem and Carnap (via Neurath) but also by Wittgenstein himself, who presented a functional conception of grammatical rules, according to which whether a sentence is a rule or an empirical statement depends on its role, i.e., on how it is used on a particular occasion (Glock 1994: 203). Wittgenstein famously distinguished between the criteria and the symptoms of something. The former are logical or internal evidences: for example, we say that it is raining on the basis of some visual impressions (water falling in drops from the sky). The latter are inductive or empirical evidences: for example, we say that it is raining if the barometer falls. However, Wittgenstein acknowledged that there can be something like "the fluctuation in grammar between criteria and symptoms" (Wittgenstein 1953: § 354), though he also warned us not to conclude that there is consequently nothing at all but symptoms.

\subsection{The Wittgensteinians in the Age of Quine}

The Wittgensteinians could have responded, in the attempt to save Wittgenstein from Quine's attack on Carnap. However, with very few exceptions, they did not. This is clearly visible when considering Roland Hall's 'Analytic-Synthetic: a Bibliography,' published in 1966 in The Philosophical Quarterly (Hall 1966). This bibliography contained 169 references from Kant to Quine and the postQuineans, but only a few of these articles belonged to the later Wittgensteinian tradition: a couple of articles on logical necessity published in 1940, written by Norman Malcolm and Casimir Lewy respectively; 'A Defense of Synthetic Necessary Truths' by Stephen Toulmin, Morris Lazerowitz's discussion of the alleged meaninglessness of self-contradictory statements, and von Wright's 'Form and Content in Logic'_(all of them published in 1949); the series of papers 'Analytic-Synthetic' by Waismann, published from 1949 to 1953; three articles by David Pears, about synthetic a priori truths (1950), the incongruity of counterparts (1952), and the problem of colour incompatibility (1953), respectively; 'Necessary Statements and Rules' by Max Black (1958a), and Erik Stenius's article on the analyticity of numerical statements (1965). ${ }^{x i}$ From a brief comparative analysis of these articles, two main considerations emerge. First, the Wittgensteinians seemed to take for granted that Wittgenstein's views of logical necessity were altogether different from the logical positivist identification of necessary, analytic and a priori statements, as typically exemplified by the account provided by Ayer in his 1936 Language, Truth and Logic (Ayer 1936): ${ }^{x i}$ for example, renovating not only the Kantian tradition but also Karl Britton's 1934 focus on the relationship between experience and necessity, Lewy, Toulmin and Pears explicitly claimed that some necessary statements are synthetic a priori, and they seemed to be aware that it was at least controversial whether statements such as ' $7+5=12$ ' and 'Nothing can be at the same time entirely red and entirely green' could be labelled 'analytic' (Lewy 1940, Toulmin 1949; Pears 1950).

Second, even after the publication of 'Two Dogmas,' the Wittgensteinians appeared not to be 
interested in Quine's attack on analyticity or, at least, not to be entirely aware of its consequences. For example: in his 1949-1953 meticulous analysis of analytic statements, Waismann referred only to Quine's 'Truth by Convention,' published in 1936; after his 1940 contribution on necessity, Malcolm, who was to become the most representative Wittgensteinian "activist" in the American academia, did not feel the need to discuss the analyticity issue any further; in his philosophical logic papers, von Wright never examined the Quine-Carnap controversy in depth, and in 1965 Stenius discussed von Wright's views without focusing on Quine's arguments. Only in 1972 would Douglas Gasking, an Australasian philosopher who had been influenced by Wittgenstein (even though he remained basically "Vienna Circle"; see Anonymous 1994) publish a paper entitled 'The AnalyticSynthetic Controversy,' in which he presented an overview of Quine's perspective on analyticity, without opposing, for that matter, Wittgenstein and Quine (Gasking 1972).

The most interesting cases are probably those of Max Black and Peter Geach. In his 1948 'Logic and Semantics,' the former had criticised Carnap for having attempted to reduce logic either to syntax or to semantics (Carnap 1934 and 1942). Six years later, a slightly revised version of this article was published with a slightly revised title ('Carnap on Logic and Semantics') in the collection of essays Problems of Analysis (Black 1954). In his 1960 review, Putnam significantly considered Black's essay "the best criticism of Carnap's work to appear to date" (Putnam 1960b: 38). In 1954 Black emphasised that the essay no longer adequately represented his views, and put Carnap's semantic project into the post-Quinean context:

Some of the high hopes that were held for the future of 'semantics' at the time this essay was written have since 'evaporated,' though some young philosophers, chiefly American, are still eloquent in metalanguages. But the views here examined have something more than historical importance, and I hope what I have written may help anybody who wishes or is compelled to work his way through the intricacies of these ambitious attempts to apply mathematical methods to philosophical problems. (Black 1954: 298)

Then in a footnote Black acknowledged, even more eloquently: "The main conclusions of this essay have been advocated by a number of other writers," and here he mentioned the functional and Cassirer-inspired views of the a priori advanced by Arthur Pap in 'Are All Necessary Propositions Analytic?,' published in The Philosophical Review in 1949 (Pap 1949; see also Stump 2011), as well as - what is most interesting for the purposes of the present chapter — Quine's 'Two Dogmas of Empiricism' (with the qualification: "especially pp. 23-34," namely, the pages devoted to challenging the first dogma) (Black 1954: 298-299; see also Quine 1951b). It seems quite clear that Black did not 
perceive Quine's attack on analyticity as potentially dangerous for the later Wittgensteinian tradition (whereas he seemed to be aware that Quine had contributed to undermining Carnap's semantic views): paradigmatically, in 1958, when he wrote the article 'Necessary Statements and Rules,' in which he explicitly focused on necessary statements that are also analytic, he discussed nothing but the intra-Wittgensteinian issues based on the analogy between necessary statements, grammatical rules and the rules of games (especially chess) (Black 1958a: 75-6).

Among the Wittgensteinians, the case of Peter Geach was perhaps even more striking. He was personally acquainted with Quine: they used to discuss philosophy and logic, with a special focus on the problem of semantic reference. They had intense correspondence, showing reciprocal respect and mutual understanding, probably based on their common logical background. For example, Geach's Reference and Generality was reviewed approvingly by Quine in 1964 (Quine 1964; see also Geach 1962); and Geach took part to the 1954 symposium on Quine's 'On What There Is_(Geach 1954; see also Quine 1948). In his 1957 book, Mental Acts, at a certain point Geach raised the question: What is the criterion of synonymy? And he succinctly invited the reader to rely on the authority of 'Two Dogmas': “On the obscurity of the term 'synonymous', see Quine" (Geach 1957: 90). At this point he briefly summarised one of Quine's main arguments:

Two expressions are equivalent to the extent to which they are intersubstitutable salva veritate; but we cannot define synonymy as a supreme degree of equivalence, intersubstitutability salva veritate in all contexts; for if occurrence in quotation is recognized, no two distinct (non-equiform) expressions are intersubstitutable salva veritate at all occurrences. (Geach 1957: 91)

Then he concluded, still following Quine:

So no objection stated in terms of 'synonymy' is going to have much weight; an attempt to define 'synonymy' strictly is likely either to yield a relation that never holds between non-equiform expressions, or to involve a vicious circle when we try to apply it. (Geach 1957: 91)

Geach added that non-technical ordinary expressions such as 'equivalent' and 'tantamount to' are better than 'synonymous' and, above all, than Carnap's 'intensional isomorphism,' since 'there is less danger that way of making a show of precision where precision is not attainable," giving the illusionary "impression that scientific rigour has been achieved" (Geach 1957: 91). This move - 
contrasting Carnap and Quine by criticising the former and approving of the latter — would become typical of Geach, who in his later years once described his different attitudes towards Carnap and Quine in the following terms: "I battled ... against the pedantry and bad reasoning of people like Carnap and R.M. Martin. I found Carnap's view of Frege dramatically wrong, once and once again. On logic and philosophy of logic I almost always agreed with Quine"xi.

So the history of analytic philosophy took its course under the influence of Quine, and the Wittgensteinians did not provide a commensurate response. But why? There may be plenty of conjectural answers to this question. Many of them are mutually intermingled, but it is likely that not all of them have the same explanatory relevance. Preliminarily, before briefly considering these possible answers in a row, it seems useful to stress that in that period there was (almost) no presence of "Carnapstein" (that is, of a confusion between Wittgenstein and Carnap) in the United Kingdom, since the differences among Carnap and Wittgenstein were much more visible there than in the United States. Arguably, partial exceptions to this state of affairs were cases of early reception of Wittgenstein in Britain, such as the case of Stebbing mentioned in the previous chapter, as well as the cases of philosophers who met Wittgenstein when they were already formed under the influence of logical positivism, such as for example von Wright. ${ }^{x i}$ On the other hand, however, the generation that was born in Britain since around 1920 had a clear view of the main philosophical and metaphilosophical differences between Carnap and the later Wittgenstein. The paradigmatic case was that of Peter Strawson (born in 1919). Not only was Strawson entirely aware of Carnap's rejection of Wittgenstein's merely descriptive and therapeutic conception of philosophy, as well as of Carnap's commitment to the view according to which philosophy — though oriented towards achieving conceptual clarity, rather than substantive knowledge — should be constructed as a rigorous axiomatic theory, but he was also particularly interested in defending Wittgenstein and criticising Carnap regarding this very metaphilosophical issue. All this manifested itself in a 1963 debate between Strawson and Carnap, published in the volume devoted to Carnap in the series The Library of Living Philosophers, edited by Paul Arthur Schilpp (Schilpp 1963). The central issue was the normative conception of philosophy: How should we philosophise? One answer was: providing a rational reconstruction by means of constructed systems, i.e, what Carnap would later call 'explication'. An alternative answer was: describing ordinary language usages, such as in Wittgenstein's 'perspicuous presentation of grammar,' Strawson's 'connective analysis,' as well as in Ryle’s 'logical geography' (Strawson 1963, Carnap 1947, 1950a and 1963b; Ryle 1949). Carnap notoriously belonged to the ideal language tradition of Frege, Russell and Tarski, so he thought that ordinary language had many mistakes and defects (such as ambiguity, vagueness, category mistakes) that needed to be corrected. Consequently, the aim of Carnap's explication was the transformation (or, better, the replacement) of an inexact concept, the explicandum, into (with) a formally more 
precise concept, the explicatum. Normally, the explicandum belongs to ordinary language, but it can also emerge from a less mature phase of scientific or philosophical development. The explicatum is introduced by providing explicit and rigorous rules for its use, typically by putting it into a formal system. Here is a list of scientific and philosophical explicanda and explicata in Carnap's sense: the ordinary concept of heat (based on the subjective experience of heat and cold) and the quantitative notion of temperature (measured by a thermometer); the ordinary concept of fish (animal living in water, and so forth) and the zoological concept of piscis (a concept such that whales, qua mammals, do not belong to it); salt and $\mathrm{NaCl}$; true and Tarski's true-in-L; Kant's analytic and Carnap's L-true; Frege's sense and Carnap's intension; informative and semantically contentful, in the sense provided by Carnap and Bar-Hillel in 1953 (Bar-Hillel and Carnap 1953). In line with his pragmatism and conventionalism, Carnap suggested that the solution to a problem of explication was, properly speaking, more or less satisfactory, rather than correct or true, the satisfactoriness depending on criteria such as resemblance with the explicatum, exactness, simplicity and fruitfulness (Carnap 1950a: $§ 1)$. Fruitfulness, the last and the most explicitly pragmatic of Carnap's desiderata, deserves a couple of additional remarks. In the natural sciences, an explicatum is fruitful if it allows more and more new true empirical generalisations (for example, there are generalisations that we can make only using the concept of piscis instead of the concept of fish). In the case of logical concepts, an explicatum is fruitful to the extent that it allows us to prove more and more (true) theorems (Carnap 1950a: ch. 1). It is less clear, however, what the fruitfulness of an explication would amount to in the case of different kinds of concepts (assuming there are any). ${ }^{x i}$ And it is even less clear how the construction of formal systems could solve the philosophical problem that consists in the misunderstanding (or in the lack of clarity concerning the use) of the explicandum.

Speaking as a sort of Oxonian mouthpiece of the later Wittgensteinian tradition, Strawson maintained that the aim of achieving conceptual clarity - an aim that was shared by Carnap himself - requires nothing but connective analysis, which "consists in the attempt to describe the complex patterns of logical behaviour which the concepts of daily life exhibit" (Strawson 1963: 503). This, it goes without saying, was the same kind of work done by most Oxford and Cambridge Wittgensteinians in the 1950s and 1960s. In line with the later Wittgensteinian tradition, Strawson claimed that in philosophy "it is not a matter of prescribing the model conduct of model words, but of describing the actual conduct of actual words; not a matter of making rules, but of noting customs" (Strawson 1963: 503). Suppose the consideration of a given philosophical problem brings a certain concept into play. After having accurately and insightfully described the way in which that concept and the related notions are used, the philosophical problem is dissolved. Nothing more is required. Furthermore, in order to identify, as Carnap aims to, a satisfactory explicatum for a given explicandum, one should understand the very source of the philosophical problem. But if, as Strawson 
claims, connective analysis is sufficient for such an understanding, then Carnap's explication (especially its replacement of the explicandum with a more precise explicatum) is, to say the least, unnecessary and therefore redundant. The possible choice of performing an explication is not substantial, but rather a question of philosophical taste or style. Putting it in a nutshell, one can say that Strawson and Carnap shared the assumption, emphasised by Wittgenstein, that philosophical problems and perplexities result from "an inappropriate use of language" (Carnap 1963b), whereas their main point of disagreement concerned the role and the status of ordinary language in philosophy: Strawson, following Wittgenstein, seemed to think that "ordinary language is all right" (Wittgenstein 1958: 28), and that philosophical problems arise from a misunderstanding or an abuse of language, typically by philosophers, whereas Carnap maintained that ordinary language itself is often inherently contradictory, mistaken and confused. They also diverged in their philosophical style, mainly because of the use — or the lack of use — of technically sophisticated tools.

As is suggested by the Strawson-Carnap debate on metaphilosophy and philosophical style, philosophers in Oxford were rather hostile to logical positivism: in the 1950s Ayer was under the crossfire of Ryle, who held most academic power in Oxford, and Austin, who in his lectures spent a lot of time caricaturing and ultimately destroying his philosophical theories (Mehta 1963: 51-52; see also Rée 1993: 9). In particular, the above-mentioned negative attitude taken by Geach towards Carnap was the rule among the Wittgensteinians. As has been already emphasised above, Black criticised Carnap's semantics in 1948. Geoffrey J. Warnock used to affirm: "I would like to say in very plain terms that I am not, nor is any philosopher of my acquaintance, a Logical Positivist" (Warnock 1956: 124; see also Rée 1993). And when in 1949 he reviewed Carnap's Meaning and Necessity, Ryle stated that "both Frege's and Carnap's theories [of meaning] are either erroneous or worse," accusing Carnap of being "guilty of hypostatisation," because of his commitment to the mistaken 'Fido'-Fido conception of meaning (i.e., the Augustinian conception of meaning, as Wittgenstein used to call it). Then Ryle concluded caustically:

My chief impression of this book is that it is an astonishing blend of technical sophistication with philosophical naïveté. Its theories belong to the age that waxed with Mill and began to wane soon after the Principles of Mathematics. The muddled terminology of extension and intension which belonged to the muddled and obsolete doctrine of terms is disinterred in order to help construct a two-dimensional relational theory of meaning, at a time when it ought to be notorious that relational theories of meaning will not do.

Carnap's influence on philosophers and logicians is very strong. The importance of semantic problems in philosophy and logic cannot be 
overestimated. It is because I fear that the solutions of these problems may be impeded by the dissemination of his mistakes that I have reviewed so scoldingly the treatise of a thinker whose views are beginning to be regarded as authoritative. (Ryle 1949/2009: 243)

Therefore, a first possible answer to the question - Why did the Wittgensteinians not provide a commensurate response to Quine's attack on analyticity? — is that they were rather hostile to Carnap and somewhat naïvely applied the maxim: "The enemy of my enemy is my friend".

A related but partly different conjecture is that the Wittgensteinians noticed some undeniable affinities between Wittgenstein and Quine: the conception of meaning as use; the related rejection of semantic platonism (Quine's "myth of the museum" and Wittgenstein myth of meaning as Bedeutungskörper); epistemological anti-foundationalism and the criticism of "cosmic exile"; the view of language acquisition as based on activity and training; semantic and epistemological holism; the rejection of de re necessity (Hacker 1996: 189-93; see also Quine 1960b; Wittgenstein 1953: §§ $138,559) .{ }^{x i}$ In this regard, it is worth noting that Quine himself sometimes adopted an attitude towards linguistic philosophy in which emphasis was placed on areas of agreement, rather than of disagreement, especially when he had to draw a line between Anglo-American analytic philosophy on the one hand, and "continental" philosophy on the other hand. Consider, for example, the general discussion at the 1958 Colloque de Royaumont, in which he took part together with Oxford philosophers such as Ryle, Austin, Strawson, Hare, Williams, and Urmson. In front of Chaïm Perelman, who chaired the discussion, and several French and Belgian philosophers such as Jean Wahl, Marc-André Béra, Ferdinand Alquié, Maurice Merleau-Ponty, Herman Van Breda and Lucien Goldmann, Quine uttered rather conciliatory words towards Oxford linguistic philosophy:

I have been asked whether I agree with Ryle and Austin. I certainly agree with them to a very large extent, and in particular regarding everything that one could refer to as method. In what I do or try to do, I am perhaps not so close to them and their group or what has been called the Oxford School, even though we have common views on some points. In any case, I believe that a common trait unites us: that our activities are focused on language. I believe that one of the main reasons that we prefer to focus on language is that if we deal directly with the problems of the foundations of reality, we are in danger of introducing a set of presuppositions that touch underlying conceptual schemes relating to the most deeply rooted habits of thinking and feeling, so that none of the participants can oppose their own point of view to that of the 
others without seemingly being guilty of a petition of principle. (Royaumont 1958/2018: 226)

Then he emphasised the common use of the method of semantic ascent: in other words, the main common ground seemed to be the rejection of metaphysics, understood as "the direct discussion of the fundamental features of reality":

Now, here is the trick: transposing the ontological discussion to a discussion of language in such a way as to insist no longer on this or that presumed irreducible ontological fact, but more on the methodological assets or goals that favour this or that discursive ontological theory. The trick is to avoid a direct discussion of the fundamental features of reality, so as to turn, rather, to the discussion of the pragmatic virtues of theories about reality.

The usefulness of such an approach that prompts us to retreat from the conceptual to the semantic level, and focus on the way we speak about things instead of focusing on things spoken of, remains, even if one thinks, as I continue to think, that the fundamental problems regarding conceptual schemes are of the same kind as the fundamental problems of physical science or of mathematical logic. (Royaumont 1958/2018: 226)

The last remark alluded to the continuity between science and philosophy, i.e., the main consequence of Quine's rejection of the analytic-synthetic distinction. But Quine just passed through it very quickly, focusing instead on "the common views," "in particular regarding everything that one could refer to as method." Seen in retrospect, Quine's description and evaluation were quite misleading. First, we now know that the main point of disagreement between Quine and linguistic philosophers was a metaphilosophical and methodological one. Second, as Mathieu Marion recently noticed, "it is telling ... - and the discussion [at Royaumont] makes it clear — that analytic philosophers felt under the pressure to provide reasons for their rejection of metaphysics," but "no one discussed Quine's critique of the analytic-synthetic distinction, which re-opened the door to metaphysics. The critique loomed large in the background, given that the debate often revolves, throughout the meeting, around the 'two kinds of knowledge' thesis. Lack of preparation is the culprit here” (Marion 2018: 205).

Yet another reason why most Wittgensteinians avoided facing the Quinean issue of analyticity might be that they assumed or took for granted that the job had already been done successfully by Grice and Strawson in their article 'In Defense of a Dogma,' published in 1956 in The Philosophical Review. In agreement with Carnap's reply to Quine (Carnap 1963b), Grice and Strawson summarised 
the main theme of Quine's article as follows:

There is a certain circle or family of expressions, of which 'analytic' is one, such that if any one member of the circle could be taken to be satisfactorily understood or explained, then other members of the circle could be verbally, and hence satisfactorily, explained in terms of it... Unfortunately each member of the family is in as great need of explanation as any other. (Grice and Strawson 1956: 147)

They noticed that the existence of borderline or dubious cases is not a real worry, considering that there are indeed clear cases as well (in fact, the existence of the former, disputable cases presupposes the existence of the latter, uncontroversial ones), and also that the philosophical community often applied the analytic-synthetic distinction to an open class of cases (Glock 2003b: 73). Moreover, supposing it is controversial whether the sentence 'What is coloured is extended' really is analytic, it is no less controversial whether this very sentence is true (Grice and Strawson 1956: 1953-4; see also Carnap 1963b). More generally, they pointed out that Quine adopted too strict a conception of satisfactory explanation, a conception that "should take the form of a pretty strict definition but should not make use of any member of a group of interdefinable terms to which the expression belongs" (Grice and Strawson 1956: 148). According to Grice and Strawson, it is dubious whether any such explanation, any 'reductive analysis' of this kind, can ever be given, not only for intensional notions but even for extensional ones (Grice and Strawson 1956: 148). On the other hand, they stressed that conceptual explanation often takes the form of a connective, non-reductive analysis, in which conceptual circularity is illuminating rather than vicious.

A further conjecture one could formulate in order to understand the later Wittgensteinians' (too) tepid reaction towards Quine's attack on Carnap has to do with the core-periphery relationship between the US and the UK briefly outlined in chapter 2 above, as well as with the social conditions of academic philosophy in Britain during the 1950s. Britain was not just a periphery or, for that matter, a semi-periphery: ${ }^{x i}$ it was a very special periphery, namely, the former core, and it took a while for British philosophers to become aware of the "downgrade". Moreover, most linguistic philosophers in Oxford were patently upper class, ${ }^{\mathrm{xi}}$ having received an élite education either in Oxford or, to a lesser extent, in Cambridge. The social context of Oxford linguistic philosophy, characterised by the presence of upper-class philosophers in a special periphery, which not many decades earlier used to be the geopolitical and philosophical core, was something that Gellner had noticed and emphasised sooner and probably better than anyone else, linking it to the metaphilosophical ideal based on the slogan "Philosophy leaves everything as it is". In an interview 
with Ved Mehta, he summarised the sociological analysis he provided in Words and Things in the following terms:

Philosophers in the past were proud of changing the world and providing a guide for political life. Around the turn of the century, Oxford was a nursery for running an empire; now it is a nursery for leaving the world exactly as it is. The linguistic philosophers have their job cut out for them — to rationalise the loss of English power. This is the sociological background which is absolutely crucial to the understanding of linguistic philosophers.

(Mehta 1963: 37-38) $)^{\mathrm{xi}}$

As Jonathan Rée rightly stressed, Gellner's sociology of academia was rather plausible: an inspection of Who's Who shows that all (except one) of Oxford's leading philosophers in the 1950s came from a high-bourgeois family, and all of them were undergraduates at Oxford (except one, who went to Cambridge instead). ${ }^{x i}$ Their social basis was extremely narrow, even by the standards of other disciplines in Oxford, and it had several features in common with that of the Bloomsbury intellectuals: "Certainly they spoke with the same accents; they liked to make use of French phrases; and - as Russell observed -- they were 'gentlemanly' in their aversion from taking things too seriously (Rée 1993: 16).

One of the consequences of this social climate was that professors of philosophy in Oxford used to regard their philosophical preferences and interests as ultimately self-justified. In particular, they did not feel the need to justify their work to the external public, understood in a broad sense, so as to include non-professional readers, non-Oxonian people and non-philosophical disciplines. It is likely that Ryle was the best candidate to personify this attitude. Consider for example his reluctance to justify his conception of philosophy during a conversation with Bryan Magee in 1971. The conversation deserves to be quoted at some length, not only because - as Austin famously put it - "le style, c'est Ryle" (Austin 1950), but also because the word choice and the overall verbal pose seem to be relevant indicators of an attitude expressing a sense of intellectual and social sophistication and superiority. ${ }^{\mathrm{xi}}$ When required to acknowledge and justify, rather than simply ignore, well-known theories such as for example Freud's psychoanalysis, with which the main thesis defended in The Concept of Mind seemed to be incompatible, Ryle replied:

Well, I don't feel very penitent. I'd never studied any psychology, and I felt as unwilling to stick my neck out on technical questions of, oh, for example, radar, astronomy, or chemistry. I don't know the ground so I don't want to 
step on it. (Magee 1971: 131)

When, later on, Magee mentioned Russell's criticism, according to which "it was pointless to write about matters like sensations and perception if you weren't thoroughly familiar with what neurologists, opticians, psychologists and other empirical observers had said about them," Ryle just remarked:

It's a pretty familiar kind of criticism... Russell thought one ought to know a lot about, say, the rods and the cones in the eye, and I don't pretend to know anything about them, and, if I may speak a bit rudely, I don't want to. (Magee 1971: 132)

Neither was he impressed by the possible doubts of "the intelligent layman" - a further figure introduced by Magee during the conversation — "who doesn't know much philosophy" but "may genuinely wonder how it is that you can deal with perceptual questions if you don't know about the rods and cones in the eye" (Magee 1971: 132).

Arguably, Quine's attack on analyticity could ultimately be regarded as a request for justification addressed to any linguistic or conceptual philosophy. This was something unacceptable from the standpoint of Ryle's and other linguistic philosophers' self-justifying attitude. Therefore indifference and nonchalance, rather than explicit response, turned out to be a natural - though, in retrospect, weak - response.

All this has to do with what is arguably the most important reason why the Wittgensteinians did not make the attempt to nip the Quinean revolution in the bud. It seems reasonable to conjecture that at that time most of them lacked the historical awareness to realise fully that the Quine-Carnap debate on analyticity (and the related issues) was not just a discussion among a rising philosopher (who apparently shared some philosophical views and attitudes with the later Wittgenstein) and his authoritative, but in a certain sense declining, teacher (whom, incidentally, many of them did not like at all); rather, that debate was part - more precisely, it was both effect and expression — of a much wider process taking place after the second world war, not only in philosophy but more generally in the humanities, especially in the United States. All this suggests that though it may be interesting to ask why the Wittgensteinians behaved as if the philosophical tradition to which they belonged were not challenged philosophically and metaphilosophically by Quine's epoch-making attack on Carnap, nonetheless, the really interesting question is: What objective conditions made Quine's attack so successful and epoch-making, so as to indirectly demolish, or at least weaken, the Wittgensteinian tradition, which was not his direct polemical target? The following will provide a brief description of 
this objective context.

\subsection{A Scientifically Oriented Culture. Philosophy, Economics, and the Humanities}

As briefly recalled in chapter 2 above, the 1950s and 1960s were a time of exponential expansion and deep transformation for higher education in the United States. At the time of the first world war, scientific research had been exclusively contracted to military scientists. During the second world war things changed and events such as for example the Manhattan project, which was dedicated to producing the first nuclear weapons, employed hundreds of thousands of people and billions of US dollars. In 1945 a crucial innovation was introduced by Vannevar Bush, the former Vice President and Dean of Engineering at the Massachusetts Institute of Technology, and later on the director of the government Office of Scientific Research and Development during the second world war (Menand 2010: 124): Bush delivered an influential report to the US President, in which he argued that the federal government should be committed to providing conspicuous funding for fundamental knowledge and basic scientific research, not only in the context of applied research and technological development directly linked to immediate social and military concerns. Arguing that without basic, unconstrained research, industrial development would stagnate in the long run, he fostered a new type of collaboration between American universities and the national government (Schauz and Kaldewey 2018: 1-3; Elzinga 2012: 419; see also Menand 2010: 125). Soon afterwards, economists such as Gary Becker and Theodore Schultz introduced the concept of human capital, thus stressing a related point and providing a further reason for government investments in higher education: educated citizens were to be regarded as a strategic resource for the nation (Menand 2010: 127-128).

Not only did the huge expansion of higher education take place during the post-war baby boom, in a period of relatively high domestic economic growth (Menand 2010:121), but, as is well-known, the cold war also acted as a major driver of investments in scientific research (Elzinga 2012: 418): the investments kept on increasing, since the connection between science and national defence became tighter, so as to put American universities systematically at the service of government-related scientific research. Events such as the Sputnik launch by the Soviet Union in 1957 fostered the international competition and the advent of so-called "big science," based on large-scale projects funded by huge public investments. These projects were, as Aant Elzinga put it, clearly a "continuation of politics by other means" (Elzinga 2012: 416). Besides the Department of Defence, other sources of funding, such as the National Aeronautics and Space Administration, the National Science Foundation, and the National Institutes of Health acquired a relevant role (Menand 2010: 127).

From the point of view of the present investigation, one of the developments fostered by the expansion of American higher education outlined above is particularly relevant, namely, the widespread dominance of a scientific model in academic research, including research in humanities 
and social sciences (Menand 2010: 137-138; see also Steinmetz 2005). Humanities were methodologically modelled on natural sciences: this process, which occurred in the American academia from the mid-1940s to the late-1960s, has been insightfully described as a "new rigourism in the human sciences" (Schorske 1998), whereas the epistemological tradition and intellectual culture relating to this methodological transformation have been called the "scientific philosophy" paradigm in human sciences (Isaac 2012: 6 and 28). The latter label explicitly evokes the title of a 1945 influential book, The Rise of Scientific Philosophy, which was written by Hans Reichenbach after his emigration to the United States with the "intention of showing that philosophy has proceeded from speculation to science" (Reichenbach 1945: vii). This science-oriented epistemological and methodological attitude or spirit concerned several disciplines, from economics to linguistics, from English literature to sociology, from social and institutional history to psychology, from political science to philosophy (Bender and Schorske 1998). ${ }^{\mathrm{xi}}$ The new disciplinary order in the humanities was not created in the form of a single, unifying research project, but rather in the form of a plurality of different projects connected by a web of resemblances: among them, rational choice theory, structural-functional sociology, information theory, behaviourism, operational research, systems engineering, modernisation theory and cognitive science (Isaac 2012: 9). Something like a common pattern is discernible in most of these projects (Schorske 1998: 309): ${ }^{x i}$ the emergence of a new scientific style based on the demand for rigour, clarity and precision; the construction of general and systematic theories and the adoption of a certain conception of causal explanation; an ahistorical spirit and the rejection of the old narrative style; mathematisation, formalism, and technical specialisation; a quest for objectivity, including ethical and political neutrality and value-free methodology; ${ }^{x i}$ the claim that in the social sciences the individual, "conceived of as a culturally programmed human agent," is the basic explanatory factor (on the last point, see Isaac 2012: 9).

Harvard University is a particularly revealing place to gain insight into the process outlined above. As shown by Joel Isaac, in the Harvard complex's "interstitial academy", i.e. in "the realms of intellectual engagement that existed [in Harvard] between more established or specialised disciplinebased departments or schools" (2012: 23), new humanistic disciplines arose and old scientific disciplines were deeply transformed: sociology, anthropology, social psychology, management science, history, sociology and philosophy of science, and, what is most relevant for the present purposes, analytic philosophy. Both faculty members and students became acquainted with the scientific spirit of the new rigourism in the human sciences by meeting their peers in clubs, societies and seminars such as "the Royce Club, the Pareto circle, the Society of Fellows, Alfred North Whitehead's Cambridge salon, the Science of Science Discussion group, the Inter-Science Discussion Group, the Institute for the Unity of Science in Boston, the Department of Social Relations and the General Education Program of James Bryant Conant” (Isaac 2012: 23). 
Among these new humanistic projects, which flourished at the extra-professional crossroads of the interstitial academia, there were for example Percy Williams Bridgman's operationalism (then brought to the humanities by Stanley Stevens), Burrhus Frederic Skinner's behaviourism, Talcott Parsons's general theory of action and Robert Merton's sociology of science (Isaac 2012: 24; see also Hands 2007: 9). ${ }^{x i}$ Yet another example is, of course, the rise of analytic philosophy in America. In the 1950s and 1960s, not least thanks to the interdisciplinary and extradisciplinary exchanges in Harvard, Quine started to forge analytic philosophy in America; his attack on Carnap's analyticity was a crucial part, perhaps the most important component of the initial part, of the forging process. As witnessed by Putnam, in that period analytic philosophy started to adopt the scientific rather than humanistic self-image, which is still one of its hallmarks (Putnam 1997: 201). ${ }^{\text {xi }}$ One step in this process was the adoption of Quine's methodological naturalism, based on the claim of the continuity between philosophy and the natural sciences, which was in turn a consequence, it goes without saying, of his rejecting Carnap's two dogmas. Another feature of the same process was the ahistorical or even antihistorical biases of analytic philosophy, typically epitomised by Quine in his autobiography:

Science and the history of science appeal to very different tempers. An advance in science resolves an obscurity, a tangle, a complexity, an inelegance, that the scientist then gratefully dismisses and forgets. The historian of science tries to recapture the very tangles, confusions and obscurities from which the scientist is so eager to free himself. (Quine 1985: 194)

Yet another aspect of the process described here is the end of eclecticism: as recently shown by Katzav and Vaesen in their quasi-quantitative review of the articles published in The Philosophical Review from the 1930s to the 1960s, the main feature of Anglo-American philosophy prior to the 1960s was "philosophical pluralism and a widespread commitment to addressing meta-philosophical issues related to such pluralism" (Katzav and Vaesen 2017, 774). The pluralistic attitude was later abandoned, mainly because of a change in the journal's editorial policy. Something similar happened in other philosophical journals too, so that the transformation of (a significant part of) American philosophy into analytic philosophy was also the result of the exclusion, at the institutional level, of the pluralistic approach (see also Katzav 2018). The end of pluralism went hand in hand with specialisation and the launch of specifically philosophical research programmes: to mention but a few of them, Quine-inspired ontological studies and Carnap's twenty-year focus on probability, induction and confirmation were early, pioneering examples (Carnap 1950a; Quine 1960b), whereas later examples were Richard Montague's and Donald Davidson's programmes in semantics, as well 
as the great variety of epistemological programs, regarded as possible responses to the problem posed by Edmund Gettier (Montague 1970, Davidson 1984b, Gettier 1963). ${ }^{x i}$

The specialisation process was also connected with the use of more technical tools such as logical formalism. This caused, among other things, the sudden disappearance, in the 1960s, of an old and until then authoritative philosophical world, a world that was in previous decades still alive on the Anglo-American philosophical scene: the world in which it was natural to refer to different logical traditions, based on non-mathematical kinds of logic, and connected to the names of philosophers such as Bradley, Hegel and above all Dewey (Bonino, Maffezioli, Tripodi, unpublished manuscript). ${ }^{\mathrm{xi}}$

Moreover, in the age of the cold war and McCarthyism, and, in addition, as a consequence of the huge quantity of federal money poured into the universities, analytic philosophy grew under the influence of the "end of ideology" ideology (Bell 1962; Vaesen and Katzav 2019; Menand 2010: 140; see also Amadae 2003). One may conjecture that even the great success of Reichenbach's distinction between the context of discovery and the context of justification could be explained by referring to the cold war climate: internal, philosophical arguments were preferred, whereas external, socioeconomic explanations of philosophy were avoided. ${ }^{\mathrm{xi}}$

Professionalisation and homogenisation of analytic philosophy in the 1950s and 1960s were also fostered by organisations such as the RAND Corporation, whose Mathematics Division attracted some logicians and analytic philosophers (Rescher 2005). These analytic philosophers - Quine, Tarski (one of Quine's logical and philosophic polestars) ${ }^{\mathrm{xi}}$ and Nicholas Rescher amongst them were usually involved in projects concerning game theory and related topics. In the heyday of the debate with Carnap on analyticity, at RAND Quine produced five contributions: 'Commutative Boolean Functions'(1949); 'On Functions of Relations with Special Reference to Social Welfare' (1949); 'A Theorem on Parametric Boolean Functions' (1949); 'A Simplification of Games in Extensive Form' (1951) (https://www.rand.org).

At RAND, as well as in the Harvard academic complex, extra-philosophical influences were very important in shaping Quine's philosophy. As is well-known, his main aim in ontology was to fill out the complete inventory of the universe, on the basis of the ontological commitment of the best scientific theories available. The best theories in question belonged no doubt to physics. It is not surprising that the leading science advisers who influenced the research policy discourse were often, indeed, physicists. As Elzinga insightfully emphasised, these scientists "tended to define the boundary between science and society in terms of concepts that portrayed themselves as 'truth speaking to power'. This is a tradition that continued in new forms when in the next generation molecular biologists and environmental scientists successively entered the policy advisory arena" (2012: 419). As is even better-known, Quine was also influenced, especially in the study of language, by the behaviourist perspective defended by his Harvard colleague Fred Skinner in his Verbal 
Behavior (Quine 1960b and Skinner 1957; see also Føllesdal 2011). Moreover, he was significantly conditioned by the Pareto circle in Harvard: for example, scholars have recently come to agree, both on the basis of a qualitative analysis (Isaac 2012: 70) and on the basis of quantitative, data-driven research (Betti, van den Berg et al. 2019), that Quine acquired the fundamental notion of 'conceptual scheme' from the legacy of Vilfredo Pareto via the mediation of the biochemist Lawrence Joseph Henderson, the founder of the Pareto circle. ${ }^{\mathrm{x}}$

One of the most interesting issues in the broad area of post-war intellectual history in the United States is the relationship and, in particular, the similarity between economics and analytic philosophy. ${ }^{x i}$ As a consequence of the work of economists such as John Hicks, Franco Modigliani, Robert Solow, James Tobin and Paul Samuelson, in the mid-1950s a consensus view in macroeconomics emerged in the United States, lasting for at least twenty years (Blanchard 2008). It was labelled 'neoclassical synthesis' by Samuelson in 1955, in the third edition of his Economics: An Introductory Analysis, originally published in 1948 and arguably the single most influential economic textbook of the second half of the twentieth century (Samuelson 1955: 212). ${ }^{\mathrm{x}}$ The synthesis was based on the attempt to combine or perhaps absorb some insights derived from the theory of employment presented by Keynes in his 1936 General Theory with the older marginalist tradition of Alfred Marshall, Stanley Jevons, Léon Walras and others (Roncaglia 2005: 282; see also Keynes 1936 and Marshall 1890). ${ }^{x i}$ From a methodological point of view, the synthesis was characterised by the search for a unified theoretical framework based on the mathematisation of economics, in particular on the development of mathematical models for economics. In 1947, in his most influential research work, Foundations of Economic Analysis, Samuelson wrote:

The existence of analogies between central features of various theories implies the existence of a general theory which underlies the particular theories and unifies them with respect to those central features. This fundamental principle of generalisation by abstraction was enunciated by the eminent American mathematician E.H. Moore more than thirty years ago. It is the purpose of the pages that follow to work out its implications for theoretical and applied economics. (Samuelson 1947: 3; see also Moore 1915)

From a theoretical point of view, the neoclassical synthesis relied on the attempt to found macroeconomics on microeconomics, and this in turn presupposed the faith in the Homo oeconomicus model of rationality, according to which economic individual agents are largely rational and tend to maximise utility as consumers as well as producers. As Modigliani clearly put it in the introduction to his collected papers: 
[One of the] basic themes that has dominated my scientific concern [has been to integrate] the main building blocks of the General Theory with the more established methodology of economics, which rests on the basic postulate of rational maximizing behaviour on the part of economic agents. (Modigliani 1980: xi)

A brief focus on the figure of Paul Samuelson seems to be promising if one aims to compare economics and analytic philosophy during les trente glorieuses, 1945-1975 (Fourastié 1979; Hobsbawm 1994). Samuelson and Quine were personally acquainted and often discussed together (Samuelson 1998: 1377; Weintraub 1991: 64). Both of them worked at Cambridge, MA: at Harvard at the beginning, whereas since the 1940 Samuelson had moved to the Massachusetts Institute of Technology. Both of them attended the Pareto circle and the Science of Science Discussion Group organised by Stevens, whose participants included, among others, Quine's and Samuelson's teachers, that is, respectively, Rudolf Carnap and Joseph Schumpeter (Hands 2007: 9; Hardcastle 1995; see also Samuelson 1951). Both of them were involved in RAND corporation in the same years (www.rand.org). Moreover, there were also many intellectual and philosophical similarities and connections among them. In a nutshell, Samuelson was, as it were, the Quine of economics:xi the most influential American author in the first thirty years after the Second World War in his discipline, and one of the founders of the new mainstream; one of the few, perhaps the only one, who could be regarded as the incarnation of the scientific establishment; a "natural" systematiser, a skilful disseminator and a "populariser"; the one mainly responsible for the mathematisation of the discipline (on this latter point see Barnett 2004: 519). But the similarities also go beyond the general. As a motto on the opening page of his Foundations, Samuelson wrote, following his mathematical mentor J. Willard Gibbs: "Mathematics is a language" (Samuelson 1947); ${ }^{x i}$ as is well-known, Quine made the very distinction between language and theory disappear or collapse (Hylton 2007: 74). Both Samuelson and Quine promoted the naturalisation of their disciplines, and both regarded physics as the science par excellence, and the model to imitate methodologically and epistemologically; as Samuelson Quineanly put it: "If we enumerate one by one the alleged differences between the social sciences and other sciences, we find no differences in kind" (1952: 61). ${ }^{x i}$ Moreover, Samuelson's neoclassical synthesis was based on two main methodological norms: to face and solve an economic problem, "(1) reduce the number of variables, and keep only a minimum set of simple economic relations; and (2) if possible, rewrite it as a constrained optimisation problem" (Barnett 2004: 521). There seem to be loose but structural analogies with Quine's ontological procedure: (1) translate the theories into a canonical notation, so as to make explicit their ontological commitment; (2) avoid the 
overpopulated ontological jungles, favouring desert landscapes instead (Quine 1948).

A last point concerns methodological individualism, a term introduced by Schumpeter in 1908 to denote a reductionist view earlier expounded by Menger in the 1880s, and later accepted and defended by Hayek, Popper, Watkins, and by Samuelson himself, a view according to which "explanations of social phenomena should appeal only to facts about individual people" (Currie 2001: 9755; see also Heath 2015): arguably, the most important milestone of every rational choice-based economics. There seems to be a historically interesting relationship between methodological individualism and Quine's philosophy. First, methodological individualism is loosely linked with Quine's ontological nominalism (conceived of in terms of the rejection of abstract entities; see Goodman and Quine 1947): given that, properly speaking, the two theses are very different from each other, in this context it would be pedantic to discuss to what extent and under what specific conditions (if any) the two theses would be logically or theoretically connected, since, as Martin Kusch made explicit at the end of his book on psychologism, philosophical controversies and debates are fuzzy and "often the members of the camps that disagreed can be identified only with hindsight"; moreover, they "are followed by a wider audience of scholars in other fields and by the public at large, and philosophers have no qualms about strengthening their position in the eyes of these larger audiences by linking their opponents' views to unreason and moral defect" (Kusch 1995: 270); ${ }^{x i}$ transposed into the present context, this means that Samuelson's methodological individualism and Quine's ontological nominalism could have looked like compatible or even allied doctrines to many, from a distant and unspecialised perspective, simply because both theories were committed to the existence of, and attributed a primary explanatory role to, spatiotemporal individuals (things or persons called 'individuals'). Secondly, and less conjecturally, at RAND Quine himself worked within the social science paradigm of methodological individualism, especially when he discussed Kenneth Arrows's theorems on individual preferences (Salles 2017).

\subsection{Grammar, Anthropology, and the Autonomy of Humanistic Understanding}

From the point of view adopted in the present book, there are some morals to draw from the story told so far. The issue of the "two cultures," as C.P. Snow described it in his influential Rede Lecture delivered in 1959, was widely discussed both in Britain and in the United States (Snow 1959/2001; see also Leavis 1962/2013 and Collini 2013). But in the older faculties, in which the science-oriented transformation of the humanities was more difficult to understand and accept, the age of new rigourism was interpreted in terms of a crisis. Crisis in the Humanities is the title of a representative and then successful book edited by the Cambridge historian John H. Plumb and published in 1964. The book focused on the crisis of the classics, history, divinity studies, literary education, fine arts, sociology and economics in the new historical and cultural context; the chapter devoted to philosophy 
was assigned to Gellner (Plumb 1964; Gellner 1964). In a period of economic expansion, the use of the term 'crisis' did not mean that the "old" humanists were expelled from the universities; quite the opposite was true, in fact (however, notice that that kind of process, that kind of crisis in the humanities, would start later, during the economic recession in the mid-1970s, and will be briefly dealt with in chapter 7 below). In the 1950s and 1960s the crisis of the humanities concerned at the same time the identity of the human sciences, their institutional place and their overall social consideration. In the introduction to the volume, Plumb described the process quite well from his viewpoint (a British viewpoint, as is worth noticing): ${ }^{\mathrm{i}}$

A hundred, fifty, even twenty years ago, a tradition of culture, based on the Classics, on Scripture, on History and Literature, bound the governing classes together and projected the image of a gentleman. It was a curious mixture of humanistic principles and national pride.

... These subjects - History, Classics, Literature, and Divinity - were, with Mathematics, the core of the educational system and were believed to have peculiar virtues in producing politicians, civil servants, Imperial administrators and legislators.

... Alas, the rising tide of industrial societies, combined with the battering of two World Wars, has shattered the confidence of humanists in their capacity to lead or to instruct. Uncertain of their social function their practitioners have taken refuge in two desperate courses - both suicidal. Either they blindly cling to their traditional attitudes and pretend their function is what it was and that all will be well so long as change is repelled, or they retreat into their own private professional world and deny any social function to their subject. And so the humanities are at the cross-roads, at a crisis in their existence: they must either change the image that they present, adapt themselves to the needs of a society dominated by science and technology, or retreat into social triviality. (Plumb 1964: 7-8)

The former solution, that of riding the tide and adapting the humanities and their self-image to the changing world and culture, was chosen, for example, by Samuelson in economics and Quine in philosophy. The latter solution was adopted in Oxford, in the milieu in which not only Ryle but most linguistic philosophers did not feel the need to provide any justification for their philosophical work and interests. That was a classist and classicist world, which Gellner described in Veblenesque terms (i.e., in terms of conspicuous triviality) because of its upper-class character and its connection with 
the view of philosophy as an ostentatiously pure, humanistic and "useless" activity, a perfect case of “art pour l'art" (Gellner 1959/1979: 37). At that time undergraduates who studied philosophy in Oxford could follow either the older and highly respected "Greats" course (Honour School of Literae Humaniores), which included a lot of Greek and Latin classics, or "Modern Greats" (Honour School of Philosophy, Politics and Economics), introduced in about 1920 for students lacking a background in classical languages (Forguson 2001: 328). As H.H. Price clearly explained in a note on 'The Study of Philosophy at Oxford,' published in 1953 in the context of an international Unesco enquiry on The Teaching of Philosophy: "For many years the school of Literae Humaniores enjoyed great prestige in this country, and indeed in other English-speaking countries, and it retains very considerable prestige to this day" (Price 1953: 129). Of course, this is not to suggest that, say, the Harvard and MIT scienceoriented philosophical world was not classist; it is very likely that it was so, though in a different way. However, as should be clear enough at this point, the above-described American intellectual and academic world was also, or was becoming much more quickly, less classicist.

Last, but not least, Wittgenstein was a strenuous advocate of the autonomy of humanistic understanding, and the later Wittgensteinian tradition fully and stubbornly belonged to humanism in the old, non-rigourist and non-scientific-oriented sense of the term (Hacker 2001, von Wright 1979/1993; see also Williams 2000 and Read 2012). Some aspects of this issue have been already discussed in chapter 3 above, in the context of the outlined comparison between Wittgenstein's and Carnap's Weltanschauungen. However, a few more specific comments may be useful here. First of all, arguably Wittgenstein would not have objected to the application to the realm of mathematics of E.H. Moore's principle of generalisation by abstraction quoted approvingly by Samuelson ("The existence of analogies between central features of various theories implies the existence of a more fundamental general theory embracing the special theories as particular instances and unifying them as to those central features") (see for example Wittgenstein 1953: $\S$ 71). However, he straightforwardly rejected its application to philosophy and to Geisteswissenschaften such as psychology (including psychoanalysis) and anthropology (e.g., Wittgenstein 1966, 1967/1979 and 1980b). According to Wittgenstein, in these areas the perspicuous description of the family resemblances among concepts, rather than the generalisation by abstraction, is a much more appropriate approach.

Secondly, Wittgenstein did not accept the conception of man, shared by economists such as Arrow and Samuelson, according to which people are simply preference calculators. Wittgenstein did not focus directly on economics but, as is well known, soon after he returned to Cambridge in 1929 the Cambridge "Circus" - the circle of economists strictly associated with John Maynard Keynes at the

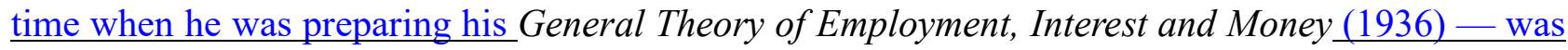
formed. There were several personal and intellectual connections between Wittgenstein and these 
Keynesians (Richard Kahn, James Meade, Joan Robinson, Austin Robinson, and Piero Sraffa among them). Notice, preliminarily, that Keynes himself, as essentially a Bloomsbury man and a member of the intellectual aristocracy, fully belonged to the humanist tradition (Andrews 2010; see also Chabtree and Thirlwall 1980). In the words of Robert Skidelsky: "His was the last generation which claimed to direct human affairs in the name of culture rather than expertise. He addressed the world as a priest, not as a technician" (Skidelsky 2003: 456). He seemed to be opposed to specialisation in economics on principled grounds; for example, in his Essays in Biography, drawing a portrait of his teacher Marshall, he famously wrote:

The master-economist must possess a rare combination of gifts... He must be mathematician, historian, statesman, philosopher - in some degree. He must understand symbols and speak in words. He must contemplate the particular, in terms of the general, and touch abstract and concrete in the same flight of thought. He must study the present in the light of the past for the purposes of the future. No part of man's nature or his institutions must be entirely outside his regard. He must be purposeful and disinterested in a simultaneous mood, as aloof and incorruptible as an artist, yet sometimes as near to earth as a politician. (Keynes 1933: 170)

More generally, and also more importantly, Keynes took economics to be a non-naturalised social science (Marchionatti and Cedrini 2016). As for the role of mathematics in economics, once again it is worth quoting a passage from Skidelsky's biography: "Keynes believed that mathematics was useful as a check to one's thoughts; he did not think his thoughts mathematically. He allowed his mathematics to rust away because, unlike Edgeworth, he was not interested in 'mathematicising' the social sciences" (Skidelsky 2003: 456). More generally, in line with Wittgenstein-inspired philosophers of the social sciences such as Winch, Keynes used to take the Aristotelian attitude "to look for precision in each class of things just so far as the nature of the subject admits" (Aristotle 1999, I. 3, 1094b; see also Winch 1958). Moreover, as insightfully noticed by John Coates, in an early draft of the General Theory written in the 1930s Keynes criticised the use of formal methods in economics in quasi-Wittgensteinian terms (Coates 1996: 83): "Much economic theorising today suffers, I think, because it attempts to apply highly precise and mathematical methods to material which is itself much too vague to support such treatment" (Keynes 1978, vol. XIV: 379). ${ }^{\text {xi Among }}$ other things (the most important of which was perhaps the presence of irrational aspects in human behaviour), the vague nature of economic reality provided Keynes with the grounds to reject the Homo oeconomicus model as a reasonable explanatory factor in macroeconomics. 
As is well-known, in that period a central figure in this Cambridge plot was that of Piero Sraffa, whom Wittgenstein credited for providing him with the main stimulus for the most original and consequential ideas expressed in the Investigations (Wittgenstein 1953: viii). Sraffa had been influenced by Antonio Gramsci's critique of modern culture. For example, in one of his letters from prison, dated 1929, Gramsci had written: "There was an abstraction determined by metaphysical intoxication, and there exists an abstraction determined by mathematical intoxication" (Gramsci 1947/1994: 242; see also Sen 2003). On the basis of the adoption of Ricardian, Marxian and Gramscian tools, Sraffa strongly criticised the marginalist tradition in economics: its subjectivism, its abstract character, its overgeneralisation (what Wittgenstein would have called its dogmatism), its unrealistic Homo oeconomicus model, which forgets the concrete, socio-anthropological aspects of human life, those depending on passions, needs and, above all, class struggle (Sraffa 1926): ${ }^{\mathrm{x}}$ it is worth noticing, in particular, that Wittgenstein told Rush Rhees in conversation that the most important thing he gained from his discussions with Sraffa was an 'anthropological' standpoint in philosophy or, more precisely, an 'anthropological' way of looking at things (Monk 1990: 261; see also Gebauer 2017); as many interpreters have observed, Wittgenstein's move, in the 1930s, from "dogmatic" theories (the logically crystalline and atomistic theory of the Tractatus, as well as the "phenomenological" theory presented in the late 1920s) to an anti-reductionist and antifoundationalist philosophical anthropology had structural analogies with Sraffa's rejection of marginalist economics. ${ }^{x i}$

"Philosophical anthropology" is a keyword in the present context. As is well-know, James Frazer's anthropology was one of the main and most interesting "case-studies," which Wittgenstein himself took into account to criticise the application to the humanities of a model of analysis based on meansend rationality (Bouveresse 2007: 360). ${ }^{x i}$ As Wittgenstein once told Drury, the most misleading aspect of Frazer's The Golden Bough was the conviction "that primitive rituals were in the nature of scientific errors," rather than "expressions of deeply felt emotions, or religious awe" (Drury 1984: 119). But this misunderstanding was not a consequence of a bad or false explanation of such rituals and ceremonies; the source of the mistake was the very attempt to provide an explanation (Bouveresse 2007: 361; see Frazer 1890 and Wittgenstein 1967/1979). Frazer's understanding was prevented by his constantly asking the scientific 'why'; in this respect he was, as Wittgenstein wrote in a remark from 1941, "like tourists, who stand in front of a building reading Baedeker, \& through reading about the history of the building's construction etc etc are prevented from seeing it" (Wittgenstein 1980a: 40).

'Philosophical anthropology' is a well-suited term to indicate the kind of grammatical investigations that the Wittgensteinians kept on presenting, in the spirit of Wittgenstein, in the years during which, seen in retrospect, they could (or perhaps should) have considered Quine's attack on 
analyticity with due gravity, thus preparing a defensive and responsive overall strategy. These investigations were descriptions of the "grammar" of philosophically relevant concepts, taken from ordinary language, the humanities and the social sciences, especially in the broad area they sometimes called 'philosophical psychology', even though a more appropriate label would have been that once suggested by Peter Hacker, i.e., indeed, 'philosophical anthropology,' interpreted in terms of the study of linguistic and non-linguistic human behaviour and practices, with a peculiar focus on the conceptual web of actions, norms and reasons (Hacker 2001). ${ }^{\mathrm{xi}}$ Besides books such as Anscombe's Intention (Basil Blackwell, 1957) and Herbert Hart's The Concept of Law (Oxford University Press, 1961), most of these works were published by Routledge and Kegan Paul, London, in the series Studies in Philosophical Psychology edited by Roy Frazer Holland: among them, the abovementioned Mental Acts by Geach (1957) and The Idea of a Social Science and its Relation to Philosophy by Peter Winch (1958), but also The Psychology of Perception by David H. Hamlyn (1957), The Concept of Motivation by Richard Stanley Peters (1958), The Unconscious: A Conceptual Study by Alasdair MacIntyre (1958), Dreaming by Malcolm (1959), The Varieties of Goodness by von Wright (1963), Free Action by Abraham Melden (1961), and Action, Emotion, and Will by Anthony Kenny (1963). ${ }^{\mathrm{xi}}$ All of them were descriptions of the logical or conceptual behaviour of a notion and its inferential web, presented with the aim of dissolving or demystifying philosophical problems in the area of philosophical anthropology. In the view of the Wittgensteinians, these problems often originated from bad intellectual habits such as the misunderstanding of language and its surface grammar (with the resulting category mistakes), the tendency to overgeneralise from few, scattered data, and above all the confusion between aims, methods and categories characteristic of the natural sciences and those which are appropriate to philosophy and the humanities. These grammatical investigations often provided the criteria for the investigated phenomena, and often did so by illustrating the paradigm-case method criticised by Watkins and Gellner, i.e., by providing examples that a semantically competent speaker is compelled to accept as correct applications of a given concept; otherwise he does not fully understand that concept.

Arguably, a single place where the tension between the later Wittgensteinian tradition and the new rigourism in the human and social sciences is condensed is Winch's book The Idea of a Social Science. Winch was aware that a later Wittgensteinian defence of the science-philosophy divide, together with the attempt to clarify the grammar of concepts belonging to the human and social sciences ran the risk of being "ranked with those reactionary anti-scientific movements, aiming to put the clock back, which have appeared and flourished in certain quarters since science began" (Winch 1958: 1-2). Equally, however, he did not retreat because of that risk:

Philosophy must be on its guard against the extra-scientific pretensions of 
science. Since science is one of the chief shibboleths of the present age this is bound to make the philosopher unpopular; he is likely to meet a similar reaction to that met by someone who criticizes the monarchy. But the day when philosophy becomes a popular subject is the day for the philosopher to consider where he took the wrong turning. (Winch 1958: 2)

He was also aware that linguistic philosophy was "a reaction against the 'master-scientist' view of the philosopher, according to which philosophy is in direct competition with science and aims to construct or refute scientific theories by purely a priori reasoning" (Winch 1958: 7). And he himself claimed: "Philosophical issues do, to a large extent, turn on the correct use of certain linguistic expressions; the elucidation of a concept is, to a large extent, the clearing up of linguistic confusions." Nevertheless, at the same time he pointed out:

The philosopher's concern is not with correct usage as such and not all linguistic confusions are equally relevant to philosophy. They are relevant only in so far as the discussion of them is designed to throw light on the question of how far reality is intelligible and what difference the fact that he could have a grasp of reality would make to the life of man. (Winch 1958: 11)

In this way, he connected the destructive element of Wittgenstein's later philosophy, namely, the linguistic analysis of philosophically misleading theories, with its constructive element, namely, its providing tools and a philosophical perspective to gain a humanistic understanding of man, culture and social life or, as Hacker once put it, "the guidelines for a kind of philosophical anthropology and hence the foundations of a philosophical understanding of humanistic studies" (Hacker 2001: 39). For example, Winch wrote as follows:

The central problem of sociology, that of giving an account of the nature of social phenomena in general, itself belongs to philosophy. In fact, not to put too fine a point on it, this part of sociology is really misbegotten epistemology. I say 'misbegotten' because its problems have been largely misconstrued, and therefore mishandled, as a species of scientific problem" (Winch 1958: 43).

In so doing Winch explicitly linked the later Wittgensteinian account of reasons (and motives) and rules (and habits) to the debate which originated with Dilthey in 1883, concerning the differences 
between Geisteswissenschaften and Naturwissenschaften, with the more recent philosophy of history of Robin George Collingwood (Winch 1958: 90; see also Dilthey 1883) ${ }^{\mathrm{xi}}$, and also with Max Weber's analysis of meaningful behaviour (Winch 1958: 45). Echoing Samuelson, but the other way around, Winch clearly stated that the difference between the natural sciences and the social sciences are "differences in kind," rather than "differences in degree" (Winch 1958: 71). Moreover, he sometimes took economics and economic behaviour as relevant case-studies (e.g., Winch 1958: 48-9 and 89) and, what is most significant, he explicitly proposed an alliance between Wittgenstein and Michael Oakeshott in rejecting the "rationalistic' misconception of the nature of human intelligence and rationality" according to which "the rationality of human behaviour comes to it from without: from intellectual functions which operate according to laws of their own and are, in principle, quite independent of the particular forms of activity to which they may nevertheless be applied" (1958: 54). He compared this misconception to a "mechanical model" (Winch 1958: 76), which forgets passions, emotions, and in general most practical, non-intellectual aspects of life; for example, he asked:

Would it be intelligent to try to explain how Romeo's love for Juliet enters into his behaviour in the same terms as we might want to apply to the rat whose sexual excitement makes him run across an electrically charged grid to reach his mate? Does not Shakespeare do this much better? (Winch 1958: 77)

Winch's work was relatively widely read outside philosophy (Shook 2005: 2626). ${ }^{\text {xi }}$ However, in the context we are focusing on in this book, namely, that of the rise of analytic philosophy in the United States, it did not enjoy a high reputation. Consider, as a perhaps flimsy but significant indication of this, the episode that occurred to Winch at the Creighton Club Meeting in New York in 1961. Winch gave a talk on the possibility of understanding systems of thinking very alien to our own. As Winch himself once recalled, the paper "was received at the conference almost universally with either derision or anger. Norman [Malcolm] was about the only person there who seemed to me to understand what I was saying — but that was perhaps because he [Malcolm] was the only one who offered me any support" (Winch 1992: 223). It is not surprising that Malcolm was also one of the very few who some years later, in the 1980s, would undertake the transatlantic travel the other way around, in order to spend his last years in London. 


\section{Notes}

xi It is of course a matter of interpretation if Wittgenstein really takes Moore's truisms as playing in our life a role similar to that of grammatical rules. Here I am following a reading similar to that provided by Annalisa Coliva, according to which in On Certainty Wittgenstein criticises Moore for considering such truisms as empirical sentences, whereas 
they are special in their being normative and, in fact, constitutive of our rationality (Coliva 2010).

xi The very existence of the recent debate on this issue, starting from Stanley and Williamson (2001), can be a sign (though of course not proof) that the issue was still not resolved in the 1950s.

xi Malcolm (1940), Lewy (1940), Toulmin (1949), Lazerowitz (1949), von Wright (1949/1957), Waismann (1949, 1950, 1951, 1952, 1953), Pears (1950, 1952, 1953), Black (1958a), and Stenius (1965).

xi Under this respect their understanding of Wittgenstein's views, as well as their philosophical self-understanding, seems not to agree with the interpretation provided by Scott Soames, according to which "it is hard not to see the double identification of the philosophical with (a subset of) the necessary and the apriori, and of these with the analytic, as central to the problem [for Wittgenstein's philosophy]. Like so many other analytic philosophers in the twentieth century, Wittgenstein comes to grief over assumptions about these different modalities that he takes to be obvious" (Soames 2003: 30; see also 2003: 60).

xi Personal communication, 2005.

xi The case of von Wright is particularly interesting. As a young man, he received a Carnapian philosophical education from his teacher Eino Kaila in Helsinki. Later on, as is well-known, he became a pupil and a friend of Wittgenstein in Cambridge, and eventually one of his literary executors. As he himself emphasised in his 1989 Intellectual Autobiography, his philosophy is a peculiar mix of Carnapian methods and Wittgensteinian insights: in a nutshell, he often constructed formal systems in the style of Carnap in order to express Wittgenstein-inspired philosophical "remarks;" think, for example, of von Wright's numerous contributions to what he called "philosophical logic," from alethic modal logic to deontic logic and the logic of preferences (von Wright 1989: 45; see also Tripodi 2002).

xi This might not be a marginal point, if one thinks for example of concepts employed in the humanities and the social sciences.

xi For a detailed comparison between Quine and ordinary language philosophy, see also Verhaegh (2018: chapter 7.2).

xi Here, as well as in chapter 2 above, the core-periphery model is used in a loose sense, adapting it for the purposes of the present investigation from the work of Immanuel Wallerstein (e.g., 1974, 1976). Actually, according to the criteria governing Wallerstein's effective world-system, the United Kingdom is a core country.

xi Most linguistic philosophers were, of course, perfectly aware of their being part of a social and intellectual élite. Here is for example Strawson recalling his lectures in Sarajevo: "I was only allowed to give one of my two scheduled lectures and had minimal contact with fellow academics; one perhaps time-serving young man in my audience suggested that my lecture revealed an essentially bourgeois outlook. I replied 'But I am bourgeois - an elitist liberal bourgeois'. My interpreter commented, sotto voce, 'They envy you"' (Strawson 1998: 14).

xi This is not to say that Gellner was right even when he suggested that linguistic philosophy (in particular, Wittgenstein's later philosophy) was politically conservative. This issue - highly controversial and difficult to resolve - goes beyond the purposes of the present book (see, e.g., Bloor 2000). However, some facts that have been insightfully noticed by Uschanov are worth mentioning here: (i) There is some evidence that Wittgenstein assigned philosophy the task of improving our "thinking about the important questions of everyday life," including political questions, broadly conceived (Malcolm 1958/2001: 93); (ii) there is biographical data which is not easily consistent with Wittgenstein's alleged conservatism (Crary and Read 2000: 142; see also Monk 1990); (iii) many Marxists and other political radicals such as Ferruccio Rossi-Landi, K.T. Fann, David Rubinstein and Gavin Kitching had a positive attitude towards Wittgenstein; it is likely that also Pierre Bourdieu should be added to the list provided by Uschanov; (iv) perhaps most importantly, among Oxford linguistic philosophers political opinions, as well as religious attitudes, were extremely diverse; for example, Hampshire was a political leftist, Strawson a centrist and Flew a rightist; Flew and Ryle were radical anti-clericalists, Anscombe, Geach and Dummett were practicing Christians (Uschanov 2000).

${ }^{x i}$ Rée provided the following list (Rée 1993, footnote 124): Elizabeth Anscombe, Sydenham High and St. Hugh's; J.L. Austin, Shrewsbury and Balliol; Isaiah Berlin, St Paul's and Corpus; Michael Dummett, Winchester and Christ Church; AG.N. Flew, Kingswood and St. John's; Phillipa Foot, privately and Somerville; Stuart Hampshire, Repton and Balliol; R.M. Hare, Rugby and Balliol; H.L.A Hart, Cheltenham College, Bradford Grammar School, New; Iris Murdoch, Badminton and Somerville; P.H. Nowell-Smith, Winchester and New; David Pears, Westminster and Balliol; Anthony Quinton, Stowe and Christchurch; Gilbert Ryle, Brighton College and Queen's; P.F. Strawson, Christ's College Finchley and St John's; Stephen Toulmin, Oundle and King's, Cambridge; J.O. Urmson, Kingswood and Corpus; G.J. Warnock, Winchester and New; Mary Warnock, St Swithun's Winchester and Lady Margaret Hall; Bernard Williams, Chigwell and Balliol.

xi On Ryle's style see also the conversation with Magee, where Ryle himself reveals that in The Concept of Mind one can find echoes of Oscar Wilde's and Saki's literary style (Magee 1971: 131).

xi In the just-mentioned volume see, in particular, the contributions by Robert Solow (on economics), David Easton (on political science) and Hilary Putnam (on philosophy).

xi Isaac characterised this web of similarities in terms of a common "mood" or "spirit," noticing also that a neologism was introduced to capture it quite well: "behavioural science" (Isaac 2012: 9). He also plausibly refers to a "web of family resemblances," rather than to a common pattern: this is just a way to specify that not all the listed features are shared by all the scientific projects or sub-disciplines.

xi In the examined context, perhaps the best-known example of the politically and morally neutral attitude of the social 
sciences is expressed by the so-called CUDO group of norms introduced by Robert K. Merton in 1942: "four sets of institutional imperatives taken to comprise the ethos of modern science... communism, universalism, disinterestedness, and organized scepticism" (Merton 1942).

xi The classical works related to the just mentioned projects are Bridgman (1928), Stevens (1939), Skinner (1957), Parsons (1951), and Merton (1942).

xi In the same context Putnam also underlined that it is a "stereotype" and a "subtle falsification" to claim that in the 1940s logical positivism was already dominant, since in fact Carnap, Reichenbach, Feigl and the others were extremely few, largely isolated and ignored (Putnam 1997: 178). This important remark, however, is compatible with the claim that is here defended, according to which Quine's critique of Carnap and its effects in the 1950s and 1960s had a constitutive role in the rise of analytic philosophy in America. Moreover, it is also worth noticing that some seminal elements of the above-outlined scientific and rigourist paradigm in the human sciences were explicitly recognised and, in fact, appreciated by the logical positivists themselves, when they arrived in the United States. For example, in his Intellectual Autobiography Carnap wrote: "I was very happy to remain permanently in America and, in 1944, I became a citizen of the United States. I was not only relieved to escape the stifling political and cultural atmosphere and the danger of war in Europe, but was also very gratified to see that in the United States there was a considerable interest, especially among the younger philosophers, in the scientific method of philosophy, based on modern logic, and that this interest was growing from year to year" (Carnap 1963a: 35).

xi For an overview of the three programs see, respectively, Janssen (2017), Speaks (2018), and Ichikawa and Steup (2018).

xi Bonino, Maffezioli and Tripodi also reported the results of a full-text search on JSTOR regarding the term 'Dewey': this term occurs in 305 articles published in The Journal of Philosophy from 1941 to 1960 (as is well-known, the journal was published, and still is, at Columbia University, where Dewey used to work). This is a significant result, if compared to the occurrences of 'Russell': 199, 'Whitehead': 155, 'Carnap': 95 and 'Wittgenstein': 66. On the other hand, 'Dewey' has only 140 occurrences from 1961 to 2010. In The Philosophical Review it has 89 occurrences in the period 1940-1960 and only 9 in the latter period (Bonino, Maffezioli, Tripodi, unpublished manuscript).

xi On the general issue, which at any rate goes beyond the purposes of this book, of the relationship between that political context and the rise of analytic philosophy, see for example Howard (2003) and Reisch (2005). It is worth emphasising, however, that the point here seems to concern analytic philosophy as an academic professional tradition and a philosophical style, rather than the political preferences of single individuals belonging to that tradition (for example, both Putnam and Davidson were notoriously left wing, Quine was politically conservative).

xi On the relationships between Quine, Tarski, and Carnap, see Frost-Arnold 2013.

xi As is well-known, this very Hendersonian notion of a conceptual scheme would later be famously criticised by Davidson as a third dogma of empiricism (Davidson 1974).

xi See for example Hands (2007), which focuses on the "uncanny similarities" between economics and philosophy of science (rather than analytic philosophy in general) in the United States in the 1950s and 1960s.

xi Samuelson is also the author of the most important single research document of the new synthesis, namely, Foundations of Economic Analysis (Samuelson 1947).

xi It is worth noticing here that the very term 'neoclassical' was introduced by Veblen in 1900 to refer to two or three main schools of economic theory, among them the marginalist tradition and the Austrian school (Veblen 1900: 261).

xi Taking a general and balanced historical perspective, it would perhaps be more appropriate to speak of Quine as the Samuelson of philosophy in America. However, in the context of a history of analytic philosophy book, it seems reasonable or at least excusable to adopt this somewhat misleading philosophy-centred viewpoint.

xi For more details on Samuelson's view of the role of mathematics in economics see also the interesting reflections presented in Samuelson (1952), as well as the late interview in which he considered the issue from a more concrete, practical point of view: "Although I've had an acquaintanceship with scores of leading world mathematicians and physicists, I've been surprised at how little help I've been able to garner from presenting orally some unsolved puzzles to them. I should not have been surprised. It is not that a Birkhoff, or Quine, or Ulam, or Levinson, or Kac, or Gleason was incapable of clearing up my open questions. Rather, it is the case that a busy mathematician has no motivation to waste his (or her) time getting intuitively briefed on someone else's models in the idiosyncratic field of mathematical economics" (Barnett 2004: 530). On the issue of mathematisation and on the passage from political economy to economic science see also Boulding (1948), Debreu (1991), Mirowski (2012), Weintrub (2002).

xi It is not surprising that Samuelson's Foundations are full of physics metaphors (Samuelson 1947: see, e.g., 3 and 8).

xi In the age of contemporary specialisation, maybe Kusch's remarks — originally referred to processes taking place in late nineteenth century and early twentieth century - require some caveats. However, they seem to be still applicable, with the due caution, to philosophy after the second world war. A further remark by Kusch is illuminating for the issue on which the present chapter focuses: "Like controversies in the natural sciences, philosophical controversies are often cases of boundary work. Controversies in philosophy are often triggered when parts or the whole of the philosophical community feel endangered by the success and appeal of one or several antidisciplines. In such cases, philosophers then start to search for hidden tendencies in each other's work, tendencies that allegedly provide an insufficient defence against usurpation" (Kusch 1995: 269-270). 
xi Snow, for example, famously criticised the British educational system for having over-rewarded the old, traditional humanities at the expense of scientific and technical education (Snow 1959/2001).

xi Coates compares Keynes's above-quoted remarks with a passage from Wittgenstein's Philosophical Remarks: “The moment we try to apply exact concepts of measurement to immediate experience, we come up against a peculiar vagueness in this experience. But that only means a vagueness relative to these concepts of measurement. And, now, it seems to me that this vagueness is not something provisional, to be eliminated later on by more precise knowledge, but that this is a characteristic logical peculiarity" (Wittgenstein 1964/1975: 263; see also Coates 1996).

xi Gunter Gebauer refers to the very interesting possibility that Wittgenstein and Sraffa discussed a short text by Karl Marx, 'Introduction to the Critique of Political Economy' (1857), in which Marx outlined his basic ideas about social production, consumption and circulation (Gebauer 2017: 145).

xi On the Sraffa-Wittgenstein connection see, for example, Roncaglia (1978), Arena (2015), Davis (2002), McLachlan and Swales (1998) on the economic side, and Marion (2005), McGuinness (2008), Venturinha (2013) on the philosophical side. Notice also, incidentally, that the Keynesians and the Wittgensteinians had the same "opponents" in Britain: the defenders of methodological individualism at the London School of Economics, namely, Hayek, Popper and Watkins. In the US things went on somewhat differently, for Milton Friedman and the Chicago School became very influential only later, in the 1970s. Notice also, even more incidentally, that (economic and philosophic) anthropology has always been, and still is, the bete noire of neoclassical economics, from Polanyi (1944) to Graeber (2011). For a general discussion see Marchionatti and Cedrini (2017).

xi The reference is, of course, to Frazer (1890) and Wittgenstein (1967/1979).

xi The similar term, 'grammatical anthropology,' has been suggested by Tomasini Bassols (2010: 56). See also Hacker 2010.

xi The complete list included also David M. Armstrong, Bodily Sensations (1962); P. Alexander, Sensationalism and Scientific Explanation (1963); Jonathan Bennett, Rationality (1964); Julius Kovessi, Moral Notions (1967); Herbert Fingarette, Self-Deception (1969); Terence Penelhum, Survival and Disembodied Existence (1970); Ilham Dilman and D.Z. Phillips, Sense and Delusion (1971); Maurice Drury, The Danger of Words(1973), Jenny Teichman, The Mind and the Soul (1974); K.V. Wilkes, Physicalism (1978); R. Bambrough, Moral Scepticism and Moral Knowledge (1979); R.W. Newell, Objectivity, Empiricism and Truth (1986). As as been noticed by Constantine Sandis, the main exception was of course that of Armstrong, "whose sympathies were far removed from those of the others" (Sandis 2015: 372).

xi Winch wrote, for example: "[A] historian or sociologist of religion must have some religious feeling if he is to make sense of the religious movement he is studying" (Winch 1958: 88).

${ }^{x i}$ According to Scopus, the 30\% of the about 80 documents in 'Peter Winch' occurs in the period 1961-2015 belong to the area 'Social sciences' (www.scopus.com). 


\section{Science, Philosophy, and the Mind}

The development of philosophy in the United States during the 1950s and 1960s was characterised, among other things, by a relatively growing interest in Wittgenstein's thought. First, more balanced and well-informed comparisons between Wittgenstein and Carnap were offered. Second, a greater awareness was achieved as to the peculiarities of Wittgenstein's later philosophical views. The former tendency was epitomised by Wilfrid Sellars (1912-1989), who studied and then lectured in Europe, including Britain, was well-acquainted with Carnap and started to use competently both the early and the later Wittgenstein for his philosophical purposes. The latter tendency was well represented by Stanley Cavell (1926-2018), who studied at Berkeley and Harvard, was heavily influenced by Austin, Wittgenstein, and Oxford linguistic philosophy, and then taught temporarily at Berkeley and for the rest of his life at Harvard.

\subsection{Wittgenstein in the United States: Sellars and Cavell}

Consider Sellars first. There were many points of philosophical agreement between Sellars and the later Wittgenstein. Anti-foundationalism in epistemology: both Wittgenstein and Sellars thought that there is no ultimate and self-justified belief, on which our knowledge is grounded. Anti-Cartesianism in the philosophy of mind: both of them argued that we do not have direct, privileged and absolutely certain knowledge of our own beliefs and sensations (Sellars 1956). Moreover, a form of normative anti-reductionism: they shared the view according to which logical, epistemological and moral normativity cannot be reduced into naturalistic terms. And also a non-continuist metaphilosophy: according to both of them, philosophy and science ultimately have different aims and operate on different levels (Sellars 1962). But let us now briefly consider, as a particularly interesting case-study, Sellars's discussion of (and comparison between) Carnap's and Wittgenstein's conceptions of semantics. $^{\text {xi }}$

When, in the late 1940s and early 1950s - more precisely, from 1947 and 1948, when 'Epistemology and the New Way of Words' and 'Realism and the New Way of Words' were published respectively, to 1953, the year of 'Inference and Meaning' — he presented a rudimentary version of his inferential or functional-role semantics, Sellars's aim was to discuss and amend Carnap's and Tarski's semantic views, especially in the form presented by Carnap in 1942 in his influential and much discussed Introduction to Semantics (Carnap 1942; Sellars 1947, 1948, 1953a; but see also Sellars 1962, and 1968). Sellars focused on semantic statements such as "“Rouge' in French means red," as they were typically formulated in a Carnap-style semantics. According to Sellars, that formulation was misleading, for it conveyed the idea that the meaning of 'rouge' is an abstract entity (a quality, a property). As is well-known, Sellars corrected Carnap's account by using his dot quoting 
device, that is, by translating the above-mentioned semantic statement as " "Rouge' in French means 'red." which in turn is equivalent to "Rouge' in French plays the same role that 'red' plays in English" (or, as he would put it later, "in the linguistic economy of English-speaking peoples") (Sellars 1956, § 31). In this way, the platonic reading of semantic statements was explained away, and semantics turned out to be an entirely intra-linguistic, inferential affair. ${ }^{\mathrm{xi}}$

Around 1953 and especially in 1954, when the article 'Some Reflections on Language Games' was published, Sellars started to present his inferential semantics by using the later Wittgenstein's vocabulary, i.e., by employing concepts such as game, language game, system of rules, grammar, use, rule-governed activity and so forth (Sellars 1954a; see also Bonino and Tripodi 2018a: 221). Moreover in 1956, in 'Empiricism and the Philosophy of Mind,' Sellars made it clear that there is a tight, clear connection between the myth of the given (its main polemical target), and the platonic conception of meaning he associated to Carnap-style semantics. To borrow, for the sake of brevity, de Vries's and Triplett's concise formulation, the myth of the given was the idea according to which any possible knowledge is ultimately based on non-inferential, immediate knowledge of basic, selfjustified and epistemically independent elements (de Vries and Triplett 2000: 186). Sellars pointed out that the myth of the given is avoided if one accepts what he called "psychological nominalism," the view according to which "all awareness of sorts, resemblances, facts, etc., in short, all awareness of abstract entities — indeed, all awareness even of particulars — is a linguistic affair" (Sellars 1956: $\S 29)$. Conversely, a special form of the myth of the given is the rejection of psychological nominalism, that is, in other words, the conviction that at least some awareness of abstract entities, or of particulars, is prelinguistic. In particular, Sellars connected the foundationalist myth with a thesis concerning language acquisition, namely, with the view according to which "there is awareness of logical space prior to, or independent of, the acquisition of a language" (Sellars 1956: $\S 31$ ). At this point Sellars explicitly referred to Wittgenstein. Not only did he evoke the "carrier of slabs" of $\S$ 2 of the Investigations, but he also stressed that the above-mentioned mistaken view of language which he now understood as a relational conception of means, according to which meaning is a relation of association between a word and a nonverbal entity - was nothing but the so-called Augustinian picture of language criticised by Wittgenstein at the beginning of the Investigations: every word has a meaning, which is the object for which it stands, so that the essential function of words is naming (Wittgenstein 1953: §1). In a similar vein, he described the Augustinian view of language acquisition in the following terms: "The process of teaching a child to use a language is that of teaching it to discriminate elements within a logical space of particulars, universals, facts, etc., of which it is already undiscriminatingly aware, and to associate these discriminated elements with verbal symbols" (Sellars 1956, § 30). Sellars argued that the Augustinian conceptions of meaning and language acquisition entail the myth of the given: a particularly dangerous form of the myth, since 
even nominalists, who believe that there are only particulars, can fall prey to it. As Sellars noticed, what H.H. Price called 'thinking in presence,' as opposed to 'thinking in absence,' is a form of the Augustinian model, in which the named object, the Augustinian meaning of the word, is so to speak there, before the language user (Sellars 1956: $§ 30$; Price 1953). After 'Empiricism and the Philosophy of Mind,' Sellars often associated his functional role semantics to Wittgenstein's later view of meaning as use. He did so, for example, in the following well-known passage, which frequently recurs in his works:

According to this analysis, meaning is not a relation for the very simple reason that 'means' is a specialized form of the copula. Again, the meaning of an expression is its 'use' (in the sense of function), in that to say what an expression means is to classify it by means of an illustrating functional sortal. (Sellars 1969/1974, 116; 1974, 431; 1980, 78; see also 1970, 158, 1962/1963, 203)

Let us now come to Cavell. In an article published in The Journal of Philosophy in 1962 with the title 'The Availability of Wittgenstein's Later Philosophy,' Cavell complained that Anglo-American philosophers had since then achieved a very poor understanding of Wittgenstein's later philosophy (Cavell 1958/1976, 1962/1976). To show this, he focused on the first monograph devoted to it, David Pole's The Later Philosophy of Wittgenstein (Pole 1958), commenting:

What I find most remarkable about this book is not the modesty of its understanding nor the pretentiousness and condescension of its criticism, but the pervasive absence of any worry that some remark of Wittgenstein's may not be utterly obvious in its meaning and implications. (Cavell 1962/1976: 45)

Cavell's main interpretive claims were the following. First, Wittgenstein's philosophical inquiry had some structural similarities with Kant's transcendental work (Cavell 1958/1976, 1962/1976). Second, a correct understanding of Wittgenstein's later investigations depended on the analysis of Wittgenstein's reliance on ordinary language uses in philosophy, on the basis of the claim that "What we do is to bring words back from their metaphysical to their everyday use" (Wittgenstein 1953: $\S$ 116). Some years before, in his seminal paper 'Must We Mean What We Say?,' published in Inquiry in 1958, Cavell had already dealt with this issue (Cavell 1958/1976). These two articles and, more generally, the collection of essays in which they were included, published in 1969 with the same title, 
Must We Mean What We Say?, represented an important step in the story reconstructed in the present book (Cavell 1969). As Sandra Laugier has recently observed, Cavell was perfectly aware that

He was upsetting a well-established American philosophical tradition, which had emerged out of the arrival of Vienna Circle philosophers, epistemologists and logicians fleeing Nazism onto the American philosophical scene. In Must We Mean What We Say? analytic philosophy was called into question for the first time in America, where it had become dominant over the course of the twentieth century, and the book proceeds from one of analytic philosophy's unassimilable, even repressed, elements: ordinary language philosophy, as represented by Austin and Wittgenstein. (Laugier 2011: 629)

Against Benson Mates, who had regarded the claims based on ordinary language usage as having an empirical nature (Mates 1958), Cavell pointed out that those claims are normative: they are not descriptions of what people do say, but they are grammatical remarks about what people may say, or ought to say, within the bounds of sense (not surprisingly, a quasi-Kantian notion) (Cavell 1958/1976). In Cavell's view the philosopher, as a competent speaker, is at least as qualified as any other member of the linguistic community to make claims about what is ordinarily said and meant. As we will see in what follows, Cavell's articles well represent the process during which a more adequate picture of Wittgenstein's later philosophy was eventually presented to the eyes of the analytic philosophers in the United States.

Yet another philosophical topos, which is worth mentioning for the present purposes, is the way in which analytic philosophers reacted to Cavell's early work on Wittgenstein: they formulated an uncompromising criticism of it. In their article 'The Availability of What We Say,' published in The Philosophical Review in 1963, Jerry Fodor and Jerrold J. Katz were rather explicit:

The position Cavell advocates in M ['Must We Mean What We Say?'] and A ['The Availability of Wittgenstein's Later Philosophy'] seems to us ... to be mistaken in every significant respect and to be pernicious both for an adequate understanding of ordinary language philosophy and for an adequate understanding of ordinary language. (Fodor and Katz 1963: 58)

It is perhaps no coincidence that the two authors were both philosophers at the Massachusetts Institute of Technology and, above all, that the former was also a psychologist, and the latter was also a professional linguist. 


\subsection{The Fifties and the Sixties: Some Data and Trends}

Resuming the train of thought interrupted in chapter 3, the early interpretation of Wittgenstein's philosophy as a dead ringer for Carnap's had had negative effects on its reception in the United States, because, among other reasons, meanwhile a conviction had been spreading that some of Carnap's philosophical milestones - analyticity, above all — had been demolished by Quine. Later on, well into the 1950s, thanks to well-informed philosophers such as Sellars the differences and even the contrasts between Wittgenstein and Carnap were highlighted. More generally, a more accurate, Carnap-independent and Oxford-influenced picture of Wittgenstein's later philosophy was at last brought into the American philosophical context by a number of authors such as for example Cavell. All this is apparent in the articles published in The Journal of Philosophy and The Philosophical Review from 1951 to 1960. There are 91 articles in which the name 'Wittgenstein' is mentioned in the full text: $9.2 \%$ of the entire corpus (990 articles). ${ }^{x i}$ Roughly $30 \%$ of these articles were entirely devoted to Wittgenstein or, at least, Wittgenstein played a central role in them, often a methodological one. The large majority of these 30 or so "Wittgensteinian" articles focused on some aspects of Wittgenstein's later philosophy. The leading position was occupied by the Wittgensteinians who worked in the department of philosophy of Cornell University: the corpus contains 5 articles by Malcolm and 3 articles by Black. Generally speaking, looking at the list one gets the impression that in the 1950s the pupils, followers and admirers of Wittgenstein (broadly conceived) had the first real opportunity to present Wittgenstein's later thought to the American philosophical academia: not only Malcolm and Black, but also philosophers such as Ambrose, Geach, Dummett, MacDonald, Toulmin and von Wright. ${ }^{\mathrm{xi}}$ It is also worth noting that, besides Malcolm, there were by then several American philosophers who proved to be well-acquainted with Wittgenstein's later philosophy: Sellars, of course, as has been shown above, but also Abraham Melden, Hilary Putnam, Leonard Linsky, Morton White, Rogers Albritton and Keith Lehrer. ${ }^{\mathrm{xi}}$

In the following decade, 1961-1970, the trend kept persisting to a certain extent, though there were also some differences with respect to the earlier period. Considering again The Journal of Philosophy and The Philosophical Review, 'Wittgenstein' was mentioned even more frequently: there were 134 articles in which it occurred at least once, $14.3 \%$ of the entire corpus. A little under $30 \%$ of these articles were really devoted to Wittgenstein: most of the articles just mentioned Wittgenstein passingly, while focusing on an entirely different topic, and there seemed to be no prevalence of the later, as opposed to the early, Wittgenstein. Other features of the 1950s corpus remained unchanged in the 1960s. The presence among the authors of linguistic philosophers belonging to the Oxford linguistic philosophy and/or to the later Wittgensteinian tradition, broadly conceived: Black, O.K. Bouswma, J.N. Findlay, Malcolm, Rush Rhees, Dummett, Geach, Stenius, Strawson, Urmson, von 
Wright, Waismann and McGuinness. ${ }^{x i}$ The emergence of further American philosophers, or philosophers permanently working in the United States, who were endowed with an adequate expertise in Wittgensteinian issues: besides the recently mentioned Bouwsma, Malcolm, Sellars, Putnam, and Cavell — and besides critics such as Fodor, Katz, Feigl and Maxwell — the list also included Richard Rorty, Arthur Danto, Sydney Morgenbesser, Newton Garver, Donald Davidson, Jaakko Hintikka and Barry Stroud. ${ }^{x i}$ The name of Burton Dreben was not included in the list but it should ideally be added, since in the same years his teaching at Harvard provided an original, influential and accurate picture of Wittgenstein's philosophy, in which peculiar emphasis was placed on the crucial metaphilosophical claim that there are no philosophical theories (Floyd and Shieh 2001; see especially John Rawls's 'Afterword' on pages 419-422).

Considering the whole corpus from 1951 to 1970, it becomes apparent that the seeds of several different stories were planted in that period. Perhaps the most important single episode relating to the history of Wittgenstein studies is the discussion that originated with Dummett's 1959 article on 'Wittgenstein's Philosophy of Mathematics,' according to which Wittgenstein was a full-blooded conventionalist, and above all with Stroud's influential reply, 'Wittgenstein and Logical Necessity,' published in 1965, in which Wittgenstein's aim was described as that of showing, by inventing imaginary cases, that our grammar, including for example the rules we employ in mathematics, is ultimately based or grounded on extremely general and contingent facts of our natural history (where the terms 'based' and 'grounded' are to be interpreted in the genetic sense of 'being caused' rather than in the epistemological sense of 'being justified') (Dummett 1959; Stroud 1965). This exegetical debate is, in a certain sense, still going on nowadays, not least thanks to the recent widespread interest in the so-called "third" Wittgenstein, the author of On Certainty (Moyal-Sharrock 2004).

Another visible tendency — represented in the considered "Wittgensteinian" corpus by five articles written by Paul Feyerabend, Norwood Russell Hanson and Stephen Toulmin, respectively ${ }^{\mathrm{xi}}$ - concerned the rise of the so-called new philosophy of science. This, as is well-known, was an epochmaking phenomenon in the history of Anglo-American philosophy, in which the publication in 1962 of Thomas Kuhn's The Structure of Scientific Revolutions played a major role (Kuhn 1962). Kuhn was introduced to the works of Wittgenstein precisely by Cavell, who — before being recruited in Harvard - was in a certain period a colleague of his at Berkeley (Bird 2018). Several later Wittgensteinian ideas were at work in Kuhn's famous book: the concept of family resemblance; the conceptions of meaning and reference; the reflections on conceptual relativism; the remarks on the presence and roles in science of 'forms of representation' and 'norms of expression'; the notion of 'seeing as' (Kuhn 1962). ${ }^{\mathrm{xi}}$

Despite their unquestionable centrality, however, the exegetical discussion stemming from the Dummett-Stroud debate and even the emergence of Kuhn's Wittgenstein-inspired philosophy of 
science were somewhat out (or perhaps, more precisely, they were at the margin) of the main line of discourse of the present book, namely, the emergence of "core" analytic philosophy and its effects on the later Wittgensteinian tradition, especially in the United States. ${ }^{x i}$ Focusing on this main line, from the analysis of the articles published in The Journal of Philosophy and The Philosophical Review from 1951 to 1970, three major topics emerge (incidentally, they confirm the correctness and accuracy of the critical evaluation provided by Cavell in the two articles mentioned above). One topic is the tenability (or, depending on the viewpoint, the untenability) of the distinction drawn by Wittgenstein between criteria and symptoms, and more generally the debate over Wittgenstein's views of the relationship between ordinary language and scientific language ${ }^{x i}$ Another topic is Wittgenstein's philosophy of action, with particular focus on his conception of reasons as opposed to causes. ${ }^{\text {xi }}$ Yet another had to do with Wittgenstein's philosophy of mind, but it will be discussed below, at the end of the present chapter. ${ }^{\mathrm{xi}}$

Let us now focus on the distinctions between criteria and symptoms, and between reasons and causes. They were two of the ways by means of which the later Wittgenstein used to draw the sciencephilosophy divide. The other two ways - the grammatical-factual distinction and the distinction between meaning-constitutive linguistic uses and non-constitutive or application uses — had already been discussed earlier: the former had been weakened, to put it mildly, by its confusion with Carnap's analytic-synthetic distinction, which had in turn been Quine's main polemical target; the latter had been criticised by Watkins and Gellner in the context of the polemic against paradigm-case arguments (see chapter 2 above). In the new context was now that of the new rigourism in the humanities described in chapter 4 - a process in which the rise of analytic philosophy was just an instance — it is not surprising to ascertain that analytic philosophers reacted with hostility towards the advent of the later Wittgensteinian tradition in the United States, with its doubts concerning the appropriateness of applying natural science methods and perspectives to the psychological, social and normative world, and its humanistic and even hermeneutical conception of the rationality of human beings. Since the use of explicit arguments was, as still is, a constitutive totem of analytic philosophy, hostility assumed the form of explicit anti-Wittgensteinian arguments: arguments aimed to defend a continuist metaphilosophy — a fortiori, a scientifically oriented philosophical style — by destroying the Wittgensteinian distinctions between criteria and symptoms, and between reasons and causes.

\subsection{Criteria and Symptoms}

The first episode had two main characters: Malcolm, the "voice" of Wittgenstein in America, and Putnam. In 1959 Malcolm published Dreaming, and three years later Putnam provided an influential critique of it (Malcolm 1959; Putnam 1962/1975). The origin of Malcolm's interest in this topic went back to his decision in 1938 to leave Harvard, where he was a graduate student, to reach Cambridge 
in Britain, where he intended to be supervised by G.E. Moore. ${ }^{x i}$ At that time, Moore was involved in the attempt to refute scepticism, challenging in particular the Cartesian dream argument, according to which one cannot prove with absolute certainty that one is awake (Moore 1939; Malcolm 1956). However, in Cambridge Malcolm met Wittgenstein and attended his 1939 lectures on the foundations of mathematics, thus becoming his devoted disciple and friend. At this point, his Moore-inspired focus on dreaming became intertwined with Wittgenstein's scattered reflections on this issue, such as for example the following:

People on waking tell us of certain incidents (that they have been in suchand-such places, etc.). Then we teach them the expression "I dreamt," which precedes the narrative. Afterwards I sometimes ask them "Did you dream anything last night?" and am answered yes or no, sometimes with an account of a dream, sometimes not...

Now must I make some assumption about whether people are deceived by their memories or not; whether they really had these images while they slept, or whether it merely seems so to them on waking. And what meaning has this question?-And what interest? Do we ever ask ourselves this when someone is telling us his dream? And if not—is it because we are sure his memory has not deceived him? (And suppose it were a man with a quite specially bad memory?-) (Wittgenstein 1953, Part 2: § VII).

More importantly, in Dreaming Malcolm ended with providing a Wittgenstein-inspired grammatical investigation of the concept of dreaming and the notions inferentially related to it. Malcolm started by providing two criteria, or sets of criteria, for sleeping. One was behavioural: the body is relaxed, the eyes are closed, the breath is regular, the sleeper tends not to respond when addressed and, in general, not to react to external stimuli (Malcolm 1959: 11). Another one was the sleeper's testimony after he awakened, a criterion which cannot be applied to animals and infants (Malcolm 1959: 22). According to Malcolm, these are the criteria of deep sleep, whereas hypnotic trance, violent nightmare and somnambulism are "natural extensions" of the meaning of the term 'sleep' (Malcolm 1959: 27-28). On the other hand, there is only one criterion for dreaming, namely, the sleepers' later reports of their dreams (Malcolm 1959: 49). Therefore, in Malcolm's account, there is a logical, necessary relation between our dreams and the impressions we tell of after we wake up (Malcolm 1959: 60). The description of the grammar of 'sleep' and 'dreaming' allowed Malcolm to challenge Cartesian scepticism. The criteria for sleep and dreaming - he noticed - clearly show that it is impossible to assert something during sleep; at most, one can dream of asserting something. 
Scepticism cannot be asserted without denying itself. It is senseless, rather than false, for it depends on a twofold misleading myth or illusion: first, the belief that dreams are inner and private mental states or processes; second, the supposition that people acquire the concept of dreaming by introspection, that is, by noticing these inner states or processes (Malcolm 1959: 54).

Malcolm's grammatical investigation on dreaming gave rise to two main claims. First, the temporal occurrence of dreams during sleep — when dreams occur during sleep — is not something empirical but is determined by the grammar of 'dreaming,' that is, by our rule-governed applications of terms such as 'dreaming' and 'sleep' in paradigmatic circumstances (Schroeder 1997). Second, the grammar of 'dreaming' does not determine any specific time interval during which dreaming occurs: the criterion of dreaming, i.e., the dreamer's report after awakening from sleep, tells us that dreaming occurs during sleep, but it does not allow us to establish its exact duration; in fact, the very notion of exact duration is not applicable in this context. Malcolm was led by these two claims to criticise not only Cartesian scepticism, but also contemporary scientific studies of dreaming, such as those presented in 1957 by the physiologists Nathaniel Kleitman and his student William Dement (Dement and Kleitman 1957; Malcolm 1959: 74). Dement and Kleitman's pioneering aim was that of correlating rapid eye movements occurring during sleep with dreaming or, more precisely, the REM phase during sleep with the length (i.e., the number of words) of the dreamer's report after sleeping, and the vertical and horizontal eye movements during sleep with the presence of vertical and horizontal "actions" and "movements" in the dreaming report. According to Malcolm, this correlation is impossible and, actually, even unintelligible, since it ultimately originates from a conceptual confusion, namely, the misleading assumption that the ordinary grammar of 'dreaming' establishes the exact duration of dreaming during sleep (on the other hand, it goes without saying, Malcolm acknowledged that the physiologists were perfectly able to measure the exact duration of the REM phase). In Malcolm's view, when they attempted to correlate rapid eye movements with what they called 'dreaming,' the physiologists were thereby stipulating a new meaning for the term 'dreaming,' a meaning by virtue of which dreaming occurs in a determined and measurable timespan. For example, the sentence 'He is halfway through his dream' has no normal use in our language; it has perhaps a new use, hence a new meaning, introduced by convention by the physiologists employing rapid eye movements as a new criterion for dreaming (Malcolm 1959: 74). Malcolm's argument was similar to that of his Cornell colleague Black against Feigl's mind-brain identity theory, according to whom not only is the sentence 'Pain is identical to the stimulation of C-fibres' semantically deviant (for it cannot be used to state something in a normal context), but that sentence can never become normal, unless one stipulates by convention a new meaning for at least one word occurring in it; typically, the word 'pain,' which is in ordinary language governed by behavioural criteria (Putnam 1960a: 28). 
Three years later, in 1962, Putnam criticised Malcom in an article entitled 'Dreaming and "Depth Grammar".' Putnam was fully aware that, to a certain extent, the real target behind his attack on Malcolm was Wittgenstein himself. At the beginning of the article he wrote:

In this paper I wish to examine certain general doctrines having to do with language which are employed by Norman Malcolm in his book Dreaming (Malcolm, 1959). I say 'employed,' not 'stated,' because Malcolm never does fully state these doctrines. Yet his arguments turn not on the linguistic properties of individual words, but on these almost formal principles, involving such notions as 'concept,' 'sense,' 'logical independence,' 'stipulation,' 'giving a use,' 'being unverifiable in principle,' 'criterion,' 'indication' and 'inference'.

His arguments are also of interest in that they can be read as simple versions of some famous arguments of Wittgenstein's as he is interpreted by Malcolm. If this interpretation of Malcolm's is faithful to what Wittgenstein had in mind, then these famous arguments are bad arguments and prove nothing. (Putnam 1962/1975: 304)

Putnam attributed to Malcolm two main mistakes, both concerning the view of how scientific theories work. The first was a verificationist view of how scientific terms refer and how scientific theories are confirmed or falsified. The second was a conventionalist view of how scientific concepts change (Putnam 1962/1975). As to the former point, he wrote:

Malcolm's is the sharpest statement of Verificationism in the 1950s. If Malcolm is right, then the 'naive' way of understanding our language and our knowledge is wrong. Thus, in Malcolm's view, it is impossible to refer to a thing (or kind of thing) if in no case do we have better than indications of its presence or absence. If this it right, then for everything in the world we can presently name there is at least one case in which we can settle with certainty whether it is present or absent. But, on the 'naive' view - i.e. in the view of present scientific theory, taken more or less literally, more or less without philosophical interpretation - there are many things for whose presence or absence we never have better than probabilistic indicators. (Putnam 1962/1975: 306) 
As Putnam stressed, the linguistic intelligibility of a scientific discourse does not depend on the possibility of verifying it with absolute certainty, but on its "ability to occur in coherent and appropriate discourses, on paraphrasability" (Putnam 1962/1975: 309). Typically, such an appropriate and coherent discourse takes the form of a general and explanatory theory, based on models and justified by whatever evidence is available, as in so-called inferences to the best explanation, which Putnam assimilated to the inverse-deductive method elaborated by Mill (Putnam 1962/1975; Mill 1843). Putnam wrote:

If someone constructed a plausible physiological model for sleep, for visual experiences, and for dreaming (considered as visual experiences, etc., during sleep) and some theory based on this model suggested the correlations between, say, rapid eye movements and rapid 'dream movements', the confirmation of those correlations would be enormously increased. Yet theories based on this type of model building are not conclusively verifiable, as has been known since the appearance of the late chapters of Mill's Logic (1848) at least. (Putnam 1962/1975: 317)

More generally, as Putnam remarked in the article 'What Theories Are Not,' published the same year, “justification in science does not proceed 'down' in the direction of observation terms. In fact, justification in science proceeds in any direction that may be handy - more observational assertions sometimes being justified with the aid of more theoretical ones, and vice versa" (Putnam 1962: 241). Putnam's perspective was soon accepted and developed by different authors, such as for example Fodor and Charles Chihara, who accused Malcolm of presenting a misleading conception of the nature of scientific confirmation, which — as they made clear - does not depend on the conclusive verification based on the application of criteria, but rather "on appeals to the simplicity, plausibility, and predictive adequacy of an explanatory system as a whole" (Chihara and Fodor, 1965/1977: 197).

These "holistic" considerations were also relevant for Putnam's latter objection to Malcolm, namely, his conception of how scientific terms change over time. Putnam presented several historical case-studies. For example, having studied philosophy of physics under Reichenbach at UCLA, he emphasised that Einstein rejected a "criterial definition" such as e $=1 / 2 \mathrm{mv}^{2}$ not by arbitrarily and conventionally modifying the meaning of 'e' ('kinetic energy'), but rather by introducing an alternative, more general and explanatory theory, to be tested as a whole; in this way, in a sense, he provided the old concept with a new sense (Putnam 1962/1975). However, Putnam shared Malcolm's interest in the relationship between ordinary and scientific language. In particular, he wanted to "protect" the possibility of scientific progress by showing that, when scientific concepts change, no change of 
meaning by stipulation occurs; rather, concepts acquire a use, a new use given the new context (on this see also Putnam 1960a). Even more importantly, when scientists change the criteria for applying a scientific term, this simply reflects the fact that their knowledge of the investigated phenomenon has increased. For example, Putnam considered the history of the term 'acid' in chemistry. In the eighteenth century, chemists used to apply the term 'acid' to a substance on the basis of two or three criteria: being soluble in water; tasting sour in water solutions; turning litmus paper red. Today they accept a different theoretical definition, according to which something is an acid just in case it is a "proton-donor". "Yet - as Putnam put it - I feel sure that any chemist would want to say that he is talking about the same chemical substances that the eighteenth century chemist called 'acids"' (Putnam 1962/1975: 311). According to Putnam, there are no reasons for rejecting this "naive" view, which is able to account for the intelligence of eighteenth-century chemists: he took it to be very likely that such chemists "knew perfectly well that their criteria were crude ways of detecting a "natural kind' of chemical; they would have thought it unlikely that their criteria exactly 'caught' the boundaries of that kind" (Putnam 1962/1975: 312).

Putnam's critique of Malcolm did much harm to the later Wittgensteinian tradition. Verificationism became an indelible black mark against it, whereas scientific realism was a growing tendency in the philosophy of science. Scientific realism was shared by many of those who felt the need to overcome positivism without falling into a Kuhnian form of relativism which — as Putnam would put it much later - made it "unintelligible that one can so much as understand earlier scientific theories" (Putnam 1997: 183). One of these realist philosophers was for example J.J.C. Smart, who had recently been converted from Wittgensteinian-Rylean behaviourism by the lesson of Ullin T. Place (Smart 1959; Place 1956). Smart was a friend of Putnam and in the academic year 1957-1958 he visited Princeton, at the time in which Putnam was assistant professor in that department. ${ }^{x i}$ Another one was Sellars, who was on the contrary — as shown at the beginning of the present chapter — very sympathetic to Wittgenstein's later ideas; however, qua scientific realist (an attitude he shared with Herbert Feigl, his friend and colleague at Iowa and Minnesota), he was also critical of them (Feigl 1958). ${ }^{x i}$ In his remarkable lecture on 'Philosophy and the Scientific Image of Man,' delivered in 1960 at the University of Pittsburgh and then published in 1962, he famously introduced two ideal types labelled 'manifest image' and 'scientific image' (Sellars 1962). Both of them are philosophical images of man and the world: the former understands men as persons who suffer, act intentionally and justify what they say and do by providing reasons; the latter, at the present stage, describes the world as a swirl of physical particles, forces and fields (Sellars 1962: 20). According to Sellars, Wittgenstein's later work provided the best philosophical analysis of the manifest image. In Sellars's words: 
I think it correct to say that the so-called 'analytic' tradition in recent British and American philosophy, particularly under the influence of the later Wittgenstein, has done increasing justice to the manifest image, and has increasingly succeeded in isolating it in something like its pure form, and has made clear the folly of attempting to replace it piecemeal by fragments of the scientific image. (Sellars 1962: 15)

The impossibility of replacing the manifest image piecemeal by fragments of the scientific image depended in particular on the impossibility of reducing normativity in naturalistic terms (O'Shea 2007). This point too seemed to fit well with Wittgenstein's rule-following considerations (Wittgenstein 1953: $\S \S 138-242)$. The two images, however, are also scientific images, since they provide disciplined and critical descriptions and explanations of events and states of affairs: the main methodological difference between them is that the manifest image allows only inductive correlation, whereas the scientific image typically introduces by postulation theoretical, unobservable entities and builds explanatory models (Sellars 1962: 7). ${ }^{x i}$ Though the two images are somewhat continuous with one another, the methodological innovation introduced by the scientific image has significant consequences:

It [the scientific image] purports to be a complete image, i.e. to define a framework which could be the whole truth about that which belongs to the image. Thus although it is methodologically a development within the manifest image, the scientific image presents itself as a rival image. From its point of view the manifest image on which it rests is an 'inadequate' but pragmatically useful likeness of a reality which first finds its adequate (in principle) likeness in the scientific image. I say, 'in principle', because the scientific image is still in the process of coming into being - a point to which I shall return at the conclusion of this chapter. (Sellars 1962: 20; see also Ackerman 1973 and Aune 1990)

Here is where Sellars departed from Wittgenstein. First, as emerged in the early 1930s from the comparison and contrast with Carnap's philosophy of science and science-oriented Weltanschauung, Wittgenstein (at least sometimes) drew a poor picture of the natural sciences, in which confirmation was ultimately based on observation and experiment, whereas the role of models and the postulation of theoretical entities was underestimated (see chapter 3 above). Second, the predominance of the scientific image was and still is simply a fact or an objective process of our times; independently of any evaluation, in order to modify such objective processes, as Wittgenstein himself once put it, 
"quite different artillery" would be needed from anything a philosopher like him was "in a position to muster" (Wittgenstein 1980a: 62); accordingly, Sellars assigned to contemporary philosophy the task to account for, rather than criticise or disapprove, the clash of the two images (famously, his solution was to provide a synoptic view) (Sellars 1962: 15, 18, 19, 26).

Besides its ability to put the finger on the weak points of the later Wittgensteinian tradition, Putnam's attack on Malcolm also fell prey to possible misunderstandings. First, Putnam seemed not to realise that Malcolm's grammatical description of the concept of dreaming had several shortcomings, which should be ascribed to Malcolm himself, rather than to the very idea of a grammatical investigation: in particular, Malcolm's purpose to refute scepticism brought him — somewhat paradoxically for a philosopher so devoted to ordinary language — to limit his inquiry to the "technical" case of dreaming occurring during deep sleep, thus arbitrarily ruling out for example the behavioural evidence characteristic of violent nightmares, which provided further indications of the exact timespan during which dreaming takes place. Second, Putnam proposed the analogy between dreams and acids: arguably, that was an overreaction to Malcolm's alleged mistakes, since it is controversial (to say the least) whether mental experiences - granting, pace Malcolm, that dreams are indeed mental experiences - are substances or natural kinds. Arguably, the success of Putnam's indirect criticism of Wittgenstein depended on external factors relating to the general philosophical atmosphere and the wider intellectual context: in a nutshell, Putnam was in agreement with the rising science-oriented philosophical attitude, and with scientific realism in particular.

\subsection{Reasons and Causes}

However, the episode involving Putnam and Malcolm is not the best place to look at if one wants to realise how, as sometimes or perhaps often happens in the history of philosophy, misunderstandings can be more effective than philosophical arguments. A clearer case was that occurring in 1963, when Donald Davidson, after a period in which he had mainly been working on decision theory (Davidson and Suppes 1957), published in The Journal of Philosophy his seminal paper 'Actions, Reasons and Causes,' where he famously criticised Wittgenstein's well-known view that reasons are not and, in fact, cannot in principle be the causes of the actions they explain and justify (Davidson 1963). ${ }^{\text {i }}$ In recent years, that view had been renovated by Wittgenstein-inspired grammatical investigations such as those of Anscombe, Winch, Kenny and von Wright. In 1957, Anscombe's Intention set the stage: the aim of grammatical investigation is to clarify the meaning of 'intentional action.' An agent acts intentionally when she responds to the question 'Why are you doing so and so?' by providing the reasons or motives for her action (Anscombe 1957: $\S \S 23-26)$. Following Wittgenstein, Anscombe 
and her Wittgensteinian colleagues criticised the causal views of action and action explanation, according to which intentional actions are bodily movements caused by mental states or events (e.g., the agent's beliefs and desires), so that the occurrence of such mental states or events causally explains the occurrence of the bodily movement (Anscombe 1957: §§ 9-11).

Wittgenstein's main anticausalist argument was that agents have first person authority about their reasons for acting (that is, something is a reason for an action just in case agents sincerely claim it is their reason), whereas we formulate fallible hypotheses or conjectures about causes, from a thirdperson perspective (Wittgenstein 1958: 15; see also Schröder 2010 and Tripodi 2015b). As Wittgenstein once put it:

Let us suppose a train driver sees a red signal flashing and brings the train to a stop. In response to the question: 'Why did you stop?', he answers perhaps: 'Because there is the signal "Stop!"' One wrongly regards this statement as the statement of a cause, whereas it is the statement of a reason. The cause may have been that he was long accustomed to reacting to the red signal in such and such a way or that in his nervous system permanent connections of pathways developed so that the action follows the stimulus in the manner of a reflex, or yet something else. The cause need not be known to him. By contrast, the reason is what he states it is. (Baker 2003: 110-12)

The Wittgensteinians presented a similar view by providing further arguments. Melden, for example, challenged the causalist conception by defending the so-called logical connection argument:

If... the motive were some event either concurrent with or antecedent to the action of raising the arm, there would need to be a logically necessary connection between two distinct events, the alleged motive and the action, however it is described. This is impossible if the sequence motive $\rightarrow$ action is a causal relation. (Melden 1961: 88)

Melden added as a qualification:

It is equally impossible if the motive is some interior mental event distinct from that event that is the action of raising the arm. Hence, if the motive explains what was done, the explanation is not and cannot be the type of explanation exhibited in the explanation of natural phenomena, whether these 
be the excitation of muscles, the movements of limbs, the explosion of petrol vapours or the behaviour of falling bodies. (Melden 1961: 89)

In Explanation and Understanding Von Wright provided a similar argument, based on the notion of "Humean" causation, according to which a cause must be logically independent from its effect, (i.e., the former can be described independently of the latter, and vice versa). But since, as von Wright noticed, an action and the reasons for which one acts are logically connected, it follows that reasons cannot be causes of action (in the Humean sense) (von Wright 1971). In further works, von Wright partly modified the argument, coming to deny that having reasons implies acting in accordance with them, even when nothing prevents the agent from acting. He supposed:

\begin{abstract}
A man firmly resolved to assassinate the tyrant. He has access to his room, aims at him with a loaded revolver, but cannot bring himself to pull the trigger. Nothing which we later find out about him would make us think that he had changed his intention or come to a different opinion about the things required of him to make it effective. (von Wright 1976: 422)
\end{abstract}

From this conceivable and logically consistent case von Wright concluded that the logical connection between reasons and action obtains only "ex post actu" (von Wright 1971).

A further argument presented by von Wright to the effect that rational explanations of intentional actions are not, and cannot be, causal relies on the notion of nomicity. That a causal relation between two events is nomic means that a causal statement (i.e., a statement asserting that a causal relation holds between the two events) requires laws governing some descriptions of the events involved. However, rational explanations - i.e., explanations of actions in terms of reasons for acting — do not involve causal laws, basically because the motivational mechanism is teleological rather than causal. $^{\text {xi }}$

Yet another Wittgensteinian anti-causalist argument is based on the distinction between explanatory mental states (or events) and justificatory contents of mental states (or events). Suppose the occurrence of a thought that $p$ may cause a person to act. Nonetheless, the reason that person would invoke to justify her action is the content, rather than the occurrence of the thought (Schroeder 2010). In short: the reason of the action is just that $p$. Similar considerations hold for propositional mental states of a different kind. For example, here is Waismann's formulation of Wittgenstein's dictations:

The attending to the rule can indeed be the cause for the rule being followed... 
[But] the cause of an action can never be referred to, to justify the action. I may justify a calculation by appealing to the laws of arithmetic, but not by appealing to my attending to these laws. The one is a justification, the other a causal explanation. (Waismann 1965a: 123)

A somewhat similar argument was presented by Anscombe in Intention. Preliminarily, she defined mental causes as "what went on in my mind and issued in the action" (Anscombe 1957: $\S 11$ ): for example, a mental cause is the sudden vision of something, which makes me jump. Mental causes can in Anscombe's sense cause intentional actions and be known by the agent "without observation." As she would put it some years later: "The effect of an intention may even be an action in execution of that intention" (Anscombe 1983: 179). ${ }^{x i}$ However, mental causes are not reasons for acting: an action is intentional not because it is caused by a mental cause, to which one refers in explaining one's action. In Anscombe's view “to think that the relation of being done in execution of a certain intention, or being done intentionally, is a causal relation between act and intention" is a grammatical mistake (Anscombe 1983: 179): intentions can be causes, but in the explanations of actions in terms of reasons they are not invoked in a causal capacity (Tripodi 2015b: 143). In Intention $\S \S 13-16$ Anscombe came to this conclusion by arguing as follows. The presence of mental causes is not a sufficient condition for an intentional action: one can do something unintentionally, but as the effect of a mental cause; this happens for example when I knock the cup over because I suddenly see a frightening face. However, having mental causes is not a necessary condition either: we often act intentionally and then explain and justify our action without referring to any mental cause; this happens for example when we answer to the special question 'Why?' by referring to a "backward looking motive". Anscombe had in mind cases of revenge and gratitude, pity or remorse, in which "something that has happened ... is given as the ground of an action... that is good or bad for the person... at whom it is aimed" (Anscombe 1957: § 13). For example, you ask me why I killed X, and I give you the reason for my action: "Because he killed my brother". The reason for my action is something that has happened: that he killed my brother (Anscombe 1957: § 14). That he killed my brother is a "fact" (or a "proposition"), in the idiom shared by many philosophers in the analytic tradition (though not by Anscombe herself). The point, however, is substantial rather than terminological: such a fact (or proposition) is not a mental cause, simply because it is not mental at all. Anscombe also pointed out that if one could show a posteriori "that either the action for which he has revenged himself, or that in which he has revenged himself, was quite harmless or was beneficial, he ceases to offer a reason" (Anscombe 1957: $§ 14,22$ ). But nothing similar happens if we deal with mental causes: if the action for which he has revenged himself came out differently — if, for example, he had not killed my brother (it was just an accident, in which X did not play a relevant role) — the 
revenge would cease to have the reasons it appeared to have, and in fact, it would no longer be a revenge; the agent would cease to offer a reason, because the fact would not obtain. ${ }^{\mathrm{xi}}$

After Quine's 1951 attack on the conceptual-factual distinction (it did not matter if the grammatical was different from the analytic both intensionally and extensionally); after Watkins's 1957 critique of the distinction between linguistic uses that are constitutive and uses that are not constitutive of linguistic competence; after Putnam's 1962 arguments against the difference between criteria and symptoms: after all this happened, it was natural to expect the last and arguably most famous among the Wittgensteinian conceptual distinctions relating to the science/philosophy divide, i.e. the distinction between reasons and causes, being put into doubt or even demolished by an analytic philosopher. And this happened too, without further ado. Or, more precisely, this was the largely prevailing interpretation of what was going on in Davidson's 1963 famous paper. Actually, this interpretation was supported by Davidson himself. First, in a footnote Davidson provided a list of his polemical targets, mentioning many of the Wittgensteinian "small red books" belonging to the series edited by Holland (Davidson 1963: footnote 1; see also chapter 3 above). Notice that Davidson was personally acquainted with some of these Wittgensteinians, having invited them to Stanford during the 1950s. Second, Davidson explicitly criticised the logical connection argument: he was familiar with Melden's 1961 version, rather than with von Wright's later and more sophisticated argument; yet, Davidson wrote and argued under the assumption that the logical connection argument was widely accepted within the entire later Wittgensteinian community. He reformulated it in the following terms: since a reason makes an action intelligible by redescribing it, we do not have two events, but only one under different descriptions, while causal relations (in the Humean sense) demand two distinct events. Then he concluded that if this is the argument, then it fails on three grounds. (i) A cause is a different thing from its effect, but also a reason is a different thing from the action it explains. (ii) The redescription of events in terms of their causes is as normal and uncontroversial as the redescription of actions in terms of their reasons ("We could redescribe this event 'in terms of a cause' by saying he was burnt", Davidson 1963: 692). (iii) It is misleading to regard causal relations as empirical rather that logical: consider the synthetic statement 'A caused B'; supposing that 'the cause of B = A', then by substitution one gets 'the cause of B caused B', which is analytic; therefore, the status as analytic or synthetic of this statement, as well as its explanatory value, depends on how events are described (Davidson 1963: 696). Third, in what is usually known as his master argument for a causalist theory of action and action explanation, Davidson argued as follows: "A person can have a reason for an action, and perform the action, and yet this reason not be the reason why he did it. Central to the relation between a reason and an action it explains is the idea that the agent performed the action because he had the reason" (Davidson 1963: 691). This 'because,' he emphasised, should be regarded as the sort of 'because' we find in causal explanations. Otherwise, 
we could not draw the distinction between mere rationalisations and rationalisations that are part of the process of deliberation that prompts the agent to act. Only if a reason is the cause of an action (rather than merely being in accordance with it) can the action depend on or be brought about by that reason. Suppose, for example, that Agnes intentionally goes to the kitchen. She could have gone there to eat, to say hello to her sister, to look for the cat, and so on and so forth. One of these reasons justifies her action. However, she acted only on one of these reasons. In other words, only one of these reasons is the reason why she went to the kitchen. Which one? The cause of her action.

The interpretation of Davidson as the champion of an anti-Wittgensteinian and causalist philosophy of action has become a long-lasting stereotype in the history of analytic philosophy. However, it can be shown that this stereotype is to a large extent misleading. On the one hand, it is true that, in the 1950s and early 1960s, some of the Wittgensteinians — though by no means all of them — defended something like Davidson's reformulation of the logical connection argument. And it is also true that Davidson's critique of such an argument had a major role in discrediting, within the analytic philosophical community, the reputation of the Wittgensteinian tradition in the philosophy of action. On the other hand, however, there are reasons for providing a more balanced interpretation. First of all, Davidson's criticism assumed and employed some basic later Wittgensteinian philosophical tools and theses, from Anscombe's notion of 'under a description' (Anscombe 1957) to Wittgenstein's functional view of grammatical rules, according to which something is a rule if it is used as a standard of correctness, so that "any empirical proposition can be transformed into a postulate, and then becomes a norm of description", but also the reverse can occur (Wittgenstein 1953: §321, but see also Wittgenstein 1969: §97). Moreover, Davidson’s master argument ultimately consisted of a descriptive, rather than revisionary, grammatical investigation of terms such as 'cause,' 'reason,' 'action' and 'explanation' (Engel 1996). In addition, the logical connection argument was by no means the core of the Wittgensteinian anti-causalist account of action and action explanation. In fact, as has been shown above, in the work of Wittgenstein and his pupils and followers there are at least three further arguments to the effect that rational explanations of intentional actions are not, and cannot be, causal: the argument from first person authority, the argument based on the objective, non-mental nature of reasons, and the argument focusing on the lack of laws in action explanations.

Finally, and more importantly, it can be shown that Davidson's was not at all a causal theory of action explanation, that is, a theory in which A causally explains B by virtue of there being a causal relation between $\mathrm{A}$ and $\mathrm{B}$, so that the explanatory capacity of the explanation consists of the reference to that relation (Stoutland 1999 and Tripodi 2015b): xi the basic reason for this alternative interpretation is the presence of a gulf, in Davidson's article, between singular causal statements (i.e, statements expressing causal relations between events) and statements that causally explain the events. In Davidson's view, causal relations hold between events, which are temporal individual 
entities that can be given under different descriptions (Davidson 1967). However, not only is the causal relation between two events independent of how the events are described (singular causal statements are extensional); but a causal relation between two events holds only if there is a "strict law" (i.e., a lawlike, precise, exceptionless and deterministic "homonomic" generalization), which can be formulated without ceteris paribus conditions and is exemplified by a true description of both events (Davidson 1970: 219; see also 1993: 8). Such causally related events must, in Davidson's view, belong to a "closed system" of the kind described by physics; therefore they must be physical events, that is, they must have a physical description (Davidson 1993). This does not entail, however, that only physical events can be causally related: there are, on the contrary, causal relations between mental events (i.e., events with a mental description), or between mental and physical events. The crucial point is that according to Davidson causal relations hold regardless of how events are described (Davidson 1970).

Davidson also maintained that we can know and describe a causal relation between two events without providing a causal explanation in his sense. This is a further consequence of his idea that causal relations hold no matter how events are described. Consider for example a sentence such as 'the cause of A caused A': it is a true but entirely non-explanatory singular causal statement (Davidson 1963: 696 and 1967: 692; see also Stoutland 1999). In addition, Davidson thought that there can be causal explanations without causal relations. What is the explanans in Davidson's theory of action? Typically, it is a mix of the agent's beliefs and pro attitudes. However, in Davidson's view, beliefs and pro attitudes are not sufficiently "dynamic" to cause something, since they are dispositional states rather than episodic events: whether or not this is persuading, Davidson explicitly stated that there cannot be a causal relation between beliefs and desires, on the one hand, and the action performed, on the other hand, because the causal relation holds only between two events (Davidson 1967: 702; see also Davidson 1963: 693). But let us go a bit deeper.

According to Davidson, mental states such as beliefs and desires causally explain actions, which are events, and this entails that there must be at least one event "associated with" these mental states that is causally related to the action. This event is often the "onslaught" (i.e., the beginning, the forming) of the relevant mental state. The onslaught is also a physical event (i.e., it has at least one physical description, probably given in neural terms), and falls under a strict law belonging to physics (Davidson 1963: 694). However, does the reference to the onslaught make Davidson's a causal theory? Not at all, for two main reasons. First of all, Davidson did not think that to provide a causal explanation of an action one is required to refer to the onslaught; on the contrary, beliefs and desires are the really explanatory factors or, in other words, the reasons for the action, but we normally provide a causal/rational explanation of our actions without knowing the onslaughts of such mental states, let alone their physical descriptions; in Davidson's view, we give a causal explanation of 
something without knowing the causal relation involved and the physical description of the relata; after all, causal explanations are essentially intensional, for they depend on how things are described. This is enough to rule out the possibility that referring to causal relations has explanatory import, since causal relations hold no matter how things are described. Identifying and referring to a causal relation is not the appropriate thing to do, according to Davidson, if one wants to explain something causally or rationally, including intentional actions. Moreover, Davidson also holds that that we normally provide causal explanations without any reference to strict laws: rather, we explain actions by using "rough heteronomic generalizations," that is, imprecise, implicit and non-exceptionless generalisations, which gives us the explanatory connection between the "cause" and the "effect" (Davidson 1970). Strict laws concern only physical events, but we hardly ever know the physical descriptions of the mental event we are focussing on. This does not prevent us from being acquainted with singular causal relations between events. ${ }^{\mathrm{xi}}$

Summing up: according to Davidson, causal explanations of actions are not statements mentioning causal relations and strict laws. Under this respect, they are not instances of the traditional causal theories that Wittgensteinian philosophers such as Anscombe, Kenny, Winch or von Wright took as their main polemical targets. But what are they, then? In his 1963 article Davidson wrote: "When we ask why someone acted as he did, we want to be provided with an interpretation". And he added that explanations of actions in his sense are nothing but redescriptions of the actions, placed "in a wider social, economic, linguistic, or evaluative context" (Davidson 1963: 691). Using an extremely broad notion of causality, so as to include even value-oriented interpretations of intentional actions, Davidson was running the risk of creating a terminological misunderstanding. But apart from terminology, Davidson's conception of action explanation did not conflict with the Wittgensteinian view. In 1971 von Wright came close to realising what was going on when he wrote: "Those who think that actions have causes often use 'cause' in a much broader sense than I do when I deny this. Or they may understand 'action' differently. It may well be, then, that 'actions' in their sense have 'causes' in my sense, or that 'actions' in my sense have 'causes' in theirs” (von Wright 1971). It is also worth noting that the central role attributed by Davidson to the concept of interpretation is strictly connected to his thesis about the normativity of the mental: in his view, we ascribe beliefs, desires and other mental states to people following principles of rationality, which tends to make sense of the mental states and maximise their overall consistency; this view was, once again, in agreement with a later Wittgensteinian perspective in the philosophy of action.

Leaving aside the terminological differences and the restricted debate over the logical connection argument, the nature and the sources of the disagreement between Davidson and the Wittgensteinians were subtle and difficult to identify. Roughly, Davidson agreed with the Wittgensteinians that rational explanations, which he somewhat misleadingly labelled 'causal explanations' are not nomic, whereas 
causal relations require (strict) laws ${ }^{\mathrm{xi}}$. Davidson also appeared to agree with the Wittgensteinians concerning the first person authority of agents in rational explanations. ${ }^{x i}$ The only real, deep philosophical disagreement between Davidson and the Wittgensteinians depended on the thesis that reasons are beliefs and pro attitudes. It is difficult to explicate what Davidson had in mind on the basis of the idea that only dispositional, static states, rather than episodic, dynamic events, can be reasons for acting. Arguably, he accepted "the linguistic evidence for a deep distinction, in our use of 'cause,' 'effect,' and related words," illustrated by Zeno Vendler, between occurrences of verb nominalisations that are fact like, and occurrences that are event like (Davidson 1967: 162; see also Vendler 1962). In Davidson's view, reasons for acting, i.e., what rationally explains an action, is the combination of two different "facts": that the agent has a certain belief and that he/she has a certain pro attitude toward the action; a combined fact of the form 'that $\mathrm{X}$ believed that $\mathrm{p}$, and that she desired that q'. This could partly explain why Davidson arrived at the misleading formulation, at the beginning of Actions, Reasons and Causes, that reasons are mental states. Here is where the real disagreement with Anscombe and the other Wittgensteinians lay: according to Anscombe, the agent's reason is often simply that $p$. This was perhaps a deep disagreement, though not deep enough to justify the reception of Davidson's 1963 arguments as the coup de grâce to the later Wittgensteinian tradition, after the blows inflicted upon it by, among others, Quine, Watkins, Popper, Gellner and Putnam. This radical and to a large extent misleading interpretation, as well as the sudden and great success of Davidson's paper, was based on expectations, rather than arguments. Or perhaps better: it depended on the expectation that an argument against the last Wittgensteinian distinction having to do with the science/philosophy divide, namely, the distinction between reasons and causes, would have been put forward in the analytic philosophical community. These expectations, it goes without saying, were in turn products of the intellectual climate and the scientific transformation of the humanities described in chapter 4 above.

\subsection{The Return of Mentalism}

Browsing the list of articles published in The Journal of Philosophy and The Philosophical Review from 1951 to 1970, a third issue clearly emerges: the critique of the later Wittgensteinian view of mind ${ }^{\mathrm{xi}}$ Focusing on this issue, during the 1950s and 1960s analytic philosophers in the United States kept on attacking and demolishing the cornerstones of Wittgenstein's later philosophy. Three factors were particularly relevant. One was the fall of psychological behaviourism - the methodological view according to which explanations in scientific psychology should rule out introspective data and, more generally, the reference to inner, unobservable mental states, limiting themselves to the consideration of behavioural stimuli and responses - and the parallel crisis of its philosophical cognate, logical behaviourism, the reductive semantic view according to which words belonging to 
mentalistic language (such as "pain", "desire", "intention" and so forth) refer to behavioural dispositions, rather than to inner mental objects (see e.g. Watson 1913 and Skinner 1957; Ryle 1949). In 1948 the psychologist Edward Tolman had shown that even a simple maze performance by rats cannot be explained unless one postulates the existence of inner cognitive maps (Tolman 1948). Then in 1959 Noam Chomsky's famous review tore apart B.F. Skinner's Verbal Behavior (Chomsky 1959; Skinner 1957). Chomsky stressed that notions such as stimulus, reinforce, conditioning and so forth, which are typically employed by the behaviourists, are defined only in extremely simplified experimental conditions. Therefore, they are not suited for explaining such a complex phenomenon as human language. Chomsky put forward his famous argument from the poverty of the stimulus: children are not exposed to sufficiently rich data within their linguistic environments to acquire language, so that having ruled out the postulation of inner, innate grammatical rules, behaviourists are not able to account for language acquisition (Chomsky 1959).

As soon as the term 'behaviourism' acquired a negative connotation, analytic philosophers associated it to Wittgenstein's philosophy of psychology, sometimes using also other pejoratives such as 'verificationism' and 'operationalism'. For example, Gustav Bergmann was particularly eloquent when he wrote:

Materialists replace philosophy by science. Or they mistake the latter for the former. The later Wittgenstein is no exception. Not surprisingly in one as preoccupied with language as he was throughout his career, the key science is the psychology and sociology of language, or if you please, of communication. Not that the Investigations is a conventional scientific book. It is merely a medley of comments. Some are very keen; some others, more or less obvious; the rest, standard armchair psychology in the standard behaviouristic style. (Bergmann 1961/1964: 354)

Similarly, Chihara and Fodor declared: "We... hold that the later writings of Wittgenstein express a coherent doctrine in which an operationalistic analysis of confirmation and language supports a philosophical psychology of a type we shall call "logical behaviorism"' (Chihara and Fodor 1965: 281). In the following years, this interpretation was shared by different philosophers such as Rorty and Robert Fogelin (Rorty 1977; Fogelin 1976). According to the Encyclopedia of Philosophy published in 1967 Wittgenstein's conception of third-person psychological statements was heavily influenced by behaviourism (Kaufmann 1967: 270). And even to this day, the Stanford Encyclopaedia of Philosophy maintains that "Analytical behaviorism may be found in the work of Gilbert Ryle (1900-76) and the later work of Ludwig Wittgenstein (1889-51)"xi (but then it adds in brackets the 
qualification: "If perhaps not without controversy in interpretation, in Wittgenstein's case") (Graham 2000).

It is a plain fact that the later Wittgenstein's philosophical reputation was ruined by the charge of behaviourism. However, was the charge fully justified? There are at least some doubts about that. As Hacker more than once emphasised, Wittgenstein was not at any rate a methodological behaviourist à la Skinner. Moreover, according to Wittgenstein there are in principle reasons to think that the meaning of a linguistic expression cannot be explicated in terms of behavioural stimulus-response patterns. In particular,

No attempt to explain the meanings of expressions in behaviouristic terms can explain the rule-governed connections within the network of language, for such connections are internal or logical, not causal, and correlation of stimuli and responses can at most establish external relations, not internal ones. (Hacker 2001: 60)

Wittgenstein was aware that for his philosophy the relationship with the label 'behaviourism' was a delicate affair to handle. In a lecture delivered in Cambridge in 1936 he explicitly raised the question: 'First of all it seems that we are partial for 'behaviour,' that we wish to explain everything in terms of it. Now why should we be biassed in this way? Is it because of some kind of materialism? What axe have we to grind?" (Wittgenstein 1936/1993: 280). Then in the Investigations he also wondered: "Why should I deny that there is a mental process?" (1953: § 306). In his view, that kind of "denial" did not get the point of his grammatical remarks: "But 'There has just taken place in me the mental process of remembering...' means nothing more than: 'I have just remembered...'. Denying the mental process would mean denying the remembering; to deny that anyone ever remembers anything" (1953: $§ 306)$. Thus he commented: “'Are you not really a behaviourist in disguise? Aren't you ultimately really saying that everything except human behaviour is a fiction?'- If I do speak of a fiction, then it is of a grammatical fiction" (1953: § 307). In fact, his purpose in the philosophy of psychology was to avoid at the same time both behaviourism and the myth of inner processes: "Our job is obviously not to reduce anything to anything, but only to avoid certain misleading ways of expression. Toothache is not a behaviour but an experience. 'We distinguish between 'behaviour' and 'experiences'. Dancing is a behaviour, toothache an experience" (1936/1993: 279). At any rate, he seemed to be fully aware of the risk that his work may be misinterpreted in behaviouristic terms: "Now it looks as if we had denied mental processes. And naturally we do not want to deny them" (Wittgenstein 1953: § 308). 
The story of the controversial representation of Wittgenstein as an outright behaviourist makes it evident that, as happened for example in the case of Davidson's critique of the anti-causalist theories of reasons and action-explanations, the success, or more precisely the lack of success, of the later Wittgensteinian tradition depended on a large extent on coarse-grained, approximate but rhetorically efficacious challenges and controversies, rather than on fine-grained, specific, rigorous arguments. Consider, as a further indication, the philosophical, rather than scientific, critiques of logical behaviourism. Besides Putnam's thought-experiment of the Super-Spartans, imaginary people who do not manifest any pain-behaviour even though they feel pain as we do (Putnam 1963), and besides Sellars's philosophical myth, in which sensations as inner mental episodes are introduced by the genius Jones as theoretical, unobservable entities that have the power to cause intelligent behaviour (Sellars 1956; see also Tripodi 2011), besides the above-mentioned arguments it is likely that the most straightforward argument against logical behaviourism was the following: logical behaviourism is false because it is impossible to define a simple mental state (such as for example the desire to climb the mountain) in purely dispositional, let alone behavioural, terms, unless one mentions other mental states too (such as for example various beliefs concerning climbing and mountains). Notice that this argument was presented in 1957 by Roderick Chisholm and, independently, by Peter Geach in Mental Acts, one of the most famous Wittgensteinian little red books. However, apparently this was not regarded as a sufficient reason to revisit in a more balanced way the picture of the relationship between behaviourism and the later Wittgensteinian conception of mind (Chisholm 1957, Geach 1957).

Another factor that fostered the fall of the later Wittgensteinian view of mind was the rise of reductionist philosophical theories. The scientific context facilitated the emergence of this kind of materialism. Consider in particular the development, in the 1950s, of biological studies of the brain, thanks to the encounter of biochemistry with electrophysiology, as well as the development of research on brain systems, both in humans and in animals, as happened for example in the study of memory (Hodgkin and Huxley 1939, Hodgking et al. 1952; Mountcastle 1957, Hubel and Wiesel 1959; Scoville and Milner 1957; see also Kandel and Squire 2000). The main reductionist view of the mind was the so-called mind-brain identity theory, according to which each type of mental state is contingently identical to a type of brain state. In the 1950s and 1960s this theory was defended by Ullin Place, J.J.C. Smart and David Malet Armstrong in Australia, and by Feigl and David Lewis in the United States (Place 1956, Smart 1959, Armstrong 1966 and 1968, Feigl 1958, Lewis 1966). Having studied in Oxford under Ryle, within the group of these materialists it was Smart who felt the need to resist the objections raised by linguistic philosophers against the mind-brain identity theory. In particular, Smart focused on the following "linguistic" objection: 
It is only a contingent fact (if it is a fact) that when we have a certain kind of sensation there is a certain kind of process in our brain. Indeed it is possible, though perhaps in the highest degree unlikely, that our present physiological theories will be as out of date as the ancient theory connecting mental processes with goings-on in the heart. It follows that when we report a sensation we are not reporting a brain-process. (Smart 1959: 147)

In line with a similar argument set up by Putnam a couple of years earlier, Smart replied: "Indeed, it is logically possible (though highly unlikely) that the electrical discharge account of lightning might one day be given up" (Smart 1959: 148; see also Putnam 1957). Nonetheless, it would be absurd to doubt that lightening is nothing but an electrical charge, or, in other words, that an adequate characterisation of lightening is provided by an intra-theoretic reduction in electromagnetic terms. Unsurprisingly, Malcolm was one of the few to criticise the mind-brain identity theory in the name of Wittgenstein (Malcolm 1965). However, there were strong enough "external” factors to jeopardise the outcome of the debate between the Wittgensteinians and the Australasian materialists. This emerged clearly in a later discussion during the 1980s, when Malcolm confronted Armstrong on consciousness, causality and the nature of mind (Armstrong and Malcolm 1984). As Armstrong summarised on that occasion,

If we take even a halfway scientific view of the matter (and that a scientific view of the matter is true, is a premise of my argument), then we will think that certain causal factors must be present. In (I) it is natural to assume that a state, presumably a brain-state, corresponds to the intention, but that the state passes away before I see the person. In (2) the state continues, and is present when I see the person. But, because of inhibiting causal factors at work, it does not have the effect of my asking the question. In (3) the state continues, and, when I see the person, the latter perception plus the state (plus many other causal factors) brings it about that I ask the question. (A strange case, $\left(3^{\prime}\right)$, is possible where I ask the question, but not as a causal result of the state.) If all this is denied, then I think that we are in the realm of magic and mystery. Human beings would not be within the causal order. Yet they manifestly are within that order. (Armstrong 1984: 214)

It would have been difficult to state it more perspicuously than Armstrong did: the realm of science and causal order versus the realm of magic and mystery. ${ }^{\mathrm{xi}}$ During the debate, this was the key to the 
success of the Australasian materialists and, respectively, the key to the lack of success of their Wittgensteinian opponents: this counted more than Malcolm's (and Wittgenstein's) more or less solid arguments, and even more than the alleged truth of Smart's and Armstrong's theories, which would in fact in the following years be criticised and replaced by plenty of different theories and approaches, from functionalism to token-token identity theories up to eliminativism.

Yet another factor causing the collapse of the later Wittgensteinian philosophical view of mind - arguably, the historically most relevant factor — was the paradigm shift that took place in the late 1950s in the study of mind, a historical process usually referred to as the 'emergence of cognitive science.' The development of computers encouraged the idea that cognitive processes could be analysed in computational terms, that is, as mechanical procedures which can in principle be realised by a Turing machine (Turing 1936). Cognitive science was a child of the science-oriented intellectual culture briefly described in chapter 4 above, a culture growing up after the second world war in the American interstitial academy (Isaac 2012). According to historiographical convention, the cognitive revolution began in 1956 at a multidisciplinary symposium held at the Massachusetts Institute of Technology (Miller 2003): George Miller gave a talk on short-term memory; Allen Newell and Herbert Simon presented a computer program that could prove mathematical theorems; Chomsky illustrated his generative-transformational linguistics. All of them noticed a deep convergence between different approaches and disciplines: they were all interested in studying human cognition; they took as a working hypothesis that cognitive processes have a computational nature; to a lesser extent, they attributed to the mind-software analogy — which would four years later be philosophically developed by Putnam — a leading explanatory role (Putnam 1960a).

It seems reasonable to say that a paradigm shift — a fortiori, one in which philosophy was only a single component of a complex, multidisciplinary scientific process - could not be contained, let alone stopped, by mere philosophical arguments (Bloor 1976). Therefore it would be inappropriate here to present a detailed analysis of the philosophical relationship between Wittgenstein's philosophy of mind and the cognitive sciences. ${ }^{x i}$ However, some comments might be worth making so as to justify the very assumption that the cognitive revolution was alien and even hostile to the later Wittgensteinian tradition. This assumption might seem controversial because it is not entirely clear whether, at least under a certain interpretation, Wittgenstein's later philosophy of mind can on the contrary be compatible with cognitive science: for example, not only did Wittgenstein's notion of family-resemblances directly influence the prototype-theory of concepts introduced by Eleanor Rosch in the 1970s (Rosch 1973), but more recently Wittgenstein-inspired conceptions of lexical competence, conceived of as an ability to speak and understand words such as 'cat' and 'chair', have been presented within the field of cognitive science (Marconi 1997), and Wittgenstein's philosophy 
of psychology have appeared to fit naturally with the cognitive perspective known as enactivism (Varela, Thompson and Rosch E. 1991; O’Regan and Noë 2001; Hutto 2013; see also Moyal-Sharrock 2016). All this notwithstanding, it is possible to show that some crucial aspects of cognitive science were indeed incompatible with the main tenets of the later Wittgensteinian conception of mind. Consider, as a general point, the view that cognitive processes are to be conceived of as calculi, in which inner representations are manipulated in accord with implicit, unconscious and innate rules: as is well-known, one of Wittgenstein's central claims in the Investigations was that understanding is not a process, let alone an inner process (Wittgenstein 1953: $§ 154$ ); the rule-following considerations seemed to be at odds as with intellectualism as with the very idea of an entirely unconscious rule (Glock 2008a: 165; see also Hacker and Baker 1985 and Bouveresse 1991); the notion of an inner representation, whose centrality was second to none in cognitive science, was arguably a polemical target of the private language argument (Fodor 1975; see also Frascolla, Marconi and Voltolini 2010: 2).

To shed some light on the real bone of contention, two episodes are worth mentioning, characterised by an interesting mix of cultural hegemony on the part of "scientific philosophy" and the usual bit of misunderstanding. The first occurred in 1975, when in his The Language of Thought Jerry Fodor accused Wittgenstein's private language argument of committing the worst philosophical sin of all: verificationism. According to Fodor, Wittgenstein's purpose was to show that the attempt to use a private language correctly was entirely meaningless (Fodor 1975: 68-9). With this purpose in mind, Wittgenstein as interpreted by Fodor characterised a private language either as a language "whose terms refer to things that only its speaker can experience or as a language for the applicability of whose terms there exist no public criteria (or rules, or conventions)" (Fodor 1975: 69). Given this definition, nobody, not even the private language speaker, is able to verify whether a term of that language is used correctly or incorrectly. Under Fodor's interpretation, the point Wittgenstein was making is that no definite sense could be attached to the notion of a private language because nobody could ascertain whether a term belonging to the private language is used correctly, but — this was the underlying assumption of Wittgenstein's private language argument — a term could be applied correctly only if someone could at least in principle verify its correct application. Since, in Fodor's view, there is nothing to be said for "the verificationist principle that an assertion cannot be sensible unless there is some way of telling whether it is true," Wittgenstein's famous private language argument "is not really any good" (Fodor 1975: 70).

Arguably, however, Fodor's attack on the private language argument was rhetorically efficacious but exegetically wrong. As Diego Marconi argued convincingly, 
The trouble with a private language is not that we have no way of assuring ourselves that a term belonging to it is being used correctly (or coherently); the trouble is that we cannot be mistaken about whether it is being used correctly, for "whatever is going to seem right to me is right". The private language is not a game at which we cannot win, it is a game at which we cannot lose. (Marconi 1995: 108)

And this is the real reason why the private language-game is entirely senseless. Wittgenstein's argument is not verificationist. All private language users know only too well how to ascertain that a term belonging to the private language is being used correctly. The verification is so simple: if it seems to them that the term is used correctly, then it is; otherwise it is not. The verification is immediate, rather than precluded (Marconi 1995: 108). Pace Fodor, the point of Wittgenstein's argument is ontological or semantic, rather than epistemological: there is no 'being right' or 'being wrong' in the use of a term belonging to a private language, whether the speaker knows it or not. ${ }^{\mathrm{xi}}$

The second telling episode in the dispute between cognitive scientists and Wittgensteinian philosophers took place during the 1980s and 1990s, when the main course of the history of analytic philosophy had already been decided. The main characters in this story were Chomsky, on the one hand, and two Oxford philosophers who were among the most authoritative interpreters of Wittgenstein, Anthony Kenny and Peter Hacker, on the other hand. As is well known, Chomsky attributed to generative linguistics the aim of explaining the knowledge of language of competent speakers. Based on native speakers' grammaticality judgements, the linguist investigates the syntactic structure of sentences, so as to build a complete theory of language, a grammar, regarded as a finite set of syntactic rules (Chomsky 1957). Therefore, prima facie, a grammar in Chomsky's sense can be seen as a mathematical codification of empirical or intuitive data taken from the linguistic behaviour of ideal language users. However, Chomsky was not content with accepting this preliminary characterisation. In his view, a grammar in his sense is also psychologically real: not only by applying the rules of a generative grammar $\mathrm{G}$ is a linguist able to generate all and only the sentences that a competent speaker would consider well-formed; but from this it is reasonable to conclude that the competent speaker knows G (Chomsky 1970 and 1986). However, how should this knowledge of grammar $G$ be conceived? As is obvious, competent speakers do not have explicit knowledge of G. According to the Wittgensteinians, however, they do not have tacit knowledge either. Black noticed that one cannot have tacit knowledge of $\mathrm{G}$ unless one is able to make it explicit, with a certain amount of ingenuity, that $\mathrm{G}$ is what one knows; but here the amount of ingenuity required was too high (Black 1970: 456). Malcolm stressed that it would be absurd to say that a speaker, let alone a child, possesses or is endowed with a theory of language (Malcolm 1971). Hacker argued as follows: "To ask someone 
how much English history he knows invites such answers as 'I know the Tudor period in great detail, but the Stuart only superficially," whereas "it makes no sense to ask a native English speaker how much English he knows, and that is not because a native speaker by definition knows a lot!" (Hacker 1990: 128). From a Wittgensteinian point of view, there is only one reasonable interpretation of the phrase "X knows grammar G": $G$ is a theory that (perhaps adequately) describes the data provided by X's ability to speak and understand his native language.

However, Chomsky in turn reacted, making it clear that he did not accept that reinterpretation of his work (Chomsky 1986, 1992, 1994). Initially he invoked a distinction from ordinary language between knowing a language and being able to use it:

Consider two people who share exactly the same knowledge of Spanish: Their pronunciation, knowledge of the meaning of words, grasp of sentence structure, and so on, are identical. Nevertheless, these two people may - and characteristically do - differ greatly in their ability to use the language. One may be a great poet, the second an utterly pedestrian language user who speaks in clichés. (Chomsky 1988: 9)

Kenny and Hacker stressed that knowledge of language and ability to speak and understand are identified by the same behavioural criteria (Kenny 1981/1984; Hacker 1990). Chomsky's alleged counterexample of the poet and, say, the journalist did not prove anything:

Does the fact that the one writes great verse and the other pedestrian prose show that knowing Spanish is a not a complex array of abilities? Not so; it merely demonstrates that one can know a language without being able to write poetry, speak a language without being able to turn an elegant phrase, or write decent letters without being a master of epistolary style. (Hacker 1990: 130)

This, however, was not the last word in the dispute, since Chomsky exhibited his philosophical skills by presenting a thought-experiment:

Suppose that Juan, a speaker of Spanish, suffers aphasia after a severe head wound, losing all ability to speak and understand. Has Juan lost his knowledge of Spanish? Of course, Juan recovers the ability to speak and understand Spanish, because it is his native language, but what was retained was not the ability, because that was lost. What was retained was a system of knowledge, a cognitive system of the mind/brain. Evidently, possession of 
this knowledge cannot be identified with ability to speak and understand or with a system of dispositions, skills, or habits. (Chomsky 1988: 10)

Chomsky's was an imaginary case, but something similar happened in reality with the so-called blindsight phenomena: after having surgically removed his occipital cortex from the right hemisphere, patient DB said he did not "see" anything in his blind field; however, if forced to guess about whether a stimulus was present in his blind field, he could succeed in a variety of discriminations. In the early 1970s Lawrence Weiskrantz interpreted this discovery as a confirmation of the existence of a divide between visual perception and visual sensation. In 1991 John Hyman, who studied at Oxford under Hacker's guidance, provided a Wittgenstein-inspired analysis of the paradoxical character of blindsight. Hyman explained that the concept of vision is normally governed by two kinds of criteria: behavioural criteria, on the one hand, and the awareness of the seeing person, which can typically be expressed in linguistic terms, on the other hand. Normally these two kinds of criteria go hand in hand, whereas in the case of DB they are divided: only the former, but not the latter, is present. That is why it would be philosophically less misleading not to raise the question 'But after all, does DB see or not?' as if it were a factual question (Hyman 1991).

In a similar vein, Kenny replied to Chomsky that normally we attribute knowledge of Spanish (i.e., the ability to speak and understand Spanish) on the basis of behavioural criteria: the person can readily speak, understand and think in Spanish. In the imaginary case, however, these criteria are not applicable. Nonetheless, normally we also take for granted that if one is able to speak Spanish today, and one has neither studied Spanish nor come in contact with it during the last month, then, if not a criterion, this is a very strong indication that one already knew Spanish one month ago. The thoughtexperiment creates a contrast between two kinds of indications that normally go in the same direction but are now "whittled away" (Kenny 1981/1984: 247). Chomsky illustrates the "fuzzy edges of the concept knowing a language" (Kenny 1981/1984: 247). Therefore there is nothing wrong in saying, against part of the evidence, that Juan knew Spanish during aphasia: it is crucial, however, to understand that in so doing we are making a decision, rather than a discovery, concerning the meaning of 'know' in that context (Kenny 1981/1984: 248). The decision is not blind, since we may be persuaded to take it by considering the second part of the evidence, namely, that Juan recovered Spanish, not Japanese, without being exposed to it. Yet, this was a decision, which could have been different.

Chomsky did not accept Kenny's move, since he was convinced that there was a fact of the matter to be observed and described empirically in order to answer the question: After all, did Juan know Spanish during aphasia? Put into the corner by Kenny, Chomsky reacted by abandoning the consideration of ordinary language and relying on the scientific character of his work. As a scientist, he 
maintained, he was free to introduce a new vocabulary. He wanted to answer affirmatively to this question even supposing that Juan never recovered the ability to speak Spanish: he was conceiving knowledge (of language) as a "cognitive structure," a "computational system of the mind/brain," since in his view when we speak of mind we are speaking of the brain at a certain level of abstraction (Chomsky 1988: 9). At that point Kenny in turn replied by supposing "that Professor Chomsky were now to die, and on opening his skull we discovered that there was nothing inside it except sawdust. This is indeed an exotic suggestion: if it happened it would be an astonishing miracle. But if it happened it would not cast the slightest doubt on what we all now know, namely, that Chomsky knows English extremely well” (Kenny 1981/1984: 250). Then Chomsky concluded: “The scientific approaches, I believe without exception, depart from the commonsense notion in several ways; these departures also affect the concepts of knowledge or understanding of language, use of language, rule of language, rule-guided linguistic behavior and others" (Chomsky 1986: 15). He also suggested that, if one likes, one could use the technical term 'cognize,' rather than the ordinary word 'know,' to refer to Juan's peculiar mental state during aphasia. Later on he would comment caustically: "I used the word 'cognize' just to avoid pointless debates caused by irrational ideologies" (Smith 1999: 236). Once again, the "dark side" of the later Wittgensteinian tradition was identified with its non-scientific nature.

\section{Notes}

${ }^{\mathrm{xi}}$ For a description and discussion of Sellars's original and intertwined uses of both Wittgensteins, see Bonino and Tripodi (2018a); for the relationship between Sellars and Carnap see Carus (2004), Olen (2016) and Gabbani (2018), as well as Sellars (1975).

${ }^{x i}$ On Sellars's philosophy of language see Marras (1973), O'Shea (2007, chapter iv), and de Vries (2016). On Sellars's use of Wittgenstein's Tractatus to solve the problem of linguistic idealism that emerged from his acceptance of the thesis that semantics is entirely intra-linguistic, see Bonino and Tripodi (2018a).

${ }^{x i}$ Some comparative data allow us to evaluate roughly the dimension of the 92 occurrences of 'Wittgenstein': in the same corpus in that period 'Dewey' has 183 occurrences, 'Carnap' 92, 'Quine' 82, 'Heidegger' 40.

${ }^{x i}$ Ambrose (1952) and (1955), Black (1959 and 1960). Geach (1956), Dummett (1956) and (1959), MacDonald (1951), Toulmin (1959), von Wright (1951) and (1955).

${ }^{x i}$ Sellars (1954b) and (1957), Melden (1956), Putnam (1957), Linsky (1957), White (1960b), Albritton (1959), Lehrer (1960).

${ }^{x i}$ Black (1962), Bouswma (1961), Findlay (1961a), Malcolm (1963) and (1967), Rhees (1963), (1965) and (1968), Dummett (1964), Geach (1965), Stenius (1965), Strawson (1968), Urmson (1969), von Wright (1969), Waismann (1965b) and McGuinness (1966).

${ }^{x i}$ Sellars (1962) and (1964), Putnam (1964), Cavell (1962 and 1965), Fodor and Katz (1963), Katz (1964 and 1965$)$, Maxwell and Feigl (1961); Rorty (1961), Danto and Morgenbesser (1963), Donnellan and Morgenbesser (1963), Davidson (1963), Hintikka (1965), Garver (1964), Stroud (1965). See also Castañeda (1962), Searle (1962), Armstrong (1963), Chihara (1963), Linsky (1969), Chisholm (1970), Churchland (1970), Harman (1968) and (1970).

${ }^{x i}$ Hanson (1958 and 1967), Feyerabend (1955 and 1960), Toulmin (1959).

${ }^{\mathrm{xi}}$ The relationship between Kuhn and the later Wittgenstein has been widely studied, and still is (see, e.g., Kindi 1995; Sharrock and Read 2002; Read 2012).

${ }^{\mathrm{xi}}$ As noticed by Isaac, post-war scientific philosophy in America, as it was shaped for example in the Harvard complex, also had an 'interpretist' trend, represented for example by the works of Charles Taylor, Kuhn, Geertz, and, later on, Rorty (Isaac 2012: 9-11, 16).

${ }^{x i}$ Malcolm (1956), Albritton (1959), Smart (1959), Ayer (1960) and (1961), Wellman (1961), Maxwell and Feigl (1961), 
Cavell (1962), Casteñeda (1962), Fodor and Katz (1963).

${ }^{x i}$ See Melden (1956), Lehrer (1960), Yolton (1958 and 1962), Danto and Morgenbesser (1963), Davidson (1963), Donnellan and Morgenbesser (1963).

${ }^{x i}$ See Putnam (1957), Smart (1959) and (1963), Bergmann (1960), Malcolm (1963), Cook (1965), Rorty (1970).

${ }^{x i}$ Malcom had arrived to Harvard after a first period of studies in Nebraska under Bouwsma.

${ }^{x i}$ Among the others, also Carl Gustav Hempel, Gregory Vlastos, Paul Ziff, and Paul Benacerraf belonged to the faculty. See https://philosophy.princeton.edu/about/fifties-snapshot.

${ }^{\mathrm{xi}}$ As is well-known, in 1949 Sellars and Feigl co-edited the textbook Readings in Philosophical Analysis and collaborated in the foundation of the journal Philosophical Studies (Feigl and Sellars 1949).

${ }^{x i}$ Notice that, according to Sellars's scientific realism, from an ontological point of view these imperceptible entities exist in the same way and the same sense as observable entities do. The difference is epistemological: we are justified in believing that they exist on the basis of exclusively theoretical or inferential grounds, rather than on observational, noninferential grounds; for example, I believe on inferential grounds that a certain gas will obey the Boyle-Charles law or even that tomorrow the sun will rise, whereas I believe that this is red on non-inferential grounds (Sellars 1961).

${ }^{\mathrm{xi}}$ The interpretation presented here relies upon Tripodi (2015b).

${ }^{x i}$ Further arguments to the same conclusions (rational explanations are not nomic) are rejected by von Wright: for example, Hempel's suggestion that the laws involved in action explanations are much more complicated than those we find in purely physical explanations (see Hempel 1968), or Popper's view that the laws involved in rational explanations of actions are so obvious that we rarely take them into account (see Popper 1945).

${ }^{x i}$ On so-called deviant causal chains, see also Hyman (2014).

${ }^{x i}$ According to Tripodi (2015b), Anscombe is here employing what would later be known as the concept of good (or normative, as opposed to motivational) reasons, thus making sense of the idea of a pratical reality (see Dancy 2000 and also Williams 1980). Good reasons are those that there are in favour (or against) the action; they are normative, since they approve (or disapprove), are favourable (or adverse) toward an action, and since they make the action right (or wrong). The paradigmatic cases of this kind of reasons are moral reasons (Tripodi 2015b: 143). Tripodi (2015b) also conjectures that Anscombe's argument based on backward looking motives is a simpler version of Dancy's anti-causalist argument, according to which "motivational reasons (the reasons in the light of which one acts) must be the sort of things capable of being among normative reasons (the reasons that there are or that one has); otherwise, it would be senseless to ask, as we in fact do in everyday discourse, whether the agent actually acted for a good reason or, which is the same, whether the reason, for which he acted, was a good reason; therefore, motivational reasons cannot be mental states or events, let alone mental causes, for a mental state, like one's believing or one's desiring, is not a fact" (Tripodi 2015b: 144; see also Dancy 2000: 118-19).

${ }^{x i}$ Arguably, Stoutland (1999) was partly under the influence of Child (1994), thus diverging from Stoutland (1976) and (1982).

${ }^{x i}$ As is well-known, all this is also compatible with Davidson's so called anomalous monism, according to which (i) there are causal relations between mental events and physical events (as well as between mental events and other mental events); (ii) events that are causally related fall under strict laws; (iii) there are no strict psychophysical laws (as opposed to rough generalisations) (Davidson 1970).

${ }^{\mathrm{xi}}$ Not all the Wittgensteinians adopted the notion of nomic causation. For example, Anscombe did not (Tripodi 2015b: 149). According to her, "causality consists of the derivativeness of an effect from its causes. This is the core, the common feature, of causality in its various kinds. Effects derive from, arise out of, come out of, their causes" (Anscombe 1971: 136).

${ }^{x i}$ More than twenty years later, as is well-known, Davidson provided a new theory of first person knowledge, which seems to be incompatible with a Wittgensteinian viewpoint (Davidson 1984a; see also Hacker's 1997). At that time, however, his 1963 article had already run its course in the history of analytic philosophy.

${ }^{x i}$ See for example Smart (1959), (1961), (1963) Bergmann (1960), Putnam (1957), Cook (1965), Rorty (1970). Malcolm (1963) was an attempt to defend Wittgenstein.

${ }^{\mathrm{xi}}$ Notice that the interpretation of Ryle as an analytic behaviourist is not unanimously accepted. According to Daniel Dennett, for example, it is nothing but an urban legend (Dennett 2000).

${ }^{\mathrm{xi}}$ Yet another aspect that is worth-emphasising here is that Smart made explicit use of Ockham's razor to justify his preference for the mind-brain identity theory over mind-body dualism (Smart 1959).

${ }^{x i}$ On this issue see for example Stern (1991), Proudfoot (1997), Bennett and Hacker (2003), Sullivan (2017).

${ }^{\mathrm{xi}} A$ fortiori, Fodor was right when he wrote that Wittgenstein's argument was not applicable against (something like) his language of thought. This was true, however, neither because Wittgenstein's argument was verificationist, hence flawed, nor because the language of thought is not private (since it is shared by different people and machines). Rather, the language of thought - not differently from a private language in Wittgenstein's sense - cannot be misunderstood or used mistakenly (in the normative sense, not in the sense in which we say that something goes wrong with the mechanisms), therefore it is not a language at all (see Marconi 1995). 


\section{Necessity, Style, and Metaphilosophy}

Even during the linguistic turn, in the 1950s and 1960s, analytic philosophers did not abandon their interest in metaphysics: not so much because of Strawson's influential but idiosyncratic use of the term (Strawson 1959), but rather due to the fact that philosophers such as for example Bergmann, Chisholm, Smart and Donald Williams kept on doing metaphysics in the traditional sense, i.e., as a theoretical and highly speculative investigation on the necessary features and deep structure of the world (Fisher 2015). However, it is difficult to deny that there is a lot of truth in the historiographical stereotype according to which the novel account of necessity and possibility made available by the works of the Princeton philosophers Saul Kripke and David Lewis - born in 1940 and 1941 respectively — had a major role in the revival of analytic metaphysics in the early 1970s (Kripke 1972/1980; Lewis 1973; see also Soames 2014: chapters 6 and 7). These works objectively contributed to a further weakening of the later Wittgensteinian tradition in the history of analytic philosophy. The adverb 'objectively' suggests that Wittgenstein's later philosophy was not the direct target of Kripke's and Lewis's philosophical attacks, though it would be an exaggeration to say that the decline of the later Wittgensteinian tradition was just one of their accidental and unintended byproducts. The relationship between Wittgenstein's view of necessity and the research programmes in metaphysics inaugurated by Lewis and Kripke is complicated and would deserve a book-length investigation (see, e.g., Kalhat 2007 and Glock 2007); for the present purposes, we have to be satisfied with a schematic outline of the story, in which emphasis is put on the issues that are likely to be more relevant to the overall history reconstructed in the present book.

\subsection{Wittgenstein and the Revival of Metaphysics}

In the Tractatus Wittgenstein had famously affirmed: "There is only a logical necessity" (Wittgenstein 1922: 6.37; see also 6.375) and "All happening and being-so is accidental" (1922: 6.41). On these points he never changed his mind. Rather he developed similar views in the context of his later grammatical investigations, using a partly new vocabulary and philosophical framework. By 'logical necessity' he meant the necessity of mathematical propositions, broadly conceived, so as to include logical laws, arithmetic equations, and geometric axioms and theorems. Realism and platonism were his main polemical targets: in his view, necessity does not inhere in things, belonging either to the physical world or to a Platonic realm, but is a by-product of our language, our forms of representation, our conceptual schemes. In a nutshell, a proposition $p$ is logically necessary if we cannot conceive of not-p; the necessary is what we could not conceive as being otherwise (Wittgenstein 1937-1944/1983: IV, § 29; see also Marconi 2010: 139). In the first Critique Kant had argued that (i) mathematical propositions are paradigm-cases of necessary propositions, i.e., propositions that could not be 
otherwise; (ii) all necessary propositions are knowable a priori, and vice versa (Kant 1781-1787/1999: A xv; B3). Therefore Wittgenstein's view of necessity - which was mutatis mutandis also shared by Carnap - can be seen as part of a broadly Kantian tradition in the philosophy of logic and mathematics (Williams 1974, Lear 1984; see also Carnap 1934 and 1947). ${ }^{x i}$ Wittgenstein regarded logical laws and mathematical propositions as disguised grammatical rules, which have "the hardness of the logical must" (Wittgenstein 1953: § 437). The necessity of such rules corresponds to the inconceivability of their negations, which does not however depend on our powers of imagination being unequal to the task (Wittgenstein 1953: § 251). It sometimes happens that we are tempted to say "I can't imagine the opposite" (Wittgenstein 1953: § 251): in such cases, it often seems to us that we discovered a necessary feature of the world, such as for example the property of being identical with itself (Wittgenstein 1953: § 216). On the contrary, Wittgenstein warned us, in such cases we have just found a grammatical connection, that is, an internal relation among concepts. According to Wittgenstein, metaphysics is just this: the confusion of a grammatical proposition, such as for example 'Every rod has a length,' with an empirical one, such as 'This table has the same length as the one over there.' Only in the latter case do we understand what it means to have a picture of the opposite, whereas in the former case "the picture attaching to the grammatical proposition could only show what is called "the length of a rod"” (Wittgenstein 1953: § 251).

Within the above-outlined Wittgensteinian view of necessity, two distinct though intertwined elements can be discerned. The first was the analysis of what logical necessity positively is. The main result of this analysis was the above-described linguistic or conceptual view of necessity, which regarded necessary statements as grammatical rules in disguise. The second element was Wittgenstein's anti-metaphysical stance, whose main expression was perhaps an argument against (the notion of) necessary facts or, more precisely, an argument to the effect that either $\mathrm{F}$ is a fact or $\mathrm{F}$ is necessary, tertium non datur. In the Tractatus the argument ran as follows (for this explicit formulation, see Marconi 2010: 145). Suppose F is a necessary fact. Given F, there is also P, the proposition that pictures F: otherwise it would not be true that "the specification of all true elementary propositions describes the world completely" (Wittgenstein 1922: 4.26) (assuming of course that "the world is the totality of facts," as it is stated in the Tractatus; Wittgenstein 1922: 1.1). As proposition P pictures a necessary fact, its negation, non-P, states an impossibility. However, "what is thinkable is possible too" (Wittgenstein 1922: 3.02) so that, by contraposition, what is impossible is unthinkable. It follows that non-P, which is impossible, is also unthinkable, hence it is not a genuine proposition or, in other words, it does not picture any state of affairs. The same can be said of $\mathrm{P}$, namely, the picture of $F$ (this is stated for example in Wittgenstein 1922: 4.0641 and 5.2341). Thus it can be concluded that $\mathrm{F}$ is not, and cannot be, a necessary fact: if $\mathrm{F}$ is necessary, it is not a fact; if it is a fact, it is not necessary. The concept of a fact is, in the theoretical framework of the Tractatus, 
logically related to the concept of contingency. However, as underlined above, the rejection of necessary facts is one of the main invariants in Wittgenstein's philosophy: even when he abandoned the philosophical apparatus presented and employed in the Tractatus, he never rejected the main rationale of the Tractatus's argument against necessary facts.

For reasons provided in chapter 3 above, which have to do with the confusion between grammatical rules and analytic sentences, the first aspect of Wittgenstein's account of necessity, namely, the view of necessity as a disguised byproduct of grammar, fell under the attack of Quine on analyticity and conceptual truth. Under this respect, and also because ontology played a major role in his philosophy, there is little doubt that Quine was among those who promoted a substantial "return" of metaphysics into the history of analytic philosophy. However, while with one hand he opened the door to metaphysics, at the same time with the other hand Quine offered analytic philosophers a powerful anti-metaphysical weapon, namely, extensionalism, characterised by radical scepticism and hostility towards modal concepts and, in particular, de re necessity. Yet, one trouble with Quine's sceptical attitude was that it was not easily compatible with a balanced philosophical evaluation of the impressive results achieved by modal logicians from the late-1950s to the mid-1960s (Prior 1957; Hintikka 1961 and 1963; Kanger 1957; Bayart 1958; Montague 1960): ${ }^{x i}$ as is well-known, a special place in this story was occupied by Kripke, a student of Quine at Harvard in the late 1950s, who introduced his highly influential possible-world semantics (Kripke 1959, 1962, 1963a, 1963b, 1965a, 1965b).

Then in 1970 Kripke delivered his famous lectures on Naming and Necessity at Princeton (Kripke 1972/1980). He started focusing on an apparently marginal point. In the axiomatic system of modal logic presented by Ruth Barcan Marcus in the mid-1940s it was possible to prove that if $a=b$, then necessarily $a=b$; for example, if Hesperus $=$ Phosphorus, then necessarily Hesperus $=$ Phosphorus. On the one hand, it was difficult to reject this conclusion, which ultimately derived from two logically solid principles: the so-called Leibniz's Law and, in particular, the half of the bi-conditional known as the principle of the indiscernibility of identicals, according to which there cannot be numerically distinct entities that have all their properties in common; and the principle of the necessity of selfidentity, according to which necessarily every entity is self-identical. On the other hand, however, there were at least two big worries about the idea that if Hesperus = Phosphorus, then necessarily Hesperus $=$ Phosphorus. First, according to a tradition dating back to Frege and Russell, proper names were to be regarded as synonyms of definite descriptions. For example, 'Hesperus' was considered a synonym of 'the heavenly body visible in the morning,' while 'Phosphorus' a synonym of 'the heavenly body visible in the evening.' Under that assumption one could easily imagine a state of affairs in which the heavenly body visible in the morning is, say, Venus, whereas the heavenly body visible in the evening is Mars, so as to conclude that 'Hesperus = Phosphorus' can be true without 
being necessarily so. As is well-known, Kripke dismissed this traditional semantic view by providing a new theory of reference, based on the idea that proper names are direct and rigid designators (Kripke 1972/1980). ${ }^{\text {xi }}$ The second worry about the necessity of 'Hesperus = Phosphorus' depended on Wittgenstein's and Carnap's Kantian views of necessity, according to which it cannot be necessary that Hesperus $=$ Phosphorus, since all necessary statements are conceptual (grammatical or analytic), therefore they are knowable a priori, whereas we know only a posteriori, thanks to a scientific discovery, that Hesperus $=$ Phosphorus.

Here Kripke came close to contrasting explicitly the second basic element contained in Wittgenstein's view of necessity, that is, his argument against necessary facts. Kripke drew a tripartition among different conceptual levels: the semantic level, which concerns the meaning of words and the concepts that we use to express thoughts; the epistemological level, which is about the way in which we obtain and justify our beliefs, either a priori or a posteriori; the metaphysical level, which has to do with the intrinsic nature of the world in itself, independently of the way in which we speak of it and the things we know about it. Then he suggested that the three notions of analytic, a priori and necessary are not co-extensional. The identity Hesperus = Phosphorus, for example, is true and necessarily so, since 'Hesperus' and 'Phosphorus' refer to the same object, Venus, not only in the actual world but in all possible worlds. However, we know that Hesperus = Phosphorus only a posteriori. Now, what is the proposition expressed by the sentence 'Hesperus = Phosphorus'? This proposition can be interpreted as the fact that Hesperus = Phosphorus: this is, however, a necessary fact, but it is knowable only a posteriori, on the basis of scientific inquiry rather than mere semantic competence. As Putnam suggested in the same period, the picture of how substance and natural kind terms work is very similar to the picture of how proper names work; therefore additional examples of necessary a posteriori facts are salt $=\mathrm{NaCl}$ and water $=\mathrm{H}_{2} \mathrm{O}$ (Kripke 1972/1980; Putnam 1975). The claim that some necessary truths are knowable a posteriori and the subsequent rehabilitation of the notion of necessary fact were a serious challenge for a Wittgenstein-inspired conception of philosophy. Kripke's a posteriori necessary facts seemed to provide counterexamples to Wittgenstein's Kantian view of necessity.

Notice, however, that abstracting from the specific context of the picture theory of meaning defended in the Tractatus, it is possible to glimpse a simple but powerful argument all along Wittgenstein's philosophical work, early and late: consider a fact such as for example the fact that, say, salt $=\mathrm{NaCl}$; it is conceivable, hence possible that this fact does not obtain; hence it is not necessary that salt $=\mathrm{NaCl}$ (Marconi calls it 'the simple argument' against necessary facts; see Marconi 2010: 149). This is not the place to provide a general discussion of Wittgenstein's antimetaphysical arguments, let alone an evaluation of costs and benefits in Wittgenstein's view, if compared with Kripke's account. For the present purposes, however, it will be enough to stress the 
following points, so as to suggest that the issue is still controversial (Marconi 2010: 150-151). First, in the post-Kripkean age, something like Wittgenstein's simple argument was discussed at length by analytic metaphysicians, especially in the context of the literature on the relationship between conceivability and possibility, and several different solutions were presented: for example, the rejection of the entailment from conceivability to possibility (Putnam 1975, Tidman 1994, Soames 2003, Fiocco 2007), but also the idea that the argument equivocates between different senses of 'conceivable' and 'possible' (Chalmers 2002; Yablo 2002).

Secondly, and perhaps more importantly, Kripke's own solution was not immune to potential troubles. According to Kripke, assuming that salt is essentially $\mathrm{NaCl}$, water is essentially $\mathrm{H}_{2} \mathrm{O}$, and Hesperus is necessarily nothing but Phosphorus, then one cannot really conceive that salt is not $\mathrm{NaCl}$, water is not $\mathrm{H}_{2} \mathrm{O}$, or Hesperus is different from Phosphorus. When we have the impression to conceive such states of affairs, this is mere seeming: we are really conceiving something else, an epistemic counterpart of salt (respectively, water, Hesperus), that is, a situation in which something which is epistemically indiscernible from salt (water, Hesperus), but is not salt (water, Hesperus), turns out not to be $\mathrm{NaCl}\left(\mathrm{H}_{2} \mathrm{O}\right.$, Phosphorus). Notice, however, that Kripke himself acknowledged that this strategy is not universally applicable: for example, he himself provided an anti-physicalist argument to the effect that it is conceivable, hence possible, that pain is not identical with stimulation of C-fibres (Kripke 1972/1980). Moreover, if one accepts that our ability to imagine counterfactual alternatives may have a breakdown, the fundamental arguments supporting Kripke's theory of reference - a theory, let us stress this point further, without which there would have been no Kripkean rehabilitation of the very notion of necessary fact — can in turn be questioned. For example, Kripke argued that the name 'Aristotle' is not a synonym with 'the author of the Metaphysics' because intuitively the sentence 'Aristotle is the author of Metaphysics' is not a tautology, so that, in other words, 'Aristotle' is not a synonym of 'the author of Metaphysics' because we can conceive of a case in which Aristotle was not a philosopher and it was, say, Theophrastus who wrote the Metaphysics. Now, it is natural to wonder: if our conceivability intuitions are open to question and may be wrong - as suggested by the cases of salt, water and Hesperus - what guarantees that they are not deceiving us in the case of 'Aristotle'? (Yablo 1993: 16; Marconi 2010: 153).

Last, but not least, it is noteworthy that in the early 1970s it was probably not so easy to understand what exactly was going on in Kripke's work: how much old-style conceptual analysis, how much metaphysical theorising, how much reliance upon sophisticated but pre-theoretical intuitions. As Williamson underlined, in 1982 Nathan Salmon was the first interpreter who explicitly claimed that in Kripke's work the linguistic aspect was marginal whereas the metaphysical aspect was crucial (Williamson 2014; see also Salmon 1982); as to the third aspect — the appeal to intuitions — it was arguably the most difficult to understand, though a suggestion in the right direction had been provided 
by Quine, when he coined the term 'Aristotelian essentialism,' emphasising and criticising a certain similarity between essentialism, a basic feature of Barcan Marcus's and Kripke's views of de re necessity, and Aristotelianism, after all a common-sense philosophy (Quine 1966).

Arguably, regardless of his philosophical genius, regardless of the subtle questions concerning the exegesis of his work, and even regardless of the soundness of his arguments, the success of Kripke's objectively anti-Wittgensteinian rehabilitation of necessary facts was also motivated by "external" reasons, that is, by its ability to satisfy a broadly cultural need, having to do with the leitmotif shared by Quine and most analytic philosophers in the United States after the second world war: the support to the scientific, rather than humanistic, self-image of philosophy. Under an additional assumption, Kripke found space for building peculiarly philosophical theories. The underlying assumption and the argument stemming from it were roughly the following: as the necessity of a statement such as 'Salt $=\mathrm{NaCl}^{\prime}$ depends on how the world is, rather than on how our linguistic framework or conceptual scheme is constructed, perhaps also the necessity of a conceptual and allegedly a priori statement such as 'Triangles have three angles,' far from being determined by the normative or, more precisely, constitutive character of a geometrical rule, depends on the necessary fact that triangles have three angles; this fact is correctly described by the statement in question. But there is no guarantee that all necessary facts are as obvious as the fact that triangles have three angles: therefore it is perhaps possible that we will discover (even by doing armchair philosophy) new, previously unknown, necessary facts, or that a conceptual, allegedly necessary statements turn out to be false: think, for example, of a statement such as 'Knowledge is true justified belief' (Gettier 1963). End of the argument. As we will see below in this chapter, this issues would be more sophisticatedly discussed by Timothy Williamson (Williamson 2007). From a historical point of view, however, David Lewis was the philosopher who was mainly responsible for occupying the space created by Kripke's successful rehabilitation of the notion of necessary fact in a Quinean, science-oriented philosophical scenario.

Lewis's contribution to metaphysics originated within the philosophy of language, in particular from the attempt to solve the problem of counterfactual conditionals, which had been previously discussed, among others, by Nelson Goodman and Robert Stalnaker (Goodman 1947; Stalnaker 1968). As is well-known, Lewis provided his own theory: "“If kangaroos had no tails, they would topple over' seems to me to mean something like this: in any possible state of affairs in which kangaroos have no tails, and which resembles our actual state of affairs as much as kangaroos having no tails permits it to, the kangaroos topple over" (Lewis 1973: 1). The basic notions used by Lewis in his analysis - possible worlds and similarity among worlds - seemed to require a metaphysical foundation (Lewis 1973: ch. 4). Lewis was ready to provide one, presenting a clearcut version of modal realism, which in the following decades was bound to be considered the benchmark and 
standard in the field of analytic metaphysics and beyond. As he made it clear, he believed that "there are possible worlds other than the one we happen to inhabit"; these worlds are "ways things could have been besides the way they actually are" (Lewis 1973: 84). Possible worlds are not, however, linguistic or abstract entities (1973: 85, 90). Lewis suggested looking at the actual world, that is, the spatiotemporal world that we happen to inhabit; possible worlds, he pointed put, are the same kind of entities as the actual world, though different things happen in them; they are fully real, but spatiotemporally and causally isolated.

The details of the theory are not particularly relevant here, for the present purposes. It is more significant to notice that Lewis justified his view by reinterpreting his $\mathrm{PhD}$ supervisor Quine, under whom he studied at Harvard during the 1960s, after spending a year in Oxford in the late 1950s, where he attended lectures by Strawson, among others, and was tutored by Iris Murdoch (Soames 2014; Williamson 2014; Janssen-Lauret and Macbride 2017; Janssen-Lauret 2017; Divers 2017). If, following Quine, to be is to be the value of a variable, then ontological and metaphysical work consists of being committed to the existence of whatever falls, in our best theories, under the range of an existential quantifier: modal discourse is indispensable to our best theories, in particular to quantified modal logic, and Lewis's modal realism is a way to take such discourse at face value, thus committing oneself to the existence of possible worlds (Lewis 1973). A theory has, in Lewis's Quineinspired view, to be ontologically austere: modal realism is qualitatively, if not quantitatively, parsimonious, and this is all we need, since we evaluate how economic a physical theory is not on the basis of the number of particles, but rather on the basis of the number of types entities - particles, forces, fields and so forth — which it postulates (Lewis 1973: 87). Naturalism and extensionalism are further Quinean constraints to satisfy: reducing counterfactuals in terms of possible worlds plus a vague but (according to Lewis) legitimate relation of similarity, and conceiving possible worlds as ordinary concrete objects, Lewis's theory ultimately reduced modal concepts to non-modal notions, thus fully vindicating Quine's program (Lewis 1973; see also Sider 2003).

Soon - within a decade or so - Lewis's modal metaphysics would occupy a central position in the history of analytic philosophy: the number of citations reported at the end of chapter 1 above offers a sufficiently clear indication of this centrality; no doubt Lewis is the most-cited author among analytic philosophers in the last thirty-five years (Buonomo and Petrovich 2018). This does not mean, however, that many - let alone most - analytic metaphysicians accepted the controversial theses of his modal realism. On the contrary, as Lewis himself complained, most of them took towards modal realism an "incredulous stare," a gesture to say that Lewis's theory was too bizarre to be possibly true (Lewis 1986: 133, 135, 165). The centrality of Lewis did not depend on particular substantive theses but rather on his metaphilosophical and methodological influence, as well as on his role in many debates as a touchstone or even a polemical target: Lewis's philosophy became a paradigm case and 
a model of a philosophical activity based on building explanatory, general and substantive theories, characterised by technical sophistication and a realistic spirit. An activity that was rooted in common sense and ordinary language: for example, the point of departure of Lewis's work in Counterfactuals was the common-sense "incontrovertible" claim that things could have been different in countless ways (Lewis 1973). An activity which was, at the same time, capable of being highly speculative, leaving aside the preoccupations deriving from the manifest image of man in the world, in a way similar to that in which contemporary theoretical physics in the twentieth century said farewell to common sense and ordinary language (Williamson 2007: 19).

Here we come close to the main metaphilosophical point, on which Lewis focused explicitly in his influential book On the Plurality of Worlds, published in 1986. He claimed that a good reason to consider true a metaphysical conjecture (such as the hypothesis that there are possible worlds in his sense) is its theoretical fruitfulness (1986: 3). A metaphysical conjecture is not meant to be conclusively verified or falsified; rather, it should be regarded as an "offer you can't refuse" after evaluating its costs and benefits "in theoretical unity and economy" (1986: 4). Under this respect, metaphysics is not different from physics and mathematics: for example, Hilbert accepted the settheoretical universe, calling it a paradise for mathematicians, since "set theories offers the mathematicians great economy of primitives and premises, in return for accepting rather a lot of entities unknown to Homo javanensis" (Lewis 1986: 4); similarly, "as the realm of sets is for mathematicians, so logical space is a paradise for philosophers. We have only to believe in the vast realm of possibilia, and there will find what we need to advance our endeavours" (1986: 4). According to Lewis in both cases the price is right, though the benefits are probably more spectacular in the mathematical parallel. But even if the benefits were not worth the cost ("because they can be had more cheaply elsewhere", 1986: 5), a philosophical methodology was set up: just as in mathematics, ontology is derived by abductive reasoning, the so-called inference to the best explanation, according to which a good, though not conclusive, reason to regard a philosophical theory as true is to consider it the most fruitful account of the available data. The structure of Lewis's book On the Plurality of Worlds - a set of replies to objections addressed to modal realism in order to show that his was the best available explanation — reveals this point clearly (Lewis 1986). Lewis's methodology, which became widely shared among analytic philosophers within the field of metaphysics and beyond, owed several debts to Quine: first, ontological questions were solved by advancing indispensability arguments (Quine 1948), though to a large extent Lewis moved beyond Quine, since he applied the same kind of non-deductive arguments to possible-worlds metaphysics (Williamson 2014); second, even though he accepted a kind of analytic-synthetic distinction (Lewis 1969), Lewis presented a methodologically continuist metaphilosophy, according to which not only are scientific results relevant to the philosophical ones, and vice versa, but philosophy and science (including both 
mathematics and the natural sciences) apply the same kind of cost-benefits analysis.

\subsection{Style and/or Metaphilosophy}

It goes without saying that Lewis's Quine-inspired methodology and metaphilosophy were alien and even hostile to the later Wittgensteinian tradition, which regarded philosophy as a humanistic discipline, whose aims and methods are qualitatively different from those of science. In the next chapter it will be shown how analytic philosophers in "the age of David Lewis" struggled for hegemony in the American academy (Bonino and Tripodi 2019). ${ }^{\mathrm{xi}}$ In what follows — for the sake of a comparison with Lewis, and with the aim of better understanding what was at stake from a methodological and metaphilosophical point of view in analytic philosophy in the 1970s and 1980s - let us redirect our glance to Britain, where the story told in this book began, briefly focusing on the two arguably most authoritative British philosophers in that period: Peter Strawson and Michael Dummett. Strawson was the Waynflete Professor of Metaphysical Philosophy at the University of Oxford from 1968 (after Ryle retired) to 1986; Dummett was the Wykeham Professor of Logic at Oxford from 1979 (when Ayer retired) to 1992. They were both sympathetic to and influenced by the later Wittgensteinian tradition, though it is obvious that they were not old-fashioned linguistic philosophers and that their philosophical style was very different not only from that of the later Wittgenstein but also from that of philosophers such as Winch, Anscombe, Kenny or Hacker.

Since the 1950s and all along his career, Strawson had defended and renovated the later Wittgensteinian tradition: in 1956 he safeguarded the analytic-synthetic "dogma" from the attack of Quine (Grice and Strawson 1956); in 1963 he disputed Carnap on behalf of Wittgenstein, whose grammatical investigations he interpreted in terms of connective analysis (Strawson 1963); when his supervisor Paul Grice told him, "If you cannot put it in symbols it's not worth saying", he retorted: "If you can put it in symbols, it's not worth saying" (O'Grady 2006); last but not least, he made Kant accessible to the ears of analytic philosophers, and this was relevant too, if Putnam in agreement with Cavell was right when he wrote that "for the most part the philosophers who find Wittgenstein's thought difficult to grasp are people who have little time for Immanuel Kant” (Putnam 1997: 193; see also Cavell 1958/1969 and 1962/1969; Strawson 1959 and 1966). ${ }^{x i}$ As is well-known, in 1959 Strawson published Individuals, thus introducing descriptive, as opposed to revisionary, metaphysics. His intended task in the book was to do descriptive metaphysics, which "is content to describe the actual structure of our thought about the world" and is not "concerned with producing a better structure" (Strawson 1959: 9). At the beginning of the essay Strawson emphasised the main similarities and differences between descriptive metaphysics and old-fashioned Oxford linguistic analysis, which is very well-known but deserves to be quoted at length: 
How should it [i.e. descriptive metaphysics] differ from what is called philosophical, or logical, or conceptual analysis? It does not differ in kind of intention, but only in scope and generality. Aiming to lay bare the most general features of our conceptual structure, it can take far less for granted than a more limited and partial conceptual inquiry. Hence, also, a certain difference in method. Up to a point, the reliance upon a close examination of the actual use of words is the best, and indeed the only sure, way in philosophy. But the discriminations we can make, and the connections we can establish, in this way, are not general enough and not far-reaching enough to meet the full metaphysical demand for understanding. For when we ask how we use this or that expression, our answers, however revealing at a certain level, are apt to assume, and not to expose, those general elements of structure which the metaphysician wants revealed. The structure he seeks does not readily display itself on the surface of language, but lies submerged: He must abandon his only sure guide when the guide cannot take him as far as he wishes to go. (Strawson 1959: 9-10)

To the extent in which it resembled connective analysis, descriptive metaphysics greatly differed from traditional, speculative metaphysics, of which Lewis's was a sophisticated variation. This issue has to be handled with the due caution since, as Williamson recently remarked, not only did Lewis in his first work - Convention. A Philosophical Study - tend to accept a form of analytic-synthetic distinction, much to his supervisor's regret (Lewis 1969; Quine 1969a), not only did he frequently go metalinguistic, but at the same time Strawson "was quite willing to speak in a ground-level metaphysical idiom" (Williamson 2014: 10; see also e.g. Strawson 1959: 103). Nevertheless, this is not enough to obliterate the differences: as Williamson himself stressed, Strawson "was more prone than Lewis to characterise philosophical questions as questions about words or concepts" (Williamson 2014: 9). The essential difference is that instead of purporting to delineate the ultimate structure of the world, Strawson's descriptive metaphysics - as an evolved version of old-style connective analysis - investigated the connections between the fundamental concepts we use to talk about ourselves and the world, in a nutshell, our conceptual scheme. Its ultimate aim was to describe and clarify such concepts, rather than explain and discover substantive truths (Hacker 2003: 49).

On the other hand, however, Strawson's descriptive metaphysics shared important features with Lewis's substantive metaphysics: abstraction, generality and systematicity. Descriptive metaphysics investigates concepts that are highly general, and they are general qua categorial, since they subsume specific concepts under them. Such concepts are also irreducible, basic and, in a special sense, non- 
contingent: examples of such concepts are material object, property, relation, causation, space and time (Hacker 2003: 54). Not only does descriptive metaphysics describe such general concepts; it systemises them.

Strawson paid his metaphilosophical debts towards Wittgenstein when he wrote:

If I share anyone's conception of what our general philosophical aim or objective should be, it is, if I have understood him correctly, that of Wittgenstein, at least in his later period. That is, our essential, if not our only, business is to get a clear view of our most general working concepts or types of concept and of their place in our lives. We should, in short, be aiming at general human conceptual self-understanding. (Strawson 2003: 12)

However, at the same time Strawson was aware that his intent to obtain an abstract, general and systematic theory of how our conceptual scheme works moved him away from Wittgenstein. In particular, while acknowledging that Wittgenstein devoted his genius and formidable powers to liberate ourselves from false understanding, tearing away "the veil of simple seductive illusions or pictures that pervaded or constituted much existing philosophical theory and that prevented us from seeing clearly," he also wrote:

But I must add, as I think, that his [Wittgenstein's] almost obsessive anxiety to liberate us from false pictures, from the myths and fictions of philosophical theory, led to a certain loss of balance in his thinking. It did so in two ways. First, it led to a distrust of systematic theorizing in general and hence to a disregard of the possibility, indeed, to my mind, the fact, that the most general concepts and categories of human thought do form in their connections and interdependencies an articulated structure that it is possible to describe without falsification. Indeed, what I tried to show in my work on Kant is that the first Critique contains, besides much else that is more questionable, the general outline of many essential features of just such a description. (Strawson 2003: 12) $)^{\mathrm{xi}}$

So there were two different tendencies in Strawson's descriptive metaphysics. One was a search for generality and systematicity, which moved it away from Wittgenstein-inspired connective analysis, resembling Lewis's metaphysics instead. The other was the conception of philosophy as a peculiarly conceptual enterprise, whose aim is to describe our conceptual scheme, rather than the intrinsic nature 
of things in the world; this tendency made Strawson's work belong to the Wittgenstein-inspired tradition of conceptual analysis, rather than to the tradition of speculative metaphysics. Putting special emphasis on the latter aspect, Hacker once remarked that Strawson's "descriptive metaphysics preserves only the letter but not the spirit of traditional metaphysics" (Glock 2003a: 2; Hacker 2003). Hacker's evaluation is correct: there is no doubt that Strawson regarded descriptive metaphysics as a conceptual enquiry rather than a substantive theory. For the present purposes, however, the very idea of preserving the letter of traditional metaphysics while rejecting its spirit requires further attention. Should the former expression, 'preserving the letter,' be interpreted as suggesting that Strawson was ready to accept something like Lewis's metaphilosophy, according to which philosophical theories are confirmed or disconfirmed on the basis of a cost-benefits analysis, as it happens in mathematics and the natural sciences? No, it does not. Rather, it may be interpreted as saying that Strawson's philosophical style — not his metaphilosophy — was similar to that of Lewis. There were of course several differences between Strawson's and Lewis's literary styles; the analysis of such differences goes far beyond the scope of this chapter. However, Strawson's and Lewis's writings had many "stylistic" similarities, in the philosophical rather than in the literary sense: they both built highly abstract, general and systematic theories; they both provided philosophical arguments; both of them sometimes went metalinguistic, introducing primitive concepts and describing complex ones, but other times they remained at the ground level of metaphysical discourse. In other words, whatever their literary style, Strawson and Lewis had a similar philosophical style; yet, they had a different metaphilosophy: one interpreted his philosophical theories as conceptual descriptions, the other as substantive explanations. ${ }^{\text {xi }}$ To see more clearly how that was possible, let us briefly focus on the figure of Dummett.

Dummett was neither a pupil nor an orthodox follower of Wittgenstein; he was supervised by Urmson and arguably his main source of inspiration was Frege. However, he was under the influence of Anscombe and Geach, and his philosophy was sprinkled with several Wittgensteinian insights. This is true first of all of his reconceptualisation of the metaphysical problem of realism in semantic terms (Dummett 1963/1978). Dummett interpreted realism as a thesis that depends on the validity of the principle of bivalence for a controversial class of propositions (arithmetic statements, statements about the past or the future, etc.) or, more precisely, as the claim according to which a statement belonging to one of such controversial classes is true or false independently from the evidence that is available even in principle (Dummett 1959); therefore realism is directly connected to a view of meaning based on transcendent truth-conditions (Dummett 1959; 1963/1978). According to Dummett, if one adopted an alternative theory of meaning based on assertibility conditions, one could defend antirealism in several fields: the philosophy of mathematics, the metaphysics of the past and the future, and so forth. This theory of meaning had to be a theory of understanding that satisfies two 
constraints: the acquisition requirement and the manifestability requirement (Dummett 1959 and 1975). Dummett's programme for an antirealist semantics borrowed many insights from Wittgenstein: the connection between meaning, understanding and use; the emphasis on the public (manifest) nature of language; the view of linguistic understanding as an ability, rather than as a form of propositional knowledge; the constitutive relation between the justification of a statement and its sense; the attention-shift from truth to the criteria of truth; the constructivist challenge to platonism in the philosophy of mathematics (Dummett 1975b and 1991).

However, like Strawson, Dummett distanced himself from Wittgenstein's metaphilosophy. He once said that after the Investigations where published, he was deeply impressed, and for some time he regarded himself — "no doubt wrongly" — as a Wittgensteinian (Dummett 1993: 169). In the preface to The Logical Basis of Metaphysics he confessed that he was aware "how antiWittgensteinian" his semantic programme was. And he commented:

\footnotetext{
We all stand, or should stand, in the shadow of Wittgenstein, in the same way that much earlier generations once stood in the shadow of Kant; and one of my complaints about many contemporary American philosophers is that they appear never to have read Wittgenstein. Some things in his philosophy, however, I cannot see any reason for accepting: and one is the belief that philosophy, as such, must never criticise but only describe. This belief was fundamental in the sense that it determined the whole manner in which, in his later writings, he discussed philosophical problems; not sharing it, I could not respect his work as I do if I regarded his arguments and insights as depending on the truth of that belief. (Dummett 1991: xi)
}

Dummett felt the need to distance himself from Wittgenstein even more radically than Strawson did before. Not only did Dummett aim to build a general and systematic theory of meaning, considering a "disadvantage" in Wittgenstein's approach "the relatively unsystematic character of his discussions" (1991: 306); not only did he state that ordinary language is not sacrosanct; but he was also convinced that his theory of meaning could not succeed without a certain amount of technical, especially logical, sophistication; actually, he said the same not only for the theory of meaning but, more generally, for analytic philosophy, to which he fully and wittingly belonged, being indeed one of those who most contributed to its "creation" as a historically well-defined phenomenon (Dummett 1994). ${ }^{\mathrm{xi}}$ For example, in the Introduction to The Logical Basis of Metaphysics he wrote:

Philosophy is, after all, a craft, as is plumbing. Many years ago a plumber 
who had come to our house to make some urgent repair which my wife had vainly attempted herself said to me, 'You don't want to go at it bald-headed, like your good lady here'. Philosophy would interest me much less if I did not think it possible for us eventually to attain generally agreed answers to the great metaphysical questions; but I should not have written this book unless I also thought that we should do better not to go at them bald-headed (Dummett 1991, 19)

So Dummett came to abandon also the penultimate Wittgenstein-inspired metaphilosophical commandment for a conception of philosophy as insubstantial qua conceptual. The metaphysical questions Dummett was interested in were traditional questions such as "Do we have free will? Can the soul, or the mind, exist apart from the body? How can we tell what is right and what is wrong? Is there any right and wrong, or do we just make it up? Could we know the future or affect the past? Is there a God?" (Dummett 1991: 1). He was convinced that, under the influence of Wittgenstein, analytic philosophy recently passed through "a destructive phase," during which "it appeared as though demolition was the principal legitimate task of philosophy." Dummett pointed out:

Now most of us believe once more that philosophy has a constructive task; but, so thoroughly was the demolition accomplished, that the rebuilding is of necessity slow... Although we no longer regard the traditional questions of philosophy as pseudo-questions to which no meaningful answer can be given, we have not returned to the belief that a priori reasoning can afford us substantive knowledge of fundamental features of the world. Philosophy can take us no further than enabling us to command a clear view of the concepts by means of which we think about the world, and, by so doing, to attain a firmer grasp of the way we represent the world in our thought. It is for this reason and in this sense that philosophy is about the world. (Dummett 1991: 1)

Now, what has been noticed above about Strawson's philosophical style — that is, its being very similar to that of Lewis, notwithstanding the ultimate metaphilosophical differences between them - is even more evident in the case of Dummett: if, as Dummett held, philosophy aims to provide by pure reflection a technically sophisticated and systematic description of the most general and structural features of reality (Glock 2008b: 128), arguably no differences at all were left between Dummett's and, say, Lewis's philosophical style; Dummett filled the last gap dividing the style of 
Lewis from the style of Strawson. ${ }^{x i}$ This is very significant because philosophical style is like history: it is written by winners. The decline of the later Wittgensteinian tradition in the history of late analytic philosophy is perhaps condensed here, in the science-oriented, rather than humanities-oriented philosophical style of the two most authoritative Wittgenstein-inspired philosophers in Britain in the 1970s and 1980s. ${ }^{\text {xi }}$

It has been suggested above that Dummett's claim that philosophy, qua general and systematic, is a substantial enterprise can be regarded as his abandonment of the penultimate Wittgenstein-inspired metaphilosophical commandment. Why 'penultimate'? Because after all, on the basis of a Wittgenstein-inspired theory of meaning, Dummett kept on regarding philosophy as a peculiarly conceptual inquiry and logic as a metalinguistic investigation, for example about the meaning of the logical constants; and also because he labelled philosophical problems 'substantive,' but nonetheless he did not mean to say that their solution depended on the existence of independent facts of the matter beyond our linguistic or conceptual frameworks. For these reasons - notwithstanding the kind of positive, systematic and general theory that he presented in his philosophy of language, or, in other words, notwithstanding his Lewis-like or science-like philosophical style — Dummett rejected the main methodological ideas behind Lewis's metaphilosophy. At the end of the 1970s, during a conversation with his $\mathrm{PhD}$ student Williamson (a full-blooded Lewisian, from a methodological point of view), he declared: "The difference between us is that you think that inference to the best explanation is a legitimate method of argument in philosophy, and I don't" (Williamson 2014: 25). As Williamson later explained, Dummett held that the issue of whether a putative metaphysical explanation is meaningful or not must be settled first before we can judge their value and explanatory import. But once the intelligibility issue has been settled, nothing much is left for inference to the best explanation to do (Williamson 2014: 25). Not only was Dummett's characterisation of the difference right, but he had a certain clairvoyance. The point of divergence on which he focussed would emerge again less than two decades later with the publication in 2007 of The Philosophy of Philosophy by Williamson: the philosopher who, after the period in which the Chair had been held by David Wiggins, have since 2000 become the Wykeham Professor of Logic at Oxford.

\subsection{Philosophy at Face Value}

Roughly, the aim of Williamson's 2007 book was twofold. First, to improve on "the usual stories about the history of twentieth-century philosophy" by providing an accurate and updated description of the methodological and metaphilosophical features of "the liveliest, exactest, and most creative achievements of the final third of that century: the revival of metaphysical theorising, realist in spirit, often speculative, sometimes common-sensical, associated with Saul Kripke, David Lewis, Kit Fine, 
Peter van Inwagen, David Armstrong and many others: work that has, to cite just an example, made it anachronistic to dismiss essentialism as anachronistic" (Williamson 2007: 19). Second, in a more "prescriptive" part of the book, to provide compelling arguments to defend this updated picture. He deliberately omitted a sustained discussion of Wittgenstein's view ("I wanted to address the situation of philosophy now, not fifty years ago"); nonetheless, as he himself recently acknowledged, some anti-Wittgensteinian arguments were implicit in the book (Williamson 2011: 130, 132, 133).

Preliminarily, Williamson made it explicit that he found Quine's arguments to the effect that "a boundary between analytic and synthetic statements simply has not been drawn" (Quine 1951b: 34) much less compelling than they once appeared, especially because he did not feel special qualms in using the term 'synonymous'; therefore he was convinced that any objection to analyticity "can hardly be based on Quine's arguments, since his only objection to defining 'analytic' in terms of 'synonymous' is to the use of 'synonymous"' (Williamson 2007: 50-51; see also Quine 1951b: 24, 35). According to Williamson, the reason why 'analytic' in contemporary philosophy "carries obsolescent philosophical baggage" has to do more with Kripke than with Quine, since Kripke showed that 'analytic' can no longer have the central role that it used to have in the work of Carnap, Wittgenstein and Strawson: "“Analytic' does neither the purely epistemological role of 'a priori' nor the purely metaphysical work of 'necessary"' (Williamson 2007: 51; see also Williamson 2011: 133).

However, Williamson clearly thought that an explicit and eventually compelling antiWittgensteinian argument was required. Whatever role had been left for conceptual truth after Quine and Kripke, he argued, it does not justify the Wittgenstein-inspired picture of philosophy as an $a$ priori enterprise, whose main statements are conceptual, hence insubstantial. To this effect, he defined conceptual sentences in terms of what he called 'epistemological analyticity': failure to assent to an epistemologically analytic sentence is constitutive of (at least partial) failure to understand at least one word occurring in it (Williamson 2007: 73; see also Tripodi 2011: 103). Then he gave counterexamples to epistemological analyticity, with the aim of illustrating "the point that even basic disagreement in logic is compatible with shared meanings" (Williamson 2011: 133). In particular, he described Peter, a competent native speaker of English, who is not disposed to assent to the logical truth 'Every vixen is a vixen' (Williamson 2007: 85 and ff.). Peter has a certain logical insight, according to which the sentence 'Every vixen is a vixen' presupposes that there is at least one vixen. He also holds the belief that there are no foxes, and never have been any: the apparent evidence to the contrary is caused by widespread fox-hallucinations organised by MI6. Based on both his deviant logical theory and his conspiracy theory, Peter does not accept 'Every vixen is a vixen,' though he has a full understanding of the words occurring in it. Stephen is a competent native speaker of English with some worries about vagueness. If asked to provide a semantic assessment of 'Every vixen is a vixen,' Stephen's immediate reaction is 'What about borderline cases?' On reflection, he believes that 
borderline cases for vague terms create truth-value gaps. Furthermore, Stephen believes that some clearly female evolutionary ancestors of foxes are borderline cases for 'fox' and consequently for 'vixen'. Therefore he does not assent to 'Every vixen is a vixen' (he is agnostic about that), but he has a full understanding of it. Williamson's point is clear enough: Peter's and Stephen's refusing to accept that simple logical truth is not the result of deviant, partial or different understanding, but rather the consequence of a genuine philosophical doubt. Moreover, "since there clearly could have been, and perhaps are, people such as Peter and Stephen, we have counterexamples to epistemological analyticity" (Williamson 2007: 91). Then he concluded: as the possible cases of Peter and Stephen show, not even the most elementary case possible of an analytic truth is epistemologically analytic; hence, no sentence at all is epistemologically analytic. In particular, no theses of philosophy are insubstantial by virtue of their being epistemologically analytic.

Williamson's arguments had been widely discussed and criticised and a detailed discussion cannot be attempted here. ${ }^{\mathrm{xi}}$ For the purposes of the present historical investigation, however, the following comments are worth making. First of all, seeing from outside the great success of The Philosophy of Philosophy and, indeed, its very publication are extremely relevant for the understanding of the historical-philosophical topic addressed in this book (Williamson 2007). No matter whether Williamson at last really found the decisive reasons against the later Wittgensteinian tradition, there is little doubt that his arguments — for obvious chronological reasons - could not have been the historically real causes of the decline. ${ }^{x i}$ It is noteworthy, however, that in 2007, at a time when the decline of the later Wittgensteinian tradition had already happened, in the arguably most authoritative and influential metaphilosophical work published in the last two decades in the analytic tradition, the author felt the need to provide new and eventually compelling arguments against Wittgenstein's metaphilosophy. This very fact - as well as the considerable success of the book in the analytic community - may be interpreted as an indirect confirmation of one of the main claims defended in this book: that in the history of analytic philosophy the later Wittgensteinian tradition was not “defeated" by mere arguments.

Moreover, arguably two central assumptions in Williamson's arguments against epistemological analyticity are Quine's confirmation holism, according to which "no given argument or statement is immune from rejection by a linguistically competent speaker" (Williamson 2007: 97), and Putnam's and Burge's semantic externalism, according to which understanding depends on participating in a social practice, rather than accepting a linguistic rule (Putnam 1975, Burge 1979; see also Williamson 2007: 91). ${ }^{x i}$ This suggests a last comment. As hinted above, Kripke's "discovery" of a posteriori necessity rehabilitated the notion of necessary facts, making room for substantial philosophical theorising. Then the space created by Kripke was occupied by Lewis's metaphysics, based on abductive reasoning. However, the passage from Kripke to Lewis relied on an underlying assumption: 
that Lewis's science-oriented methodology was applicable universally or at least in many philosophically interesting cases, not only to study the facts known a posteriori by the natural scientists, in which substance and natural kind names were involved, that is (in other words, not only in the cases that were most favourable to a Kripke-style treatment, such as for example ' $\mathrm{Salt}=\mathrm{NaCl}^{\prime}$ ). Williamson's anti-exceptionalist metaphilosophy put the finger on this very point. In his view, philosophically interesting questions about, say, knowledge, meaning or justice are never merely about the concepts of knowledge, meaning or justice (2007: 77); rather, they should always be taken at face value $(2007: 23,31)$. This seems to suggest that they should always be treated scientifically, as we treat, say, salt, water or cats. In other words, if knowledge is like salt, meaning like water and justice like cats, we could investigate and hopefully discover their essence. Philosophy is nothing but metaphysics, and metaphysics in turn coincides with science: same method (inference to the best explanation), same purposes ("to acquire, in the long run, some sort of knowledge of how things are") (Williamson 2010: 17).

One thing that a reader of The Philosophy of Philosophy can perhaps notice is that at a certain point Williamson no longer argues for his methodological and metaphilosophical preferences; he takes it to be enough to refute the theories of meaning on which philosophical exceptionalism, including Wittgensteinian exceptionalism, is based. Therefore his ultimate move seems to be that of shifting the burden of proof to his exceptionalist opponents: it is up to you, he seems to argue, proving that knowledge is not quite like salt, that meaning is not quite like water and that justice is not quite like cats, so that we should not investigate them as if they were substances or natural kinds whose essence we want to discover by working scientifically. It may be controversial whether this step is legitimate or not. However, the story of the decline of the later Wittgensteinian tradition reconstructed in this book, which is part of the wider history of the loss of centrality of the humanities in the postWWII cultural context, in the US first and consequently also in the UK, may help one understand why many philosophers, especially in the analytic community but also beyond, find that move rather natural.

A related controversial issue concerns the restrictions that a scientifically oriented and long run perspective might put on the choice of topics. In a reply to Adrian Moore's 2009 review, Williamson directly considered "an alternative way of doing philosophy to the one urged in The Philosophy of Philosophy: more humanistic, concerned to preserve unsystematic insights, respectful of the complexities of actual life and language, sensitive to deep differences in conversational and historical context." And he commented: "When one examines his text more closely, however, one finds that its unsystematic, unscientific air depends not on avoiding theoretical commitments but on avoiding making good on them. This is particularly clear in his repeated invocation of unspecified rules. If he were to state the content of the supposed rules, and provide some evidence that they are really in 
force, his claims would then be open to testing and challenge of kinds that only the evasiveness of his presentation now protects them from. He would become embroiled in just the kind of 'scientific' discourse he shuns" (Williamson 2009: 135). The historical analysis of the new rigourism in the humanities provided in chapter 4 above seems to pose a problem — or at lest a question — to such a perspective, suggesting with Keynes and Wittgenstein that in some cases, in the short run in which we live, we are not able to apply scientific and systematic theorising — and its rigid and fully explicit rules - to a philosophical, cultural, social and economic "material which is itself much too vague to support such treatment" (Keynes 1978, vol. XIV: 379; see also Wittgenstein 1964/1975). Arguably, in such cases the alternative - in practice, if not in principle - is not between treating the material scientifically or investigating it humanistically, but rather between going humanistically and changing topic, taking into account a less complex and vague material; yet in some cases, for example in economics, the topic change may not be without consequences.

\section{Notes}

${ }^{x i}$ For different interpretations see for example Conant (1991), Putnam (1994), Forster (2004).

${ }^{\mathrm{xi}}$ As is well-known, during the 1940s Ruth Barcan Marcus anticipated some of these results in her pioneering studies (Barcan Marcus 1946 and 1947).

${ }^{\mathrm{xi}}$ There might be some interest in the fact that among the misleading pictures of naming in Naming and Necessity Kripke briefly discussed Wittgenstein's considerations on the name 'Moses' in the Investigations (Kripke 1972/1980: 31; Wittgenstein 1953: § 79).

${ }^{x i}$ On the overall sense of the expression 'the age of David Lewis' see the Introduction to Bonino and Tripodi (2018b) and also Eric Schliesser's comments in his blog: https://digressionsnimpressions.typepad.com/digressionsimpressions/2016/05/on-late-analytic-philosophy-or-the-age-of-david-lewis.html (Schliesser 2016). It is also worth recalling that at the University of Manchester Helen Beebee and Fraser Macbride are guiding a research project devoted to this issue: The Age of Metaphysical Revolution. David Lewis and His Place in the History of Analytic Philosophy (http://www.projects.socialsciences.manchester.ac.uk/lewis/).

${ }^{x i}$ More precisely, while many American analytic philosophers had low familiarity with Kant, in Britain Kant was studied as a historical subject (Glock 2003a; see also Körner 1955, Bennett 1966).

${ }^{x i}$ Strawson also suggested that Wittgenstein's anxiety to liberate us from false theories and his obsessive mission to destroy the "houses of cards" led Wittgenstein "to minimise or dismiss, or at least give too little acknowledgement to, some pervasive features of our experience and of our ordinary non-philosophical thought": in particular, "the reality of subjective experience in all its richness and complexity", and "the inescapable presence in our thought of abstract intensional objects" (Strawson 2003: 12).

${ }^{\mathrm{xi}}$ This is the second or third time this book has drawn a distinction between philosophical style and metaphilosophy. In particular, please see the considerations on the reception of Gellner's Words and Things in chapter 2 above. In that case, however, what was at stake was, first and foremost, Gellner's literary style or, if you like, the literary genre of Words and Things.

${ }^{x i}$ It is interesting to read how Lynd Forguson in her 'Oxford and the "Epidemic" of Ordinary Language Philosophy' described Dummett: “Among those who had disapproved of Austin's influence at Oxford was Michael Dummett, who looked to Frege for philosophical inspiration, and who was much more interested in the developments in the more formal, systematic analytic philosophy then being produced in the United States than he ever was in the concerns of the Oxford linguistic philosophers" (Forguson 2001: 340).

${ }^{\mathrm{xi}}$ Notice that in the 1970s Davidson visited Oxford many times, spending in particular an entire academic year in Oxford in 1973-1974. He presented his programme for the construction of a theory of meaning, which he regarded as a philosophical and semantic parallel of Chomsky's generative linguistics. He often confronted Dummett and they gave joint seminars (Davidson1999). Incidentally, in the late 1980s most of Oxford philosophers who took part in the debate over the theory of meaning favoured Davidson. However, they did not interpret the discussion as a metaphilosophical, let alone 
a stylistic one (Davidson 1984). More generally, as Williamson once recalled, "most Oxford philosophers hoped to avoid his [Dummett's] anti-realism. Indeed, many of them spent their time struggling desperately to do so. Yet they felt it always there, ready to engulf them if they made one false move. They tried to beat Dummett at his own game, perhaps with one or two changes in the rules" (Williamson 2018: 154)

${ }^{\mathrm{xi}}$ Another leading analytic philosopher who contributed to keep the name of philosophical theorising high, without being a metaphysician, was John Rawls. His awareness of the Wittgensteinian a-theoretical and anti-theoretical views depended on his confrontation with Dreben at Harvard. According to Dreben, there are no theories in philosophy, and this is why metaphysics is nonsense. As Rawls once explained: "One thing he [Dreben] means is that philosophical arguments rest on premises, or taking certain things as given - on 'data,' as he often says... Burt would not, of course, deny the plain fact that philosophers make many complicated arguments. But he thinks that at bottom there are no arguments one philosopher can use to convince another of a metaphysical point. At the basic level, philosophers simply rely on and appeal to different "data." It is a standoff with no resolution by argument. Burt has said that Quine is a metaphysician, a metaphysician of science. By that he means that Quine does not argue for physicalism, or scientific realism. He assumes it and works out his view from there. There is no theory of truth, no theory of meaning, no theory of knowledge, no theory of perception, and the rest, despite centuries of philosophers discussing these things....[T]he theory of quantification is a theory, but he stresses that it is a theory in logic and mathematics. It is not philosophy, which has to do with understanding and should lead to that" (Rawls, 2001: 419, 421-422).

${ }^{x i}$ See for example Schröder (2009); Wikforss (2009); Moore (2009); Kornblith (2009); Boghossian (2011); Horwich (2011); Marconi (2011); Tripodi (2011).

${ }^{x i}$ Williamson is not the only leading philosopher in Oxford who recently felt the need to deal with issues coming from the past of linguistic philosophy: Ofra Magidor is the Waynflete Professor of Metaphysical Philosophy at the University of Oxford; her Category Mistakes is a further example of the same kind of work (Magidor 2013).

${ }^{\mathrm{xi}}$ Williamson makes a subtle qualification: "But neither epistemological holism nor semantic externalism figured as premises of the argument. Rather, the argument appealed to features of the relevant systems of belief that make epistemological holism plausible, and to features of our ascription of beliefs that make semantic externalism plausible" (Willliamson 2007: 91) 


\section{Concluding Remarks. The Last Decades}

The starting point of the present book was a fact to be explained: the decline of Wittgenstein in the history of analytic philosophy. In the 1950s Oxford and to a lesser extent Cambridge were the mecca of analytic philosophy, and the influence of Wittgenstein was pervasive. During that period, most Oxbridge philosophers shared a body of views and attitudes stemming from Wittgenstein's teaching. In particular, most of them were convinced that science and philosophy lay on different levels and have different aims and methods. The British scenario made it reasonable to suppose that the Wittgensteinian paradigm was about to have a similar impact on the philosophical landscape of all English-speaking countries, including the United States. However, things went on differently, so that the later Wittgensteinian tradition — not only its assumptions and methods but also its purposes and philosophical style — has been largely forgotten or rejected by present-day analytic philosophers.

\subsection{A Synopsis}

To set the stage for the required explanation, the book has preliminarily focused on the earliest attacks against the later Wittgensteinian tradition, which were part of the intellectual war between the London School of Economics and the Universities of Oxford and Cambridge. The main characters of this story were Popper, Watkins and, above all, Ernest Gellner, the author of Words and Things, published in 1959. Gellner's philosophical and sociological critique of Oxford linguistic philosophy was influential. He addressed issues such as the hostility of linguistic philosophy towards science, its opposition to philosophical progress, its naif use of paradigm case arguments and its sacred devotion to ordinary language, its relativism and, above all, its trivialisation of the task of philosophy. Yet, it would be an overstatement to suppose that the decline of Wittgenstein in the history of analytic philosophy depended on Gellner's impact. Not only did most Anglo-American analytic philosophers react with hostility towards Words and Things, mainly because of its non-academic style; but it is also worth noticing that Gellner (as well as Watkins and Popper) taught in London and criticised Oxford philosophy, while from a geopolitic, economic, and even philosophic point of view the centre of the world had moved, and Britain had irremediably become more peripheral, with respect to the United States. Accordingly, a lesson that can be drawn from this early story is that the explanation of the decline of Wittgenstein has to be searched for, first of all, in the United States, the core country, within the analytic philosophical community (interpreting the meaning of 'analytic,' at least as a first step, in terms of a recognisable philosophical style).

The most remote but still significant reason for the decline of Wittgenstein is that American philosophy was for a long time, as it were, a-Wittgensteinian, lacking acquaintance with Wittgenstein's thought, early and late. The early reception of Wittgenstein's philosophy in the United 
States was characterised by incomplete and distorted understanding or, more precisely, by its confusion with logical positivism, and Carnap's philosophy in particular. In the present book this has been shown by providing some data concerning the articles published in The Journal of Philosophy and The Philosophical Review between the 1920s and 1950s. The confusion between Wittgenstein and Carnap was partly justified: Wittgenstein and Carnap had similar semantic views, based on the notions of grammar and syntax, respectively, and a similar account of a priori statements; they both rejected platonism in the philosophy of mathematics and, perhaps more importantly, they agreed that natural science is a substantive theory, which aims to discover new facts, whereas philosophy operates a priori, aiming to obtain conceptual clarity. On the other hand, there were also deep differences between them. From a broadly cultural point of view, Wittgenstein was a strenuous advocate of the autonomy of humanistic understanding, including philosophical understanding, whereas Carnap defended a scientific conception of man and the world, and to a certain extent he was involved in the unity of science project; moreover, Carnap didn't share entirely Wittgenstein's concerns with non-empirically verifiable theories, be them scientific or philosophical. On the whole, taking into account the similarities and differences between Wittgenstein and Carnap, it seems reasonable to conclude that the confusion between them had negative consequences for the early reception of Wittgenstein in the United States, mainly because in the same period Carnap found himself under the fire of Quine. In particular, Quine pushed philosophy towards methodological naturalism, the view according to which science and philosophy are continuous with each other, for any statement of the former can be relevant to the latter, and vice versa. Methodological naturalism was at odds with the metaphilosophical views held not only by Carnap but also by Wittgenstein and the entire later Wittgensteinian tradition.

Arguably, in the 1950s and 1960s there were grounds to claim that Quine's attack on Carnap's analytic-synthetic distinction could not be automatically applied to Wittgenstein's grammaticalempirical distinction. However, with very few exceptions, the Wittgensteinians did not provide a commensurate response to Quine. Perhaps they were not fully aware of the historically objective conditions that made Quine's attack so successful and epoch-making, so as to indirectly weaken the Wittgensteinian tradition, which was not Quine's direct polemical target. After the second world war in the United States, during a huge expansion of higher education, the style and methods of the humanities and the social sciences were modelled on the natural sciences. In chapter 4 above this process - the so-called new rigourism in the human sciences - has been presented by comparing the rise of analytic philosophy in America in the hands of Quine with the transformation of economics in the hands of Paul Samuelson and his neoclassical colleagues. This may be seen as the central chapter of this book. Standing out among the explanatory factors of the decline of Wittgenstein is the contrast between Wittgenstein's later philosophical style - firmly anchored in the humanistic camp, 
in the old, non-rigourist and non-scientifically oriented sense of the term — and the style and methods of analytic philosophy.

The period 1951-1970 was also characterised by the "advent" of the later Wittgenstein in the United States, thanks to well-informed authors such as for example Sellars and Cavell. However, in the context of the new rigourism in the humanities, analytic philosophers reacted with hostility. The book focuses on three main episodes or groups of episodes: Putnam's 1962 attack on Malcolm's grammatical investigation of dreaming; Davidson's 1963 criticism of Wittgenstein's view that reasons cannot be causes; and a variety of critiques of the later Wittgensteinian view of mind (in particular, the book briefly examines the fall of behaviourism and the rise of cognitive science, discussing Fodor's critique of Wittgenstein's private language argument and the later debate between Chomsky and the Wittgensteinians on knowledge of language). In most, if not all, cases, the science-philosophy divide was questioned, and it clearly emerged that the "dark side" of the later Wittgensteinian tradition was widely identified with its non-scientific nature. Some of the anti-Wittgensteinian arguments presented by American analytic philosophers, such as for example Putnam's, were relatively solid (though perhaps not perfectly targeted); others, such as Fodor's, were based on a misleading interpretation of Wittgenstein; yet others, such as Davidson's, depended on terminological, rather than substantial, divergences. Most of these arguments, if not all of them, are better interpreted as expressions of the just mentioned new rigourism in the humanities - a sociocultural process that to a large extent was objectively hostile to the later Wittgensteinian tradition rather than as refutations of Wittgenstein's later philosophy. Arguably, this may raise some doubts on one of the founding myths of analytic philosophy, namely, the idea that analytic philosophy constitutively proceeds by proofs and refutations.

A further point concerned Wittgenstein's view of necessary statements as grammatical rules in disguise, and his arguments against the very notion of necessary fact. In the Quinean, science-oriented philosophical scenario of the 1970s and early 1980s, Kripke's rehabilitation of necessary facts created a new space, which was promptly occupied by David Lewis and his methodologically continuist metaphilosophy. In the book the work of Lewis has been compared with that of the two arguably most authoritative British philosophers during the same period, Strawson and Dummett, both deeply influenced by Wittgenstein. Significantly, there is a strong similarity in philosophical style between Lewis, the metaphysician, and Strawson and Dummett, the Wittgenstein-inspired conceptual analysts. More precisely: all of them built general and systematic philosophical theories; Lewis and Dummett shared, in addition, the use of logically sophisticated tools. Identity of style doesn't entail full metaphilosophical and methodological agreement, especially in presence of a disagreement on the theory of meaning; nonetheless, it is a clear sign of the analytic hegemony and the decline of Wittgenstein (arguably, philosophical style matters for the explanation of the decline of Wittgenstein 
more than specific arguments and views about modalities and metaphysics).

\subsection{The Wittgensteinian Field}

In the early 1980s the decline of the later Wittgensteinian tradition was already apparent: for example, as emphasised in chapter 1 of this book, in the period 1986-2015 Wittgenstein occupied the $63^{\text {rd }}$ position in the ranking of the most cited authors in analytic philosophy journals (Buonomo and Petrovich 2018: 166). Thus, it is natural to wonder: What happened in the last decades? The first thing to be noticed is that, even after the decline happened, Anglo-American academic culture has experienced, as it were, a sort of rediscovery of various forms of philosophy somewhat inspired by Wittgenstein's later thought. An accurate picture of the heterogeneous ways in which AngloAmerican philosophers have been Wittgensteinian in the last thirty-five years or so (especially in epistemology, in the philosophy of language and mind, or from a stylistic and methodological point of view) falls outside the limits of this book. However, as a possible guide for future work, some data taken from the Web of Science are worth consideration (https://apps.webofknowledge.com).

The analysis of the citation indexes that are included in the Web of Science dataset allows a focus on the presence and role of the later Wittgenstein, rather than of Wittgenstein in general, in recent Anglo-American philosophy. Within the Web of Science Core Collection three citation indexes are selected in the period 1986-2015: Arts \& Humanities Citation Index (A\&HCI), Conference Proceedings Citation Index - Social Science \& Humanities (CPCI-SSH), and Book Citation Index Social Sciences \& Humanities (BKCI-SSH). In this dataset there are approximately 2350 articles belonging to the fields "Philosophy", "Ethics", "Logic" or "History and Philosophy of Science," in which Wittgenstein's Philosophical Investigations are cited (Wittgenstein 1953). Co-citation analysis is applied to this corpus by using the open source software tool VOSviewer (www.vosviewer.com; van Eck and Waltman 2010 and 2014). Co-citation analysis measures the similarity between two documents by calculating the number of times in which they are cited together in the references of all documents belonging to a given corpus (Small 1973 and 1999). In the present case, the given dataset is the just mentioned 'humanistic' sub-corpus of Web of Science, in which the Investigations are cited. Co-citation analysis indicates the number of times in which the works are cited together with the Investigations within the given corpus. For the sake of simplicity, only documents having at least 30 citations are taken into account. Arguably, co-citation analysis can serve as a proxy to measure the "areas of influence" of Wittgenstein's Investigations or, perhaps more precisely, its "areas of interest" in the considered period. Using VOSviewer, the results of co-citation analysis can be visualised on a map, as in figures 1 below. The size of an item's label and circle depends on the strength of the item, i.e., the number of times in which this document is cited together with the Investigations. The distance between two documents in the visualisation approximately indicates the 
relatedness of the documents in terms of co-citation links, where a co-citation link is a link between two items that are both cited by the same document (van Eck and Waltman 2019: 26). On the basis on the co-citation strength among the documents, the software makes some co-citation patterns emerge (in the form of coloured clusters). This is an unsupervised, data-driven and bottom-up process, which depends only on the data and algorithms. However, clusters in themselves have no meaning; when possible, they are recognised and labelled by an interpreter. Since, as is obvious, the Investigations themselves are by far the work that is most frequently cited together with the Investigations, the item 'Philosophical Investigations' has been removed manually from the map.

In the considered period - 1986-2015 - the Cited reference search tool of Web of Science individuates 2354 articles and 48104 co-cited references, 60 of which have at least 30 citations. ${ }^{\text {xi }}$ Figure 1 below visualises the results of co-citation analysis on a map.

Figure 1. Wittgenstein's Investigations: co-citation map (1986-2015)

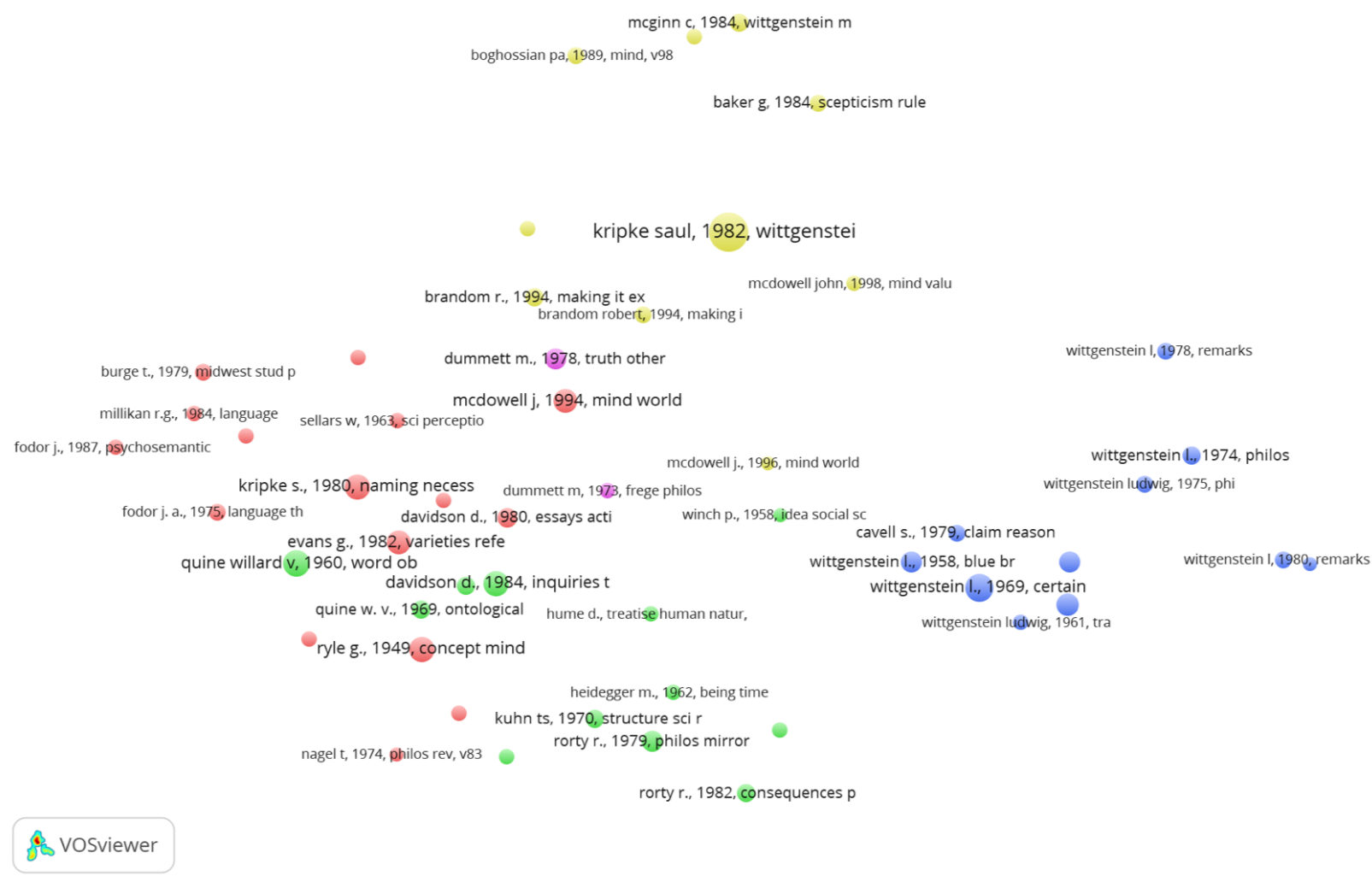

On the map above four main clusters can be easily discerned (i.e., a domain expert is able to attach an appropriate label to each cluster). First, the red cluster seems to represent analytic philosophy. This cluster includes Davidson's Essays on Actions and Events (Davidson 1980), Fodor's The Language of Thought and Psychosemantics (Fodor 1975), Kripke's Naming and Necessity (Kripke 1972/1980), Evans's The Varieties of Reference (Evans 1980), Millikan's Language, Thought, and Other Biological Categories, Searle's Intentionality (Searle 1983), Nagel's 'What is like to be a Bat' (Nagel 1974), 
Putnam's 'The Meaning of "Meaning"' (Putnam 1975), Burge's 'Individualism and the Mental' (Burge 1979), as well as Sellars's Science, Perception and Reality and McDowell's Mind and World (Sellars 1963; McDowell 1994); it is worth noting that Ryle's The Concept of Mind belongs to this cluster (Ryle 1949), and also that Dummett's Truth and Other Enigmas (Dummett 1978b) and Frege: Philosophy of Language (Dummett 1973) seem to be strictly related to this cluster, though the algorithm assigns them a different colour (fuchsia).

The second co-citation pattern, the blue one, is the cluster of Wittgenstein studies: On Certainty is the biggest circle in it, i.e., the work that is most frequently cited together with the Investigations; other co-cited works are the Tractatus, Culture and Value, Zettel, The Blue and Brown Book, Philosophical Grammar, Remarks on the Foundations of Mathematics and Remarks on the Philosophy of Psychology (Wittgenstein 1969, 1922, 1980a, 1967, 1958, 1974, 1978, 1980b); notice also that Cavell's The Claim of Reason is frequently cited together with these Wittgensteinian documents (Cavell 1979).

The third, yellow cluster indicates the debate on Wittgenstein's rule-following considerations. The biggest item in this cluster is Kripke's Wittgenstein on Rules and Private Language (Kripke 1982) — the most cited item of the entire map — but also Brandom's Making it Explicit and Articulating Reasons (Brandom 1994 and 1999), McGinn’s 'Wittgenstein on Meaning' (McGinn 1984), Baker and Hacker's ‘Scepticism, Rules and, Language' (Baker and Hacker 1984), Boghossian's ‘The RuleFollowing Considerations' (Boghossian 1989) and McDowell's Mind, Value and Reality (McDowell 1998) belong to it.

The fourth cluster is green and seems to refer to the issues of anti-foundationalism and relativism: the most frequently co-cited items here are Quine's Word and Object and Ontological Relativity and Other Essays (Quine 1960b and 1969), Davidson's Inquiries into Truth and Interpretation (Davidson 1980 and 1984b), Rorty's Philosophy and the Mirror of Nature and Consequences of Pragmatism (Rorty 1979 and 1982), Kuhn's The Structure of Scientific Revolutions (Kuhn 1970), Heidegger's Being and Time (Heidegger 1927/1962) and Hume's A Treatise on Human Nature (Hume 1739).

\subsection{The Sociology of Academia and the Decline of Wittgenstein}

Whatever the variety of the recent rediscoveries of Wittgenstein's Philosophical Investigations, another general feature that emerges in the last three or four decades is the decline of Wittgenstein from the point of view of the sociology of academia. A starting point for this kind of consideration may be a brief evaluation of Kripke's account of Wittgenstein's rule-following remarks in terms of a sceptical paradox: "No course of action could be determined by a rule, because any course of action can be made out to accord with the rule" (Wittgenstein 1953: $\S 201$; Kripke 1982). The topic is very well-known, so that here it will suffice to summarise it by using Kripke's own words: 
The basic point is this. Ordinarily, I suppose that, in computing " $68+57$ " as I do, I do not simply make an unjustified leap in the dark. I follow directions I previously gave myself that uniquely determine that in this new instance I should say " 125 ". What are these directions? (Kripke 1982: 10)

Kripke's interpretation was not welcomed by Wittgensteinians such as Winch, Baker and Hacker, Anscombe, and Malcolm; the Wittgensteinians did not focus, as most commentators would in the next decades, on singular points of divergence; rather, they straightforwardly denied that the Investigations contain the rulefollowing paradox as Kripke described it (Winch 1983, Baker and Hacker 1984, Anscombe 1985, Malcolm 1986). Analytic philosophers, on the other hand, took a much more positive attitude towards Kripke's work. Not only were Kripke's typically and uncompromisingly analytic style and his specific views on Wittgenstein's rule-following considerations significantly similar to the style and views of his contemporary Crispin Wright, a British philosopher and a leading figure in the analytic community, professor of philosophy at St. Andrews and then at New York University, where he defended a Dummett-inspired form of anti-realism in the philosophy of mathematics and a theory of meaning based on assertibility conditions (Wright 1980); but in the following years Kripke's essay was also discussed, either sympathetically or critically, by a number of other leading analytic philosophers such as for example David Lewis, John McDowell, Simon Blackburn, Paul Boghossian, Philip Pettit, and Paul Horwich. ${ }^{\mathrm{xi}}$ This lively debate, together with the results of co-citation analysis provided above - which show that Kripke's Wittgenstein on Rules and Private Language is the work that in the last decades, in Anglo-American philosophy, is most frequently cited together with Wittgenstein's Philosophical Investigations - partly explains the widespread feeling that Kripke's essay on Wittgenstein had a significant impact and occupied a central position in the recent history of analytic philosophy. ${ }^{\mathrm{xi}}$ Nonetheless, the issue requires further attention and a subtler analysis, since some details are still missing.

In a recent article attention has been focussed on a corpus provided by Proquest, which contains the metadata - author, title, year, university, abstract and more - of the more than 30,000 doctoral dissertations in philosophy discussed in the United States from the late nineteenth century to 2010 (www.proquest.com) (Bonino and Tripodi 2019). Within this corpus, the metadata has been selected from the 329 dissertations in philosophy in which the name 'Wittgenstein' occurs in the abstract. It is worth noticing that over the period 1981-2010 only 22 out of 329 dissertations are devoted to Kripke's work on Wittgenstein's rule-following considerations (Bonino and Tripodi 2019: footnote 12). Prima facie, this result, which corresponds to the $\underline{6.6 \%}$ of the $1981-2010$ corpus, is difficult to accommodate with the above-mentioned widespread sentiment of the strong impact of Kripkenstein in the recent history of philosophy (a feeling which seems to be confirmed by co-citation analysis). Looking closer at the data, however, a possible explanation emerges: 15 out of the 22 Kripkensteinian dissertations were defended in high-ranked universities such as Princeton, Harvard, Columbia, Michigan, Berkeley and so forth. Among them there was, to mention just one example, Essays on Meaning and Belief, the dissertation written by Paul Boghossian, the future professor of philosophy at New York University: a thesis discussed at Princeton in 1987 under the supervision of Paul Benacerraf.

There seem to be three clues here: the widespread feeling, at least partially supported by the analysis of 
co-citations, that Kripke's Wittgenstein had a great impact on analytic philosophy in the last thirty-five years; the small number of American $\mathrm{PhD}$ dissertations in philosophy devoted to Kripke's Wittgenstein in the same period; the prevalence of high-ranked universities within the set of dissertations dedicated to Kripke's Wittgenstein. What does all this suggest? Roughly, that in the considered period analytic philosophy, as it is represented for example by Kripke's work and the replies provided by most of its commentators, has shaped the historical views of contemporary philosophers (hence the widespread feeling mentioned above). Strictly speaking, analytic philosophy has not been prevailing, in the sense of being approved by the majority of philosophers in the United States (never mind in the entire Western world) (cf. Searle 1996, Glock 2008b: 1); rather, it has been hegemonic, in Gramsci's sense of being a form of cultural supremacy, which is produced by a socially - or, in this case, institutionally - powerful group (Gramsci 1948-51: Q. 19, § 24). These considerations invite a further enquiry in the social (or academic) context of analytic philosophy, and more generally of the humanities, in the Anglo-American world, especially in the United States, since the late 1970s and early 1980 s.

In Saul Bellow's last novel, published in 2000, the protagonist Abe Ravelstein - a literary alterego of Allan Bloom, the conservative political theorist who used to be an old friend of Bellow in Chicago and in 1987 became famous for his book The Closing of the American Mind - provided a gloomy picture of the state of the humanities in American higher education:

\begin{abstract}
A summary of his [Ravelstein's] argument was that while you could get an excellent technical training in the U.S., liberal education had shrunk to the vanishing point. We were in thrall to the high tech, which had transformed the modern world. The older generation saved toward the education of its children. The cost of a B.A. had risen to $\$ 150,000$. Parents might as well flush these dollars down the toilet, Ravelstein believed. No real education was possible in American universities except for aeronautical engineers, computerists, and the like. The universities were excellent in biology and the physical sciences, but the liberal arts were a failure. The philosopher Sidney Hook had told Ravelstein that philosophy was finished. "We have to find jobs for our graduates as medical ethicists in hospitals," Hook had admitted. (Bellow 2000: 80; see also Bloom 1987)
\end{abstract}

This passage is a vivid description of the crisis of the humanities that had occurred in the United States since around 1975: an institutional legitimacy crisis in the context of economic stagnation; whereas people were confident that there was a good return on investment in, say, physics research, it became more and more doubtful whether there was any return on investment in the humanities (Menand 2000: 118, 130). 'Crisis' had been the suggestive term used by Plumb in 1964 to announce the scientifically oriented redefinition of the humanities after the second world war (Plumb 1964; see also chapter 4 above); the same word, 'crisis,' literally described the state of the humanities in the United States since around the mid-1970s. In both cases it was a crisis of legitimation with respect to 
the scientific and technical disciplines (Menand 2000: 175). However, only the more recent crisis the crisis in the literal sense - was characterised by serious economic pressures on the liberal arts college and humanities departments (Menand 2000: 130): the country went into a recession, the college population decreased, a long-term job-crisis for American PhD candidates started, the demand for college professors dropped and, as a consequence, the resources for research in the humanities dropped as well.

Therefore, Ravelstein's complaint seemed to be well-justified. Interestingly enough, in reviewing Bloom's bestseller Cavell identified several points of agreement concerning the evaluation of the recent crisis in the humanities:

\begin{abstract}
A first agreement concerns the illustriousness (in Emerson's sense, which includes illustrativeness) of the university in the life of a democracy; a second concerns the irreplaceability of Great Books -- what Thoreau calls scriptures — in (let's call it) a humanistic education; a third concerns the unaware imbibing of European thought by a chronically unprepared American constitution ...; a fourth moment of agreement concerns the goal of a democratic university education as keeping open the idea of philosophy as a way of life, call it the life of the mind ...; a fifth sense of my agreement with Bloom concerns the threat that a discourse about such issues, such as the prose fashioned in Bloom's book (manifestly the product of a lifetime of reading and of a devotion to teaching), is becoming unintelligible to the culture that has produced it, and not only to the young (in my experience, less to them than to others). (Cavell 1989: 606-607; see also Bloom 1987)
\end{abstract}

The state of affairs described by Bellow, Bloom and Cavell was a child of its times. The oil crises in the 1970s and the consequent stagflation had major consequences for the history of economic thought: as John Kenneth Galbraith once put it, that was the moment when "the age of John Maynard Keynes gave way to the age of Milton Friedman" (as is well-known, the leading economist of the Chicago school, a critic of state intervention in the economy, profoundly influenced by von Hayek) (Galbraith 1987: 273); this era, which lasted until the present day, is sometimes labelled the age of neoliberalism (Harvey 2005). ${ }^{\mathrm{xi}}$ Si parva licet, at the time when Keynesianism suffered its worst decline and monetarism came to the fore, the reduction in government expenditures on science and the subsequent demand "to do better with less" had also consequences on the single humanistic disciplines, including philosophy (Elzinga 2012: 420). In a nutshell: in the new context of scarcity the struggle for hegemony changed its features, becoming a very concrete battle for academic positions.

All this had effects on analytic philosophy and the Wittgensteinian tradition, as is clearly visible, for example, in the analysis of the academic success of $\mathrm{PhD}$ candidates in philosophy in the context of American universities in the period from 1951 to 2010 (Bonino and Tripodi 2019). In the 1950s and 1960s - in a period of relatively high economic growth and consequent increase in scientific investments, including 
investments in the developing human sciences - the candidates who chose Wittgenstein as the topic of their dissertations had not yielded a lower academic success than the candidates who chose other topics, including analytic philosophy; on the contrary, the later period - 1981-2010 - corresponds to an entirely different picture, characterised by a significant difference between the two groups, so as to make the decline of Wittgenstein clearly manifest in the relatively low academic success of the Wittgensteinian candidates. Not only does the data allow one to approximately identify the time at which the process began: the 1970s or at the latest the 1980s, when the academic success of Wittgensteinian candidates suddenly decreased, becoming much lower than that of their analytic colleagues (Bonino and Tripodi 2019: 13). The data also suggests the metaphoric place where the academic decline began. Over the considered period, 1951-2010, Wittgenstein never ceased to be a much-discussed topic in the dissertations; he was the second most mentioned twentieth-century philosopher both in the abstracts and in the titles of the theses, just after Heidegger. This seems to make it very unlikely the hypothesis that the academic decline of Wittgenstein was due, so to speak, to the adverse Zeitgeist; presumably, in that case, people would simply have written few dissertations on him. On the contrary, the decline seems to be a consequence "of a process driven from the top, a process guided by a relatively small number of people, i.e. those academics who hold the power of influencing the recruitment policies in philosophy departments" (Bonino and Tripodi 2019: 28). Once again, all this suggests that analytic philosophy is hegemonic in Gramsci's sense, rather than numerically prevailing. After the 1980s, the percentage of Wittgensteinian dissertations consistently decreased: perhaps the PhD students in philosophy gradually realised that writing a dissertation on Wittgenstein would be a disadvantage in their academic career; better stand on the analytic side (Bonino and Tripodi 2019: 28). ${ }^{\mathrm{x}}$

\section{Notes}

${ }^{x i}$ If the minimum number of citations of a cited reference is 20 , of the 48104 cited references, 123 meet the threshold. If the minimum is 10 , then 368 cited references meet the threshold. A detailed analysis of such complex Wittgensteinian maps is left for future work. Here it is enough to observe that in the more complex maps approximately the same clusters are visible.

${ }^{x i}$ Lewis (1983), McDowell (1984), Blackburn (1984), Boghossian (1989), Pettit (1990), Horwich (1990); see also Kusch (2006). It is also worth noticing that Kripke is American and worked at Princeton, and that his pioneering work on modal logic (as well as its use of logic in philosophy) fully belongs to the so-called new rigourism in the human sciences (on this see chapter 4 above).

${ }^{x i}$ Incidentally, this is the kind of belief that can make some readers of the present book somewhat perplexed, notwithstanding all the evidence for the decline of Wittgenstein provided in the previous chapters.

${ }^{x i}$ The relationship between the history of economic theories and the history of other human sciences, including philosophy, would deserve an extensive separate investigation. It can be noticed, however, that arguably in the 1950s and 1960s economics was already, to a certain extent, an "imperialistic" science (chapter 4 above contains some loose indication of this state of affairs). But it was only soon after the rise of monetarism and the decline of Keynesianism that economics started to claim explicitly to be so (Stiegler 1984; see also Mäki 2012). In particular, it would be interesting to understand the ways in which the British dialectic between Cambridge and the London School of Economics continued in the United States, both in economics and in philosophy; unfortunately, this, too, goes well beyond the feasible scope of the present book.

${ }^{x i}$ The article retrieves and counts in the Wittgensteinian abstracts and in the analytic ones a list of "metaphilosophical" terms: 'theory,' 'account,' 'problem,' 'argument,' 'claim,' 'thesis,' 'explanation,' 'solution,' 'objection,' 'system, ' 'puzzle,' 'result,' 'conclusion,' 'assumption,' 'constraint,' 'hypothesis,' 'consequence,' 'defence,' 'requirement,' and 'attack'. The terms belonging to this list are typical of a scientifically oriented philosophical style (and, with some caveats, of a science-oriented metaphilosophy). They occur in the analytic abstracts more than twice the number of times than they do in the Wittgensteinian ones. This conclusion is welcomed here, as a nice confirmation of a claim made more than once in this book concerning the crucial role of a science-like philosophical style in the story of the decline of the later Wittgensteinian tradition in the history of analytic philosophy. 


\section{References}

Ackerman R. (1973), 'Sellars and the Scientific Image', Nô̂s, 7 (2), 138-51

Acton, H.B. (1959), 'Review of Gellner 1959,' The Listener, 10 December, 1045-7

Akehurst T.L. (2010), The Cultural Politics of Analytic Philosophy: Britishness and the Spectre of Europe, London: Continuum 
Albritton R. (1959), 'On Wittgenstein's Use of the Term "Criterion”,' The Journal of Philosophy, 56 (22), 845-57

Alexander P. (1963), Sensationalism and Scientific Explanation, London: Routledge and Kegan Paul Amadae S.M. (2003), Rationalizing Capitalist Democracy: The Cold War. Origins of Rational Choice Liberalism, Chicago: University of Chicago Press

Ambrose A. (1952), 'Linguistic Approaches to Philosophical Problems,' The Journal of Philosophy 49 (9), 289-301

Ambrose A. (1955), 'Wittgenstein on Some Questions in Foundations of Mathematics,' The Journal of Philosophy, 52 (8), 197-214

Anderson B. (1983), Imagined Communities: Reflections on the Origin and Spread of Nationalism, London: Verso

Anderson P. (1968), English Questions, London: Verso

Andrews D. (2010), Keynes and the British Humanist Tradition: The Moral Purpose of the Market, London: Routledge

Anonymous (1994), 'Douglas Gasking (1911-1994)', Australasian Journal of Philosophy, 72 (3), 410

Anonymous [= Thomson, J.F.] (1959), 'Polemical Intentions,' Times Literary Supplement, 20 November

Anscombe G.E.M. (1957), Intention, Oxford: Basil Blackwell

Anscombe G.E.M. (1971), Causality and Determination, London: Cambridge University Press

Anscombe G.E.M. (1983), 'The Causation of Action,' in Knowledge and Mind. Philosophical Essays, New York: Oxford University Press

Anscombe G.E.M. (1985), 'Review of Wittgenstein on Rules and Private Language,' Ethics, 95, 34252

Apel K.-O. (1965), 'Wittgenstein un Heidegger: Die Frage nach dem Sinn von Sein und der Sinnlosigkeitsvedacht gegen alle Metaphysik,' Philosophische Rundschau, 75, 56-94

Arena R. (2015), 'Order, Process and Morphology: Sraffa and Wittgenstein,' Cambridge Journal of Economics, 39 (4), 1087-1108 
Arendt H. (1958), The Human Condition, Chicago: University of Chicago Press

Aristotle (1999), Nicomachean Ethics, Indianapolis-Cambridge: Hackett

Armstrong D.M. (1962), Bodily Sensations, London: Routledge

Armstrong, D.M. (1963), 'Is Introspective Knowledge Incorrigible?', The Philosophical Review, 72 (4), $417-32$

Armstrong D.M.(1966), 'The Nature of Mind,' Arts. Proceedings of The Sydney University Arts Association, 3, 37-48

Armstrong D.M. (1968), A Materialist Theory of the Mind, London: Routledge

Armstrong D.M. and Malcolm N. (1984), Consciousness and Causality. A Debate on the Nature of Mind, Oxford: Blackwell

Arrighi G. (1994), The Long Twentieth Century: Money, Power and the Origins of Our Times, London-New York: Verso

Aune B. (1990), 'Sellars' Two Images of the World,' The Journal of Philosophy, 87, 537-45

Austin J.L. (1950), 'Intelligent Behaviour: a Critical Review of The Concept of Mind', Times Literary Supplement, 7 April

Austin J.L. (1962a), Sense and Sensibilia, Oxford: Oxford University Press

Austin J.L. (1962b), How to Do Things with Words: The William James Lectures delivered at Harvard University in 1955, Oxford: Clarendon Press

Austin J.L. (1979), Philosophical Papers, Oxford: Oxford University Press

Ayer A.J. (1936), Language, Truth and Logic, London: Victor Gollancz

Ayer A.J (1940), The Foundations of Empirical Knowledge, New York: Macmillan

Ayer, A. J. (1959) "Linguistic Philosophy," Spectator, 20 November 1959: 714-716

Ayer A.J. (1960), 'Professor Malcolm on Dreams,' The Journal of Philosophy, 57 (16), 517-35

Ayer A.J. (1961), 'Rejoinder to Professor Malcolm,' The Journal of Philosophy, 58 (11), 297-9 
Baker G. (2003) (ed.), The Voices of Wittgenstein. The Vienna Circle, by Ludwig Wittgenstein and Friedrich Waismann, London: Routledge

Baker G. and Hacker P.M.S. (1984), 'On Misunderstanding Wittgenstein: Kripke’s Private-Language Argument,' Synthese, 58, 407-50

Baker G.P. and Hacker P.M.S. (1985), Wittgenstein: Rules, Grammar and Necessity, Oxford: Blackwell

Bakhtin M.M. (1981), Voprosy literalury i estetiki/ The Dialogic Imagination, Austin: University of Texas Press

Bakhtin M.M. (1984), Problemy poetiki Dostoevskogo/Problems of Dostoevsky's Poetics, Minneapolis-London: University of Minnesota Press

Bakhtin M.M. (1986), Estetika slovesnogo tvorchestva/Speech Genres and Other Late Essays, Austin: University of Texas Press

Balmer B., Godwin M. and Gregory J. (2009), 'The Royal Society and the "Brain Drain": Natural Scientists Meet Social Science, Notes and Records of the Royal Society of London, 63 (4): 339-53

Bambrough R. (1979), Moral Scepticism and Moral Knowledge, London: Routledge and Kegan Paul

Bar-Hillel Y. and Carnap R. (1953), 'Semantic Information,' The British Journal for the Philosophy of Science, 4, 147-57

Barcan Marcus R. (1946), 'A Functional Calculus of First Order Based on Strict Implication', The Journal of Symbolic Logic, 11, 1-16

Barcan Marcus R. (1947), 'The Identity of Individuals in a Strict Functional Calculus of Second Order,' The Journal of Symbolic Logic, 12, 12-5

Barnett W.A. (2004), ‘An Interview with Paul A. Samuelson,' Macroeconomic Dynamics, 8, 519-42

Bateson G. (1972), Steps to an Ecology of Mind, Chicago: University of Chicago Press

Bayart A. (1958), 'Correction de la logique modale du premier et du second ordre S5,' Logique et Analyse, 1, 28-45

Beaney M. (2013), The Oxford Handbook of the History of Analytic Philosophy, Oxford: Oxford University Press 
Beaney M. and Chapman S. (2017), 'Susan Stebbing,' in E.N. Zalta (ed.), The Stanford Encyclopedia of Philosophy (Summer 2017 Edition), https://plato.stanford.edu/archives/sum2017/entries/stebbing/

Bell D. (1962), The End of Ideology: On the Exhaustion of Political Ideas in the Fifties, New York: The Free Press

Bellow S. (2000), Ravelstein, New York: Penguin

Bender T. and Schorske C.E. (1998) (eds.), American Academic Culture in Transformation: Fifty Years, Four Disciplines, Princeton: Princeton University Press

Bennett J. (1964), Rationality, London: Routledge and Kegan Paul

Bennett J. (1966), Kant's Analytic, Cambridge: Cambridge University Press

Bennett M.R. and Hacker, P.M.S. (2003), Philosophical Foundations of Neuroscience, Oxford: Wiley-Blackwell

Berger P.L. and Luckmann T. (1966), The Social Construction of Reality: a Treatise in the Sociology of Knowledge, London: Penguin

Bergmann G. (1944), 'Pure Semantics, Sentences, and Propositions,' Mind, 53, 238-57

Bergmann G. (1945), ‘A Positivistic Metaphysics of Consciousness,' Mind, 65, 193-226

Bergmann G. (1955), 'Professor Quine on Analyticity,' Mind, 64, 254-8

Bergmann G. (1960), ‘Strawson's Ontology,' The Journal of Philosophy, 57 (19), 601-22

Bergmann G. (1961/1964), 'The Glory and the Misery of Ludwig Wittgenstein,' in Logic and Reality, Madison, The University of Wisconsin Press, 225-41

Betti A., van den Berg H. et al. (2019), 'History of Philosophy in Ones and Zeros,' in M. Curtis and E. Fischer (eds.), Methodological Advances in Experimental Philosophy, London: Boomsbury, 295-332

Bird A. (2018), 'Thomas Kuhn,' in E.N. Zalta (ed.), The Stanford Encyclopedia of Philosophy (Winter 2018 Edition), https://plato.stanford.edu/archives/win2018/entries/thomas-kuhn

Black M. (1945), 'Review of Rudolf Carnap, Introduction to Semantics, and Formalization of Logic,' Mind, 54, 171-76 
Black M. (1954), 'Carnap on Semantics and Logic,' in Problems of Analysis, New York: Cornell University Press

Black M. (1958a), 'Necessary Statements and Rules,' The Philosophical Review, 67, 3, 313-41

Black M. (1958b), Making Something Happen, in S. Hook (ed.), Determinism and Freedom, New York: Collier

Black M. (1959), 'Linguistic Relativity: The Views of Benjamin Lee Whorf,' The Philosophical Review, 68 (2), 228-38

Black M. (1960), 'Possibility,' The Journal of Philosophy, 57 (4), 117-26

Black M. (1962), 'Dewey's Philosophy of Language,' The Journal of Philosophy, 59 (19), 505-23

Black M. (1970), 'Comment,' in R. Borger and F. Cioffi (eds.), Explanations in the Behavioral Sciences, New York: Cambridge University Press

Blackburn S. (1984), 'The Individual Strikes Back,' Synthese, 58, 281-302

Blanchard O. (2008), 'Neoclassical Synthesis', in S.N. Durlauf and L.E. Blume (eds.), The New Palgrave Dictionary of Economics, 2nd edition, London: Palgrave Macmillan, 896-8

Bloom A. (1987), The Closing of the American Mind: How Higher Education Has Failed Democracy and Impoverished the Souls of Today's Students, New York: Simon and Schuster

Bloor D. (1976), Knowledge and Social Imagery, Chicago and London: University of Chicago Press

Bloor D. (2000), 'Wittgenstein as a Conservative Thinker,' in M. Kusch (ed.), The Sociology of Philosophical Knowledge, The New Synthese Historical Library (Texts and Studies in the History of Philosophy), vol. 48, Dordrecht: Springer, 1-14

Blumberg A.E. and Feigl H. (1931), 'Logical Positivism,' The Journal of Philosophy, 28 (11), 28196

Boghossian P. (1989), ‘The Rule-Following Considerations', Mind, 98 (392), 507-49

Boghossian P. (2006), Fear of Knowledge: Against Relativism and Constructivism, Oxford: Oxford University Press 
Boghossian P. (2011), 'Williamson on the A Priori and the Analytic,' Philosophy and Phenomenological Research, 82, 488-97

Bonino G. (2007), 'The First Station of Gustav Bergmann's Odyssey,' in L. Addis, G. Jesson and E. Tegtemeier (eds.), Ontology and Analysis. Essays and Recollections About Gustav Bergmann, Frankfurt am Main: Ontos Verlag, 31-50

Bonino G. and Damele G. (2018), 'Divergenze teoriche e vite parallele. Gustav Bergmann, Hans Kelsen e le teoria pura del diritto', Quaderni fiorentini per la storia del pensiero giuridico moderno, 47, 507-39

Bonino G. and Tripodi P. (2018a), 'Sellars and Wittgenstein, Early and Late,' in L. Corti, A. Nunziante (eds.), Sellars and the History of Philosophy, London: Routledge, 216-32

Bonino G. and Tripodi P. (2018b), History of Late Analytic Philosophy, monographic issue of Philosophical Inquiries, 6 (1)

Bonino G. and Tripodi P. (2019), 'Academic Success in America: Analytic Philosophy and the Decline of Wittgenstein', British Journal for the History of Philosophy, https://doi.org/10.1080/09608788.2019.1618789, 1-34

Bonino G. and Tripodi P. (forthcoming), 'Autobiografie analitiche. Ruolo storiografico, conformismo e autoinganno,' Historia Philosophica

Bonino G., Pulizzotto D. and Tripodi P. (2018), 'Exploring the History of American Philosophy in a Computer-Assisted Framework,' in JADT'18 - Proceedings of the 14th International Conference on Statistical Analysis of Textual Data, 134-41

Bonino G., Maffezioli P., Tripodi P. (unpublished manuscript), Logic in Analytic Philosophy (19412010): a Quantitative Analysis

Boulding K.E. 'Samuelson's Foundations: The Role of Mathematics in Economics', Journal of Political Economy, 56 (3), 1948, 187-99

Bourdieu P. (1977), Esquisse d'une théorie de la pratique/Outline for a Theory of Practice, Cambridge: Cambridge University Press

Bourdieu P. (1984a), Homo academicus, Paris: Minuit, 1984 
Bourdieu P. (1984b), La distinction/Distinction: A Social Critique of the Judgement of Taste, London: Routledge

Bourdieu P. (1990), Le sens pratique/The Logic of Practice, Stanford: Stanford University Press

Bourdieu P. (1991), Langage et pouvoir symbolique/Language and Symbolic Power, Cambridge: Polity Press

Bourdieu P. (1999), 'Les conditions sociales de la circulation internationale des idées'/'The social conditions of the international circulation of ideas', in Shusterman R .(ed.), Bourdieu: A Critical Reader, London: Blackwell, 220-28

Bouveresse J. (1991), Philosophie, mythologie et pseudo-science. Wittgenstein lecteur de Freud, Paris: L'Eclat

Bouveresse J. (2007), 'Wittgenstein's Critique of Frazer,' Ratio, 20, 357-76

Bouveresse J. (2011), 'Wittgenstein, von Wright and the Myth of Progress', Paragraph 34.3, 301-21

Bouveresse J. (2012), 'Rudolf Carnap and the Legacy of Aufklärung', in P. Wagner (ed.), Carnap's Ideal of Explication and Naturalism, Basingstoke: Palgrave Macmillan, 47-62

Bouwsma, O.K., 'The Blue Book,' The Journal of Philosophy, 58 (6), 141-62

Brandom R. (1994), Making It Explicit, Cambridge (MA): Harvard University Press

Brandom R. (2000), Articulating Reasons: An Introduction to Inferentialism, Cambridge (MA): Harvard University Press

Braudel F. (1979), Civilisation matérielle, économie et capitalisme, XVe-XVIIIe siècle, Paris: Armand Colin

Braudel F. (1980/1997), L'histoire, mesure du monde', in Les Ecrits de Fernand Braudel, vol. II, Paris: De Fallois

Bridgman P.W. (1928), 'The Logic of Modern Physics,' Mind 37 (147), 355-61

Britton K. (1947), 'Counting, A Philosophical Analysis', The Journal of Philosophy, 44 (12) 309318

Broad C.D. (1925) Mind and Its Place in Nature, London: Kegan Paul, Trench, Trubner and Co 
Broad C.D. (1958), 'Philosophy', Inquiry, I, 99-129

Bruner J.S. (1990), Acts of Meaning, Cambridge (MA)-London: Harvard University Press

Buonomo, V. and Petrovich E. (2018), 'Reconstructing Late Analytic Philosophy: a Quantitative Approach', Philosophical Inquiries, 6 (1), 149-80

Burge T. (1979), 'Individualism and the Mental,' Midwest Studies in Philosophy, 4 (1), 73-122

Burge T. (1992), 'Philosophy of Language and Mind. 1950-1990', The Philosophical Review, 101, $3-51$

Butler J. (1990), Gender Trouble: Feminism and the Subversion of Identity, London: Routledge

Carnap R. (1928a), Der logische Aufbau der Welt, Berlin-Schlachtensee: Weltkreis-Verlag

Carnap R. (1928b), Scheinprobleme in der Philosophie: das Fremdpsychische und der Realismusstreit, Berlin-Schlachtensee: Weltkreis-Verlag

Carnap R. (1932), Über Protokollsätze, in “Erkenntnis”, 3, pp. 215-28.

Carnap R. (1934), Die logische Syntax der Sprache, Wien: Springer

Carnap R. (1936), ‘Testability and Meaning', Philosophy of Science, 3, 419-71; 4, 1-40

Carnap R. (1939), Foundations of Logic and Mathematics, in International Encyclopedia of Unified Science, vol. I, Chicago: University of Chicago Press

Carnap R. (1942), Introduction to Semantics, in Studies in Semantics, vol. 2, Cambridge (MA): Harvard University Press

Carnap R. (1947), Meaning and Necessity: A Study in Semantics and Modal Logic, Chicago: University of Chicago Press (2nd expanded ed. 1956)

Carnap R. (1950a), Logical Foundations of Probability, Chicago: Chicago University Press

Carnap R. (1950b), 'Empiricism, Semantics and Ontology,' Revue Internationale de Philosophie, 4, $20-40$

Carnap R. (1952), 'Meaning Postulates', Philosophical Studies, 3, 65-73 
Carnap R. (1956), The Methodological Character of Theoretical Concepts, Minnesota Studies in the Philosophy of Science, 1, 38-76

Carnap R. (1963a), 'Intellectual Autobiography,' in P.A. Schilpp (ed.), The Philosophy of Rudolf Carnap, La Salle: Open Court, 1-84

Carnap R. (1963b), 'P.F. Strawson on Linguistic Naturalism,' inin P.A. Schilpp (ed.), The Philosophy of Rudolf Carnap, La Salle: Open Court, 933-40

Carnap R., Hahn H., Neurath O. (1929), Wissenschaftliche Weltauffassung. Der Wiener Kreis, Herausgegeben von Verein Ernst Mach, Wien: Wolf

Carus A.W. (2004), 'Sellars, Carnap, and the Logical Space of Reasons,' in S. Awodey and C. Klein (eds.), Carnap Brought Home: The View from Jena, Chicago: Open Court, 317-55

Carus A.W. (2007), Carnap and Twentieth-Century Thought: Explication as Enlightment, Cambridge: Cambridge University Press

Castañeda H.-N. (1962), 'Criteria, Analogy, and Knowledge of Other Minds.', The Journal of Philosophy, 59 (20), 533-46

Cavell S. (1958/1976), 'Must We Mean What We Say?,' in Must We Mean What We Say?, Cambridge: Cambridge University Press, 1-43

Cavell S. (1962/1976), 'The Availability of Wittgenstein's Later Philosophy,' in Must We Mean What We Say?, Cambridge: Cambridge University Press, 44-72

Cavell S. (1965), 'Austin at Criticism,' The Philosophical Review, 74 (2), 204-19

Cavell S. (1969), Must We Mean What We Say?, New York: Scribner

Cavell S. (1979), The Claim of Reason: Wittgenstein, Skepticism, Morality, and Tragedy, Oxford: Oxford University Press

Cavell S. (1989), 'Who Disappoints Whom?,' Critical Inquiry, 15 (3), 606-10

Cavell S. (1990), Conditions Handsome and Unhandsome the Constitution of Emersonian Perfectionism, Chicago: University of Chicago Press

Chabtree D. and Thirlwall A.P. (1980) (eds.), Keynes and the Bloomsbury Group, London and Basingstoke: Macmillan 
Chalmers D. (2002), 'Does Conceivability Entail Possibility?', in T. Szabo Gendler and J. Hawthorne (eds.), Conceivability and Possibility, Oxford: Oxford University Press. pp. 145-200

Chihara C. and Fodor J.A. (1965), 'Operationalism and Ordinary Language: A Critique of Wittgenstein,' American Philosophical Quarterly, 2, 281-95

Chihara C.S. (1963), 'Mathematical Discovery and Concept Formation,' The Philosophical Review, $72(1), 17-34$

Child W. (1994), Causality, Interpretation, and the Mind, Oxford: Oxford University Press

Chisholm R. (1951), 'Philosophers and Ordinary Language', The Philosophical Review, 60, 317-28

Chisholm R.M. (1957), Perceiving: A Philosophical Study, Ithaca (NY): Cornell University Press

Chisholm R.M. (1970), 'The Structure of Intention,' The Journal of Philosophy, 67 (19), 633-47

Chomsky N. (1957), Syntactic Structures, The Hague: Mouton

Chomsky N. (1959), 'Review of Verbal Behavior by B.F. Skinner,' Language, 35, 26-57

Chomsky N. (1965), Aspects of the Theory of Syntax, Cambridge (MA): The MIT Press

Chomsky N. (1970), 'Problems of Explanation in Linguistics,' in R. Borger e F. Cioffi (eds.), Explanations in the Behavioral Sciences: New York: Cambridge University Press, 425-51

Chomsky N. (1986), Knowledge of Language: Its Nature, Origin, and Use: New York: Praeger Publishers

Chomsky N. (1988), Language and Problems of Knowledge: The Managua Lectures, Cambridge (MA): MIT Press

Chomsky N. (1992), 'Language and Interpretation: Philosophical Reflections and Empirical Inquiry,' in J. Barman (ed.), Inference, Explanation and Other Frustrations: Essays in the Philosophy of Science, Berkeley: University of California Press

Chomsky N. (1994), 'Naturalism and Dualism in the Study of Language and Mind,' International Journal of Philosophical Studies, 2

Churchland P.M. (1970), 'The Logical Character of Action-Explanations,' The Philosophical Review, 79 (2), 214-36 
Clark H.H. (1996), Using Language, Cambridge: Cambridge University Press

Coakley S. (2002), 'Powers and Submissions: Spirituality, Philosophy and Gender,' Oxford: Blackwell

Coates J. (1996), The Claims of Common Sense: Moore, Wittgenstein, Keynes and the Social Science, Cambridge: Cambridge University Press

Coffa A. (1991), The Semantic Tradition From Kant to Carnap: To the Vienna Station, Cambridge: Cambridge University Press

Cohen, M. (1960) 'The Angry Young Philosopher', Commentary, 30, 178-80

Coliva A. (2010), Moore and Wittgenstein: Scepticism, Certainty, and Common Sense, Basingstoke: Palgrave Macmillan

Collini S. (2013), 'Introduction', in F.R. Leavis, Two Cultures?: The Significance of C. P. Snow (Canto Classics), Cambridge: Cambridge University Press,1-49

Conant J. (1991), 'The Search for Logically Alien Thought: Descartes, Kant, Frege and the Tractatus,' Philosophical Topics, 20, 115-80

Cook J.W. (1965), 'Wittgenstein on Privacy,' The Philosophical Review, 74 (3), 281-314

Cottingham J. (2010), 'Wittgenstein, Religion, and Analytic Philosophy,' in H.-J. Glock and J. Hyman (eds.), Wittgenstein and Analytic Philosophy: Essays for P.M.S. Hacker, Oxford: Oxford University Press

Crary A. and Read R. (2000) (eds.), The New Wittgenstein, London: Routledge

Currie G. (2001), 'Methodological Individualism:Philosophical Aspects,' International Encyclopedia of the Social \& Behavioral Sciences, 9755-9760

Damasio A. (1994), Descartes' Error, New York: Avon Books

Damasio A.(1999), The Feeling of What Happens, New York-San Diego-London: Harcourt Brace \& Company

Dancy J. (2000), Practical Reality, Oxford: Oxford University Press 
Danto A, and Morgenbesser S. (1963), 'What We Can Do,' The Journal of Philosophy, 60 (15), 43545

Davidson D. (1963), 'Actions, Reasons, and Causes,' The Journal of Philosophy, 60, 685-700

Davidson D. (1967), 'Causal Relations,' The Journal of Philosophy, 64, 691-703

Davidson D. (1969), 'True to the Facts,' The Journal of Philosophy, 66, 748-64

Davidson D. (1970), 'Mental Events,' in L. Foster and J.W. Swanson (eds.), Experience and Theory, London: Duckworth

Davidson D. (1974), 'On the Very Idea of a Conceptual Scheme,' Proceedings and Addresses of the American Philosophical Association, 47, 5-20

Davidson D. (1980), Essays on Actions and Events, Oxford: Oxford University Press

Davidson D. (1984a), 'First-Person Authority,' Dialectica, 38, 101-12

Davidson D. (1984b), Inquiries into Truth and Interpretation, Oxford: Clarendon Press

Davidson D. (1993), 'Thinking Causes,' in J. Heil and A. Mele (eds.), Mental Causation, Oxford: Clarendon Press

Davidson D. (1999), 'Intellectual Autobiography.' in E.L. Hahn (ed.). The Philosophy of Donald Davidson, The Library of Living Philosophers, Chicago and La Salle: Open Court, 1-70

Davidson D. (2001), Subjective, Intersubjective, Objective, Oxford: Clarendon Press

Davidson D. and Suppes, P. (1957), Decision-Making: An Experimental Approach, Stanford: Stanford University Press

Davis J.B. (2002), 'A Marxist influence on Wittgenstein via Sraffa,' in G. Kitching and N. Pleasants (eds.), Marx and Wittgenstein: Knowledge, Morality and Politics, London: Routledge, 131-43

Dawkins R. (1976), The Selfish Gene, Oxford: Oxford University Press

De Caro M. and Macarthur D. (2004) (eds.), Naturalism in Question, Cambridge (MA): Harvard University Press

de Certeau M. (1984), Arts de faire/The Practice of Everyday Life, Berkeley and Los Angeles: University of California Press 
de Vries W. (2016), 'Wilfrid Sellars,' in E.N. Zalta (ed.). The Stanford Encyclopedia of Philosophy (Winter 2016 Edition), https://plato.stanford. edu/archives/win2016/entries/sellars

de Vries W.A. and Triplett, T. (2000), Knowledge, Mind, and the Given: A Reading of Sellars's 'Empiricism and the Philosophy of Mind', Indianapolis and Cambridge: Hackett Publishing

Deacon T. (1997), The Symbolic Species, New York \& London: Norton \& Company

Debreu G. (1991), 'The Mathematization of Economic Theory,' American Economic Review, 81 (1), $1-7$

Deleuze G. and Guattari F. (1987), Mille plateaux/A Thousand Plateaus: Capitalism and Schizophrenia, Minneapolis: University of Minnesota Press

Dement W. and Kleitman N. (1957), 'The Relation of Eye Movements During Sleep to Dream Activity: an Objective Method for the Study of Dreaming,' Journal of Experimental Psychology, 53, $339-46$

Dennett D. (1987), The Intentional Stance, Cambridge (MA): MIT Press

Dennett D. (1991), Consciousness Explained, Boston (MA): Little Brown and Company

Dennett D. (2000), 'Re-Introducing The Concept of Mind,' in The Concept of Mind, London: Penguin, viii-xix

Derrida J. (1976) De la grammatologie/Of Grammatology, Baltimore and London: Johns Hopkins University Press

Derrida J. (1978), L'ecriture et la difference/Writing and Difference, Chicago : University of Chicago Press

Diamond C. (2001), 'On Wittgenstein', Philosophical Investigations, 24

Dilman I. and Phillips D.Z. (1971), Sense and Delusion, London: Routledge and Kegan Paul

Dilthey W. (1883), Einleitung in die Geisteswissenschaften. Versuch einer Grundlegung für das Studium der Gesellschaft und der Geschichte, Duncker \& Humblot, Leipzig

Divers J. (2017), 'De Re Modality in the Late 20th Century: The Prescient Quine.' in M. Sinclair (ed.) The Actual and the Possible: Modality and Metaphysics in Modern Philosophy, Oxford: Oxford University Press, 217-36 
Donagan A. (1959), Words and Things, Correspondence in The Times, 23 November

Doney, W. (1962) 'Review of Gellner 1959,' The Philosophical Review, 71, 252-257

Donnellan K.S. (1967), Paradigm-Case Argument, in P. Edwards (ed.), The Encyclopedia of Philosophy, New York: Macmillan, 39-44

Donnellan K.S. and Morgenbesser S. (1963), 'Knowing What I Am Doing,' The Journal of Philosophy, 60 (14), 401-9

Dretske F. (1981), Knowledge and the Flow of Information, Cambridge (MA): MIT Press

Dretske F. (1995), Naturalizing the Mind, Cambridge (MA): MIT Press

Drury M.O’.C. (1973), The Danger of Words, London: Routledge and Kegan Paul

Drury M.O'.C. (1984), 'Conversation with Wittgenstein', in R. Rhees (ed.), Recollections of Wittgenstein, Totowah: Rowman and Littlefield, 112-89

Duhem P. (1906), La théorie physique, son object e sa structure, Paris: Chevalier et Rivière

Dummett M. (1956), 'Nominalism,' The Philosophical Review, 65 (4), 491-505

Dummett M. (1959a), 'Truth,' in Proceedings of the Aristotelian Society, 59, 141- 62

Dummett M. (1959b), 'Wittgenstein's Philosophy of Mathematics,' The Philosophical Review, 68, $324-48$

Dummett M. (1960/1978), 'Oxford Philosophy,' in Dummett (1978b), 431-436

Dummett M. (1963/1978), 'Realism,' in Dummett (1978b), 145-65.

Dummett M. (1964), 'Bringing About the Past,' The Philosophical Review, 73 (3), 338-59

Dummett M. (1973), Frege: Philosophy of Language, London: Duckworth

Dummett M. (1975/1993), 'What is a Theory of Meaning (I),' in The Seas of Language, Oxford: Oxford University Press

Dummett M. (1978a), 'Reckonings: Wittgenstein on Mathematics', Encounter, 50, 63-8

Dummett M. (1978b), Truth and Other Enigmas, London: Duckworth 
Dummett M. (1991), The Logical Basis of Metaphysics, London: Duckworth

Dummett M. (1993), The Origins of Analytical Philosophy, Cambridge (MA): Harvard University Press

Dworkin R. (1986), Law's Empire, Cambridge (MA)-London: Harvard University Press

Edwards P. (1949), 'Necessary Propositions and the Future,' The Journal of Philosophy, 46 (6) 155 7

Elzinga A. (2012), 'Features of the Current Science Policy Regime: Viewed in Historical Perspective,' Science and Public Policy, 39 (4), 416-28

Engel P. (1996), Philosophie et psychologie, Paris: Gallimard

Evans G. (1982), The Varieties of Reference, Oxford: Oxford University Press

Feigl H. (1958), 'The "Mental" and the "Physical",' in Feigl H., Scriven M., Maxwell G. (eds.), Concepts, Theories and the Mind-Body Problem, Minnesota Studies in the Philosophy of Science, 2, Minneapolis: University of Minnesota Press, 370-497

Feigl H. and Sellars W. (1949) (eds.), Readings in Philosophical Analysis, New York: AppletonCentury-Crofts

Feyerabend P. K. (1960), 'Patterns of Discovery,' The Philosophical Review, 69 (2), 247-52

Feyerabend P.K. (1955), 'Wittgenstein's Philosophical Investigations,' The Philosophical Review, 64 (3), $449-83$

Feyerabend P.K. (1995), Killing Time: The Autobiography of Paul Feyerabend, Chicago: University of Chicago Press

Findlay, J.N. (1961a), 'The Methodology of Normative Ethics,' The Journal of Philosophy, 58 (24), 757-64

Findlay, J.N. (1961b), ‘Critical Notice of Gellner 1959,' Indian Journal of Philosophy, 3, 130-8

Fingarette H. (1969), Self-Deception, London: Routledge and Kegan Paul

Fiocco M.O. (2007), 'Conceivability, Imagination and Modal Knowledge,' Philosophy and Phenomenological Research, 74 (2), 364-80 
Fish S. (1980), Is There a Text in This Class?, Cambridge (MA): Harvard University Press

Fisher A.R.J. (2015), 'David Lewis, Donald C. Williams, and the History of Metaphysics in the Twentieth Century,' Journal of the American Philosophical Association, 1, 3-22

Flew A.G.N. (1951) (ed.), Logic and Language, Oxford: Blackwell

Flew A.G.N. (1956), 'Philosophy and Language', in A.G.N. Flew (ed.), Essays in Conceptual Analysis, London: Macmillan

Flew A.G.N. (1957), 'Farewell to the Paradigm-Case Argument: A Comment,' Analysis, 18, 34-40

Floyd J. and Shieh S. (2001) (eds.), Future Pasts: The Analytic Tradition in Twentieth Century Philosophy, Oxford: Oxford University Press

Fodor J. (1975), The Language of Thought, Hassocks: Harvester

Fodor J. (1983), The Modularity of Mind, Cambridge (MA): The MIT Press

Fodor J.A. and Katz J.J. (1963), 'The Availability of What We Say,' The Philosophical Review, 72 (1), 57-71

Fogelin R.J. (1976), Wittgenstein, London: Routledge \& Kegan Paul

Føllesdal D. (2011), 'Developments in Quine's Behaviorism,' American Philosophical Quarterly. 48, 273-82

Forguson L. (2001), 'Oxford and the 'Epidemic' of Ordinary Language Philosophy', The Monist 84 (3), 325-45

Forster M.N. (2004), Wittgenstein on the Arbitrariness of Grammar, Princeton: Princeton University Press

Foucault M. (1972), L'archéologie du savoir/The Archeology of Knowledge, New York: Pantheon Books

Foucault M. (1976), Surveiller et punir/Discipline and Punish, New York: Pantheon Books

Foucault M. (1980), Power/Knowledge, New York: Pantheon Books

Fourastié J. (1979), Les Trente Glorieuses, ou la révolution invisible de 1946 à 1975, Paris: Fayard, 1979 
Frascolla P., Marconi D. and Voltolini A. (2010) (eds.), Wittgenstein: Mind, Meaning and Metaphilosophy, Palgrave Macmillan, Basingstoke

Frazer J. (1890), The Golden Bough: A Study in Comparative Religion, London: Macmillan

Frege G. (1879), Begriffsschrift, eine der arithmetischen nachgebildete Formelsprache des reinen Denkens, Halle: Nebert

Frege G. (1892), 'Über Sinn und Bedeutung,' Zeitschrift für Philosophie und philosophische Kritik, $100,25-50$

Frenkel R. and Rapetti M. (2009), 'A Developing Country View of the Current Global Crisis: What Should Not Be Forgotten and What Should Be Done,' Cambridge Journal of Economics, 33, 685702

Friedman M. (1987), 'Carnap's Aufbau Reconsidered,' Noûs, 21, 521-45

Friedman M. (1992), 'Epistemology in the Aufbau,' Synthese, 93, 15-57

Frost-Arnold G. (2013), Carnap, Tarski, and Quine at Harvard: Conversations on Logic, Mathematics, and Science, Chicago: Open Court

Gabbani C. (2018), 'Sellars and Carnap: Science and/or Metaphysics', in L. Corti and A. Nunziante (eds.), Sellars and the History of Modern Philosophy, New York: Routledge, 197-215

Gadamer H.-G. (1960), Wahrheit und Methode, Tubingen: J.C.B. Mohr

Gadamer H.-G. (1975), Wahrheit und Methode/Truth and Method, New York: Seabury Press

Galbraith J.K. (1987), Economics in Perspective: A Critical History, Boston: Houghton Mifflin

Galison P. (1993), 'The Cultural Meaning of Aufbau', in F. Stadler (ed.), Scientific Philosophy: Origins and Developments, Vienna Circle Institute Yearbook, Dordrecht: Springer, 75-93

Garfinkel H. (1967), Studies in Ethnomethodology, Englewood Cliffs, NJ: Prentice-Hall

Garver N. (1964), 'Criterion of Personal Identity,' The Journal of Philosophy, 61 (24), 779-84

Garver N. (1987), 'Wittgenstein's Reception in America', Modern Austrian Literature, 20 (3/4), 207 - 
Gasking D.A.T. (1972), 'The Analytic-Synthetic Controversy,' Australasian Journal of Philosophy, $50,107-23$

Geach P.T. (1954), ‘On What There Is', Journal of Symbolic Logic, 19 (3), 222-223

Geach, P.T. (1956), ‘The Third Man Again,’ The Philosophical Review 65 (1), 72-82

Geach P.T. (1957), Mental Acts, London: Routledge \& Kegan Paul

Geach P.T. (1962), Reference and Generality: An Examination of Some Medieval and Modern Theories, Itacha: Cornell University Press

Geach P.T. (1965), 'Assertion,' The Philosophical Review, 74 (4), 449-65

Gebauer G. (2017), Wittgenstein's Anthropological Philosophy, Basingstoke: Palgrave Macmillan

Geertz C. (1973), The Interpretation of Cultures, New York: Basic Books

Geiger L.R. (1999), 'The Ten Generations of American Higher Education,' in P.G. Altbach, R.O. Berdahl, and P.J. Gumport (eds.), American Higher Education in the Twenty-first Century: Social, Political, and Economic Challenges, Baltimore: Johns Hopkins University Press

Gellner E. (1951), 'Maxims', Mind, 60 (239), 383-93

Gellner E. (1959/1979), Words and Things: An Examination of, and an Attack on, Linguistic Philosophy, London: Routledge \& Kegan Paul

Gellner E. (1964). 'The Crisis in the Humanities and the Mainstream of Philosophy,' in J.H. Plumb (ed.), Crisis in the Humanities, Harmondsworth: Penguin, 45-81

Gettier E. (1963), 'Is Justified True Belief Knoweldge?,' Analysis, 23, 121-3

Giannoccolo P. (2004), ‘The Brain Drain. A Survey of the Literature,' Working Papers 526, Dipartimento Scienze Economiche, Università di Bologna

Gibson J.J. (1979), The Ecological Approach to Visual Perception, Boston: Houghton Mifflin

Giddens A. (1984), The Constitution of Society, Berkeley and Los Angeles: University of California Press

Giddens A. (1991), Modernity and Self-Identity: Self and Society in the Late Modern Age, Stanford: Stanford University Press 
Giere R.N. (1996), 'From Wissenschaftliche Philosophic to Philosophy of Science,' in R.N. Giere and A. Richardson (eds.), Origins of Logical Empiricism, Minneapolis-London: University of Minnesota Press, 335-377

Glock H.-J. (1994), 'Wittgenstein vs Quine on Logical Necessity,' in S. Teghrarian (ed.), Wittgenstein and Contemporary Philosophy, Bristol: Thoemmes Press

Glock H.-J. (1996), A Wittgenstein Dictionary, Oxford: Blackwell

Glock H.-J. (2003a) (ed.), Strawson and Kant, Oxford: Oxford University Press

Glock H.-J. (2003b), Quine and Davidson on Language, Thought and Reality, Cambridge: Cambridge University Press

Glock H.-J. (2007), 'Necessity and Language: In Defence of Conventionalism,' Philosophical Investigations, 31, 1, 24-47

Glock H.-J. (2008a), 'The Influence of Wittgenstein on American Philosophy', in C. Misak, The Oxford Handbook of American Philosophy, Oxford: Oxford University Press, 375-402

Glock H.-J. (2008b), What is Analytic Philosophy?, Cambridge: Cambridge University Press

Glock H.-J. and Hyman J. (2009) (eds.), Wittgenstein and Analytic Philosophy: Essays for P.M.S. Hacker, Oxford: Oxford University Press

Gödel K. (1931), 'Über formal unentscheidbare Sätze der Principia Mathematica und verwandter Systeme I', Monatshefte für Mathematik, 38, 173-98

Goffman E. (1956), The Presentation of Self in Everyday Life, New York: Anchor Books

Goffman E. (1974), Frame Analysis, New York: Harper Colophon Books

Goidberg A.E. (1995), Constructions: A Construction Grammar Approach to Argument Structure, Chicago: The University of Chicago Press

Goodman N. (1947), 'On Infirmities of Confirmation-Theory,' Philosophy and Phenomenological Research, 8, 149-51

Goodman N. (1949), 'On Likeness of Meaning,' Analysis, 10, 1-7

Goodman N. (1951), The Structure of Appearance, Cambridge (MA): Harvard University Press 
Goodman N. (1978), Ways of Worldmaking, New York: Hackett

Goodman N. and Quine W.V.O. (1947), ‘Steps Toward a Constructive Nominalism,' The Journal of Symbolic Logic, 12, 105-22

Graeber D. (2011), Debt: The First 5,000 Years, New York: Melville House

Graham G., 'Behaviorism,' in E.N. Zalta (ed.), The Stanford Encyclopedia of Philosophy (Spring 2019 Edition), https://plato.stanford.edu/archives/spr2019/entries/behaviorism

Gramsci A. (1948-1951), Quaderni del carcere, Collana Opere di Antonio Gramsci, Torino: Einaudi

Gramsci A. (1947/1994), Lettere dal carcere/Letters from Prison, New York: Columbia University Press

Grice P. (1975), 'Logic and Conversation,' in Cole P. and Morgan J.L. (eds.), Syntax and Semantics 3: Speech Arts, New York: Academic Press, 41-58

Grice, P. (1957), 'Meaning,' The Philosophical Review, 66, 377-88

Grice, P. (1989), Studies in the Way of Words, Cambridge (MA): Harvard University Press

Grice P. and Strawson P. (1956), 'In Defense of a Dogma,' The Philosophical Review, 65 (2), 14158

Habermas J. (1967), 'Zur Logik der Sozialwissenschaften,' Philosophische Rundschau, 14, special issue

Habermas J. (1984), Theorie des kommunikativen Handelns/The Theory of Communicative Action, Boston: Beacon Press

Habermas J. (1989), Strukturwandel der Öffentlichkeit. Untersuchungen zu einer Kategorie der bürgerlichen Gesellschaft/The Structural Transformation of the Public Sphere: An Inquiry into a Category of Bourgeois Society, Cambridge: Polity Press

Hacker P.M.S. (1990), 'Chomsky’s Problems,' Language and Communication, 10, 127-48

Hacker P.M.S. (1996), Wittgenstein's Place in Twentieth-Century Analytic Philosophy, Oxford: Blackwell 
Hacker P.M.S. (1997), 'Davidson on First-Person Authority,' Philosophical Quarterly, 47 (188), 285-304

Hacker P.M.S. (2001), Wittgenstein and the Autonomy of Humanistic Understanding, in R. Allen and M. Turvey (eds.), Wittgenstein: Theory and the Arts, Routledge: London, 39-74

Hacker P.M.S. (2003), 'On Strawson's Rehabilitation of Metaphysics,' in H.-J. Glock (ed.), Strawson and Kant, Oxford: Oxford University Press

Hacker P.M.S. (2010), 'Wittgenstein's Anthropological and Ethnological Approach,' in J. Padilla Galvez (ed.), Philosophical Anthropology - Wittgenstein's Perspective, Frankfurt: Ontos Verlag, $15-32$

Hall E.W. (1944), 'The Extra-Linguistic Reference of Language II: Designation of the Object Language,' Mind, 53, 25-47

Hall J.A. (2010), Ernest Gellner. An Intellectual Biography, London: Verso

Hall R. (1966), ‘Analytic-Synthetic. A Bibliography', Philosophical Quarterly, 16, 178-81

Haller R. (1992) (ed.), ‘Alfred Tarski: Drei Briefe an Otto Neurath,' Grazer Philosophische Studien, $43,1-32$

Hamlyn D.W. (1957), The Psychology of Perception, London: Routledge \& Kegan Paul

Hands, D.W. (2007), '2006 HES Presidential address a Tale of two Mainstreams: Economics and Philosophy of Natural Science in the Mid-Twentieth Century,' Journal of the History of Economic Thought, 29 (1), 1-13

Hanfling O. (2000), Philosophy and Ordinary Language, London-New York: Routledge

Hanson N.R. (1958), ‘The Logic of Discovery,' The Journal of Philosophy, 55 (25), 1073-089

Hanson N.R. (1967) , 'An Anatomy of Discovery,' The Journal of Philosophy, 64 (11), 321-52

Haraway D.J. (1991), Simians, Cyborgs, and Women: the Reinvention of Nature, New York: Routledge

Hardcastle G.L. (1995), 'S.S. Stevens and the Origins of Operationism,' Philosophy of Science, 62 (3): 404-24 
Hare R.M. (1960), 'A School for Philosophers,' Ratio, 2, 107-20

Harman G.H. (1968), ‘Three Levels of Meaning,' 5 (19), 590-602

Harman G.H. (1970), 'Knowledge, Reasons, and Causes,' The Journal of Philosophy, 67 (21), 1970, $841-55$

Hart H.L.A. (1961), The Concept of Law, Oxford: Clarendon Press

Harvey D. 2005, A Brief History of Neoliberalism, Oxford: Oxford University Press

Heath J., 'Methodological Individualism,' in E.N. Zalta (ed.), The Stanford Encyclopedia of Philosophy (Spring 2015 Edition), https://plato.stanford.edu/archives/spr2015/entries/methodologicalindividualism

Heath P. L. (1962), 'Review of Gellner 1959,' Philosophy 37, 176-7

Hegel G.W.F. (1977), Phänomenologie des Geistes/The Phenomenology of Spirit, Oxford: Oxford University Press

Heidegger M. (1927/1962), Sein und Zeit, Tübingen: Max Niemeyer Verlag, english translation Being and Time, London, SCM Press

Hempel C.G. (1958), 'The Theoretician's Dilemma', in H. Feigl, M. Scriven and G. Maxwell, Concepts, Theories and the Mind-Body Problem, Minnesota Studies in the Philosophy of Science, 2, Minneapolis: University of Minnesota Press, 173-226

Hempel C.G. (1965), Aspects of Scientific Explanation and Other Essays in the Philosophy of Science, New York: Free Press

Hempel C.G. (1968), 'Explanation in Science and in History,' in P.H. Niddicht (ed.), The Philosophy of Science, Oxford: Oxford University Press

Hempel C.G. (1973), 'The Meaning of Theoretical Terms: A Critique to the Standard Empiricist Construal,' in Logic, Methodology and Philosophy of Science, vol. IV, Amsterdam-London-New York: North Holland/American Elsevier

Heritage J. (1984), Garfinkel and Ethnomethodology, Cambridge: Polity Press 
Hertzberg L. (2006), 'Trying to Keep Philosophy Honest', in A. Pichler \& S. Säätelä (eds.), Wittgenstein: The Philosopher and his Works, Publications of the Austrian Ludwig Wittgenstein Society, Band 2, Heusenstamm bei Frankfurt: Ontos Verlag, 82-97

Hintikka J. (1961), 'Modality and Quantification,' Theoria, 27, 119-28

Hintikka J. (1963), 'The Modes of Modality,' Acta Philosophica Fennica, 16, 65-82

Hintikka J. (1965), 'Are Logical Truths Analytic?,' The Philosophical Review, 74 (2), 178-203

Hobsbawm E. (1994), The Age of Extremes: The Short Twentieth Century, 1914-1991, New York: Pantheon Books-Random House

Hochberg H. (1994), 'From Carnap's Vienna to Meinong’s Graz: Gustav Berg- mann's Ontological Odyssey,' Grazer Philosophischen Studien, 48, 1-49

Hochberg H. (2001), The Positivist and the Ontologist: Bergmann, Carnap, and Logical Realism, Amsterdam: Rodopi

Hodgkin A.L. e Huxley A.F. (1939), ‘Action Potentials Recorded from Inside a Nerve Fibre,' Nature, $144,710-11$

Hodgkin A.L. et al. (1952), 'Measurement of Current-Voltage Relations in the Membrane of the Giant Axon of Loligo,' Journal of Physiology, 116, 424-48

Horwich P. (1990), 'Wittgenstein and Kripke on the Nature of Meaning,' Mind and Language, 5 (2), $105-21$

Horwich P. (2010), Wittgenstein's Metaphilosophy, Oxford: Oxford University Press

Horwich P. (2011), 'Williamson's Philosophy of Philosophy,' Philosophy and Phenomenological Research, $82(2), 524-33$

Horwich P. (2013), 'Reply to Timothy Williamson's Review of Wittgenstein's Metaphilosophy', European Journal of Philosophy, 21 (S3): e18-e26

Howard D. (2003), 'Two Left Turns Make a Right: On the Curious Political Career of North American Philosophy of Science at Midcentury,' in Hardcastle G.L. and Richardson A. (eds.), Logical Empiricism in North America, Minneapolis: University of Minnesota Press 
Hubel D.H. and Wiesel T.N. (1959), 'Receptive Fields of Single Neurons in the Cat's Striate Cortex,' Journal of Physiology, 148, 574-91

Hume D. (1739), A Treatise on Human Nature, London: John Noon

Hunter G. (1995), 'Quine's “Two Dogmas of Empiricism”,' Philosophical Investigations, 18 (4), $305-$ 28

Husserl E. (1970), Die Krisis der europäischen Wissenschaften und die transzendentale Phänomenologie/The Crisis of European Sciences and Transcendental Phenomenology, Evanston: Northwestern University Press

Hutchins E. (1983), Cognition in the Wild, Cambridge (MA): The MIT Press

Hutto D.D. (2013), 'Enactivism, from a Wittgensteinian Point of View,'American Philosophical Quarterly, 50 (3), 281-302

Hylton P. (2007), Quine, New York e London: Routledge

Hyman J. (2014), 'Desires, Dispositions and Deviant Causal Chains,' Philosophy, 89, 83-112

Ichikawa J.J. and Steup M. (2018), 'The Analysis of Knowledge,' in E.N. Zalta (ed.), The Stanford Encyclopedia of Philosophy (Summer 2018 Edition), https://plato.stanford.edu/archives/sum2018/entries/knowledge-analysis

Isaac J. (2012), Working Knowledge: Making the Human Sciences from Parsons to Kuhn, Harvard: Harvard University Press

Isenberg, A. (1961), 'Review of Gellner 1959,' The Journal of Philosophy, 58, 110-112

James W. (1890), The Principles of Psychology, New York : Holt

Janik A. and Toulmin S., Wittgenstein's Vienna, New York: Simon and Schuster

Janssen T.M.V. (2011), 'Montague Semantics,' in E.N. Zalta (ed.), The Stanford Encyclopedia of Philosophy (Spring 2017 Edition), https://plato.stanford.edu/archives/spr2017/entries/montague-semantics

Janssen-Lauret F. (2017), 'The Quinean Roots of Lewis's Humeanism,' The Monist, 100 (2), 249-65. 
Janssen-Lauret F. and Macbride F. (2018), 'David Lewis's Place in the History of Late Analytic Philosophy: His Conservative and Liberal Methodology', in G. Bonino and P. Tripodi (eds.), History of Late Analytic Philosophy, special issue of Philosophical Inquiries, 6 (1), 53-74

Johnson M. (1987), The Body in the Mind, Chicago: University of Chicago Press

Kaldewey D. and Schauz D. (2018) (eds.), Basic and Applied Research: The Language of Science Policy in the Twentieth Century, New York-London: Berghahn

Kalhat J. (2007), 'Has the Later Wittgenstein Accounted for Necessity?,' Philosophical Investigations, 31, 1-23

Kandel E. and Squire L. (2000), 'Neuroscience: Breaking Down Scientific Barriers to the Study of Brain and Mind,' Science, 290, 1113-20

Kanger S. (1957), 'On the Characterization of Modalities,' Theoria, 23, 152-5

Kant I. (1781-1787/1999), Kritik der reinen Vernunft, Riga: Hartknoch, English translation Critique of Pure Reason, Cambridge: Cambridge University Press

Katz J.J. (1964), 'Semantic Theory and the Meaning of "Good”,' The Journal of Philosophy, 61 (23), 739-66

Katz J.J. (1965), 'The Relevance of Linguistics to Philosophy,' The Journal of Philosophy, 62 (20), 590-602

Katzav J. (2018), ‘Analytic Philosophy, 1925-1969: Emergence, Management and Nature,' British Journal for the History of Philosophy, 1197-1221

Katzav J. and Vaesen K. (2017),'On the emergence of American analytic philosophy,' British Journal for the History of Philosophy, 25 (4), 772-98

Kaufmann A.A. (1967), 'Behaviorism,' in P. Edwards (ed.), The Encyclopedia of Philosophy, New York: Macmillan

Kenny A. (1963), Action, Emotion, and Will, London: Routlegde and Kegan Paul

Kenny A. (1981/1984), 'Language and Mind,' in The Legacy of Wittgenstein, Oxford: Blackwell, $136-49$

Kenny A. (2005), Wittgenstein, 2nd ed., Oxford: Blackwell 
Keynes J.M. (1933), Essays in Biography, London: Macmillan

Keynes J.M. (1936), The General Theory of Employment, Interest and Money, London: Macmillan

Keynes J.M. (1978), The Collected Writings of John Maynard Keynes, vol. 14, London: Royal Economic Society

Kindi V.P. (1995), 'Kuhn's The Structure of Scientific Revolutions revisited,' Journal for General Philosophy of Science, 26 (1), 75-92

Kneale W. (1960), 'Review of Gellner 1959,' Hibbert Journal, 58, 196-8

Kornblith H. (1999), 'Timothy Williamson's The Philosophy of Philosophy', Analysis, 69 (1), 10916

Körner S. (1955), Kant, Harmondsworth: Penguin

Körner S. (1961), 'Review of Gellner 1959,' Philosophical Quarterly, 11, 376-379

Korsgaard C.M. (1996), The Sources of Normativity, Cambridge: Cambridge University Press

Kovessi J. (1967), Moral Notions, London: Routledge and Kegan Paul

Kraus K. (1909/1987), 'Der Fortschritt', in Schriften, Frankfurt: Suhrkamp Verlag

Krikorian H. (1944) (ed.), Naturalism and the Human Spirit, New York: Columbia University Press

Kripke S. (1959), 'A Completeness Theorem in Modal Logic,' The Journal of Symbolic Logic, 24, 114

Kripke S. (1962), 'The Undecidability of Monadic Modal Quantification Theory,' Zeitschrift für mathematische Logik und Grundlagen der Mathematik”, 8, 113-6

Kripke S. (1963a), 'Semantical Considerations on Modal Logic', Acta Philosophica Fennica, 16, 8394

Kripke S. (1963b), ‘Semantical Analysis of Modal Logic I, Normal Propositional Calculi,' Zeitschrift für mathematische Logik und Grundlagen der Mathematik, 9, 67-96

Kripke S. (1965a), 'Semantical Analysis of Intuitionistic Logic I,' in J.N. Crossley and M. Dummett (eds.), Formal Systems and Recursive Functions, Amsterdam: North Holland. 92-130 
Kripke S. (1965b), 'Semantical Analysis of Modal Logic II, Non-Normal Modal Propositional Calculi,' in J.W. Addison, A. Tarski and L. Henkin (eds.), The Theory of Models, Amsterdam: North Holland, 206-20Kripke S. (1972), Naming and Necessity, Cambridge (MA): Harvard University Press, 2nd ed. 1980

Kripke S. (1972/1980), Naming and Necessity, Cambridge (MA): Harvard University Press

Kripke S. (1982), Wittgenstein on Rules and Private Language, Oxford: Blackwell

Kristal E. (2002), ““Considering Coldly...”: A Response to Moretti,' New Left Review, 2 (15), 61-74

Kuhn T. (1962), The Structure of Scientific Revolutions, Chicago: University of Chicago Press

Kuhn T. (1970), The Structure of Scientific Revolutions, second edition, enlarged, Chicago: University of Chicago Press

Kuklick B. (2001), A History of Philosophy in America. 1720-2000, New York: Oxford University Press

Kusch M. (1995), Psychologism: A Case Study in the Sociology of Philosophical Knowledge, London: Routledge

Kusch M. (2000) (ed.), The Sociology of Philosophical Knowledge, Dordrecht: Springer

Kusch M. (2006), A Sceptical Guide to Meaning and Rules: Defending Kripke's Wittgenstein, London: Mcgill-Queen's University Press

Kusch M. (2011), 'Disagreement and Picture in Wittgenstein's Lectures on Religious Belief,' in R. Heinrich et al. (eds.), Image and Imaging in Philosophy, Science and the Arts, vol. 1, 35-58, Frankfurt: Ontos Verlag

Lacey N. (2004), A Life of H.L.A. Hart: The Nightmare and the Noble Dream, Oxford: Oxford University Press

Lakoff G. (1987), Women, Fire, and Dangerous Things, Chicago: The University of Chicago Press

Lakoff G. and Johnson M. (1980), Metaphors We Live By, Chicago: Chicago University Press

Lakoff G. and Johnson M. (1999), Philosophy in the Flesh: The Embodied Mind and its Challenge to Western Thought, New York: Basic Books 
Langacker R.W. (1987), Cognitive Grammar: A Basic Introduction, New York: Oxford University Press

Latour B. (1993), Nous $n$ 'avons jamais ete modernes/We Have Never Been Modern, Cambridge (MA): Harvard University Press

Latour B. (2005), Reassembling the Social, Oxford: Oxford University Press

Laugier S. (2011), 'Introduction to the French edition of Must We Mean What We Say?,' Critical Inquiry, 37 (4), 627-51

Lave J. and Wenger E. (1991), Situated Learning. Legitimate Peripheral Participation, Cambridge: Cambridge University Press

Lazerowitz M. (1949), ‘Are self-contradictory expressions meaningless?,' The Philosophical Review, $58,563-84$

Lear J. (1984), 'The Disappearing “We", Proceedings of the Aristotelian Society, Supplementary Volume, 58, 219-58

Leavis F.R. (1962/2013), Two Cultures?: The Significance of C. P. Snow (Canto Classics). Cambridge: Cambridge University Press

Lehrer K. (1960), 'Can We Know That We Have Free Will by Introspection?,' The Journal of Philosophy, 57 (5), 145-57

Leiter B. (2004), 'When will Britain Try to Recruit Its Leading Philosophers Home?,' https://leiterreports.typepad.com

Leitgeb H. (2011), 'New Life for Carnap's Aufbau?,' Synthese, 180, 265-99

Levinson S.C. (1983), Pragmatics, Cambridge: Cambridge University Press

Levinson S.C. (2000), Presumptive Meanings: the Theory of Generalized Conversational Implicature, Cambridge (MA): MIT Press

Lewis D.K. (1966), 'An Argument for the Identity Theory,' The Journal of Philosophy, 63, 17-2

Lewis D.K. (1969), Convention: A Philosophical Study, Cambridge (MA): Harvard University Press Lewis D.K. (1973), Counterfactuals, Oxford: Blackwell 
Lewis D.K. (1983), 'New Work For a Theory of Universals,' Australasian Journal of Philosophy, $61,343-77$

Lewis D.K. (1986), On the Plurality of Worlds, Oxford: Blackwell

Lewy C. (1940), 'Logical Necessity', The Philosophical Review, 49 (1), 62-8

Linsky L. (1957), 'Wittgenstein on Language and Some Problems of Philosophy,' The Journal of Philosophy, 54 (10), 285-93

Linsky L. (1969), 'Reference, Essentialism, and Modality,' The Journal of Philosophy, 66 (20), 687 700

Locke J. (1690), An Essay Concerning Human Understanding, London: Eliz. Holt for Thomas Basset

Lodge K. (2018), Interview with Professor Adrian Moore, http://www.thefreethinktank.com

Lyotard F. ( 1979/1984), La condition postmoderne: rapport sur le savoir, Paris: Les Éditions de Minuit, English translation The Postmodern Condition, Minneapolis: University of Minnesota Press

MacDonald M. (1951), 'Professor Ryle on the Concept of Mind,' The Philosophical Review, 60 (1), 80-90

MacIntyre A. (1958), The Unconscious: A Conceptual Study, London: Routledge and Kegan Paul

MacIntyre A. (1959), ‘The Hunt Is Up!,' New Statesman, 31 October, 597-8

Mackie J.L. (1977), Ethics, Inventing Right and Wrong, Middlesex: Penguin Books

Magee, B. (1971), Modern British Philosophy, Oxford: Oxford University Press

Magidor O. (2013), Category Mistakes, Oxford: Oxford University Press

Malcolm N. (1940), ‘Are Necessary Propositions Really Verbal?,' Mind, 49, 189-203

Malcolm N. (1942/1964), 'Moore and Ordinary Language', in V. C. Chappell (ed.), Ordinary Language, Englewood Cliffs: Prentice-Hall, 5-23

Malcolm N. (1951), 'Philosophy for Philosophers,' The Philosophical Review, 60 (3), 329-40 
Malcolm N. (1954), 'Wittgenstein's Philosophical Investigations,' The Philosophical Review, 63 (4), $530-59$

Malcolm N. (1956), 'Dreaming and Skepticism,' The Philosophical Review, 65 (1), 14-37

Malcolm N. (1958), 'I. Knowledge of Other Minds,' The Journal of Philosophy, 55 (23), 969-78

Malcolm N. (1958/2001), Ludwig Wittgenstein: A Memoir, Oxford: Clarendon Press

Malcolm N. (1959), Dreaming, London: Routledge and Kegan Paul

Malcolm N. (1960), ‘Anselm’s Ontological Arguments', The Philosophical Review, 69 (1) , 41-62

Malcolm N. (1963), 'Scientific Materialism and the Identity Theory: Comments,' The Journal of Philosophy, 60 (22), 662-63

Malcolm N. (1965), 'Scientific Materialism and the Identity Theory,' Dialogue, 3, 115-25

Malcolm N. (1967), 'Wittgenstein's Philosophische Bermerkungen,' The Philosophical Review, 76 (2), 220-9

Malcolm N. (1971), 'The Myth of Cognitive Processes and Structures,' in T. Mischel (ed.), Cognitive Development and Epistemology, New York: Academic Press, 385-92

Malcolm N. (1986), Wittgenstein's Criticism of His Early Thought, Oxford: Blackwell, 154-81

Malcolm, N. (1993), Wittgenstein: A Religious Point of View?, Oxford: Blackwell

Mancosu P. (2005), 'Harvard 1940-1941: Tarski, Carnap and Quine on a Finitistic Language of Mathematics for Science,' History and Philosophy of Logic, 26, 327-57

Mancosu P. (2008), 'Tarski, Neurath, and Kokoszynska on the Semantic Conception of Truth,' in D. Patterson (ed.), New Essays on Tarski and Philosophy, Oxford: Oxford University Press, 192-224

Marchionatti R. and Cedrini M. (2016), Economics as Social Science: Economics Imperialism and the Challenge of Interdisciplinarity, London: Routlegde

Marconi D. (1995), 'Fodor and Wittgenstein on Private Language', in R. Egidi (ed.), Wittgenstein: Mind and Language, Synthese Library (Studies in Epistemology, Logic, Methodology, and Philosophy of Science), vol 245, Dordrecht: Springer

Marconi D. (1997), Lexical Competence, Cambridge (MA): The MIT Press 
Marconi D. (2009), 'Being and Being Called', The Journal of Philosophy, 106 (3), 113-136

Marconi D. (2010), Wittgenstein and Necessary Facts, in Frascolla, Marconi, Voltolini (eds.), Wittgenstein: Mind, Meaning and Metaphilosophy, Palgrave Macmillan, Basingstoke, 139-65

Marconi D. (2011), 'Wittgenstein and Williamson on Conceptual Analysis,' in R. Davies (ed.), Analisi, Mimesis, Milano, 91-101

Marconi D. (2012), 'Quine and Wittgenstein on the Science/Philosophy Divide', in C. Gabbani, Between Two Images: the Manifest and Scientific Conceptions of the Human Being, 50 Years On, Humana Mente, 5(21), 173-89

Marcuse H. (1964), One-Dimensional Man. Studies in the Ideology of Advanced Industrial Society, London: Routledge

Marion M. (2000), 'Oxford Realism: Knowledge and Perception', Parts I and II, British Journal for the History of Philosophy, 8, 299-338, 485-519

Marion M. (2005), 'Sraffa and Wittgenstein: Physicalism and Constructivism,' Review of Political Economy, 17, 381-406

Marion M. (2018), 'Was Royaumont Merely a dialogue de sourds? An Introduction to the discussion générale', in G. Bonino and P. Tripodi (eds.), History of Late Analytic Philosophy, special issue of Philosophical Inquiries, 197-2014

Marras A. (1973). 'On Sellars' Linguistic Theory of Conceptual Activity,' Canadian Journal of Philosophy, 2, 471-83

Marshall A. (1890), Principles of Economics, London: Macmillan

Martin R.M. (1952), ‘On “Analytic”, Philosophical Studies, 3, 42-7

Mates B. (1951), 'Analytic Sentences,' The Philosophical Review, 60, 525-34

Mates B. (1958), 'On the Verification of Statements about Ordinary Language,' Inquiry: An Interdisciplinary Journal of Philosophy, 1 (1-4), 161-71

Maxwell G. and Feigl H. (1961), 'Why Ordinary Language Needs Reforming,' The Journal of Philosophy, 58 (18), 488-98

McDowell J. (1984), ‘Wittgenstein on Following a Rule,' Synthese, 58, 325-64 
McDowell J. (1994), Mind and World, Cambridge (MA): Harvard University Press

McDowell J. (1998), Mind, Value, and Reality, Cambridge (MA): Harvard University Press

McDowell J. (2002), Responses, in N. Smith (ed.), Reading McDowell, London: Routledge, 269-305

McGuinness B.F. (1966), 'The Mysticism of the Tractatus,' The Philosophical Review, 75 (3), $305-$ 28

McGuinness B.F. (2008), 'What Wittgenstein Owed to Sraffa,' in G. Chiodi, L. Ditta (eds.), Sraffa or An Alternative Economics, London: Palgrave Macmillan, 227-35

Mead G.H. (1934), Mind, Self and Society, Chicago: The University of Chicago Press

Mehta, V. (1962), Fly and the Fly-Bottle: Encounters with British Intellectuals, Little: Brown

Melden A.I. (1956), 'Action,' The Philosophical Review, 65 (4), 523-41

Melden A.I. (1961), Free Action, London: Routledge and Kegan Paul

Menand L. (2010), The Marketplace of Ideas, London: W. Norton \& Company Ltd

Merleau-Ponty M. (1962), Phénomènologie de la perception/Phenomenology of Perception, London and New York: Routledge

Merton R.K. (1942), Social Theory and Social Structure, New York: The Free Press

Metzger W. (1987), 'The Academic Profession in the United States,' in B.R. Clark (ed.), The Academic Profession: National, Disciplinary, and Institutional Settings, Berkeley: University of California Press, 123-208

Mill J.S. (1843), A System of Logic Ratiocinative and Inductive, London: Longmans, Green and Co.

Miller G.A. (2003), 'The Cognitive Revolution: a Historical Perspective. Trends in Cognitive Sciences', 7 (3), 141-4

Millikan R.G. (1984), Language, Thought, and Other Biological Categories, Cambridge (MA)-London: MIT Press

Minsky H.P. (1982), 'The Financial-Instability Hypothesis: Capitalist Processes and the Behavior of the Economy', Hyman P. Minsky Archive, 282, https://digitalcommons.bard.edu/hm_archive/282 
Mirowski P. (2012), 'The Unreasonable Efficacy of Mathematics in Modern Economics,' in U. Mäki at al. (eds.), Philosophy of Economics. North Holland: Elsevier, 159-97

Modigliani F. (1980), 'Introduction,' in The Collected Papers of Franco Modigliani, Cambridge (MA): A. Abel

Monk R. (1990), Ludwig Wittgenstein the Duty of Genius, London: Jonathan Cape Ltd

Montague R. (1960), 'Logical Necessity, Physical Necessity, Ethics, and Quantifiers,' Inquiry, 3, 259-69

Montague R. (1970), 'English as a Formal Language,' in B. Visentini et al. (eds.), Linguaggi nella Società e nella Tecnica, Milano: Edizioni di Comunità, 188-221

Moore, A.W. (2009), 'Not to be Taken at Face Value,' Analysis, 69 (1), 116-25

Moore E.H. (1915), 'Definition of Limit in General Integral Analysis,' 1, (12), Proceedings of the National Academy of Sciences of the United States of America, 628-632

Moore G.E. (1903), Principia Ethica, Cambridge: Cambridge University Press

Moore G.E. (1939), 'Proof of an External World', Proceedings of the British Academy, 25, 273-300

Moran R.A. (2001), Authority and Estrangement: An Essay on Self-Knowledge, Princeton: Princeton University Press

Moretti F. (2000/2013), 'Conjectures on World Literature,' in Distant Reading, London: Verso, 4362

Moretti F. (2003/2013), ‘More Conjectures', in Distant Reading, London: Verso, 107-19

Moretti F. (2005), Graphs, Maps, and Trees: Abstract Models for Literary History, London: Verso

Moretti F. (2013), Distant Reading, London: Verso

Morgenbesser S. (1963), 'Introductory Remarks,' The Journal of Philosophy, 60 (14), 365-67

Mormann T. (1999), 'Neurath's Opposition to Tarskian Semantics,' in F. Stadler and J. Woleński (eds.), Tarski and the Vienna Circle, Vienna Circle Institute Yearbook, 6, 165-78

Mosedale F.E. (1978), 'On Saying What is Obvious', Metaphilosophy, 9 (1), 14-22. 
Mountcastle V.B. (1957), 'Modality and Topographic Properties af Single Neurons af Cat's Somatosensory Cortex,' Journal of Neurophysiology, 20, 408-34

Moyal-Sharrock D. (2004) (ed.), The Third Wittgenstein: The Post-Investigations Works, London: Ashgate

Moyal-Sharrock D. (2014), 'Revolutionary Insight', Interview on Wittgenstein, https://simplycharly.com/interviews

Moyal-Sharrock D. (2016), 'Wittgenstein Today,' Wittgenstein-Studien, 7 (1), 1-14

Mulhall, S. (1994), 'Review of G. Ryle, Aspects of Mind,' Philosophical Investigations 17, 444-456

Musgrave A. (1999), 'Obituary: Professor John Watkins', Independent, August 5

Nagel E. (1936), 'Impressions and Appraisals of Analytic Philosophy in Europe', The Journal of Philosophy, 33, 5-24, 29-53

Nagel T. (1974), 'What is it Like to Be a Bat?,' The Philosophical Review, 83, 435-50

Nagel T. (1986), A View from Nowhere, Oxford: Oxford University Press

Newell R.W. (1986), Objectivity, Empiricism and Truth, London: Routledge and Kegan Paul

Noë A. (2005), Action in Perception, Cambridge (MA): MIT Press

Nozick R. (1974), Anarchy, State, and Utopia, New York: Basic Books

Nozick R. (1981), Philosophical Explanations, Cambridge (MA): Harvard University Press

Nuchelmans G. (1961), 'Mr Gellner's Attack on Linguistic Philosophy,' Synthese 13, 88-97

O’Grady J. (2006), 'Sir Peter Strawson', The Guardian, 15 February

O’Regan J.K. and Noë A. (2001), 'A Sensorimotor Account of Vision and Visual Consciousness ,' Behavioral and Brain Sciences, 24, 939-1031

O’Shea J. (2007), Wilfrid Sellars: Naturalism with a Normative Turn, London: Polity Press

Olen P. (2016), Wilfrid Sellars: The Foundations of Normativity, London: Palgrave Macmillan

Pap A. (1949), Elements of Analytic Philosophy, New York: Macmillan 
Parfit D. (1984), Reasons and Persons, Oxford: Oxford University Press

Parsons T. (1951), The Social System, Chicago: Free Press

Pascal B. (1670/1976), Pensées, Paris: GF-Flammarion

Peacocke C. (1992), A Study of Concepts, Cambridge (MA): MIT Press

Pears D. (1950), 'Synthetic Necessary Truth,' Mind, 59, 199-208

Pears D. (1952), 'The Incongruity of Counterparts,' Mind, 61, 78-81

Pears D. (1953), 'Incompatibilities of Colours,' in A. Flew (ed.), Logic and Language, Oxford: Blackwell, 112-22

Penco C. (2010), 'The Influence of Einstein on Wittgenstein's Philosophy,' Philosophical Investigations, 33 (4), 360-79

Penelhum T. (1970), Survival and Disembodied Existence, London: Routledge and Kegan Paul

Peters R.S. (1958), The Concept of Motivation, London: Routledge and Kegan Paul

Pettit P. (1990), 'The Reality of Rule-Following,' Mind, 99 (393), 1-21

Pivcevic E. (1989), ‘An Interview with Professor Sir Peter Strawson', Cogito, 4, 3-8

Place U.T. (1956), Is Consciousness a Brain Process?, British Journal of Psychology, 47, 1, 44-50

Plumb J.H. (1964), Crisis in the Humanities, Harmondsworth: Penguin Books Ltd.

Polanyi K. (1944), The Great Transformation, Boston: Beacon

Pole D. (1958) The Later Philosophy of Wittgenstein, London: Athlone Press

Popper K. (1935/1959/2002), Logik der Forschung, Vienna: Verlag von Julius Springer, 1935, English translation The Logic of Scientific Discovery, 1959 and 2002, London: Routledge

Popper K. (1945), The Open Society and Its Enemies, London: Routledge \& Kegan Paul Popper K. (1945/2009), The Open Society and Its Enemies, London: George Routledge \& Sons 
Price H.H. (1953a), 'The Study of Philosophy at Oxford,' in The Teaching of Philosophy: An international enquiry of Unesco, Paris: United Nations Educational, Scientific and Cultural Organization, $128-30$

Price H.H. (1953b), Thinking and Experience, London: Hutchinson

Prior A.N. (1957), Time and Modality, Oxford: Oxford University Press

Proudfoot D. (1997), ‘On Wittgenstein on Cognitive Science,' Philosophy. 72, 189 - 217

Putnam H. (1957), 'Psychological Concepts, Explication, and Ordinary Language,' The Journal of Philosophy, 54 (4), 94-100

Putnam H. (1960a), 'Minds and Machines,' in S. Hooke (ed.), Dimensions of Mind, New York: Collier

Putnam H. (1960b), 'Review of Max Black, Problems of Analysis: Philosophical Essays,' The Journal of Philosophy, 57 (1), 38-44

Putnam H. (1962), What Theories are not, in E. Nagel et al. (eds.), Logic, Methodology and Philosophy of Science, Stanford: Stanford University Press, 240-252

Putnam H. (1962/1975), 'Dreaming and “Depth Grammar",' in Mind, Language and Reality: Philosophical Papers, vol. 2, Cambridge (MA): Cambridge University Press, 304-324

Putnam H. (1963), 'Brains and Behavior,' in R.J. Butler (ed.), Analytical Philosophy, Second Series, Oxford: Basil Blackwell, 211-35

Putnam H. (1964), 'Robots: Machines or Artificially Created Life?,' The Journal of Philosophy, 61 (21), 668-91

Putnam H. (1975), 'The Meaning of "Meaning",', in K. Gunderson (ed.), Language, Mind, and Knowledge, Minnesota Studies in the Philosophy of Science, 7, 131-93

Putnam H. (1981), Reason, Truth and History, Cambridge: Cambridge University Press

Putnam H. (1987), The Many Faces of Realism, La Salle: Open Court

Putnam H. (1994), 'Rethinking Mathemtical Necessity,' in J. Conant (ed.), Words and Life, Cambridge (MA): Harvard University Press, 245-63 
Putnam H. (1997), 'A Half Century of Philosophy, Viewed from Within,' in Daedalus: Procee-dings of the American Academy of Arts and Sciences, 126, 1, 175-208

Quine W.V.O. (1934), A System of Logistic, Cambridge (MA): Harvard University Press

Quine W.V.O. (1936/1966), ‘Truth by Convention', in W.V.O. Quine (1966), 77-106

Quine W.V.O. (1943), 'Notes on Existence and Necessity', The Journal of Philosophy, 40, 113-27

Quine W.V.O. (1947), 'The Problem of Interpreting Modal Logic,' The Journal of Symbolic Logic, $12,43-8$

Quine W.V.O. (1948), 'On What There Is,' The Review of Metaphysics, 2, 21-36

Quine W.V.O. (1951a), 'On Carnap's Views on Ontology,' Philosophical Studies, 2, 65-72

Quine W.V.O. (1951b), 'Two Dogmas of Empiricism,' The Philosophical Review, 60, 20-43

Quine W.V.O. (1953a), 'Reference and Modality', in From a Logical Point of View, Cambridge (MA): Harvard University Press, 139-59

Quine W.V.O. (1953b), From a Logical Point of View, Cambridge (MA): Harvard University Press

Quine W.V.O. (1960a), 'Carnap and Logical Truth,' Synthese, 12, 350-74

Quine W.V.O. (1960b), Word and Object, Cambridge (MA): The MIT Press

Quine W.V.O. (1964), 'Review of P.T. Geach, Reference and Generality', The Philosophical Review, $73(1), 100-4$

Quine W.V.O. (1966), The Ways of Paradox, New York: Random

Quine W.V.O. (1969a), 'Foreword,' in Lewis D.K. 1969), Convention: A Philosophical Study, Cambridge (MA): Harvard University Press, xi-xii

Quine W.V.O. (1969b), Ontological Relativity and Other Essays, New York: Columbia University Press

Quine W.V.O. (1985), The Time of My Life: An Autobiography, Cambridge (MA): The MIT Press

Quine W.V.O. (1995), From Stimulus to Science, Cambridge (MA): Harvard University Press 
Quinton A. (1961), 'Review of Gellner 1959,' British Journal for the Philosophy of Science, 11, 337344

Ramsey F. (1931), The Foundations of Mathematics and other Logical Essays, London-New York: Kegan Paul, Trench, Trubner \& Co., Harcourt, Brace and Company

Rawls J. (1971), A Theory of Justice, Cambridge: MIT Press

Rawls J. (1993), Political Liberalism, New York: Columbia University Press

Rawls J. (2001), 'Afterword: a Reminiscence,' in J. Floyd and S. Shieh (eds.), Future Pasts: The Analytic Tradition in Twentieth-Century Philosophy, Oxford: Oxford University Press, 417-3

Read R. (2012), Wittgenstein among the Sciences: Wittgensteinian Investigations into the "Scientific Method", Farnham: Ashgate

Recanati F. (2002), Literal Meaning, Cambridge: Cambridge University Press

Reck E.H. (2013), 'Developments in Logic: Carnap, Gödel and Tarski,' in M. Beaney (ed.), The Oxford Handbook of the History of Analytic Philosophy, Oxford: Oxford University Press, 54671.

Reck E.H. (2013), The Historical Turn in Analytic Philosophy, Basingstoke: Palgrave Macmillan

Rée J. (1993), 'English Philosophy in the Fifties,' Radical Philosophy, 65, 3-21

Reichenbach H. (1945), The Rise of Scientific Philosophy, Berkeley: University of California Press

Reisch G.A. (2005), How the Cold War Transformed Philosophy of Science: To the Icy Slopes of Logic, Cambridge: Cambridge University Press

Rescher N. (2005), 'Logicians at RAND,' in Studies in 20th Century Philosophy, Frankfurt: Ontos, $181-208$

Rhees R. (1963), 'The Tractatus: Seeds of Some Misunderstandings,' The Philosophical Review, 72 (2), 213-20

Rhees R. (1965), 'III: Some Developments in Wittgenstein's View of Ethics,' The Philosophical Review, 74 (1), 17-26

Rhees R. (1968), 'I: Note on the Text,' The Philosophical Review 77 (3), 271-75 
Richardson A. (1998), Carnap's Construction of the World, Cambridge: Cambridge University Press

Richman R.J. (1961), 'On the Argument of the Paradigm Case', Australasian Journal of Philosophy, $39(1), 75-81$

Robertson A. (1977), 'Conrad Hal Waddington F.R.S.', in Biographical Memoirs of Fellows of the Royal Society, vol. 23, 575-622

Rollins C.D. (1985), 'O.K. Bouwsma: 1937 and Later', Philosophical Investigations, 8, 208-216

Roncaglia (1978), Sraffa and the Theory of Prices, New York: Wiley

Roncaglia A. (2005), The Wealth of Ideas: a History of Economic Thought, Cambridge: Cambridge University Press

Rorty R. (1961), 'Pragmatism, Categories, and Language,' The Philosophical Review, 70 (2), 197 223

Rorty R. (1970), 'Incorrigibility as the Mark of the Mental,' The Journal of Philosophy, 67 (12), 399424

Rorty R. (1977), 'Wittgensteinian Philosophy and Empirical Psychology,' Philosophical Studies, 31, $151-72$

Rorty R. (1979), Philosophy and the Mirror of Nature, Princeton: Princeton University Press

Rorty R. (1982), Consequences of Pragmatism, Minneapolis: University of Minnesota Press

Rorty R. (1989), Contingency, Irony, and Solidarity, Cambridge: Cambridge University Press

Rosch E. (1973), 'Natural Categories,' Cognitive Psychology, 4 (3), 328-50

Rosch E. (1975), 'Cognitive Representations of Semantic Categories,' Journal of Experimental Psychology: General, 104 (3), 192-233

Rosch E. (1978), Cognition and Categorization, Hillsdale: Lawrence Erlbaum

Rosch E. and Mervis C. (1975), 'Family Resemblances: Studies in the Internal Structure of Categories,' Cognitive Psychology, 7, 573-605

Royal Society (1963), Emigration of Scientists from the UK, London: Royal Society 
Royaumont (1958/2018), 'General discussion, Royaumont Colloquium 1958 - Analytic Philosophy,' in G. Bonino and P. Tripodi (eds.), History of Late Analytic Philosophy, special issue of Philosophical Inquiries, 215-55

Russell B. (1905), 'On Denoting,' Mind, 114 (456), 873-87

Russell B. (1912), The Problems of Philosophy, London: Williams and Norgate

Russell B. (1922), Introduction, in Wittgenstein (1922), ix-xxii

Russell B. (1959), My Philosophical Development, London: Allen and Unwin

Russell B. (1959b), Introduction, in E. Gellner, Words and Things: An Examination of, and an Attack on, Linguistic Philosophy, London: Gollanz, 13-15

Russell B. (1997), The Collected Papers of Bertrand Russell, vol. 11, Last Testament: 1943:68, London and New York: Routledge

Ryle G. (1947), 'Review of The Open Society and Its Enemies by K.R. Popper', Mind, 167-172

Ryle G. (1949), The Concept of Mind, London-New York: Hutchinson's University Library

Ryle G. (1949/2009), 'Discussion of Rudolf Carnap: "Meaning and Necessity”,' in Collected Papers, vol. 1, London: Routledge, 225-235

Ryle G. (1951/2009), 'Ludwig Wittgenstein', Analysis, 12, reprinted in Collected Papers, vol. 1, London: Routledge, 257-66

Ryle G. (1957) 'Review of Ludwig Wittgenstein: Remarks on the Foundations of Mathematics', Scientific American, 117, reprinted in Collected Papers, vol. 1, London: Routledge, 267-77.

Sacks H. Harvey, Schegloff E.A. and Jefferson G. (1974), 'A Simplest Systematics for the Organization of Turn-Taking for Conversation,' Language, 50 (4), 696-735

Salles M. (2017), 'On Quine on Arrow', Social Choice and Welfare, 1-10

Salmon N. (1982), Reference and Essence, Oxford: Blackwell

Samuelson P.A. (1947), Foundations of Economic Analysis, Harvard: Harvard University Press

Samuelson P.A. (1951), 'Schumpeter as a Teacher and Economic Theorist.' Review of Economics and Statistics, 33 (2): 98-103 
Samuelson P.A. (1952), 'Economic Theory and Mathematics - An Appraisal,' American Economic Review, 42 (2), 56-66

Samuelson P.A. (1955), Economics, $3^{\text {rd }}$ edition, New York: McGraw-Hill

Samuelson P.A. (1998), 'How Foundations Came to Be,' Journal of Economic Literature, 36 (3), 1375-86

Sandis C. (2015), 'One Fell Swoop Small Red Book Historicism Before and After Davidson,' Journal of the Philosophy of History, 9 (5), 37-9

Scanlon T. (1998), 'What We Owe to Each Other,' Cambridge (MA): Belknap Press of Harvard University Press

Schank R.C. and Abelson R.P., (1977), Scripts, Plans, Goals and Understanding, an Inquiry into Human Knowledge Structures, Hillsdale: Lawrence Erlbaum Associates

Schilpp P.A. (1963) (ed.), The Philosophy of Rudolf Carnap, La Salle: Open Court

Schlick M. (1936), 'Meaning and Verification', The Philosophical Review, 45 (4), 339-69

Schliesser E. (2016), 'On Late Analytic Philosophy: or the Age of David Lewis,' https://digressionsnimpressions.typepad.com/digressionsimpressions/2016/05/on-late-analytic-philosophy-orthe-age-of-david-lewis.html

Schorske C.E. (1980), Fin de siècle Vienna: Politics and Culture, New York: Knopf

Schorske C.E. (1998), 'The New Rigorism in the Human Sciences, 1940-1960,' in T. Bender, C. E. Schorske (eds.), American Academic Culture in Transformation: Fifty Years, Four Disciplines, Princeton: Princeton University Press, 309-30

Schroeder S. (1997), 'The Concept of Dreaming: on Three Theses by Malcolm,' Philosophical Investigations, $20,15-38$

Schroeder S. (2007), 'The Tightrope Walker', Ratio (new series), XX, 442-63

Schroeder S. (2009), 'Analytical truths and grammatical propositions,' in H.-J. Glock and J. Hyman (eds.), Wittgenstein and Analytic Philosophy, Oxford: Oxford University Press, 83-108

Schroeder S. (2010), 'Wittgenstein,' in T. O’Connor and C. Sandis (eds.), A Companion to the Philosophy of Action, Oxford: Wiley-Blackwell, 554-61 
Schwartz C.A. (1995), 'Research Specialization and the Refereeing Process', Proceedings and Addresses of the American Philosophical Association, 69 (2), 147-53

Scoville W.B. and Milner .B (1957), 'Loss of Recent Memory after Bilateral Hippocampal Lesions,' Journal of Neurology, Neurosurgery, Psychiatry, 20, 11-21

Searle J.R. (1962), 'Meaning and Speech Acts,' The Philosophical Review, 71 (4), 423-32

Searle J.R. (1969), Speech Acts, Cambridge: Cambridge University Press

Searle, J.R. (1980), 'Minds, Brains, and Programs,' Behavioral and Brain Sciences, 3 (3): 417-57

Searle J.R. (1983), Intentionality, Cambridge: Cambridge University Press

Searle J.R. (1992), The Rediscovery of the Mind, Cambridge: MIT Press

Searle J.R. (1995), The Construction of Social Reality, New York: Free Press

Searle J.R. (1996), Contemporary Philosophy in the United States, in N. Bunnin and E.P. Tsui-James (eds.), The Blackwell Companion to Philosophy, Oxford: Blackwell, 1-24

Sebestik J. (1990), 'Premières réactions continentales au Tractatus (Jean Cavaillès, Jan Patočka), Acta du colloque Wittgenstein, Collège International de Philosophie, 1988, Mauzevin: TER,197209

Sellars R.W. (1946), 'The Philosophy and Physics of Relativity,' Philosophy of Science, 13 (3), $177-$ 195

Sellars R.W., Mcgill V.J. and Farber M. (1949), Philosophy for the Future: The Quest of Modern Materialism, New York: Macmillan

Sellars W. (1947), 'Epistemology and the New Way of Words,' The Journal of Philosophy: 645-60

Sellars W. (1948), 'Realism and the New Way of Words,' Philosophy and Phenomenological Research, 8, 601-34

Sellars W. (1953a), 'Inference and Meaning,' Mind, 62, 313-38

Sellars W. (1953b), 'Is There a Synthetic A Priori?,' Philosophy of Science, 20, 121-38

Sellars W. (1954a), ‘Some Reflections on Language Games,' Philosophy of Science 21 (3), 204-28 
Sellars W. (1954b), 'Presupposing,' The Philosophical Review, 63 (2), 197-215

Sellars W. (1956), 'Empiricism and the Philosophy of Mind,' in H. Feigl and M. Scriven (eds.), Minnesota Studies in The Philosophy of Science, Vol. I: The Foundations of Science and the Concepts of Psychology and Psychoanalysis, Minneapolis: University of Minnesota Press, 253-329

Sellars W. (1957), 'I. Substance and Form in Aristotle,' The Journal of Philosophy, 54 (22), 688-99

Sellars W. (1961), 'The Language of Theories,' on H. Feigl and G. Maxwell (eds.), Current Issues in the Philosophy of Science, New York: Holt, Rinehart and Winston, 57-77

Sellars W. (1962), 'Philosophy and the Scientific Image of Man,' in R. Colodny (ed.), Frontiers of Science and Philosophy, Pisttsburgh: University of Pittsburgh Press, 35-78

Sellars W. (1962/1963), 'Truth and “Correspondence”,' in Sellars W. (1963), 197-224

Sellars, Wilfrid (1963), Science, Perception and Reality, London: Routledge \& Kegan Paul

Sellars W. (1964), 'Notes on Intentionality,' The Journal of Philosophy, 61 (21), 655-65

Sellars W. (1968), Science and Metaphysics: Variations on Kantian Themes, London: Routledge \& Kegan Paul

Sellars W. (1969/1974), 'Language as Thought and as Communication,' in Essays in Philosophy and its History, Dordrecht, Holland: D. Reidel, 93-117

Sellars W. (1970), 'Belief and the Expression of Belief,' in H.E. Kiefer and M.K. Munitz, Language, Belief, and Metaphysics, 146-58, Albany, NY: State University of New York Press, 146-58

Sellars W. (1974), 'Meaning as Functional Classification (A Perspective on the Relation of Syntax to Semantics),' Synthese, 27, 417-37

Sellars W. (1975), 'Autobiographical Reflections,' in H.-N. Castañeda (ed.), Action, Knowledge and Reality, New York: Bobbs-Merrill, 277-93

Sellars, Wilfrid (1980), Naturalism and Ontology, Atascadero, CA: Ridgeview Publishing Company

Sen A.K. (2003), 'Sraffa, Wittgenstein, and Gramsci,' Journal of Economic Literature, 41, 1240-55

Sharrock W. and Read R. (2002), Kuhn: Philosopher of Scientific Revolutions, Cambridge: Polity Press 
Shook J.R. (2005) (ed.), The Dictionary of Modern American Philosophers, Bristol: Thoemmes

Sider T. (2003), 'Reductive Theories of Modality,' in M.J. Loux, and D. W. Zimmerman (eds.), The Oxford Handbook of Metaphysics, Oxford: Oxford University Press, 180-208

Simons P. (2013), 'Metaphysics in Analytic Philosophy,' in M. Beaney (ed.), The Oxford Handbook of the History of Analytic Philosophy, Oxford: Oxford University Press, 709-28

Skidelsky R. (2003), John Maynard Keynes 1883-1946: Economist, Philosopher, Statesman, London: Macmillan

Skinner B.F. (1957), Verbal Behavior, New York: Appleton-Century-Crofts

Small H. (1973), 'Co-Citation in the Scientific Literature: A New Measure of the Relationship Between Two Documents,' Journal of the American Society for Information Science, 24, 265-8

Small H. (1999), 'Visualizing Science by Citation Mapping,' Journal of the American Society of Information Science, 50, 799-813

Smart J.J.C. (1959), 'Sensations and Brain Processes,' The Philosophical Review, 68, 141-56

Smart J.J.C. (1961), 'Further Remarks on Sensations and Brain Processes,' The Philosophical Review, $70(3), 406-7$

Smart J.J.C. (1963), 'Materialism,' The Journal of Philosophy, 60, 651-63

Smith N. (1999), Chomsky: Ideas and Ideals, Cambridge: Cambridge University Press

Snow C.P. (1959/2001), The Two Cultures. London: Cambridge University Press

Soames S. (2003), Philosophical Analysis in the Twentieth-Century, 2 voll., Princeton: Princeton University Press,

Soames S. (2004), Philosophical Analysis in the Twentieth-Century, 2 voll., Princeton: Princeton University Press

Soames S. (2008/2014), 'Analytic Philosophy in America', in Analytic Philosophy in America: And Other Historical and Contemporary Essays, Princeton: Princeton University Press: 3-34

Soames S. (2014), David Lewis's Place in Analytic Philosophy, in B. Loewer, J. Schaffer (eds.), A Companion to David Lewis, Princeton: Princeton University Press,139-66 
Speaks J. (2019), 'Theories of Meaning,' in E.N. Zalta (ed.), The Stanford Encyclopedia of Philosophy (Fall 2019 Edition), https://plato.stanford.edu/archives/fall2019/entries/meaning

Sperber D. and Wilson D. (1986), Relevance: Communication and Cognition, Oxford: Blackwell

Sraffa P. (1926), 'The Laws of Returns under Competitive Conditions,' The Economic Journal, 36, $535-50$

Stalnaker R. (1968), 'A Theory of Conditionals,' in N. Rescher (ed.), Studies in Logical Theory, Oxford: Blackwell, 98-112

Stanley J. and Williamson T. (2001), 'Knowing How,' The Journal of Philosophy, 98 (8), 411-44

Steinmetz G. (2005), The Politics of Method in the Human Sciences: Positivism and Its Epistemological Others, Durham-London: Duke University Press

Stenius E. (1965), 'Are True Numerical Statements Analytic or Synthetic?,' The Philosophical Review, 74, 357-72

Stern D.G. (1991), 'Models of Memory: Wittgenstein and Cognitive Science,' Philosophical Psychology, 4 (2), 203-18

Stern, D.G. (2002) 'Nestroy, Augustine, and the Opening of the Philosophical Investigations,' in R. Haller and K. Puhl (eds.), Philosophical Investigations, Wien: Hölder-Pichler-Tempsky

Stern D.G. (2004), Wittgenstein's Philosophical Investigations: An Introduction, Cambridge: Cambridge University Press

Stevens S.S. (1939), 'Psychology and the Science of Science,' Psychological Bulletin, 36, 221-63

Stoutland F. (1976), 'The Causation of Behavior,' in J. Hintikka (ed.), Essays on Wittgenstein in Honor of G.H. von Wright, Amsterdam: North Holland, 286-325

Stoutland F. (1982), 'Philosophy of Action: Davidson, von Wright, and the Debate over Causation,' in G. Fløistad (ed.), Contemporary Philosophy, Vol. 3, Philosophy of Action, Dordrecht: Martinus Nijhoff Publishers, 45-72 
Stoutland F. (1999), 'Intentionalists and Davidson on Rational Explanation,' in G. Meggle (ed.), Action, Norms and Values. Discussions with G.H. von Wright, Berlin-New York: Walter de Gruyter, 191-208

Strawson P.F. (1959), Individuals: An Essay in Descriptive Metaphysics, London: Methuen

Strawson P.F. (1960), ‘The Post-Linguistic Thaw', Times Literary Supplement, 9 September 1960

Strawson P.F. (1963), 'Carnap's Views on Constructed Systems Versus Natural Languages in Analytic Philosophy,' in P.A. Schilpp (ed.), The Philosophy of Rudolf Carnap, La Salle: Open Court,503-18

Strawson P.F. (1966), The Bounds of Sense, London: Methuen

Strawson P.F. (1968), 'Bennett on Kant's Analytic,' The Philosophical Review, 77 (3), 332-39

Strawson P.F. (1998), 'Intellectual Autobiography,' in L. Hahn (ed.), The Philosophy of P.F. Strawson, Chicago: Open Court

Strawson P.F. (2003), 'A Bit of Intellectual Autobiography,' in H.-J. Glock (ed.), Strawson and Kant, Oxford: Oxford University Press, 7-14

Stroud B. (1965), 'Wittgenstein and Logical Necessity', The Philosophical Review, 74, 504-18

Stump D. (2011), 'Arthur Pap's Functional Theory of the A Priori,' Hopos: The Journal of the International Society for the History of Philosophy of Science, 1 (2), 273-90

Sullivan G. (2017), Wittgenstein's Philosophy in Psychology: Interpretations and Applications in Historical Context, Basingstoke: Palgrave Macmillan

Tanney J. (2015), 'Gilbert Ryle,' The Stanford Encyclopedia of Philosophy (Spring 2015 Edition), E.N. Zalta (ed.), https://plato.stanford.edu/archives/spr2015/entries/ryle

Tarski A. (1933/1935), 'Pojęcie prawdy w językach nauk dedukcyjnych'/'Der Wahrheitsbegriff in den formalisierten Sprachen', Studia Philosophica, 1935, 1, 261-405

Tarski A. (1936), 'Über den Begriff der logischen Folgerung', in Actes du Congrès International de Philosophie Scientifique, fasc. 7, Actualités Scientifiques et Industrielles, 394, Paris: Hermann et Cie, $1-11$ 
Taylor C. (1989), Sources of the Self: The Making of the Modern Identity, Cambridge (MA): Harvard University Press

Taylor C. (2007), A Secular Age, Cambridge (MA): Harvard University Press

Taylor, L. (1998), 'Capital Market Crises: Liberalisation, Fixed Exchange Rates and Market-Driven Destabilization,' Cambridge Journal of Economics, 22, 663-76

Teichman J. (1974), The Mind and the Soul, London: Routledge and Kegan Paul

Tidman P. (1994), 'Conceivability as a Test for Possibility,' American Philosophical Quarterly, 31 (4), 297-309

Tolman E.C. (1935), 'Psychology Versus Immediate Experience,' Philosophy of Science, 2 (3), 35680

Tolman E.C. (1948), 'Cognitive Maps in Rats and Men,' The Psychological Review, 55, 189-208

Tolstoy L. (1896), Краткое Изложение Евангелия/The Gospel in Brief, New York: Thomas Y. Cromwell Company

Tomasello M. (1999), The Cultural Origins of Human Cognition, Cambridge (MA)-London: Harvard University Press

Tomasello M. (2003), Constructing a Language: a Usage-Based Theory of Language Acquisition, Cambridge (MA): Harvard University Press

Tomasello M. et al. (2005), 'Understanding and Sharing Intentions: The Origins of Cultural Cognition,', Behavioral and Brain Sciences, 28, 675-735

Tomasini Bassols A. (2010), 'Meaning and Action,' in J. Padilla Gálvez (ed.), Philosophical Anthropology: Wittgenstein's Perspective, Frankfurt-New Brunswick: Ontos Verlag, 47-60

Toulmin S. (1949), ‘A Defence of Synthetic Necessary Truth,' Mind, 59, 164-77

Toulmin S. (1959), 'Criticism in the History of Science: Newton on Absolute Space, Time, and Motion, II,' The Philosophical Review, 68 (2), 203-27

Tripodi P. (2002), 'La logica filosofica di Georg Henrik von Wright fra Wittgenstein e Carnap,' Rivista di Filosofia, 93, 429-58 
Tripodi P. (2011), 'Revisiting Sellars: Behaviorism and the Myth of Jones,' History of Philosophy Quarterly, 28, 85-105

Tripodi P. (2011), Peter, Stephen, and ... Ludwig, in R. Davies (ed.), Analisi, Mimesis, Milano, 10315

Tripodi P. (2013a), 'Wittgenstein: Necessity, Imagination, and Metaphilosophy,' Philosophical Inquiries, 1 (2), 55-78

Tripodi P. (2013b), 'Wittgenstein on the Gulf between Believers and Non-Believers,' Philosophia: Philosophical Quarterly of Israel, 41, 63-79

Tripodi P. (2015), 'Davidson and the Wittgensteinians on Reasons and Causes,' in D. Moyal-Sharrock, V. Munz, A. Coliva (eds.), Mind, Language \& Action, Berlin/Munich/Boston: Walter de Gruyter, 137-56

Turing A. (1936), 'On Computable Numbers, with an Application to the Entscheidungsproblem,' Proceedings of the London Mathematical Society, 2 (42), 230-65

Urmson J.O. (1956), 'Some Questions concerning Validity’, in A. Flew (ed.), Essays in Conceptual Analysis, London: Macmillan, 120-33

Urmson J.O. (1961/1967), 'Discussion of Urmson's "The History of Analysis" at the Royaumont Colloquium', in R. Rorty (ed.), The Linguistic Turn: Recent Essays in Philosophical Method, 30211, Chicago: University of Chicago Press

Urmson J.O. (1969), 'Russell on Acquaintance with the Past,' The Philosophical Review, 78 (4), 510-15

Uschanov T.P. (2000), The Strange Death of Ordinary Language Philosophy, http://www.helsinki.fi/ tuschano/writings/strange/

Uschanov T.P. (2002), Ernest Gellner's Criticisms of Wittgenstein and Ordinary Language Philosophy, in G. Kitching and N. Pleasants (eds.), Marx and Wittgenstein: Knowledge, Morality and Politics, London: Routledge, 23-47

Vaesen K. and Katzav J. (2019), 'The National Science Foundation and Philosophy of Science's Withdrawal from Social Concerns,' Studies in History and Philosophy of Science, Part A, online first: https://doi.org/10.1016/j.shpsa.2019.01.001 
van Eck N.J. and Waltman L. (2010), 'Software Survey: VOSviewer, a Computer Program for Bibliometric Mapping,' Scientometrics, 84, 523-38

van Eck N.J. and Waltman L. (2014), 'Visualizing Bibliometric Networks,' in Ding, Y., Rousseau R. and Wolfram D. (eds.), Measuring Scholarly Impact: Methods and Practice, Berlin: Springer, 285320

van Eck N.J. and Waltman L. (2019), 'VOSviewer Manual', 2019, http://www.vosviewer.com/gettingstarted\#VOSviewer\%20manual

van Fraassen B. (1975), The Scientific Image, Oxford: Oxford University Press

Varela F., Thompson E. and Rosch E. (1991), The Embodied Mind: Cognitive Science and Human Experience, Cambridge (MA): MIT Press

Veblen T. (1899), The Theory of the Leisure Class: An Economic Study of Institutions, New York: Macmillam

Veblen T. (1900), 'The Preconceptions of Economic Science: III,' Quarterly Journal of Economics, $14(2), 240-69$

Vendler Z. (1962), 'Effects, Results and Consequences,' in R.J. Butler (ed.), Analytic Philosophy, New York: Barnes and Noble

Venturinha N. (2013), 'Wittgenstein's Debt to Sraffa,' in G.J. Padilla and G. Margit (eds.), Forms of Life and Language Games, Frankfurt: Ontos, 187-95

Verhaegh S. (2018), Working from Within: The Nature and Development of Quine's Naturalism, New York: Oxford University Press

von Wright G.H. (1949/1957), 'Form and Content in Logic: An Inaugural Lecture,' in Logical Studies, London: Routledge \& Kegan Paul, 1-21

von Wright G.H. (1951), 'Carnap's Theory of Probability,' The Philosophical Review, 60 (3), 362 74

von Wright G.H. (1955), 'Ludwig Wittgenstein, A Biographical Sketch,' The Philosophical Review, $64(4), 527-45$

von Wright G.H. (1963), The Varieties of Goodness, London: Routledge and Kegan Paul 
von Wright G.H. (1969), 'Special Supplement: The Wittgenstein Papers,' The Philosophical Review, $78(4), 483-503$

von Wright G.H. (1971), Explanation and Understanding, Ithaca: Cornell University Press, London: Routledge \& Kegan Paul

von Wright G.H. (1976), 'Determinism and the Study of Man,' in J. Manninen and R. Tuomela (eds.), Essays on Explanation and Understanding, Dordrecht: Reidel

von Wright G.H. (1979/1993), 'Humanism and the Humanities,' in The Tree of Knowledge and Other Essays, Leiden: Brill, 155-71

von Wright G.H. (1989), 'Intellectual Autobiography,' in P.A. Schilpp and L.E. Hahn (eds.), The Philosophy of G.H. von Wright, La Salle (Illinois): Open Court, 2-55

von Wright G.H. (1993), 'Analytical Philosophy: A Historico-Critical Survey', in The Tree of Knowledge and Other Essays, Brill: Leiden, 25-52

Vygotsky L. (1978), Mind in Society, Cambridge (MA)-London: Harvard University Press

Vygotsky L. (1986), Myshlenie i rech'/Thought and Language, Cambridge (MA)-London: The MIT Press

Wagner P. (2009) (ed.), Carnap’s Logical Syntax of Language, Basingstoke: Palgrave Macmillan

Waismann F. (1949), 'Analytic-Synthetic I,' Analysis, 10, 25-40

Waismann F. (1950), ‘Analytic-Synthetic II,’ Analysis, 11, 25-38

Waismann F. (1951a), 'Analytic-Synthetic III,' Analysis, 11, 49-61

Waismann F. (1951b), 'Analytic-Synthetic IV,' Analysis, 11, 115-24

Waismann F. (1952), 'Analytic-Synthetic V,'Analysis, 13, 1-14

Waismann F. (1953), ‘Analytic-Synthetic VI,'Analysis, 13, 73-89

Waismann F. (1965a), The Principles of Linguistic Philosophy, London: Macmillan

Waismann F. (1965b), 'II: Notes on Talks with Wittgenstein,' The Philosophical Review, 74 (1), 12 16 
Waismann F. (1977), 'Hypotheses', in Philosophical Papers, Dordrecht: Reidel, 38-59

Waismann F. (1979), Wittgenstein and the Vienna Circle: Conversations, New York: Rowman \& Littlefield Publishers

Wallerstein I. (1974), The Modern World-System: Capitalist Agriculture and the Origins of the European World-Economy in the Sixteenth Century, New York: Academic Press

Wallerstein I. (2000), The Essential Wallerstein, New York: The New Press

Warnock G.J. (1956), The Revolution in Philosophy, London: Macmillan

Warnock G.J. (1958), English Philosophy Since 1900, London: Oxford University Press

Watkins J.W.N. (1957a), 'Farewell to the Paradigm-Case Argument', Analysis, 18, 25-33

Watkins J.W.N. (1957b), ‘A Reply to Professor Flew’s Comment', Analysis, 18, 41-42

Watson J.B. (1913), 'Psychology as the Behaviorist Views it,' Psychological Review, 20, 158-77

Weatherson B. (2014), 'Centrality and Marginalisation', Philosophical Studies, 171, 517-33

Weintraub E.R. (1991), Stabilizing Dynamics: Constructing Social Knowledge, Cambridge: Cambridge University Press

Weintraub, E.R. (2002), How Economics Became a Mathematical Science, Durham and London: Duke University Press

Wellman C. (1961), 'Our Criteria for Third-Person Psychological Sentences,' The Journal of Philosophy, 58 (11), 281-93

Wenger E. (1998), Communities of Practice: Learning, Meaning and Identity, Cambridge: Cambridge University Press

White M. (1950), 'The Analytic and the Synthetic: An Untenable Dualism,' in S. Hook (ed.), John Dewey: Philosopher of Science and Freedom, New York: Dial Press, 272-86

White M. (1960a), 'A Logical Positivist's Case Against the School of Linguistic Philosophy,' Scientific American, 202 (3), 205-11

White M. (1960b), 'Memories of G.E. Moore,' The Journal of Philosophy, 57 (26), 805-10 
Whorf B.L. (1956), Language, Thought, and Reality, Cambridge (MA): Technology Press of Massachusetts Institute of Technology

Wikforss Å. (2009), 'Are There Understanding-Assent Links?,' The Baltic International Yearbook of Cognition, Logic and Communication, 5 (12)

Wilkes K.V. (1978), Physicalism, London: Routledge and Kegan Paul

Williams B.A.O. (1974), 'Wittgenstein and Idealism,' in ed. G.N.A. Vesey (ed.), Understanding Wittgenstein, London: Macmillan

Williams B.A.O. (1980), 'Internal and External Reasons,' in R. Harrison (ed.), Rational Action, Cambridge: Cambridge University Press

Williams B.A.O. (1985), Ethics and the Limits of Philosophy, Cambridge (MA): Harvard University Press

Williams B.A.O. (2000), 'Philosophy as a Humanistic Discipline,' Philosophy, 75, 477-96

Williams B.A.O. (2001), 'The Spell of Linguistic Philosophy', in B. Magee (ed.), Talking Philosophy: Dialogues with Fifteen Leading Philosophers, Oxford: Oxford University Press, 2001110 24

Williams C.J.F. (1961), 'More on the Argument of the Paradigm Case', Australasian Journal of Philosophy, 49, 276-78

Williams R. (1976), Keywords: a Vocabulary of Culture and Society, London: Fontana Paperbacks

Williamson T. (2000), Knowledge and Its Limits, Oxford: Oxford University Press

Williamson T. (2007), The Philosophy of Philosophy, Oxford: Blackwell

Williamson T. (2009), 'Replies to Kornblith, Jackson and Moore,', Analysis, 69 (1), 125-35

Williamson T. (2010), 'Modality \& Other Matters' (interview by Paal Antonsen), Perspectives: International Postgraduate Journal of Philosophy (Dublin), 3, 16-29

Williamson T. (2011), 'Three Wittgensteinians and a Naturalist on The Philosophy of Philosophy,' in R. Davies (ed.), Analisi, Mimesis, Milano, 127-37 
Williamson T. (2013), 'Wittgenstein's Metaphilosophy - By Paul Horwich,' European Journal of Philosophy, 21 (S2): e 7-e10

Williamson T. (2013), Modal Logic as Metaphysics, Oxford: Oxford University Press

Williamson T. (2014), 'How did we get here from there? The transformation of analytic philosophy', Belgrade Philosophical Annual, 27, 7-37

Williamson T. (2015), Tetralogue: I'm Right, You're Wrong, Oxford: Oxford University Press

Williamson T. (2018), 'Dummett on the Relation Between Logics and Metalogics,' in M. Frauchiger (ed.), Truth, Meaning, Justification, and Reality: Themes from Dummett, Lauener Library of Analytical Philosophy, Berlin: de Gruyter, 153-75

Winch P. (1958), The Idea of a Social Science, London: Routledge and Kegan Paul

Winch P. (1983), 'Critical Study: Facts and Superfacts,' Philosophical Quarterly, 33, 398-404

Winch P. (1992), 'Norman Malcolm,' Philosophical Investigations, 15, 223-6

Wittgenstein L. (1922), Tractatus Logico-philosophicus, London: Kegan Paul, Trench, Trubner \& Co.

Wittgenstein L. (1936/1993), 'Notes for Lectures on "Private Experience” and "Sense Data", , in J.C. Klagge and A. Nordmann (eds.), Philosophical Occasions: 1912:1951, Indianapolis: Hackett, 202,89

Wittgenstein L. (1937-1944/1983), Bemerkungen Uber Die Grundlagen Der Mathematik/Remarks on the Foundations of Mathematics, Cambridge (MA): The MIT Press

Wittgenstein L. (1953), Philosophische Untersuchungen/ Philosophical Investigations, Oxford: Blackwell

Wittgenstein L. (1956), Bemerkungen Uber Die Grundlagen Der Mathematik/Remarks on the Foundations of Mathematics, Oxford: Blackwell

Wittgenstein L. (1958), The Blue and Brown Books, Oxford: Blackwell

Wittgenstein, L. (1964/1975), Philosophische Bemerkungen/Philosophical Remarks, Oxford: Blackwell 
Wittgenstein L. (1966), Lectures and Conversations on Aesthetics, Psychology and Religious belief, Oxford: Blackwell

Wittgenstein L. (1967), Zettel, Oxford: Blackwell

Wittgenstein L. (1967/1979), Bemerkungen über Frazers Golden Bough \& Remarks on Frazer's Golden Bough, New Jersey: Brynmill.

Wittgenstein L. (1969), Über Gewissheit/On Certainty, Oxford: Blackwell

Wittgenstein L. (1978), Bemerkungen Uber Die Grundlagen Der Mathematik/Remarks on the Foundations of Mathematics, Oxford: Blackwell

Wittgenstein L. (1980a), Vermischte Bemerkungen/Culture and Value, revised edition, Oxford: Blackwell

Wittgenstein L. (1980b), Bemerkungen über Die Philosophie Der Psychologie/Remarks on the Philosophy of Psychology, Oxford: Blackwell

Wittgenstein L. (1980c), Bemerkungen über Die Philosophie Der Psychologie/Remarks on the Philosophy of Psychology, Oxford: Blackwell

Wright C. (1980), Wittgenstein on the Foundations of Mathematics, London: Duckworth

Wright C. (1992), Truth and Objectivity, Cambridge (MA): Harvard University Press

Wright C. (1996), 'Human Nature?,' European Journal of Philosophy, 4, 235-54

Yablo S. (1993), 'Is Conceivability a Guide to Possibility?,' Philosophy \& Phenomenological Research, 53, 1-42

Yablo S. (2002), 'Coulda, Woulda, Shoulda,' T. Szabó Gendler and J. Hawthorne (eds.), Conceivability and Possibility, Oxford: Oxford University Press, 441-92

Yolton J.W. (1958), 'Philosophical and Scientific Explanation,' The Journal of Philosophy, 55 (4), $133-43$

Yolton J.W. (1962), 'Act and Circumstance,' The Journal of Philosophy, 59 (13), 337-50 